Maiara da Silva Santos

\title{
Desenvolvimento de Métodos de RMN para Controle de Qualidade de Produtos Farmacêuticos e Agrícolas
}

Tese apresentada ao Instituto de Química de São Carlos da Universidade de São Paulo como parte dos requisitos para a obtenção do título de Doutor em Ciências - Programa de Química.

Área de Concentração: Química Analítica e Inorgânica

Orientador: Dr. Luiz Alberto Colnago

São Carlos

2014 


\section{DEDICATÓRIA}

Dedico este trabalho ao Dr. Colnago, como agradecimento por toda sua compreensão... fundamental para a concretização de meu doutorado. 


\section{AGRADECIMENTOS}

Ao Doutor Luiz Alberto Colnago, quem eu admiro muito, pela orientação, pelos conhecimentos transmitidos e pela amizade que contribuíram muito para o meu crescimento profissional e pessoal.

Ao Professor Doutor Guido F. Pauli, que me recebeu em seu grupo de pesquisa para a realização dos estudos envolvendo $R \mathcal{M N}$ e a planta Cardo-leiteiro, me dando a oportunidade de adquirir novas experiências acadêmicas e de vida.

Ao Professor Daniel R. Cardoso por ter disponibilizado o uso da balança de seu laboratório, viabilizando a validação do método para quantificação de glifosato.

Aos funcionários da Embrapa Instrumentação pela ajuda nos momentos necessários, principalmente aos técnicos do laboratório de RMN, Viviane e Marcelo. Especialmente ele, pela construção dos padrões externos.

A todos os alunos do grupo de RMMN da Embrapa Instrumentação desses 5 anos de trabalho... em especial, à Roberta, à Dani e ao Tiago pela amizade e contribuição nos ensaios de precisão intermediária. Agradeço também ao Tiago pela parceria no estudo do FDM e à Dani pela parceria nas análises de azeites.

Aos alunos do grupo do Professor Pauli que conviveram comigo durante os seis meses que estive por lá, me ajudando sempre com muita paciência e compreensão. Principalmente ao José pelos ensinamentos e a Joo-Won pela amizade.

Aos meus familiares... em especial, minha irmã, Francine, minha mãe, Luzia, e meu pai, Francisco, por mais uma vez acreditarem em mim e me darem o suporte necessário nos momentos difíceis.

Ao Renato pela compreensão, apoio e palavras de incentivo, sempre com muito amore carinho. E aos pais dele, Antonio Carlos Vigatto e Elisabeth da Silva Vigatto, por toda colaboração, possibilitando a conclusão deste trabalho.

A todos os amigos pelas discussões científicas, bate-papos e momentos de descontração.

A FAPESP e a CAPES pelos apoios financeiros.

A Deus, sempre me fortalecendo. 


\section{EPÍGRAFE}

"If the daass of perception were cleansed everything would appear to man as it is, infinite." 


\section{RESUMO}

A necessidade de um controle de qualidade seguro e confiável em produtos e/ou matérias-primas provenientes das indústrias farmacêuticas e agrícolas torna as análises de seus ativos e constituintes extremamente importantes para os fabricantes, bem como para os usuários desses produtos. Apesar da espectroscopia de Ressonância Magnética Nuclear (RMN) ser uma das mais importantes ferramentas de análise qualitativa, ainda é pouco usada para fins quantitativos. Considerando esses fatos, métodos para análises de produtos farmacêuticos e agrícolas, empregando técnicas de RMN, foram desenvolvidos no presente trabalho. Um método quantitativo de $\mathrm{RMN}$ de ${ }^{1} \mathrm{H}$ em alta resolução para análise de paracetamol em diferentes formulações farmacêuticas foi validado de acordo com a Resolução RE $n^{0}$ 899. Neste método foi usado um padrão interno, tornando desnecessária a construção de uma curva analítica. Outros ativos presentes nas formulações também puderam ser quantificados e alguns excipientes, identificados. De acordo com NBR 14029, foram desenvolvidos e validados métodos empregando RMN em alta resolução de ${ }^{1} \mathrm{H}$ e ${ }^{31} \mathrm{P}$ para análise de glifosato em agrotóxicos. Neste caso, foi empregado um padrão externo, o qual possibilitou análises quantitativas sequenciais dos diferentes núcleos sem a necessidade de um novo preparo de amostra. A RMN em alta resolução de ${ }^{1} \mathrm{H}$ também foi avaliada como um método alternativo para a determinação de ácidos graxos em óleos e azeites, dispensando as reações de transesterificações necessárias para as análises cromatográficas. A RMN no domínio do tempo (RMN-DT) foi usada no desenvolvimento de um método para detecção de adulteração de azeites de oliva com óleo de soja. Esse método baseou-se na diferença de viscosidade do azeite e do óleo e possui a grande vantagem de poder ser aplicado em embalagens lacradas. Por fim, diferentes abordagens analíticas empregando a RMN em alta resolução foram feitas para análises do fitoterápico Cardo-Leiteiro (Silybum marianum L. Gaertn., Asteraceae), possibilitando a quantificação simultânea de sete constituintes ativos, incluindo dois pares de diastereoisômeros. Assim, demonstrou-se no presente trabalho o potencial das técnicas de RMN quantitativas, para o controle de qualidade de produtos farmacêuticos e agrícolas, com algumas vantagens sobre os outros métodos analíticos normalmente usados nessas análises. 


\section{ABSTRACT}

The need for effective and reliable quality control in products and/or raw materials from pharmaceutical and agricultural industries make analyses of their actives compounds and constituents very important to manufacturers and consumers. Nuclear Magnetic Resonance spectroscopy (NMR) is one of the most important tools for qualitative analysis but it is rarely used as quantitative method. Considering these facts, quantitative NMR methods (qNMR) for analysis of pharmaceutical and agricultural products were developed in this thesis. A high resolution ${ }^{1} \mathrm{H}$ qNMR method for paracetamol, in different pharmaceutical formulations, was validated according to RE Resolution № 899. An internal standard was used in this method, therefore, the construction of a calibration curve was unnecessary. Other actives constituents present in the formulations could also be quantified and some excipients, identified. According to NBR 14029, high resolution qNMR ${ }^{1} \mathrm{H}$ and ${ }^{31} \mathrm{P}$ methods were developed and validated for glyphosate. In this case, an external standard was used, which enabled sequential quantitative analyses of different nuclei without the need to prepare a new sample. The high-resolution qNMR ${ }^{1} \mathrm{H}$ was also used as an alternative method for fatty acids determination in oils and olive oils, dispensing transesterifications reactions required for GC analysis. Time domain NMR (TD-NMR) was used to develop a method to detect adulteration of olive oil with soybean oil. This method was based on the viscosity difference between olive oil and soybean oil, and has a great advantage, because it can be applied in sealed packages. Finally, different analytical approaches using high resolution NMR ${ }^{1} \mathrm{H}$ were studied to qualitative and quantitative analysis of milk thistle (Silybum marianum L. Gaertn., Asteraceae), a botanical dietary supplement, enabling the simultaneous quantification of seven active constituents, including two pairs of diastereoisomers. Therefore, it was demonstrated in this thesis the potential of qNMR techniques to quality control of pharmaceutical and agricultural products, with some advantages over other analytical methods, normally used in these analyses. 


\section{LISTA DE FIGURAS}

Figura 1 - Representações esquemáticas das sequências de pulsos mais empregadas para determinação dos tempos de relaxação longitudinal (A) e transversal (B) .25

Figura 2 - Estrutura química do paracetamol

Figura 3 - Dissociação do glifosato de acordo com seu comportamento ácido-básico .33

Figura 4 - Fórmulas estruturais dos constituintes químicos da silimarina .38

Figura 5 - Representação esquemática da sequência de pulso empregada para a aquisição dos espectros de ${ }^{1} \mathrm{H}$ e de ${ }^{31} \mathrm{P}$ 44

Figura 6 - Espectro de RMN de ${ }^{1} \mathrm{H}\left(9,4 \mathrm{~T} ; 2^{\circ}{ }^{\circ} \mathrm{C}\right.$ e DMSO-d $\left.\mathrm{d}_{6}\right)$ da amostra R3a e as estruturas químicas do analito (paracetamol) e do padrão interno $\left(\mathrm{DMSO}_{2}\right)$. 66

Figura 7 - Curva analítica obtida no ensaio de Lineraridade da validação do método de RMNq para determinação de paracetamol. 68

Figura 8 - Espectro de RMN de ${ }^{1} \mathrm{H}\left(9,4 \mathrm{~T} ; 23^{\circ} \mathrm{C}\right.$ e DMSO- $\left.\mathrm{d}_{6}\right)$ das amostras comercias de paracetamol analisadas 78

Figura 9 - Espectro de RMN de ${ }^{1} \mathrm{H}\left(9,4 \mathrm{~T} ; 23^{\circ} \mathrm{C}\right.$ e DMSO-d6) da amostra ResC. Acima, ampliação da região de 9,40 a 7,57 ppm para visualização do sinal do maleato de clorfeniramina

Figura 10 - Espectro de RMN de ${ }^{1} \mathrm{H}\left(9,4 \mathrm{~T} ; 23^{\circ} \mathrm{C}\right.$ e $\left.\mathrm{D}_{2} \mathrm{O}\right)$ da amostra SonC. Acima, ampliação da região de 7,87 a 7,09 ppm para visualização do sinal da cafeína........84 Figura 11 - Ampliação do espectro de RMN de ${ }^{1} \mathrm{H}$ (4,25 a 0,50 ppm) da amostra Res ilustrando a atribuição dos excipientes identificados: A) álcool etílico; B) propilenoglicol e C) metilparabeno .86

Figura 12 - Região espectral de RMN de ${ }^{1} \mathrm{H}(4,80$ a 4,40 ppm) destacando o sinal do macrogol das formulações líquidas: A) Ty e B) Gen .86

Figura 13 - Espectros de $\mathrm{RMN}$ de ${ }^{1} \mathrm{H}$ de amostras em $\mathrm{D}_{2} \mathrm{O}$ contendo trifenil fosfato (estrutura química ilustrada) e dimetil sulfona. Em $\mathrm{A}$ ) espectro adquirido em um espectrômetro de 9,4 T e em B) em um espectrômetro de 14,1 T

Figura 14 - A) Ampliação do espectro de $\mathrm{RMN}$ de ${ }^{1} \mathrm{H}(8,0$ - 2,5 ppm) e B) Espectro de $\mathrm{RMN}$ de ${ }^{31} \mathrm{P}$ de uma das amostras analisadas nos ensaios de exatidão/repetitividade $\left(9,4 \mathrm{~T} ; 23^{\circ} \mathrm{C}\right.$ e $\left.\mathrm{D}_{2} \mathrm{O}\right)$ 
Figura 15 - Curvas analíticas obtidas no ensaio de linearidade das validações dos métodos de $\mathrm{RMNq}$ de ${ }^{1} \mathrm{H}$ e de ${ }^{31} \mathrm{P}$ 100

Figura 16 - Espectros de $\mathrm{RMN}$ de ${ }^{1} \mathrm{H}\left(14,1 \mathrm{~T} ; 2^{\circ}{ }^{\circ} \mathrm{C}_{\text {e }} \mathrm{D}_{2} \mathrm{O}\right)$ das amostras comerciais de herbicidas contendo glifosato 105

Figura 17 - Espectros de RMN de ${ }^{31} \mathrm{P}\left(14,1 \mathrm{~T} ; 23^{\circ} \mathrm{C}\right.$ e $\left.\mathrm{D}_{2} \mathrm{O}\right)$ das amostras comerciais de herbicidas contendo glifosato 106

Figura 18 - Gráfico de barras para comparação entre os teores de glifosato $(\% \mathrm{~m} / \mathrm{m})$ determinados pelos métodos de $\mathrm{RMNq}$ de ${ }^{1} \mathrm{H}$ e ${ }^{31} \mathrm{P}$ desenvolvidos e os valores descritos nos rótulos dos produtos

Figura 19 - Representação esquemática do processamento de dados através do FDM

Figura 20 - Gráfico da correlação da razão das áreas do analito e do $\mathrm{PI}\left(\mathrm{A}_{\text {analito }} / \mathrm{A}_{P \mathrm{PI}}\right)$ obtidas a partir dos espectros processados via FT (eixo x) e FDM (eixo y) 113

Figura 21 - Espectro de RMN de ${ }^{1} \mathrm{H}$ : a) processado via $\mathrm{FT}$, no qual se observam os sinais largos em 5,07 e 4,42 ppm, e b) processado via FDM, no qual observa-se, em preto, os sinais largos que foram subtraídos e, em vermelho, após a exclusão das linhas largas

Figura 22 - Ampliações de espectros de RMN de ${ }^{1} \mathrm{H}$ nos quais se visualizam os sinais da cafeína sobrepostas no espectro original (A), processado via $F T$, e o espectro editado (B), processado via FDM

Figura 23 - Espectros de $\mathrm{RMN}$ de ${ }^{1} \mathrm{H}\left(9,4 \mathrm{~T} ; 23 \stackrel{\circ}{\circ} \mathrm{C}\right.$ e $\left.\mathrm{CDCl}_{3}\right)$ da amostra AT869 com as atribuições dos sinais referentes aos ácidos graxos , cujas estruturas químicas, retiradas da fonte citada abaixo, estão ilustradas

Figura 24 - Gráfico de correlação entre os resultados obtidos por RMN e os obtidos por CG.

Figura 25 - Decaimentos de amostras de óleo de soja e azeite de oliva obtidos a partir da sequência CPMG para medidas de $T_{2}$

Figura 26 - Fotos do espectrômetro empregado nas medidas de RMN-DT dos azeites de oliva.

Figura 27 - Curva analítica obtida no ensaio de Linearidade da validação do método para detecção de adulteração de azeites com óleo de soja

Figura 28 - Espectro de RMN de ${ }^{1} \mathrm{H}\left(14,1 \mathrm{~T} ; 23^{\circ} \mathrm{C}\right.$ e DMSO-d $\left.\mathrm{d}_{6}\right)$ : A) do extrato padrão de referência; B) a primeira tentativa de extração e C) a segunda tentativa de extração 
Figura 29 - Fotografias do extrato em pó obtido após otimização do processo de extração das sementes da planta Cardo-leiteiro

Figura 30 - Espectros de RMNq de ${ }^{1} \mathrm{H}\left(14,1 \mathrm{~T} ; 23^{\circ} \mathrm{C}\right.$ e DMSO- $\left.\mathrm{d}_{6}\right)$ dos extratos das sementes da planta Cardo-leiteiro obtidos

Figura 31 - Espectros de RMNq de ${ }^{1} \mathrm{H}\left(14,1 \mathrm{~T} ; 23^{\circ} \mathrm{C}\right.$ e DMSO- $\left.\mathrm{d}_{6}\right)$ dos produtos comerciais contendo extratos das sementes da planta Cardo-leiteiro 130

Figura 32 - Assinalamento dos sinais de RMN de ${ }^{1} \mathrm{H}$ empregados para a quantificação dos constituintes da silimarina.

Figura 33 - Gráfico comparativo dos teores dos constituintes $(\% \mathrm{~m} / \mathrm{m})$ da silimarina (silibinas - lilás; isosilibinas - violeta; silicristina - amarelo; isosilicristina - verde; silidianina - rosa) entre todas as amostras analisadas 133

Figura 34 - Ilustração do resultado espectral obtido empregando o método HiFSA135 Figura 35 - Ilustração da região espectral empregada nas simulações via HiFSA para determinação das silibinas $A$ e $B$ e isosilibinas $A$ e $B$ 136

Figura 36 - Gráfico comparativo dos teores $(\% \mathrm{~m} / \mathrm{m})$ da silibina $A$, em azul, e da silibina $\mathrm{B}$, em vermelho, entre todas as amostras analisadas

Figura 37 - Gráfico comparativo dos teores $(\% \mathrm{~m} / \mathrm{m})$ da isosilibina A, em verde, e da isosilibina $\mathrm{B}$, em amarelo, entre todas as amostras analisadas 138 Figura 38 - Representação esquemática da forma de visualização bidimensional dos resultados de PCA 139

Figura 39 - Gráfico de scores dos extratos das sementes da planta Cardo-leiteiro obtido por PCA: PC1 (38,13\%) x PC2 (24,34\%), à esquerda, e PC2 x PC3 $(14,62 \%)$, à direita 140

Figura 40 - Gráfico de scores dos produtos comerciais contendo extratos das sementes da planta Cardo-leiteiro obtido por PCA: PC1 (48,87\%) x PC2 (26,96\%), à esquerda, e PC2 x PC3 (8,42\%), à direita

Figura 41 - Gráfico de scores de todas as amostras (padrões em verde, extratos em azul e produtos comerciais em preto) obtido por PCA: PC1 (32,16\%) x PC2 $(21,65$ $\%)$ 


\section{LISTA DE TABELAS}

Tabela 1 - Parâmetros espectrais avaliados na validação do método de RMNq para determinação de paracetamol

Tabela 2 - Parâmetros espectrais empregados nos estudos preliminares do método de RMNq para determinação de glifosato .

Tabela 3 - Parâmetros espectrais empregados no método validado de RMNq para determinação de glifosato

Tabela 4 - Parâmetros espectrais empregados no método de RMNq para determinação dos constituintes da silimarina.

Tabela 5 - Massas de PI e SR utilizadas no ensaio de Linearidade/Intervalo (L) do método de RMNq para determinação de paracetamol..

Tabela 6 - Massas de PI e SR utilizadas nos ensaios de Exatidão e Repetitividade $₫$ do método de RMNq para determinação de paracetamol.

Tabela 7- Massas de PI e SR utilizadas no ensaio de Precisão Intermediária (Pi) do método de RMNq para determinação de paracetamol

Tabela 8- Massas de PI e SR utilizadas nos ensaios de Robustez (RB) do método de RMNq para determinação de paracetamol.

Tabela 9 - Dados sobre o preparo das amostras comerciais líquidas de paracetamol

Tabela 10 - Dados sobre o ensaio de recuperação das amostras comerciais líquidas de paracetamol.

Tabela 11 - Dados sobre o preparo das amostras comerciais sólidas de paracetamol

Tabela 12 - Dados sobre os ensaios de recuperação das amostras comerciais sólidas de paracetamol

Tabela 13 - Dados sobre o preparo das amostras comerciais de paracetamol para análise de outros analitos

Tabela 14 - Massas de glifosato (PA) utilizadas nos ensaios de Repetitividade e Exatidão dos estudos preliminares do método de RMNq para a determinação de gifosato.

Tabela 15 - Massas de glifosato (PA) utilizadas nos testes do método de RMNq para determinação de glifosato 
Tabela 16 - Massas (g) do padrão analítico de glifosato utilizadas nos ensaios de Exatidão e Precisão do método de RMNq para determinação de glifosato

Tabela 17 - Massas de azeites de oliva e de óleo de soja utilizadas no preparo das amostras* $^{*}$ para o ensaio de Linearidade

Tabela 18 - Massas de azeites de oliva e de óleo de soja utilizadas no preparo das amostras* para os ensaios de Repetitividade e Precisão Intermediária.

Tabela 19 - Condições empregadas na extração acelerada por solvente no Dionex 350 das sementes de Cardo-leiteiro.

Tabela 20 - Massa de sementes moídas da planta Cardo-leiteiro utilizada nas extrações.

Tabela 21 - Massas de extratos analisadas nas medidas de RMNq e a concentração da solução de PI utilizada

Tabela 22 - Massas de produto comercial analisadas nas medidas de RMNq e a concentração da solução de PI utilizada

Tabela 23 - Resultados obtidos no ensaio de Exatidão da validação do método de RMNq para determinação de paracetamol.

Tabela 24 - Resultados obtidos no ensaio de Repetitividade da validação do método de RMNq para determinação de paracetamol.

Tabela 25 - Resultados obtidos no ensaio de Precisão Intermediária da validação do método de RMNq para determinação de paracetamol 71

Tabela 26 - Resultados obtidos no ensaio de Robustez (variação da massa de PI) da validação do método de RMNq para determinação de paracetamol

Tabela 27 - Resultados obtidos no ensaio de Robustez (variação da massa de PI e solvente) da validação do método de RMNq para determinação de paracetamol ....72 Tabela 28 - Resultados obtidos na avaliação da estabilidade das replicatas da amostra RIII. .73

Tabela 29 - Resultados obtidos nos experimentos de variação de pw/p1 e de d1 ....74 Tabela 30 - Resultados obtidos nos experimentos de variação de np/td e de at/aq .74

Tabela 31 - Resultados obtidos nos experimentos de variação de nt/ns .75

Tabela 32 - Resultados obtidos nos experimentos de variação de receiver gain/rg..75

Tabela 33 - Resultados obtidos nos experimentos de variação de giro ....................76

Tabela 34 - Resultados obtidos nos experimentos de variação de lb ......................76

Tabela 35 - Resultados obtidos nos experimentos de variação de fn/si....................77 
Tabela 36 - Quantificação das amostras comerciais líquidas de paracetamol analisadas

Tabela 37 - Ensaio de recuperação para as amostras comerciais líquidas de paracetamol.

Tabela 38 - Quantificação dos amostras comerciais sólidas de paracetamol analisadas

Tabela 39 - Ensaios de recuperação para as amostras comerciais sólidas de paracetamol

Tabela 40 - Dados sobre os outros analitos quantificados em amostras comerciais de paracetamol.

Tabela 41 - Quantificação simultânea de paracetamol (A) e maleato de clorfeniramina (B) na amostra Res.

Tabela 42 - Quantificação simultânea de paracetamol (A) e cafeína (B) na amostra Son. .85

Tabela 43 - Fórmula estrutural dos excipientes identificados na amostra Res .85

Tabela 44 - Identificação de alguns dos excipientes identificados na amostra Res..85

Tabela 45 - Resultados obtidos nas padronizações do PE de trifenil fosfato...... .89 Tabela 46 - Resultados obtidos nos ensaios preliminares de Exatidão/Repetitividade das análises de $\mathrm{RMNq}$ de ${ }^{1} \mathrm{H}$ para determinação de glifosato .90

Tabela 47. Resultados obtidos nos ensaios preliminares de Exatidão/Repetitividade das análises de $\mathrm{RMN}$ de ${ }^{31} \mathrm{P}$ para determinação de glifosato. .91

Tabela 48 - Média global das 21 amostras analisadas nos ensaios de

Exatidão/Repetitividade do estudo preliminar para determinação de glifosato

Tabela 49 - Resultados obtidos no Teste 1 do método para determinação de glifosato

Tabela 50 - Resultados obtidos no Teste 2 do método para determinação de glifosato

Tabela 51 - Resultados obtidos nos ensaios de Exatidão/Repetitividade das análises de RMN de ${ }^{1} \mathrm{H}$ na validação do método para determinação de glifosato .95

Tabela 52 - Resultados obtidos nos ensaios de exatidão/repetitividade das análises de RMN de ${ }^{31} \mathrm{P}$ na validação do método para determinação de glifosato .96 Tabela 53 - Resultados obtidos nos ensaios de Precisão Intermediária (Pi) e Robustez (RB) das análises de $\mathrm{RMNq}$ de ${ }^{1} \mathrm{H}$ na validação do método para determinação de glifosato 
Tabela 54 - Resultados obtidos nos ensaios de Precisão Intermediária (Pi) e Robustez (RB) das análises de RMN de ${ }^{31} \mathrm{P}$ na validação do método para determinação de glifosato

Tabela 55 - Média global das 21 amostras analisadas nos ensaios de

Exatidão/Repetitividade na validação do método para determinação de glifosato ....99

Tabela 56 - Valores de incertezas de massas atômicas 102

Tabela 57 - Resultados obtidos na quantificação da amostra comercial sólida de glifosato (S) por RMNq de ${ }^{1} \mathrm{H}$ e de ${ }^{31} \mathrm{P}$ 106

Tabela 58 - Resultados obtidos na quantificação das amostras comerciais líquidas de glifosato por RMNq de ${ }^{1} \mathrm{H}$

Tabela 59 - Resultados obtidos na quantificação das amostras comerciais líquidas de glifosato por RMNq de ${ }^{31} \mathrm{P}$ 109

Tabela 60 - Resultados obtidos no teste de recuperação da amostra comercial líquida $\mathrm{R}$

Tabela 61 - Incertezas Expandidas dos resultados obtidos para as amostras comerciais líquidas de glifosato

Tabela 62 - Comparação entre precisão e exatidão obtidas a partir do processamento feito via FT e via FDM.

Tabela 63 - Comparação dos resultados de teor de paracetamol obtidos através do processamento via FT e via FDM com exclusão de linhas

Tabela 64 - Resultados obtidos a partir do processamento via FT (linhas a) e via FDM (demais linhas)

Tabela 65 - Resultado obtido no ensaio de Repetitividade da validação do método para detecção de adulteração de azeites com óleo de soja

Tabela 66 - Resultado obtido no ensaio de Precisão Intermediária da validação do método para detecção de adulteração de azeites com óleo de soja.

Tabela 67 - Resultado obtido no ensaio de Robustez da validação do método para detecção de adulteração de azeites com óleo de soja.

Tabela 68 - Resultado obtido no ensaio de Exatidão da validação do método para detecção de adulteração de azeites com óleo de soja

Tabela 69 - Dados referentes aos rendimentos obtidos nas extrações das sementes da planta Cardo-leiteiro 
Tabela 70 - Resultados de Precisão e Exatidão obtidos no teste de preparo de amostra do método de análise dos extratos e amostras comerciais da planta Cardoleiteiro

Tabela 71 - Teor dos constituintes da silimarina nos extratos determinados via RMNa 132

Tabela 72 - Teor dos constituintes da silimarina nas amostras comerciais determinados via $\mathrm{RMNq}$ 132

Tabela 73 - Teores de silimarina descritos na bulas e determinados via RMNq 133

Tabela 74 - Teor dos isômeros (iso)silibinas A e B presentes nos extratos das sementes da planta Cardo-leiteiro determinado via HiFSA e RMNq

Tabela 75 - Teor dos isômeros (iso)silibinas A e B presentes nas amostras comerciais contendo extratos das sementes da planta Cardo-leiteiro determinado via HiFSA e RMNq. 


\section{LISTA DE ABREVIATURAS E SÍMBOLOS}

A

ABNT

ANVISA

AOAC

AOCS

ASTM

at / aq

$\mathrm{B}_{0}$

BPA

BPE

BPI

BS

BSR

BST

$\mathrm{CDCl}_{3}$

$\mathrm{CG}$

CIPAC

CPMG

CV

CWFP

d1

$\mathrm{D}_{2} \mathrm{O}$

$\mathrm{DMSO}_{2}$

DMSO-d 6

DP

DPR

FDA

FDM

FID

$\mathrm{fn} / \mathrm{si}$

FT

área

Associação Brasileira de Normas Técnicas

Agência Nacional de Vigilância Sanitária

Association of Analiytical Communities

American Oil Chemists' Society

American Society for Testing and Materials

tempo de aquisição

campo magnético principal

branco do padrão analítico

branco do padrão externo

branco do padrão interno

branco do solvente

branco da substância de referência

branco de amostra

clorofórmio deuterado

cromatografia gasosa

Collaborative International Pesticides Analytical Council

sequência de pulso Carr, Pucell, Meiboom e Gill

coeficiente de variação

Continuous Wave-Free Precession

tempo de intervalo entre a aquisição e o próximo pulso

água deuterada

dimetil sulfona

dimetil sulfóxido deuterado

desvio padrão

desvio padrão relativo

U.S. Food and Drug Administration

Filter Diagonalization Method

Free Induction Decay

número de pontos para processamento

transformada de Fourier 


\begin{tabular}{|c|c|}
\hline FTIR & infravermelho médio \\
\hline G & Teste de Grubbs \\
\hline $\mathrm{G}_{\mathrm{c}}$ & valor crítico para o Teste de Grubbs \\
\hline HiFSA & ${ }^{1} \mathrm{H}$ iterative Full Spin Analysis \\
\hline HPLC & cromatografia líquida de alta eficiência \\
\hline HPTLC & cromatografia em camada delgada de alta eficiência \\
\hline IBAMA & $\begin{array}{l}\text { Instituto Brasileiro do Meio Ambiente e dos Recursos Naturais } \\
\text { Renováveis }\end{array}$ \\
\hline INMETRO & Instituto Nacional de Metrologia, Qualidade e Tecnologia \\
\hline IR & sequência de pulso de inversão e recuperação \\
\hline ISO & International Organization for Standardization \\
\hline IUPAC & International Union of Pure and Applied Chemistry \\
\hline$J$ & constante de acoplamento \\
\hline$L$ & linearidade \\
\hline $\mathrm{lb}$ & $\begin{array}{l}\text { multiplicação exponencial aplicada no FID para que seja aumentada } \\
\text { a relação sinal/ruído do espectro (line broadening) }\end{array}$ \\
\hline LDE & limite de detecção do equipamento \\
\hline LDM & limite de detecção do método \\
\hline LQ & limite de quantificação \\
\hline $\mathrm{m}$ & massa \\
\hline MAPA & Ministério da Agricultura, Pecuária e Abastecimento \\
\hline MM & massa molar \\
\hline MMS & Molecular Modeling Software \\
\hline MRC & material de referência certificado \\
\hline NIR & infravermelho próximo \\
\hline NIST & National Institute of Standards and Technology \\
\hline $\mathrm{np} / \mathrm{td}$ & números de pontos para aquisição \\
\hline $\mathrm{ns} / \mathrm{nt}$ & número de transientes \\
\hline$P$ & pureza \\
\hline PA & padrão analítico \\
\hline PCA & Principal Components Analysis \\
\hline $\mathrm{PE}$ & padrão externo \\
\hline $\mathrm{pH}$ & potencial hidrogeniônico \\
\hline
\end{tabular}




$\begin{array}{ll}\mathrm{Pi} & \text { precisão intermediária } \\ \mathrm{PI} & \text { padrão interno } \\ \mathrm{pw} / \mathrm{p} 1 & \text { tempo de duração do pulso (largura) } \\ \mathrm{r} & \text { coeficiente de correlação } \\ \mathrm{R} & \text { repetitividade } \\ \mathrm{r}^{2} & \text { coeficiente de regressão } \\ \mathrm{RB} & \text { robustez } \\ \mathrm{RMN} & \text { Ressonância Magnética Nuclear } \\ \mathrm{RMD}-\mathrm{DT} & \text { Ressonância Magnética Nuclear no Domínio do Tempo } \\ \mathrm{RMNq} & \text { Ressonância Magnética Nuclear quantitativa } \\ \mathrm{SFC} & \text { Solid Fat Content } \\ \mathrm{SR} & \text { substância de referência } \\ \mathrm{S} / \mathrm{R} & \text { razão sinal/ruído } \\ \mathrm{SSFP} & \text { Steady-State Free Precession } \\ \text { sw / swh } & \text { tamanho da janela espectral } \\ \mathrm{T} & \text { temperatura } \\ \mathrm{T}_{1} & \text { tempo de relaxação longitudinal } \\ \mathrm{T}_{2} & \text { tempo de relaxação transversal } \\ \mathrm{T}_{2}{ }^{*} & \text { tempo de decaimento do FID } \\ \text { TMS } & \text { tetrametilsilano } \\ u & \text { incerteza padrão } \\ U & \text { incerteza expandida } \\ \text { u.a. } & \text { unidade arbitrária } \\ u_{c} & \text { incerteza combinada } \\ \text { UV-Vis } & \text { ultravioleta visível } \\ \mathrm{V} & \text { volume } \\ \delta & \text { deslocamento químico } \\ \omega & \text { frequência de precessão } \\ & \end{array}$




\section{SUMÁRIO}

1 INTRODUÇÃO .20

1.1 Medidas Quantitativas de RMN em Alta Resolução (RMNQ) .......................20

1.2 Medidas Quantitativas de RMN No DomínIO do TEMPo (RMN-DT) .................24

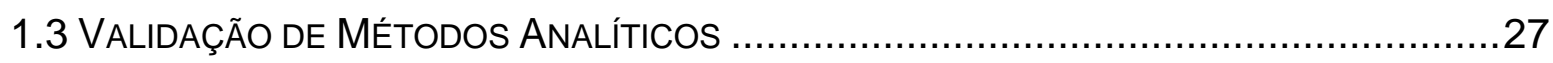

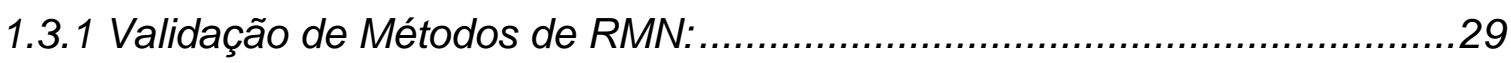

1.4 Produtos Agrícolas E FarmacÊUticos Estudados .......................................

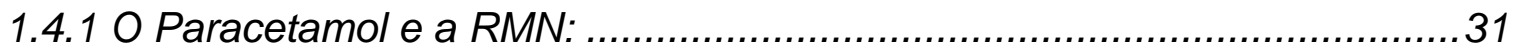

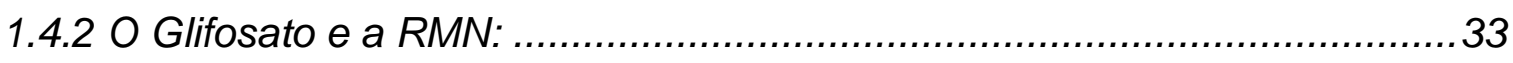

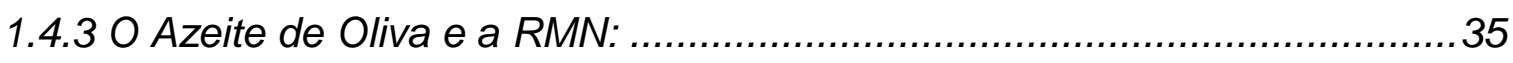

1.4.4 O Fitoterápico Cardo-leiteiro e a RMN :...................................................37

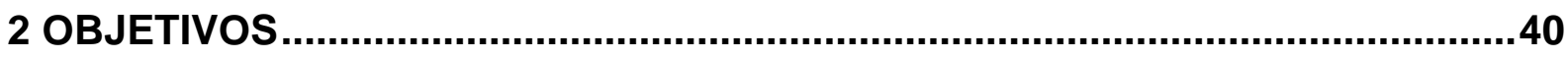

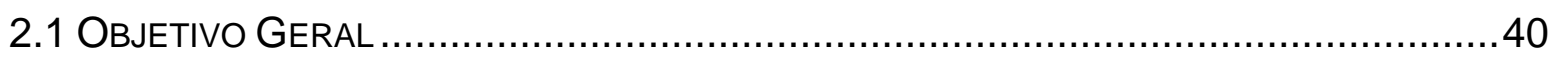

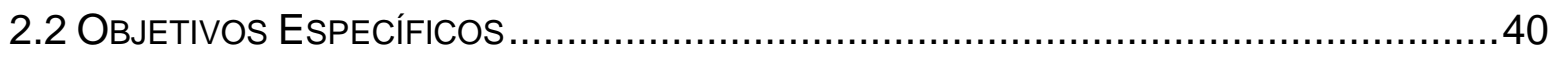

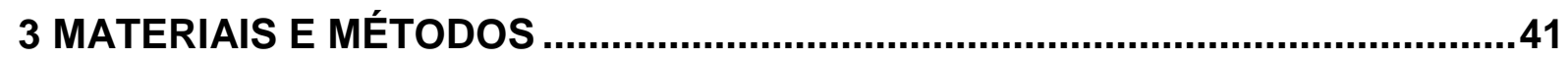

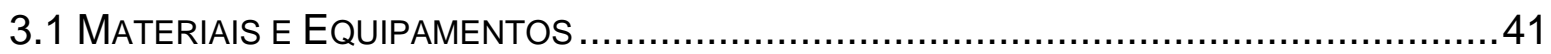

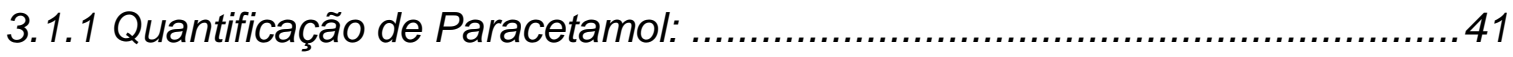

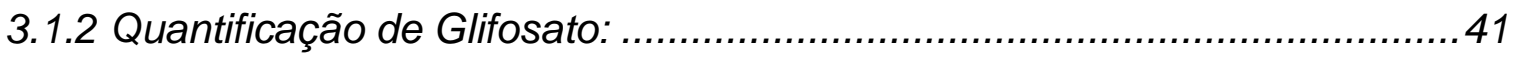

3.1.3 Quantificação de Ácidos Graxos em Óleos e Azeites: ..............................42

3.1.4 Detecção de Adulteração de Azeites com Óleo de Soja em Embalagens

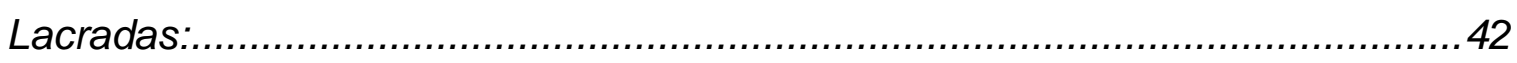

3.1.5 Quantificação dos Constituintes da Silimarina: ...................................... 42

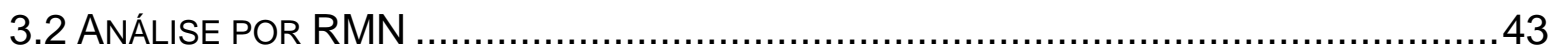

3.2.1 Método para Quantificação de Paracetamol: ...........................................4 44

3.2.2 Método para Quantificação de Glifosato: .................................................45

3.2.3 Método para Quantificação de Ácidos Graxos em Óleos e Azeites: ...........46

3.2.4 Método para Detecção de Adulteração de Azeites com Óleo de Soja em

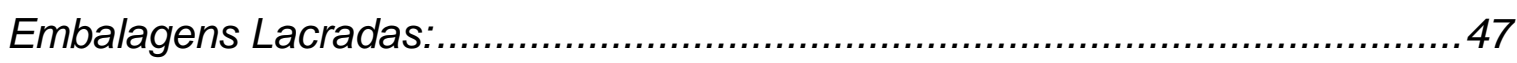

3.2.5 Método para Quantificação dos Constituintes da Silimarina: .....................47

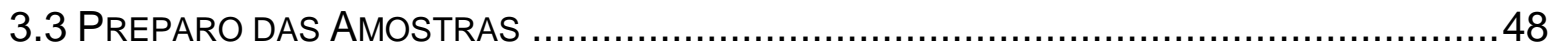

3.3.1 Método para Quantificação de Paracetamol: .......................................... 48 
3.3.2 Método para Quantificação de Glifosato:

3.3.3 Método para Quantificação de Ácidos Graxos em Óleos e Azeites:

3.3.4 Método para Detecção de Adulteração de Azeites com Óleo de Soja em

Embalagens Lacradas:. .59

3.3.5 Método para Quantificação dos Constituintes da Silimarina: .....................60

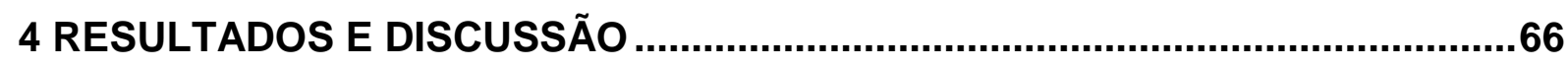

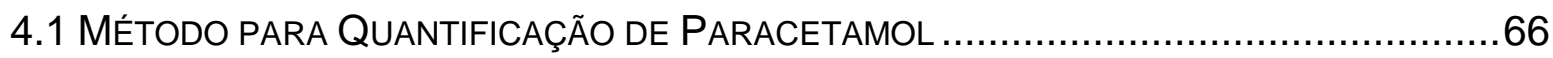

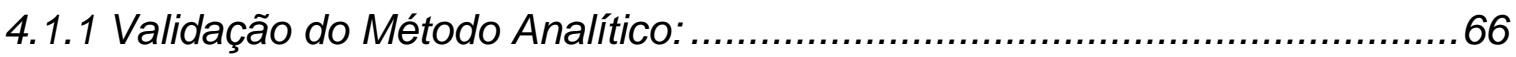

4.1.2 Alteração dos Parâmetros Espectrais: .................................................. 73

4.1.3 Quantificação das Amostras Comerciais:.............................................77

4.1.4 Quantificação Simultânea de Outros Analitos: ....................................... 82

4.1.5 Análises Qualitativas das Formulações Comerciais:.................................85

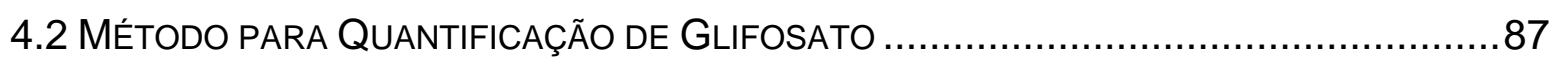

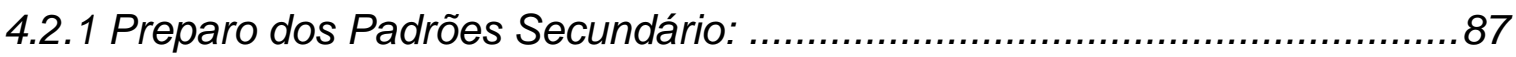

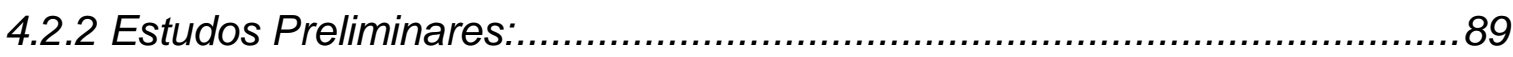

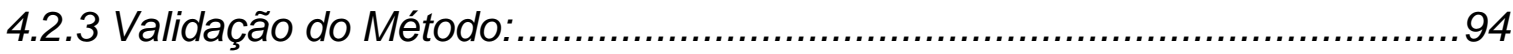

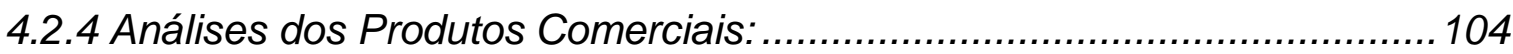

4.3 AVAliAÇÃo do Emprego do MÉtodo de Diagonalização FILTRAda (FDM) PARA

Processamento de EsPECTROS dE RMN QuANTITATIVOS......................................112

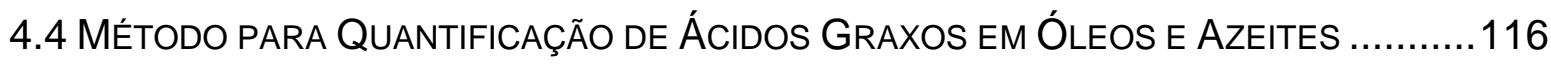

4.5 MÉtodo para Detecção de Adulteração de Azeite com Óleo de Soja em

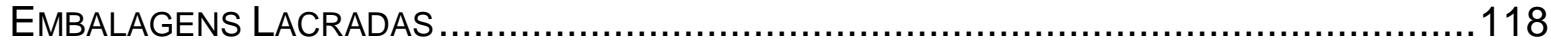

4.6 MÉTOdO PARA QUANTIFICAÇÃO DOS CONSTITUINTES DA SILIMARINA ....................125

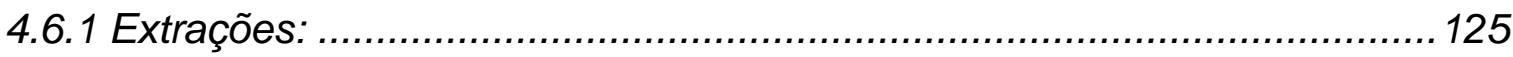

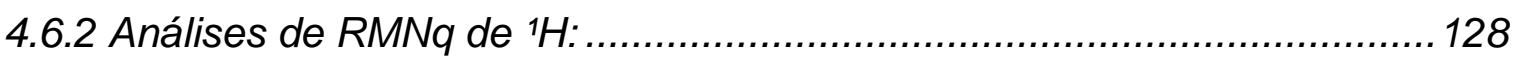

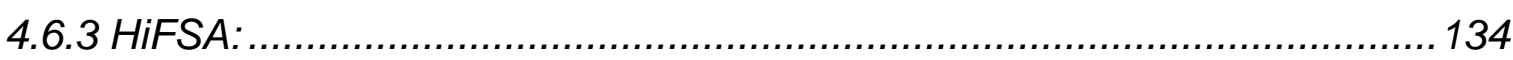

4.6.4 Análise de Componentes Principais:.................................................138

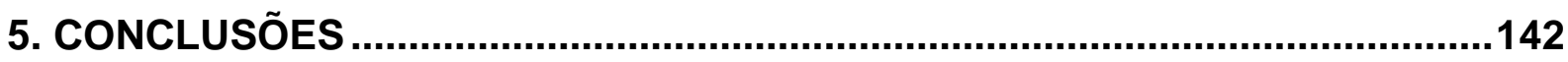

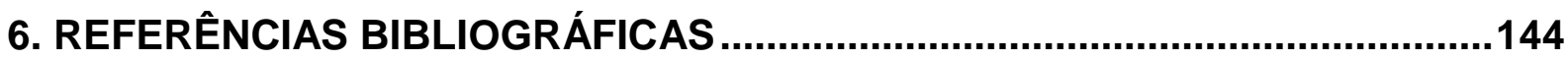




\section{INTRODUÇÃO}

A necessidade de um controle de qualidade seguro e confiável em produtos e/ou matérias-primas provenientes das indústrias farmacêuticas e agrícolas torna as análises de seus ativos e constituintes extremamente importantes para os fabricantes, bem como para os usuários desses produtos.

Além disso, anteriormente à comercialização, esses produtos precisam possuir seus devidos registros perante aos órgãos regulamentadores e, para isso, uma série de estudos físico-químicos e toxicológicos deve ser realizada. Dentre os ensaios necessários, encontra-se a determinação do teor do ativo e de seus constituintes, sejam na matéria-prima ou no produto final.

As técnicas mais empregadas neste tipo de quantificação, tanto em métodos oficiais quanto em estudos reportados na literatura, são as cromatográficas acopladas a detectores diversos, ${ }^{1-7}$ além das técnicas espectroscópicas na região do ultravioleta visível (UV-Vis), na região do infravermelho médio (FTIR) e infravermelho próximo (NIR). ${ }^{7-13}$

O uso dessas técnicas espectroscópicas está se destacando em aplicações quantitativas, principalmente por serem métodos simples, rápidas, não-destrutivos, podendo ser aplicados em amostras intactas, até mesmo dentro de embalagens. ${ }^{14-18}$

Apesar da espectroscopia de Ressonância Magnética Nuclear (RMN) ser uma das mais importantes ferramentas de análise qualitativa, ainda é pouco usada para fins quantitativos. Assim, demonstra-se nesta tese o potencial das técnicas de RMN quantitativas, para o controle de qualidade de produtos farmacêuticos e agrícolas, com algumas vantagens sobre os outros métodos analíticos normalmente usados nessas análises.

\subsection{Medidas Quantitativas de RMN em Alta Resolução (RMNq)}

A Ressonância Magnética Nuclear (RMN) é um fenômeno bastante conhecido e descrito em diversos livros textos. ${ }^{19-21}$

Nos espectrômetros pulsados, a condição de ressonância é satisfeita com a aplicação de um pulso de curta duração e alta potência na região da frequência de precessão $(\omega)$ dos núcleos a serem analisados. Após esse pulso, os spins excitados passam a relaxar por dois mecanismos distintos e simultâneos: a relaxação 
longitudinal $\left(\mathrm{T}_{1}\right)$ e a relaxação transversal $\left(\mathrm{T}_{2}\right)$. É durante esse tempo que se observa o sinal induzido pela magnetização dos spins, o FID (Free Induction Decay), que contém todas as frequências espectrais sobrepostas. ${ }^{22}$

Em análises de RMN em alta resolução é necessário aplicar ao FID uma operação matemática, denominada transformada de Fourier, para que o sinal no domínio do tempo seja levado ao domínio de frequências. Dessa forma, se obtém um espectro de RMN, no qual informações como o deslocamento químico e multiplicidade estão presentes.

Embora o emprego qualitativo das análises espectroscópicas por RMN seja mais difundido, seu uso quantitativo, apesar de possuir uma grande potencialidade, ainda é pouco explorado mesmo sendo um método não destrutivo, rápido e que exige o mínimo preparo de amostra, diferentemente dos métodos tradicionais.

A mais importante relação fundamental das medidas quantitativas de RMN em alta resolução $(\mathrm{RMNq})$ é que a área do sinal de resposta $\left(A_{x}\right)$ em um espectro é diretamente proporcional ao número de núcleos que absorvem energia na radiofrequência referente a esta linha de ressonância $\left(N_{x}\right)$ :

$$
A_{x}=K_{s} N_{x} \quad \text { equação } 1
$$

onde, $K_{s}$ é uma constante do espectrômetro. ${ }^{23,24}$

Para que esta relação seja verdadeira em um experimento com mais de um pulso, é necessário que os spins excitados retornem ao equilíbrio térmico antes de se aplicar um novo pulso na amostra. Esse retorno transcorre com uma constante de tempo $T_{1}$, ou com uma taxa de relaxação $1 / T_{1}$, de acordo com a equação $2:^{19,20,25}$

$$
M_{z}(t)=M_{0}\left[1-\exp \left(\frac{-t}{T_{1}}\right)\right] \quad \text { equação } 2
$$

Nas medidas de RMNq, o intervalo de tempo entre os pulsos, ou seja, o tempo de aquisição (aq/at) somado ao tempo de espera (d1), deve ser no mínimo igual a $5 \mathrm{~T}_{1}$, considerando um pulso de $90^{\circ}$. Isso é necessário para que 99,33\% dos spins retornem em equilíbrio térmico antes do próximo pulso e, assim, manter a informação quantitativa no espectro. ${ }^{20,25}$ 
Após a aquisição, o espectro obtido de uma única substância, geralmente, pode apresentar várias linhas de ressonância, porém, para resultados quantitativos o monitoramento de apenas uma delas para cada composto é suficiente. ${ }^{24}$

Um fator que pode afetar a largura dessas linhas de ressonância, comprometendo a resolução espectral e, consequentemente, o resultado da medida, é o tempo de relaxação $T_{2}{ }^{*}$. Este é uma constante de tempo do decaimento efetivo do FID, o qual abrange o tempo de relaxação transversal $\left(T_{2}\right)$, além da heterogeneidade de $\mathrm{B}_{0}$, da seguinte maneira: ${ }^{19,} 20,26$

$$
\frac{1}{T_{2}^{*}}=\frac{1}{T_{2}}+\gamma \Delta B_{0}
$$

equação 3

O tempo de relaxação transversal corresponde à perda de coerência de fase entre os momentos magnéticos individuais na sua precessão. Este processo é responsável pelo decaimento exponencial da intensidade da magnetização $M_{x y}$, quando na presença de um campo magnético estático ideal $\left(\Delta \mathrm{B}_{0}=0\right)$, e é caracterizado por uma constante $T_{2}$, conforme a equação $4:^{19,} 20,26$

$$
M_{y}(t)=M_{x y} \cos \omega_{0} t \exp \left(\frac{-t}{T_{2}}\right)
$$

equação 4

Para minimizar o efeito da heterogeneidade do campo magnético no decaimento do FID, e consequentemente da largura das linhas espectrais, é necessário que seja realizado, anteriormente à aquisição do FID, um procedimento denominado "shimming", no qual se faz a homogeneização do campo magnético.

Este procedimento é indispensável para análises em alta resolução, pois resulta em uma melhora significativa na resolução dos espectros, evitando possíveis sobreposições dos sinais e possibilitando a observação dos desdobramentos dos mesmos (multiplicidades) quando houver.

A maneira mais simples de se obter uma informação quantitativa através desses espectros de RMN é a determinação relativa, na qual a razão molar de dois compostos pode ser calculada empregando uma simples razão: ${ }^{23,24}$ 


$$
\frac{n_{x}}{n_{y}}=\frac{A_{x}}{A_{y}} \frac{N_{y}}{N_{x}}
$$

equação 5

Onde,

$n=$ quantidade de matéria de um composto;

$A$ = área referente à linha de ressonância;

$N$ = número de núcleos que absorvem na frequência da linha de ressonância.

Consequentemente, a fração molar de um determinado composto $X$ em uma mistura com $m$ componentes também pode ser calculada: $:^{23,24}$

$$
\frac{n_{x}}{\sum_{i=1}^{m} n_{i}}=\frac{A_{x} / N_{x}}{\sum_{i=1}^{m} A_{i} / N_{i}} \quad \text { equação } 6
$$

Foi utilizando este tipo de quantificação que os primeiros estudos quantitativos de RMN sugiram. Em 1963 Jungnickel e Forbes determinaram a razão de tipos de ${ }^{1} \mathrm{H}$ intramolecular em vinte e seis compostos orgânicos puros. ${ }^{27}$ Enquanto que Hollis, neste mesmo ano, analisou três analitos (aspirina, cafeína e fenacetina) em diferentes misturas previamente preparadas. ${ }^{28}$

Para a obtenção do teor de um analito em uma determinada matriz, uma abordagem diferente deve ser utilizada, denominada "quantificação absoluta". Para isso é necessário o emprego de um padrão interno de pureza conhecida $(\mathrm{PI})$ e a partir da razão da área da linha de ressonância correspondente ao padrão interno e da área do analito, apenas efetuar-se o cálculo: $:^{23,24}$

$$
P_{x}=\frac{A_{x}}{A_{P I}} \frac{N_{P I}}{N_{x}} \frac{M M_{x}}{M M_{P I}} \frac{m_{P I}}{m} P_{P I}
$$

equação 7

Onde,

$P=$ pureza $(\% \mathrm{~m} / \mathrm{m})$;

$A$ = área da linha de ressonância;

$N$ = número de núcleos que absorvem na frequência da linha de ressonância;

$M M=$ massa molar;

$m=$ massa pesada. 
Nesse contexto, a medição quantitativa absoluta de RMN em alta resolução pode ser considerada como um método de padronização primária, uma vez que para a realização da mesma é desnecessária a construção de uma curva de calibração, bem como o emprego de padrões de referência idênticos aos analitos.

Esta é uma grande vantagem da RMNq quando comparada às técnicas cromatográficas e as demais técnicas espectroscópicas, as quais necessitam desses padrões para a construção da curva analítica, pois a aquisição desses compostos padronizados, muitas vezes, é um processo demorado (quando envolve importação) e nem sempre os mesmos estão disponíveis no mercado mundial.

Apesar do seu considerado alto custo, outras vantagens do emprego da RMNq também podem ser destacadas tais como: a possibilidade de determinação de estruturas a nível molecular (análise qualitativa simultânea à quantitativa); as medidas podem ser realizadas em tempo relativamente curtos (considerando núcleos abundantes); dispensa isolamento do analito quando o mesmo estiver presente em mistura (desde que haja a seletividade necessária); possibilidade de análise simultânea de outros compostos de interesse, tais como excipientes, outros ativos, impurezas e produtos de degradação (se houver seletividade); entre outras. $^{23,24}$

Além disso, resultados obtidos por RMNq vêm se mostrando similares ou superiores aos obtidos através de técnicas cromatográficas quando o analito se encontra em alta concentração (constituinte majoritário), como é o caso dos ativos em produtos formulados. Esta comparação pode ser observada em publicações encontradas na literatura. ${ }^{29-31}$

Devido a fatos como esses, somados ao desenvolvimento de novos espectrômetros com maior sensibilidade e resolução, os métodos quantitativos via RMN estão em ascendência.

\subsection{Medidas Quantitativas de RMN no Domínio do Tempo (RMN-DT)}

Diferentemente das análises em alta resolução, nas quais se utilizam as informações dos espectros obtidos após a transformada de Fourier, os dados gerados nas análises em baixo campo são avaliados no domínio do tempo (RMNDT). 
As análises de RMN-DT são fundamentadas nas diferenças de tempo de relaxação longitudinal $\left(\mathrm{T}_{1}\right)$ e/ou transversal $\left(\mathrm{T}_{2}\right)$ dos vários componentes da amostra. Os valores de $T_{1}$ de $T_{2}$ podem ser determinados através de sequências de pulsos específicas, sendo a de Inversão e Recuperação - IR (Figura 1A), a mais empregada para medidas de $T_{1}$, e a Carr, Pucell, Meiboom e Gill - CPMG (Figura 1B) para as medidas de $\mathrm{T}_{2}$.

Na sequência de IR, inicialmente um pulso de $180^{\circ}$ é dado para inverter a população de spin. Em seguida, após um tempo $\tau$, é dado um pulso de $90^{\circ}$ e ocorre a detecção. Este procedimento é realizado sucessivas vezes variando-se o valor de $\tau$. No início, quando $\tau=0$, o sinal terá máxima intensidade negativa. No decorrer da medida, esta intensidade vai diminuindo, passa pelo zero (valor de $\tau$ usado nas estimavas de $\mathrm{T}_{1}$ ) e, então, se inicia o sinal com intensidade positiva, a qual aumentará até atingir um máximo e permanecer constante. Nesta condição $\tau \cong$ $5 \mathrm{~T}_{1}{ }^{19,20,26}$

Figura 1 - Representações esquemáticas das sequências de pulsos mais empregadas para determinação dos tempos de relaxação longitudinal $(A)$ e transversal (B)

A) IR

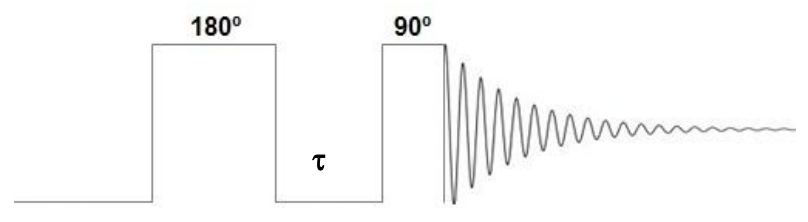

B) $C P M G$

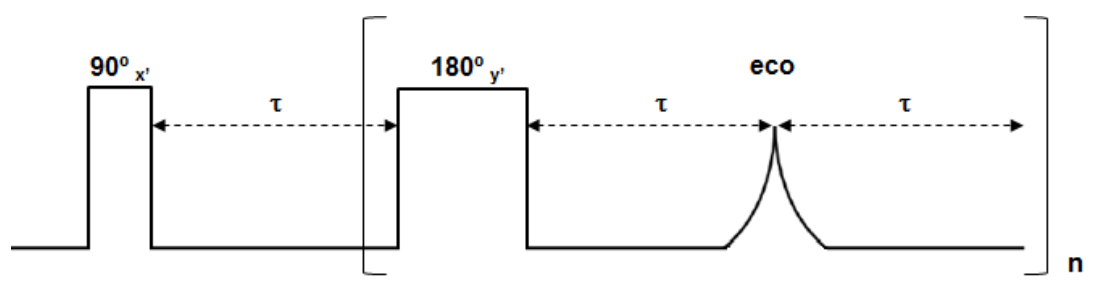

Na CPMG, após o pulso inicial de 90 espera-se um tempo $\tau$, no qual ocorre uma pequena defasagem nos vetores magnetização que estão no plano x'y', devido ao processo de relaxação transversal e à não homogeneidade do campo magnético. Então, aplica-se um trem de pulsos de $180^{\circ}$ e os vetores devido a nãohomogeneidade de campo são refocalizados em $2 \tau$, sob a forma de ecos. A 
constante de tempo do decaimento da intensidade máxima dos $n$ ecos gerados durante o experimento CPMG é o $\mathrm{T}_{2}{ }^{19,20,26}$

Como as análises RMN-DT não se beneficiam do efeito do deslocamento químico, suas aplicações abrangem medidas de componentes totais, de componentes parciais em amostras heterogêneas ou de medidas de propriedades físicas de seus componentes como viscosidade, difusão, porosidade, etc. ${ }^{25,32}$

Nestas circunstâncias, as quantificações se baseiam na correlação linear entre a intensidade do sinal (FID ou eco) e a variável estudada, portanto, a construção de uma curva de calibração é necessária. ${ }^{25}$

Apesar disso, a técnica RMN-DT apresenta várias vantagens: baixo custo; rapidez da análise (segundos); não é destrutiva (a análise pode ser repetida na mesma amostra); dispensa preparo de amostra sofisticado, o que pode prescindir o uso de produtos químicos adicionais, e as análises podem ser realizadas em tecidos vegetais "in vivo", o que permite o uso ou consumo das próprias amostras analisadas. $^{22}$

Mesmo com as limitações relacionadas à baixa sensibilidade e resolução, a RMN-DT tem muitas aplicações. Nas área de materiais é usada para determinação do grau de polimerização do poliestireno, densidade de ligações cruzadas em borracha, temperatura de transição vítrea, porosidade em concretos entre outras. $\mathrm{Na}$ área de alimentos é muito usada para medida de umidade e gordura/óleo em sementes, carnes e teor de sólidos solúveis totais em frutas e em produtos industrializados. Em medicina, tem sido usada na análise e diagnóstico de tecidos cancerosos, em análises de plasma sanguíneo, na caracterização de agentes de contrastes para imagens, entre outras aplicações. Na área de petróleo a RMN-DT é usada para determinação do teor de hidrogênio em combustíveis, da viscosidade de petróleo e derivados, da porosidade de rochas reservatório entre muitas outras aplicações. $^{25}$

Existem métodos normatizados que empregam RMN-DT para determinações do teor de óleo e umidade em sementes e grãos. A ISO 10565:1995 é um exemplo de um método oficial que emprega análises de RMN-DT para a quantificação simultânea de óleo e umidade em sementes intactas. ${ }^{33}$

Essa análise simultânea de óleo e umidade é possível devido à diferença entre o tempo de relaxação transversal $\left(T_{2}\right)$ que existe entre os vários componentes das sementes oleaginosas. Seus principais constituintes são os carboidratos, as 
proteínas, a água de hidratação, a água livre e o óleo. Como o valor de $\mathrm{T}_{2}$ é dependente da mobilidade molecular, os sinais dos materiais sólidos não são observados porque têm $\mathrm{T}_{2}$ muito curto (da ordem de microssegundos). ${ }^{34}$

Medidas como essas fazem parte do cotidiano do grupo de RMN da Embrapa Instrumentação, a qual vem desenvolvendo trabalhos na área há anos para fins qualitativos e quantitativos, tais como: medição de gordura intramuscular em carne bovina; monitoramento de reações de transesterificação usadas na produção de biodiesel; estudos de amadurecimento de frutos; teor de umidade em madeiras; determinação do teor de óleo em sementes diversas; entre outras. ${ }^{35-40}$

Além de pesquisas relacionadas à aplicação direta da metodologia, também são realizados estudos para melhorias nos métodos empregados. Azeredo e colaboradores demonstraram a viabilidade do emprego das sequências SSFP (Steady-State Free Precession) e CWFP (Continuous Wave-Free Precession), as quais resultaram em medidas de RMN-DT ultra-rápidas. ${ }^{41,42}$

Mais recentemente, estudos teóricos e experimentais sobre o uso de baixa potência aplicada nos pulsos de refocalização da sequência CPMG proporcionaram resultados similares empregando uma potência de apenas $25 \%$ da utilizada nas sequências convencionais, as quais aqueciam a sonda, quando realizadas em análises online. ${ }^{43}$

\subsection{Validação de Métodos Analíticos}

"A validação das metodologias quantitativas é indispensável para garantir, por meio de estudos experimentais, que o método desenvolvido atenda às exigências das aplicações analíticas, assegurando a confiabilidade dos resultados". ${ }^{4}$ E para que estes sejam reconhecidos pelos órgãos regulamentadores, tais como ANVISA (Agência Nacional de Vigilância Sanitária), IBAMA (Instituto Brasileiro do Meio Ambiente e dos Recursos Naturais Reniváveis), INMETRO (Instituto Nacional de Metrologia, Normalização e Qualidade Industrial) e MAPA (Ministério da Agricultura, Pecuária e Abastecimento), essas validações devem ser baseadas nas normativas específicas para cada caso.

Nesse contexto, considerando as análises de fármacos, as exigências da Resolução RE no 899 - Guia para Validação de Métodos Analíticos e Bioanalíticos devem ser atendidas e para as análises de agrotóxicos devem ser considerados os 
parâmetros presentes na normativa NBR 14029 - Agrotóxicos e afins: Validação de Métodos Analíticos. ${ }^{44,45}$

Apesar das particularidades de cada uma dessas normativas e de não existir um consenso sobre quais parâmetros devem ser incluídos em um processo de validação de um método analítico, alguns parâmetros são normalmente incluídos na maioria das validações: ${ }^{44,45}$

> Especificidade/Seletividade: capacidade do método em medir exatamente um composto em presença de outros componentes, tais como: impurezas, produtos de degradação e constituintes da matriz;

$>$ Linearidade: habilidade de um método analítico produzir resultados que sejam diretamente proporcionais à concentração do analito em amostras em uma dada faixa de concentração;

> Faixa de Trabalho: intervalo entre os níveis inferior e superior de concentração do analito no qual foi demonstrado ser possível a determinação com precisão, exatidão e linearidade exigidas;

$>$ Limite de Detecção: menor quantidade de analito presente em uma amostra que pode ser detectada;

> Limite de Quantificação: menor quantidade de analito presente em uma amostra que pode ser determinada com precisão e exatidão aceitáveis;

$>$ Exatidão: concordância entre o resultado de um ensaio e o valor de referência aceito como convencionalmente verdadeiro;

$>$ Recuperação: relação entre a quantidade do componente de interesse analisado e a quantidade teórica na amostra;

$>$ Repetitividade: grau de concordância entre os resultados das medições de um mesmo mensurando, efetuadas sob as mesmas condições;

> Precisão Intermediária: grau de concordância entre os resultados das medições de um mesmo mensurando, efetuadas no mesmo laboratório, sob condições variadas;

> Robustez: capacidade do método em resistir a pequenas e deliberadas variações dos parâmetros analíticos;

> Incerteza de Medição: parâmetro associado ao resultado de uma medição, que caracteriza a dispersão dos valores que podem ser fundamentadamente atribuídos a um mensurando. 


\subsubsection{Validação de Métodos de RMN:}

Apesar da crescente aplicação da RMN quantitativa em alta resolução, poucos desses métodos têm sido validados. Alguns dos casos de validação relatados na literatura são os descritos a seguir.

Tavares e Ferreira desenvolveram e validaram um método em alta resolução empregando uma curva analítica para quantificação de cafeína em cafés comerciais. A metodologia apresentou resultados quantitativos satisfatórios, além de fornecer informações qualitativas adicionais. ${ }^{46}$

A validação de experimentos de $\mathrm{RMN}$ de ${ }^{1} \mathrm{H}$ e de ${ }^{31} \mathrm{P}$, também em alta resolução, foi realizada por Maniara e colaboradores visando sua aplicação em análises de agrotóxicos. ${ }^{47}$ Neste trabalho a exatidão e a precisão obtidas foram melhores que $1 \%$, para os componentes majoritários e impurezas abaixo de $0,1 \%$ puderam ser quantificadas. ${ }^{47}$

Métodos de RMNq empregando ${ }^{19} \mathrm{~F}$ e ${ }^{31} \mathrm{P}$ também foram validados para a quantificação de misturas de fluoro-polifosfatos e ${ }^{1} \mathrm{H}$ para a determinação de cloridrato de metformina e carvedilol em formulações farmacêuticas e para quantificação de cloreto de benzetônio em extratos de sementes de toronja. ${ }^{48-51}$

Malz e Jancke desenvolveram e validaram um protocolo detalhado para medidas $\mathrm{RMNq}$ de ${ }^{1} \mathrm{H}$. O estudo foi inicialmente incentivado pelo péssimo desempenho que essa técnica havia apresentado na primeira comparação interlaboratorial nacional. Diante disso, os autores se propuseram a identificar as várias fontes de erros. ${ }^{24}$

Para a validação e nova intercomparação, três misturas modelos foram preparadas gravimetricamente. Com essas amostras, realizaram-se os ensaios de robustez, nos quais se variaram parâmetros de aquisição e processamento, além de equipamentos e sondas. Empregando os parâmetros otimizados, realizaram-se os ensaios relacionados à precisão e exatidão analisando as mesmas amostras em quintuplicatas. Uma incerteza menor que $1,5 \%$ foi obtida para um intervalo de confiança de $95 \% .{ }^{24} \mathrm{O}$ ensaio de linearidade, o qual resultou em um coeficiente de correlação ( $r$ ) maior que 0,999, foi realizado com treze soluções previamente preparadas contendo diferentes razões molares do analito e do padrão interno. ${ }^{24}$

Após o estabelecimento das condições experimentais, o protocolo desenvolvido foi utilizado para análises dessas mesmas misturas em trinta e três 
laboratórios e um desvio menor que $2 \%$, em relação aos valores gravimétricos de referência, foi obtido. ${ }^{24}$

Considerando este resultado ficou evidenciada a necessidade do desenvolvimento e estabelecimento de um protocolo de análise para medidas quantitativas via RMN. E esta necessidade tem motivado pesquisas recentes relacionadas a análises quantitativas de $\mathrm{RMN}$ de produtos naturais, incluindo fitoterápicos, e de biomarcadores em estudos de metaboloma.

Göedecke e colaboradores desenvolveram e validaram um método quantitativo de RMN genérico a ser empregado em análises de produtos naturais e fitoterápicos e verificaram que os parâmetros de aquisição, de processamento e o software de processamento são igualmente importantes e devem ser considerados ao se desenvolver e validar um método. ${ }^{52}$

Enquanto que Wang e colaboradores investigaram como a razão sinal/ruído (S/R) e o método de normalização interferem no coeficiente de variação das linhas de ressonância de metabólitos em urina sintética e concluíram que, para metabólitos em baixa concentração, uma validação mais criteriosa é necessária, uma vez que para estes compostos a reprodutibilidade foi mais pobre. ${ }^{53}$

No entanto, alguns métodos de RMN em alta resolução já foram reconhecidos e oficializados por farmacopéias internacionais. ${ }^{54}$ Nestes casos, a validação é desnecessária, pois foi previamente realizada e assegurada com ensaios interlaboratoriais.

Como exemplo, as monografias do citrato de orfenadrina e do nitrito de amila podem ser citadas. A primeira aborda a quantificação do isômero orto (analito de interesse) em relação aos isômeros meta e para, os quais não podem ultrapassar $3,0 \%$ na formulação farmacêutica. Já a monografia do nitrito de amila aborda sua identificação e quantitificação absoluta empregando, para isso, o composto benzoato de benzila como padrão interno. ${ }^{55}$

O mesmo ocorre para a técnica RMN-DT, a qual possui diversos métodos oficializados.

A medida relativa do conteúdo de sólidos em matérias graxas (SFC - Solid Fat Content) por RMN de ${ }^{1} \mathrm{H}$ é a aplicação mais difundida da RMN-DT e, por isso, existem muitos métodos oficias homologados: métodos diretos que medem diretamente a amplitude do sinal proveniente das duas fases - AOCS Cd $16 \mathrm{~b}-93^{56} \mathrm{e}$ ISO $8292-1^{57}$ e métodos indiretos que medem diretamente o sinal da fase líquida e 
calcula a amplitude do sinal da fase sólida - AOCS $16 \mathrm{~b}-81^{58}$, ISO $8292-2^{59}$ e o IUPAC $2.150^{60}$.

Assim como a ISO 10565:1995 ${ }^{33}$, descrita anteriormente, há outros métodos oficiais para a determinação absoluta do teor de óleo e umidade em grãos e sementes: AOCS AK 4-9561, também para sementes intactas, e ISO $10632^{62}$ e AOCS AK 5-0135 63 , para resíduos de sementes.

Além desses métodos, a determinação do conteúdo de hidrogênio por RMN de ${ }^{1} \mathrm{H}$ no domínio do tempo em destilados médios derivados do petróleo, em que se enquadra o combustível para aviação, está descrita norma ASTM D7171 ${ }^{64}$.

Como os métodos oficiais de RMN-DT têm uma grande abrangência de aplicações, não há muitos trabalhos na literatura que abordam a validação de métodos.

A validação de um método de RMN-DT desenvolvido para a determinação do teor de óleo em sementes de mamona pode ser citado. Os resultados obtidos mostraram-se precisos e foram equivalentes ao obtidos através do método oficial (extração tipo Soxhlet com hexano). ${ }^{65}$

\subsection{Produtos Agrícolas e Farmacêuticos Estudados}

\subsubsection{O Paracetamol e a RMN:}

O paracetamol, (N-(4-hidroxifenil)etanamida), cuja estrutura química está ilustrada na Figura 2, foi introduzido na medicina em 1893 por Von Mering devido a suas propriedades farmacológicas antipiréticas e analgésicas de grande eficácia. ${ }^{66}$ Há mais de 50 anos é comercializado para medicação caseira e, atualmente, é um dos medicamentos mais vendidos no mundo. ${ }^{66}$ De acordo com o FDA (U.S. Food and Drug Administration) no ano de 2008, foram vendidas 26,8 bilhões de doses. ${ }^{67}$

Figura 2 - Estrutura química do paracetamol<smiles>CC(=O)Nc1ccc(O)cc1</smiles> 
Diante a esta grande e crescente demanda, é de suma necessidade e importância garantir o controle de qualidade das formulações nas quais o paracetamol é o princípio ativo.

Com este objetivo, a Farmacopéia Brasileira recomenda para análise de paracetamol, em diferentes formulações farmacêuticas, a utilização da espectrofotometria de absorção no ultravioleta e da cromatografia líquida de alta eficiência, as quais exigem trabalhosas etapas de preparação de amostra. ${ }^{7}$

Além de métodos oficiais, muitas métodos alternativos para a quantificação desse composto são encontradas na literatura. ${ }^{15,66,68-72}$

Recentemente, Baptistao e colaboradores desenvolveram um método empregando espectroscopia de imagem na região do NIR aliada a métodos quimiométricos visando o controle de qualidade do fármaco paracetamol. Neste trabalho, foi possível se determinar o teor do ativo e excipientes com erros abaixo de $5 \%$, além de se obter informações qualitativas sobre as formas polimórficas dos comprimidos. $^{73}$

Gandhi e colaboradores empregaram a técnica de cromatografia em camada delgada de alta eficiência (HPTLC) para determinação simultânea de nabumetona e paracetamol em forma combinada em comprimidos. As porcentagens obtidas nos ensaios de exatidão e precisão foram 99,89 $\pm 1,15$, para a nabumetona, e 101,10 \pm 0,71 , para o paracetamol. ${ }^{74}$

E em 2013, Güzel e colaboradoes utilizaram um eletrodo de grafite modificado para a determinação voltamétrica de paracetamol em formulações comerciais. A validade e aplicabilidade do método proposto foram testadas, revelando-o satisfatório para este tipo de aplicação. ${ }^{75}$

Alguns trabalhos envolvendo o paracetamol e a RMN têm explorado 0 potencial dessa técnica para estudos de metabólitos. ${ }^{76-78}$ Outros têm empregado a RMN no estado sólido para estudo da morfologia, mobilidade e interação molecular. ${ }^{79,80}$

Rundlof e colaboradores quantificaram uma amostra comercial de paracetamol empregando a $\mathrm{RMN}$ de ${ }^{1} \mathrm{H}$ para exemplificar o resultado de seu estudo com padrões internos, previamente realizado. ${ }^{81} \mathrm{E}$ Husain e colaboradores, determinaram simultaneamente paracetamol e ácido mefenâmico em formulações farmacêuticas, empregando o terc-butanol como padrão interno. ${ }^{82}$ 


\subsubsection{O Glifosato e a RMN:}

De acordo com o primeiro relatório sobre o uso de agrotóxicos no Brasil, publicado em 2010 pelo IBAMA, o agrotóxico mais comercializado no Brasil é o glifosato ( $\mathrm{N}$-(fosfonometil)glicina). ${ }^{83}$ Sendo que na safra que envolve $\mathrm{o}$ segundo semestre de 2010 e o primeiro semestre de 2011 liderou o ranking com uma fatia de $29 \%$ do mercado brasileiro de agrotóxicos, quando comparadas às vendas por ingredientes ativos. ${ }^{84}$

O glifosato é um herbicida sistêmico de ação total, uma vez absorvido é transladado facilmente na planta, provocando a morte do sistema radicular e de estruturas reprodutivas de plantas perenes. Além disso, possui rápida absorção pelo solo, o que permite a semeadura imediata, após sua aplicação. No entanto, o herbicida não é seletivo, ou seja, é incapaz de fazer a distinção entre erva daninha e cultura agrícola. ${ }^{85}$

Este herbicida tem fórmula molecular $\mathrm{C}_{3} \mathrm{H}_{8} \mathrm{NO}_{5} \mathrm{P}$ e também é comercializado em forma de sal de isopropilamônio, apresentando acrescido um grupo $\left(\mathrm{CH}_{3}\right)_{2} \mathrm{CHNH}_{3}{ }^{+}$. De acordo com Cikalo e colaboradores, quando dissociado, o glifosato possui um comportamento zwiteriônico. Na Figura 3 estão ilustradas as estruturas químicas das etapas de dissociação previstas por eles. ${ }^{86,87}$

Figura 3 - Dissociação do glifosato de acordo com seu comportamento ácido-básico<smiles>O=C(O)C[NH2+]CP(=O)(O)O</smiles>

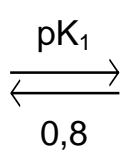<smiles>O=C(O)C[NH2+]CP(=O)([O-])O</smiles>
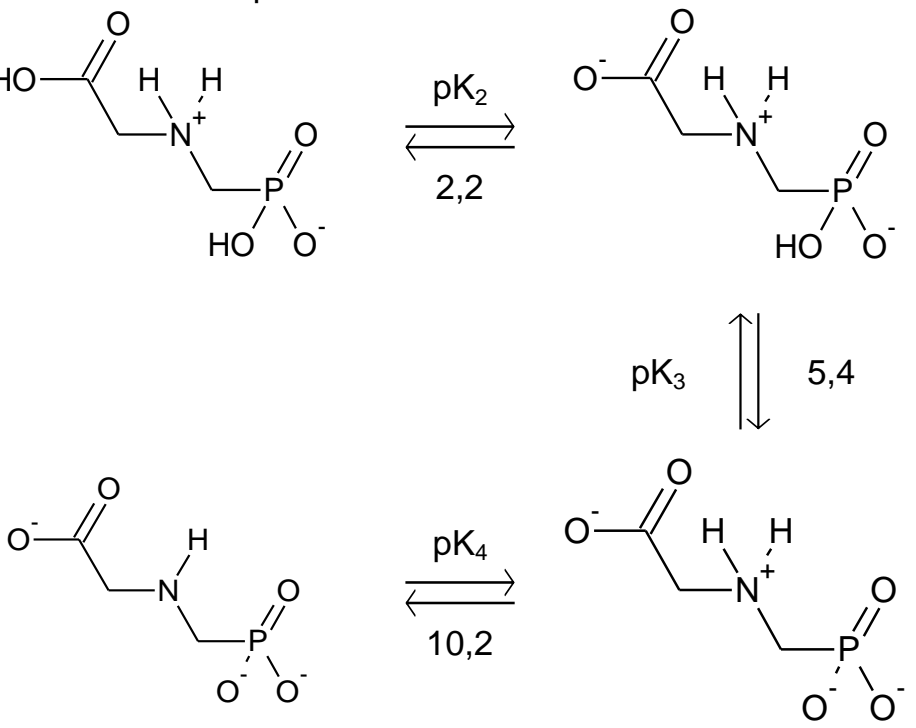

A grande maioria dos métodos encontrados na literatura que abordam a determinação de glifosato são métodos para análises de resíduo em diferentes tipos 
de matrizes. ${ }^{88-93}$ Esses métodos são importantes, pois, devido à toxicidade desse herbicida, sua quantidade residual deve ser monitorada e se manter dentro do permitido pela legislação para que seja conservada a saúde humana e o ambiente.

Não menos importante, a análise do teor do ingrediente ativo em formulações garante a eficácia dos produtos, além de possibilitar o registro dos mesmos perante aos órgãos regulamentadores, os quais também fiscalizarão seu uso e sua comercialização.

Há poucas pesquisas que abordam este tipo de análise para controle de qualidade dos produtos técnicos e/ou formulados de glifosato. ${ }^{93-96}$ No entanto, para isso, existem métodos oficiais, tais como os da AOAC (Association of Analiytical Communities) e da CIPAC (Collaborative International Pesticides Analytical Council), porém estes são bastante trabalhosos, além de desatualizados. ${ }^{97,98}$

Apesar desses métodos não abordarem análises de RMN, o emprego dessa técnica é recomendado aqui no Brasil para análises de cinco bateladas (Five Batch Analysis) e aparece descrita na instrução normativa brasileira, a qual teve sua última consulta pública realizada em janeiro de $2011 .^{99}$

$\mathrm{Na}$ literatura encontram-se alguns trabalhos, nos quais métodos de RMN de ${ }^{1} \mathrm{H}$ e de ${ }^{31} \mathrm{P}$ são empregados para a determinação do teor de glifosato.

Em 2002, Al Deen e colaboradores desenvolveram e validaram métodos de RMN de ${ }^{1} \mathrm{H}$ e de ${ }^{31} \mathrm{P}$ para a exemplificação de análises de cinco bateladas de produtos a base de glifosato e profenofós. Neste trabalho eles empregaram quatro tipos diferentes de padrão interno (uma para cada método e para cada analito), os quais foram padronizados a partir do dimetil sulfona $\left(\mathrm{DMSO}_{2}\right)$, padrão analítico certificado, e obtiveram desvios-padrão inferiores a 0,6, considerando replicatas de um mesmo lote. Além disso, estabeleceram um perfil de impurezas para ambos os analitos e as quantificaram. ${ }^{100}$

Posteriormente, esses mesmos pesquisadores estudaram a incerteza desse método e obtiveram o valor de $0,66 \%$ no método de ${ }^{1} \mathrm{H}$ e $0,82 \%$, no de ${ }^{31} \mathrm{P}$, com intervalo de confiança de $95 \%$ e k=2 para ambos. Neste estudo também verificaram que a maior fonte de incerteza do método é proveniente da pureza do padrão interno. ${ }^{101}$

Mais recentemente, em 2012, Shamsipur e colaboradores, publicaram um trabalho no qual aplicam a RMN de ${ }^{31} \mathrm{P}$ em ensaios de pureza simultâneos de cinco pesticidas organofosforados em produtos técnicos e formulados, dentre eles, o 
glifosato. Para isso, empregaram ácido fosfórico como padrão interno e houve excelente concordância entre os resultados por RMN e aqueles obtidos por métodos padrão. O método proposto se mostrou rápido, simples e seguro, pois são analisadas amostras tóxicas sem a necessidade de pré-tratamento, permitindo a análise de rotina de pesticidas em amostras reais. ${ }^{102}$

Além disso, a RMN de ${ }^{1} \mathrm{H}$ e de ${ }^{31} \mathrm{P}$ também têm sido empregada em análises de fluidos biológicos para a determinação de glifosato, em casos de envenenamento. ${ }^{103,104}$

\subsubsection{O Azeite de Oliva e a RMN:}

De acordo com a Instrução Normativa № 1, de 30 de janeiro de 2012 do MAPA, a qual pretende estabelecer o regulamento técnico do azeite de oliva e entrou em vigor em 03/08/2012, o azeite de oliva é:

o produto obtido somente do fruto da oliveira (Olea europaea L.) excluído todo e qualquer óleo obtido pelo uso de solvente, por processo de reesterificação ou pela mistura com outros óleos, independentemente de suas proporções. ${ }^{105}$

Ainda de acordo com esta normativa,

Azeite de oliva virgem é o produto obtido do fruto da oliveira (Olea europaea L.), somente por processos mecânicos ou outros meios físicos, em condições térmicas, que não produzam alteração do azeite, e que não tenha sido submetido a outros tratamentos além da lavagem, decantação, centrifugação e filtração. ${ }^{105}$

As propriedades nutricionais e terapêuticas do azeite vêm sendo demonstradas em vários trabalhos científicos. ${ }^{106-109}$ Há muitas evidências de que esse tipo de gordura pode ter efeitos benéficos na prevenção de doenças cardiovasculares e do câncer, principalmente o azeite não refinado ou virgem. Ele é praticamente isento de gordura saturada e contêm 0 ácido oleico, altas concentrações de vitamina $E$, beta caroteno e polifenóis, além da típica gordura monoinsaturada presente em todos os tipos de azeite. A associação desses compostos provavelmente seja a responsável pela sua atividade antioxidante e antiinflamatória. ${ }^{106-109}$

Esses fatores, somados às suas propriedades organolépticas, fazem do azeite um produto altamente consumido. Segundo o Conselho Internacional do Azeite, no ano de 2012, o consumo mundial foi de 3,137 milhões de toneladas, 
sendo a Espanha o maior produtor, produzindo 1,613 milhões de toneladas, e a Itália o maior consumidor, consumindo 724,5 mil toneladas. ${ }^{110}$

Devido ao alto preço do azeite de oliva, este vem sendo alvo constante de falsificações. De acordo com uma reportagem da revista Veja, a qual cita o livro Extra Virginity: The Sublime and Scandalous World of Olive Oil, publicado em dezembro de 2011 pelo jornalista americano Tom Mueller, os maiores produtores do mundo ganham muito dinheiro misturando óleos de variados tipos com o caro azeite de oliva. ${ }^{111}$

Este fato tem motivado estudos que resultem em métodos alternativos para análises de azeites e detecção deste tipo de adulterações, uma vez que os métodos oficiais para a determinação da composição dos ácidos graxos em óleos diversos se limitam às análises cromatográficas, as quais, por sua vez, exigem métodos oficiais para a realização das reações de transesterificação necessárias. ${ }^{1113}$

Nesse contexto, inúmeras pesquisas são encontradas na literatura, nas quais diversos métodos são desenvolvidos com este intuito, empregando as mais diferentes ferramentas analíticas. ${ }^{113-120} \mathrm{~A}$ maioria dos trabalhos que envolvem RMN e azeites utilizam as informações da RMN em alta resolução. ${ }^{121-124}$

Uma possibilidade estudada por Yalcin e colaboradores é a predição da composição de ácidos graxos em óleos vegetais a partir da avaliação de suas propriedades reológicas. ${ }^{125}$ Neste estudo, investigou-se a aplicabilidade de modelos não lineares para a determinação dos ácidos graxos em sete óleos vegetais e, a partir desta determinação, foi possível se obter rapidamente informações sobre a adulteração. $^{125}$

O mesmo pode vir a ser feito por RMN-DT, uma vez que o decaimento do sinal CPMG está diretamente relacionado com a viscosidade do óleo e esta, por sua vez, é dependente da composição química do mesmo.

Embora hajam métodos normatizados que empregam a RMN no domínio do tempo (RMN-DT) para análises de sementes, de óleos e de gorduras animal e vegetal ainda não há método oficial algum que empregue a RMN-DT em análises específicas de azeite, como detecção de adulteração, por exemplo. ${ }^{33,57,59}$

Zhang e colaboradores têm explorado a RMN-DT para discriminar óleo comestível adulterado com óleo usado em frituras baseando em seus diferentes tempos de relaxação transversal $\left(\mathrm{T}_{2}\right) .{ }^{126}$ Uma vantagem da utilização desta técnica, não explorada nesse trabalho, é a possibilidade de análises do produto diretamente 
nas embalagens, sem a necessidade de rompimento do lacre, o que permitiria a posterior comercialização do mesmo produto analisado.

Análises de vinhos em embalagens já têm sido realizadas por RMN em alta resolução e por RMN-DT. ${ }^{127-129}$

Em 2003, Weekley e colaboradores descreveram e utilizaram uma sonda e um espectrômetro de RMN capaz de investigar garrafas de vinhos intactas. Neste trabalho, eles estudaram uma série de vinhos Cabernet Sauvignons através da RMN de ${ }^{1} \mathrm{H}$ e amostras selecionadas foram analisadas por ${ }^{13} \mathrm{C}$. Obtiveram-se informações sobre os açúcares, fenóis e componentes minoritários. ${ }^{127}$

Sobieski e colaboradores desenvolveram em 2006 um método rápido de RMN de ${ }^{1} \mathrm{H}$ empregando uma sequência de pulsos editada para estudar a oxidação dos vinhos ocorrida no interior das garrafas. ${ }^{128}$

E em 2011, foi avaliado por Harley e colaboradores a aplicação de RMN-DT aliada à Análise de Componentes Principais (PCA) para verificar falsificação de vinhos sem a necessidade de violação do lacre. ${ }^{129}$

No entanto, a aplicação da RMN-DT para análises de azeites diretamente nas garrafas lacradas, conforme realizado no presente estudo, é inédita.

\subsubsection{O Fitoterápico Cardo-leiteiro e a RMN:}

O estudo quali-quantitativo via RMN para fitoterápicos foi particularizado para a planta medicinal popularmente conhecida como Cardo-leiteiro (Silybum marianum L. Gaertn., Asteraceae). Esta planta, também popularmente conhecida por cardo-santo ou cardo-maria, é uma erva bianual, oriunda da Europa e ambientada no Brasil, sendo cultivada como planta ornamental no sul do país e utilizada também em saladas. Seus frutos acumulam grande quantidade de lipídeos (20 a 30 \%), além de proteínas, carboidratos e alguns flavonóides. ${ }^{130}$

O cardo leiteiro é o fitoterápico de maior tradição de uso em distúrbios hepáticos e, por isso, vem sendo investigada com muito interesse em vários países. $\mathrm{Na}$ Europa, nos Estados Unidos e também no Brasil são comercializados produtos contendo extratos padronizados, com indicação em disfunções hepáticas, inclusive cirrose hepática. ${ }^{130}$

Como componentes de ação anti-hepatotóxica considera-se a mistura de substâncias denominada silimarina, presente entre 1,5 a 3,0\% do peso da droga. 
Esta mistura é constituída por várias flavolignanas, sendo a silibina (também conhecida como silibinina) o constituinte majoritário, acompanhada de outros isômeros. Os outros principais constituintes da silimarina são a silidianina, a silicristina, a isosilicristina e a taxofolina. Na Figura 4 podem ser visualizadas as fórmulas estruturais desses compostos. ${ }^{130,131}$

Figura 4 - Fórmulas estruturais dos constituintes químicos da silimarina<smiles>COc1cc([C@H]2Oc3cc([C@@H]4Oc5cc(O)cc(O)c5C(=O)[C@H]4O)ccc3O[C@H]2CO)ccc1O</smiles>

silibina A<smiles>COc1cc([C@H]2Oc3ccc([C@@H]4Oc5cc(O)cc(O)c5C(=O)[C@H]4O)cc3O[C@H]2CO)ccc1O</smiles>

isosilibina $\mathrm{A}$<smiles>COc1cc(C2Oc3c(O)cc([C@@H]4Oc5cc(O)cc(O)c5C(=O)C4O)cc3[C@@H]2CO)ccc1O</smiles>

silicristina

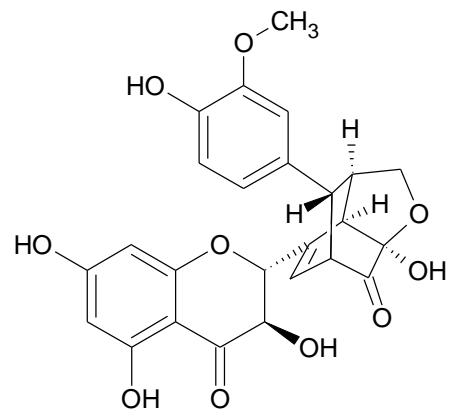

silidianina<smiles>COc1cc(C2Oc3cc([C@@H]4Oc5cc(O)cc(O)c5C(=O)[C@H]4O)ccc3O[C@@H]2CO)ccc1O</smiles>

silibina B<smiles>COc1cc([C@H]2Oc3ccc([C@@H]4Oc5cc(O)cc(O)c5C(=O)[C@H]4O)cc3O[C@H]2CO)ccc1O</smiles>

isosilibina B<smiles>COc1cc(C2Oc3c(O)ccc(C4Oc5cc(O)cc(O)c5C(=O)C(O)C4O)c3C2CO)ccc1O</smiles>

isosilicristina<smiles>O=C1c2c(O)cc(O)cc2O[C@@H](c2ccc(O)c(O)c2)[C@@H]1O</smiles>

taxofolina

O parâmetro qualidade é muito complexo quando se trabalha com espécies botânicas, tais como a Silybum marianum L. Gaertn, e por isso é um dos maiores desafios para as indústrias que trabalham com medicamentos a base de plantas. 
Considerando este fato, um novo método que avalia os extratos vegetais complexos em sua totalidade tem sido estudado e desenvolvido. Essa nova abordagem é denominada perfil metabólico e utiliza, de uma maneira geral, o fingerprint das espécies em estudo. ${ }^{132-138}$

Um exemplo deste tipo de estudo envolvendo a aplicação da RMN foi desenvolvido por Santos e colaboradores para controle de qualidade de drogas vegetais a base de plantas do gênero Phyllantus, popularmente conhecida como "Quebra-Pedra". Neste trabalho foram criados fingerprints de cinco espécies distintas desse mesmo gênero e, a partir das análises quimiométricas dos dados de RMN, foi possível diferenciá-las e construir modelos para classificação de amostras comerciais. $^{132}$

Nesse contexto, a espectroscopia de ressonância magnética nuclear vem se mostrando uma ferramenta analítica de grande utilidade, uma vez que possui a capacidade de fornecer simultaneamente informações qualitativas e quantitativas, mesmo em amostras complexas, as quais contêm diversos compostos químicos presentes, tais como os extratos de plantas. ${ }^{139-141}$

Apesar disso, a grande maioria dos trabalhos encontrados na literatura empregando RMN neste tipo de estudo utilizam apenas as informações qualitativas fornecidas pela técnica. ${ }^{132-138}$

As informações quantitativas têm sido recentemente exploradas em estudos de plantas medicinais diversas por pesquisadores do Departamento de Química Medicinal e Farmacognosia da Faculdade de Farmácia, na Universidade de Illinois em Chicago. ${ }^{142-145}$

Por exemplo, no ano de 2012, Napolitano e colaboradores desenvolveram um método empregando RMNq para quantificar simultaneamente os marcadores da planta conhecida como Ginkgo Biloba, assim como Gödecke e colaboradores, em seu trabalho com a planta Angélica. ${ }^{144,145}$

Assim, considerando a potencialidade da espectroscopia de RMN para análises quali-quantitativas e a necessidade de controle de qualidade em produtos fitoterápicos provenientes de plantas medicinais diversas, o desenvolvimento de novos métodos se faz pertinente. 


\section{OBJETIVOS}

\subsection{Objetivo Geral}

O objetivo do presente trabalho foi 0 desenvolvimento de métodos empregando técnicas de Ressonância Magnética Nuclear (RMN) para controle de qualidade de produtos farmacêuticos e agrícolas.

\subsection{Objetivos Específicos}

- Desenvolvimento e validação de método por RMN em alta resolução de ${ }^{1} \mathrm{H}$, para a quantificação do fármaco paracetamol em diferentes tipos de formulações, de tal forma que atenda as exigências contidas na normativa Resolução RE no 899;

- Desenvolvimento e validação de métodos por RMN em alta resolução de ${ }^{1} \mathrm{H}$ e ${ }^{31} \mathrm{P}$ consecutivos, para a quantificação do agrotóxico glifosato em diferentes formulações, de tal forma que atendam as exigências contidas na NBR 14029;

- Desenvolvimento e validação de método quantitativo empregando RMN no domínio do tempo para determinação de adulteração em azeites de oliva com óleo de soja em embalagens lacradas;

- Desenvolvimento de método quantitativo e qualitativo por RMN para a caracterização dos fitoconstituintes dos extratos e dos fitoterápicos provenientes da planta Cardo-Leiteiro (Silybum marianum L. Gaertn., Asteraceae). 


\section{MATERIAIS E MÉTODOS}

\subsection{Materiais e Equipamentos}

\subsubsection{Quantificação de Paracetamol:}

O composto dimetil sulfona - $\mathrm{DMSO}_{2}$ (Material de Referência Certificado MRC, rastreável ao National Institute of Standards and Technology - NIST) 99,65 \pm $0,08 \%$, empregado como padrão interno (PI) foi adquirido da Sigma Aldrich e a substância de referência (SR) de paracetamol 99,8\%, da Fiocruz. Os medicamentos comerciais avaliados foram adquiridos no mercado local.

Todas as pesagens foram realizadas em uma balança semi-micro analítica, modelo AUW 220D da marca Shimadzu. Para as transferências de volumes utilizaram-se micropipetas automáticas, modelo Research ${ }^{\circledR}$ da marca Eppendorf, de volumes variáveis $10 \mu \mathrm{L}-100 \mu \mathrm{L}$ e $100 \mu \mathrm{L}-1000 \mu \mathrm{L}$.

As medidas espectroscópicas de RMN de ${ }^{1} \mathrm{H}$ foram executadas com uma sonda multinuclear de observação direta de $5 \mathrm{~mm}$, em um espectrômetro Varian Inova 400, de 9,4 Tesla (399,993 MHz para a frequência do hidrogênio) localizado no Laboratório de RMN da Embrapa Instrumentação. O processamento foi realizado utilizando o software do espectrômetro, VNMRJ (Varian, Inc.), operando em plataforma Linux versão RedHat e, alternativamente, o MestReNova versão 8.1.

Para a realização dos cálculos foram utilizadas planilhas no software Excel versão 2003 e/ou 2010.

\subsubsection{Quantificação de Glifosato:}

Os padrões analítico (PA) de Glifosato PESTANAL ${ }^{\circledR} 99,2 \%$ e $99,9 \%$ foram adquiridos da Sigma Aldrich e os produto comerciais, adquiridos no mercado local. A solução $0,0485 \mathrm{~mol} / \mathrm{L}$ de trifenil fosfato em clorofórmio deuterado foi obtida a partir dos padrões de referência fornecidos pelo fabricante do equipamento Varian/Agilent.

Nos estudos preliminares foram utilizados os mesmos materiais $\mathrm{e}$ equipamentos descritos no método desenvolvido para o paracetamol. Neste caso, os espectros também foram processados no software VNMRJ (Varian, Inc.), operando em plataforma Linux versão RedHat e, alternativamente, no MestReNova versão 8.1.

Para as demais análises, além das mesmas micropipetas, empregou-se a balança semi-microanalítica mecânica Mettler H54AR e espectrômetro Bruker 
AVANCE III HD de 14,1T (600,13 MHz para a frequência do hidrogênio), também utilizando uma sonda multinuclear de $5 \mathrm{~mm}$, mas de detecção inversa. Os espectros adquiridos nesse equipamento foram processados no software TopSpin versão 3.2 e, alternativamente, no MestReNova versão 8.1 .

Os cálculos também foram efetuados em planilhas do software Excel versão 2003 e/ou 2010.

\subsubsection{Quantificação de Ácidos Graxos em Óleos e Azeites:}

Doze amostras de óleos de amendoins previamente extraídos das sementes e analisados por cromatografia gasosa foram medidas por RMN em alta resolução empregando o espectrômetro Varian Inova 400, de 9,4 Tesla (399,993 MHz para a frequência do hidrogênio) utilizando uma sonda multinuclear de observação direta de $5 \mathrm{~mm}$ e o processamento foi realizado no software ACD/NMRProcessor Academic Edition.

\subsubsection{Detecção de Adulteração de Azeites com Óleo de Soja em Embalagens}

\section{Lacradas:}

O azeite de oliva e o óleo de soja, considerados padrões, foram adquiridos no comércio local, assim como as amostras de azeites posteriormente avaliadas pelo método desenvolvido.

O mesmo espectrômetro e processamento empregados nas análises dos óleos de amendoins foram utilizados para a análise do azeite considerado padrão.

As demais análises foram realizadas um espectrômetro SLK CA02.12 de campo magnético estático de 0,21 $\mathrm{T}\left(8,5 \mathrm{MHz}\right.$ para $\left.{ }^{1} \mathrm{H}\right)$ e área de detecção de 10 $\mathrm{cm}$ de diâmetro por $10 \mathrm{~cm}$ de comprimento. Os softwares empregados nos processamentos foram o Condor IDE (Spinlock Magnetic Resonance Solutions, Córdoba, Ar) e o OriginPro 8.0.

\subsubsection{Quantificação dos Constituintes da Silimarina:}

Sementes certificadas (Material de Referência Botânica), codificadas por BRM, foram adquiridas da American Herbal Pharmacopoeia (AHP) e um extrato padrão de referência, codificado por USP, foi obtido da United States Phamacopoeia (USP). 
Onze amostras de produtos comerciais foram adquiridas em farmácias americanas (B, C, G, NA, NB, NH, NW, P, SB, SN, SP) e sete amostras de sementes foram adquiridas em fontes comerciais de diferentes partes do mundo $\mathrm{Br}$ - Brasil, C - Croácia, B - Bulgária, P - Polônia, WF - Estados Unidos, E - Egito e I - Estados Unidos); sendo que as sementes codificadas por E e I correspondem a plantas com flores brancas, diferentemente das demais, as quais possuem flores púrpuras.

Os compostos dimetilsulfona $(99,73 \pm 0,05 \%)$ e 3,5 ácido dinitrobenzóico $(99,54 \pm 0,05 \%)$, ambos MRCs rastreáveis ao NIST, foram adquiridos da Sigma Aldrich.

Todas as pesagens foram realizadas em uma balança semi-micro analítica, modelo XP205, marca Mettler Toledo. Para as transferências de volumes utilizaramse micropipetas automáticas, modelo Research da marca Eppendorf, de volumes variáveis $0,5 \mu \mathrm{L}-10 \mu \mathrm{L}$ e $100 \mu \mathrm{L}-200 \mu \mathrm{L}$.

As extrações foram realizadas empregando um Extrator Acelerado por Solvente, Dionex $350^{\oplus}$.

Os espectros foram adquiridos em um espectrômetro Bruker AVANCE 14,1 T, equipado com uma sonda criogênica de $5 \mathrm{~mm}$, localizado no Centro de Biologia Estrutural da Universidade de Illinois em Chicago. Os espectros foram processados no software TopSpin versão 3.0. Alternativamente, também se empregou o software MestReNOva versão 8.1.

Os dados obtidos foram também avaliados através dos softwares PERCH NMR versão 2010.1 e AMIX versão 3.7.

Planilhas do software Excel foram empregadas para a efetuação dos cálculos.

\subsection{Análise por RMN}

Todas as medidas de $\mathrm{RMN}$ foram realizadas à temperatura do laboratório ( $\mathrm{T} \cong$ $23 \stackrel{\circ}{\circ}$ ). Para as análises de ${ }^{1} \mathrm{H}$ empregou-se a sequência de pulsos esquematizada na Figura 5, e a aquisição dos espectros de ${ }^{31} \mathrm{P}$ foram feitas com o desacoplador de ${ }^{1} \mathrm{H}$ ligado durante todo o tempo de aquisição (canal não ilustrado na Figura 5).

Anteriormente a qualquer aquisição espectral, foram realizados os ajustes de sintonia fina da frequência (matching e tuning). O ajuste da homogeneidade do 
campo magnético (shimming), foi otimizado para cada uma das replicatas analisadas.

Figura 5 - Representação esquemática da sequência de pulso empregada para a aquisição dos espectros de ${ }^{1} \mathrm{H}$ e de ${ }^{31} \mathrm{P}$

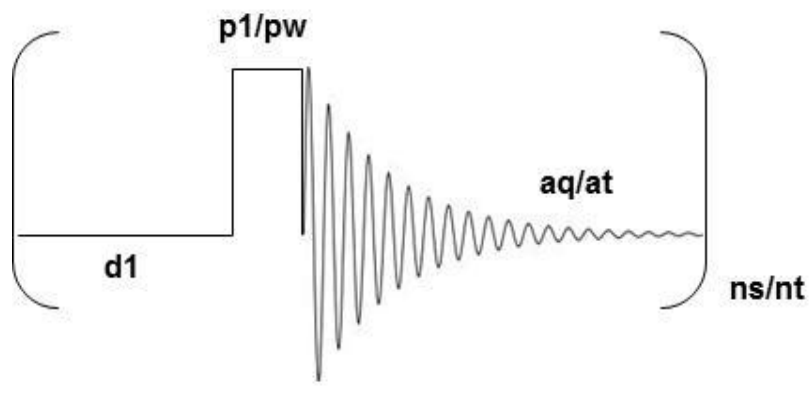

O valor $T_{1}$ das amostras analisadas quantitativamente foi previamente estimado determinando o tempo de espera em que o sinal é anulado ( $\tau_{\text {null }}$ ) na sequência de pulsos de Inversão e Recuperação (Figura 1A) e a relação descrita na equação 8:

$$
T_{1}=\frac{\tau_{\text {null }}}{\ln 2}=1,443 \tau_{\text {null }}
$$

equação 8

\subsubsection{Método para Quantificação de Paracetamol:}

Considerando o valor de $\mathrm{T}_{1}$ previamente estimado, utilizou-se um tempo de aquisição (at/aq) igual a 6,7 segundos e um tempo de espera (d1) de 20 segundos entre a aquisição e o próximo pulso. Foram acumulados 8 transientes (nt/ns) com 64000 pontos durante a aquisição (np/td) em uma janela espectral (swh) de 4799,9 $\mathrm{Hz}$ e um ganho igual a 42, para as ensaios de validação, e 22, para algumas das amostras comerciais. As aquisições foram feitas com as amostras girando a uma velocidade igual $20 \mathrm{~Hz}$.

A escala de deslocamento químico dos espectros foi referenciada pelo sinal do TMS (tetrametilsilano), em 0,00 ppm. Em casos de ausência do TMS, como por exemplo, na aquisição dos brancos, esta escala foi referenciada pelo sinal residual do solvente (DMSO- $\mathrm{d}_{6}$ ) em 2,50 ppm e no caso particular dos espectros obtidos em $\mathrm{D}_{2} \mathrm{O}$, o referenciamento da escala de deslocamento químico foi feito a partir do sinal da água (HOD) em 4,81 ppm. 
Os espectros foram processados com 65536 pontos (fn/si). Utilizou-se uma multiplicação exponecial com um $\mathrm{lb}=0,3 \mathrm{~Hz}$, correções automática da linha de base e manual da fase. As integrações também foram realizadas manualmente, respeitando um intervalo de 20 vezes a largura de linha à meia altura do sinal (20 x $\left.\Delta v_{1 / 2}\right)$, que corresponde a aproximadamente $97 \%$ da área total de um sinal lorentziano. ${ }^{146}$

Para avaliação da interferência de alguns parâmetros de aquisição e de processamento no resultado da medida, esses foram variados e tiveram valores diferentes dos descritos acima (Tabela 1).

Tabela 1 - Parâmetros espectrais avaliados na validação do método de RMNq para determinação de paracetamol

\begin{tabular}{cc|cc|cc}
\hline parâmetro & valores & parâmetro & valores & parâmetro & valores \\
\hline pw/p1 & $30^{\circ}$ e $45^{\circ}$ & giro & $0 \mathrm{~Hz}$ & $\mathrm{nt} / \mathrm{ns}$ & 1 e 16 \\
$\mathrm{~d} 1$ & $6,67 \mathrm{~s} \mathrm{e}$ & $\mathrm{np} / \mathrm{td}$ & $32000 \mathrm{e}$ & $\mathrm{fn} / \mathrm{si}$ & $32 \mathrm{k} \mathrm{e} 96 \mathrm{k}$ \\
& $8,57 \mathrm{~s}$ & & 128000 & & $0 \mathrm{~Hz}$ e 1,0 \\
ganho/rg & 22 & $\mathrm{at} / \mathrm{aq}$ & $3,33 \mathrm{~s} \mathrm{e}$ & $\mathrm{lb}$ & $\mathrm{Hz}$ \\
\hline
\end{tabular}

\subsubsection{Método para Quantificação de Glifosato:}

\section{I) Estudos Preliminares}

Os parâmetros empregados na aquisição e no processamento dos espectros de ambos os núcleos, se encontram na Tabela 2.

Tabela 2 - Parâmetros espectrais empregados nos estudos preliminares do método de RMNq para determinação de glifosato

\begin{tabular}{ccc}
\hline parâmetro & ${ }^{1} \mathbf{H}$ & ${ }^{31} \mathbf{P}$ \\
\hline $\mathrm{pw} / \mathrm{p} 1\left(90^{\circ}\right)$ & $19,5 \mu \mathrm{s}$ & $7,225 \mu \mathrm{S}$ \\
$\mathrm{d} 1$ & $41 \mathrm{~s}$ & 32 \\
ganho/gain & 50 & 60 \\
giro & 0 & 0 \\
$\mathrm{np} / \mathrm{nt}$ & 64000 & 64000 \\
$\mathrm{at} / \mathrm{aq}$ & $8 \mathrm{~s}$ & $2,47 \mathrm{~s}$ \\
$\mathrm{nt} / \mathrm{ns}$ & 8 & 8 \\
$\mathrm{swh}$ & $4000 \mathrm{~Hz}$ & $12959,7 \mathrm{~Hz}$ \\
$\mathrm{fn} / \mathrm{si}$ & $65 \mathrm{k}$ & $65 \mathrm{k}$ \\
$\mathrm{lb}$ & $0,3 \mathrm{~Hz}$ & $5,0 \mathrm{~Hz}$ \\
\hline
\end{tabular}


O refenciamento da escala de deslocamentos químicos foi feito pelo sinal residual do solvente (HDO) em 4,81 ppm, nos espectros de ${ }^{1} \mathrm{H}$, e em -17,8 ppm para o sinal do trifenil fosfato (padrão externo - PE), nos espectros de ${ }^{31} \mathrm{P}$.

As correções de fase foram feitas manualmente e as de linha de base, automaticamente. Os intervalos de integração foram definidos automaticamente, com exceção do sinal de ${ }^{1} \mathrm{H}$ do trifenil fosfato, o qual teve que ser limitado manualmente, pois a integração automática considerava a região aromática como um todo.

\section{II) Método Validado}

$\mathrm{Na}$ Tabela 3 estão descritos os parâmetros empregados na aquisição e no processamento dos espectros de ambos os núcleos. A escala de deslocamento químico foi referenciada da mesma maneira feita no método preliminar.

As correções de fase foram feitas manualmente, as de linha de base, automaticamente e os intervalos de integração foram fixados para as replicatas de cada ensaio da validação ou amostra comercial.

Tabela 3 - Parâmetros espectrais empregados no método validado de RMNq para determinação de glifosato

\begin{tabular}{ccc}
\hline parâmetro & ${ }^{1} \mathbf{H}$ & ${ }^{31} \mathbf{P}$ \\
\hline $\mathrm{pw} / \mathrm{p} 1\left(90^{\circ}\right)$ & $9,87 \mu \mathrm{s}$ & $11,30 \mu \mathrm{s}$ \\
$\mathrm{d} 1$ & $41 \mathrm{~s}$ & 32 \\
ganho/gain & 16 & 2050 \\
giro & 0 & 0 \\
$\mathrm{np} / \mathrm{td}$ & $192 \mathrm{k}$ & $256 \mathrm{k}$ \\
$\mathrm{at} / \mathrm{aq}$ & $8,06 \mathrm{~s}$ & $1,36 \mathrm{~s}$ \\
$\mathrm{nt} / \mathrm{ns}$ & 8 & 8 \\
$\mathrm{swh}$ & $12195,122 \mathrm{~Hz}$ & $96153,844 \mathrm{~Hz}$ \\
$\mathrm{fn} / \mathrm{si}$ & $512 \mathrm{k}$ & $256 \mathrm{k}$ \\
$\mathrm{lb}$ & $0,3 \mathrm{~Hz}$ & $3,0 \mathrm{~Hz}$ \\
\hline
\end{tabular}

\subsubsection{Método para Quantificação de Ácidos Graxos em Óleos e Azeites:}

As medidas de $\mathrm{RMN}$ de ${ }^{1} \mathrm{H}$ foram executadas girando a amostra a $20 \mathrm{~Hz}$, com $\mathrm{pw} / \mathrm{p} 1\left(90^{\circ}\right)=13,6 \mu \mathrm{s}, \mathrm{sw}=4799,9 \mathrm{~Hz}, \mathrm{np} / \mathrm{td}=32000$, at $/ \mathrm{aq}=6,67 \mathrm{~s}$ e $\mathrm{d} 1=1,0 \mathrm{~s}$. Os 
espectros foram processados com $\mathrm{lb}=0,3 \mathrm{~Hz}$, zero filling $=32728$ e correções automática da linha de base. O ajuste de fase e as integrações foram realizados manualmente. Os deslocamentos químicos foram referenciados pelo sinal do TMS em 0,00 ppm.

\subsubsection{Método para Detecção de Adulteração de Azeites com Óleo de Soja em Embalagens Lacradas:}

As medidas de RMN-DT foram realizadas a $22,0 \pm 0,5{ }^{\circ} \mathrm{C}$ utilizando-se a sequência de pulsos Carr-Purcel-Meiboom-Gill (CPMG), ilustrada na Figura 1B, nas seguintes condições: $\mathrm{P} 90=5,96 \mu \mathrm{s} ; \mathrm{P} 180=11,72 \mu \mathrm{s} ; \tau=1 \mathrm{~ms} ; 600$ ecos; $\operatorname{Tr}(\mathrm{at}+\mathrm{d} 1)=$ 1,5 s e 4 scans.

\subsubsection{Método para Quantificação dos Constituintes da Silimarina:}

Os parâmetros de aquisição e processamento dos espectros quantitativos de ${ }^{1} \mathrm{H}$ estão descritos na Tabela 4.

Os deslocamentos químicos de ${ }^{1} \mathrm{H}(\bar{\delta})$ foram expressos em ppm, referenciados pelo sinal residual do solvente DMSO- $\mathrm{d}_{6}$ (DMSO- $\mathrm{d}_{5} ; 2,500$ ppm relativo à escala do TMS). As correções de fase, de linha de base e a determinação dos intervalos de integração foram feitas manualmente.

Tabela 4 - Parâmetros espectrais empregados no método de RMNq para determinação dos constituintes da silimarina

\begin{tabular}{cc}
\hline parâmetro & valor \\
\hline $\mathrm{p} 1\left(9^{\circ}\right)$ & $8,70 \mu \mathrm{s}$ \\
$\mathrm{d} 1$ & $30 \mathrm{~s}$ \\
$\mathrm{rg}$ & 64 \\
giro & 0 \\
td & 148000 \\
$\mathrm{aq}$ & $3,999 \mathrm{~s}$ \\
$\mathrm{~ns}$ & 16 \\
$\mathrm{sw}$ & $17985,61 \mathrm{~Hz}$ \\
$\mathrm{si}$ & $256 \mathrm{k}$ \\
$\mathrm{lb}$ & $0,3 \mathrm{~Hz}$ \\
\hline
\end{tabular}




\subsection{Preparo das Amostras}

\subsubsection{Método para Quantificação de Paracetamol:}

\section{I) Ensaio de Seletividade/ Especificidade}

Nos ensaios de seletividade/especificidade foram analisados os brancos: do solvente (BS); do padrão interno (BPI) e da substância de referência (BSR). Para isso, primeiramente transferiu-se uma alíquota de $600 \mu \mathrm{L}$ do solvente ser empregado nas análises - dimetil sulfóxido deuterado $\left(\mathrm{DMSO}-\mathrm{d}_{6}\right)$ - para um tubo de RMN de 5 $\mathrm{mm}$.

Após aquisição espectral do BS, solubilizou-se $0,00432 \mathrm{~g}$ do PI no solvente previamente analisado, transferiu-se a solução obtida para um tubo de $\mathrm{RMN}$, no qual foram adicionados aproximadamente $10 \mu \mathrm{L}$ de TMS (tetrametilsilano) para a calibração do espectro $(\delta=0,00)$ e o ajuste da homogeneidade do campo magnético principal, e um novo espectro foi obtido. Por fim, $0,00418 \mathrm{~g}$ da SR foi dissolvida em uma outra alíquota de $600 \mu \mathrm{L}$ do DMSO- $\mathrm{d}_{6}$ e procedeu-se o preparo similarmente ao BPI.

Também foram adquiridos, da mesma maneira descrita para o DMSO- $\mathrm{d}_{6}$, os brancos do metanol deuterado e da água deuterada $\left(\mathrm{D}_{2} \mathrm{O}\right)$. O primeiro foi empregado em um dos ensaios de robustez e o segundo na análise simultânea de ativos para uma das amostras comerciais.

\section{II) Ensaio de Linearidade e Intervalo}

Para o ensaio de linearidade pesaram-se, em cinco microtubos tipo Eppendorf de 2,0 mL, massas de PI e massas da SR, de acordo com a Tabela 5.

Tabela 5 - Massas de PI e SR utilizadas no ensaio de Linearidade/Intervalo ( $L$ ) do método de RMNq para determinação de paracetamol

\begin{tabular}{ccc}
\hline Código & massa de PI (g) & massa de SR (g) \\
\hline$L 1$ & 0,00588 & 0,00110 \\
$L 2$ & 0,00509 & 0,00319 \\
$L 3$ & 0,00515 & 0,00539 \\
$L 4$ & 0,00549 & 0,00710 \\
$L 5$ & 0,00471 & 0,01022 \\
\hline
\end{tabular}


A cada um desses microtubos foram adicionados, com auxílio da micropipeta, $600 \mu \mathrm{L}$ DMSO-d . Então, agitou-se manualmente até completa solubilização. Em seguida, transferiu-se as soluções obtidas para os tubos de RMN de $5 \mathrm{~mm}$, nos quais foram adicionados aproximadamente $10 \mu \mathrm{L}$ de TMS com os mesmos objetivos descritos no item anterior.

III) Ensaios de Exatidão, Repetitividade, Robustez e Precisão Intermediária

Para os demais ensaios da validação foram preparadas amostras, em triplicatas, de três massas de SR diferentes, da mesma maneira descrita para o Ensaio de Linearidade e Intervalo. As massas de PI e de SR pesadas para cada um dos ensaios estão descritas nas Tabelas 6 a 8 . Em um dos ensaios de Robustez ( $R B I, R B I l$ e RBIII), as massas pesadas foram dissolvidas em metanol deuterado e não em DMSO-d $\mathrm{d}_{6}$, como nos outros ensaios.

Tabela 6 - Massas de PI e SR utilizadas nos ensaios de Exatidão e Repetitividade $\AA^{\circledR}$ do método de RMNa para determinação de paracetamol

\begin{tabular}{ccc}
\hline Código & massa de PI (g) & massa de SR (g) \\
\hline$R 1 a$ & 0,00498 & 0,00100 \\
$R 1 b$ & 0,00498 & 0,00125 \\
$R 1 c$ & 0,00491 & 0,00111 \\
\hline$R 2 a$ & 0,00479 & 0,00530 \\
$R 2 b$ & 0,00515 & 0,00539 \\
$R 2 c$ & 0,00507 & 0,00528 \\
$R 3 a$ & 0,00471 & 0,01022 \\
$R 3 b$ & 0,00585 & 0,01008 \\
$R 3 c$ & 0,00631 & 0,01005 \\
\hline
\end{tabular}

Tabela 7- Massas de PI e SR utilizadas no ensaio de Precisão Intermediária (Pi) do método de RMNq para determinação de paracetamol

\begin{tabular}{ccc}
\hline Código & massa de PI (g) & massa de SR (g) \\
\hline Pi1a & 0,00574 & 0,00136 \\
Pi1b & 0,00588 & 0,00110 \\
Pi1c & 0,00532 & 0,00098
\end{tabular}

(continua) 
(conclusão)

\begin{tabular}{ccc}
\hline Código & massa de PI (g) & massa de SR (g) \\
\hline Pi2a & 0,00573 & 0,00551 \\
Pi2b & 0,00524 & 0,00523 \\
Pi2c & 0,00446 & 0,00535 \\
Pi3a & 0,00687 & 0,00993 \\
Pi3b & 0,00522 & 0,01005 \\
Pi3c & 0,00530 & 0,00999 \\
\hline
\end{tabular}

Tabela 8- Massas de PI e SR utilizadas nos ensaios de Robustez (RB) do método de RMNq para determinação de paracetamol

\begin{tabular}{|c|c|c|}
\hline Código & massa de PI (g) & massa de SR (g) \\
\hline$R B 1 a$ & 0,00183 & 0,00112 \\
\hline$R B 1 b$ & 0,00177 & 0,00106 \\
\hline$R B 1 c$ & 0,00137 & 0,00118 \\
\hline$R B 2 a$ & 0,00149 & 0,00537 \\
\hline$R B 2 b$ & 0,00153 & 0,00517 \\
\hline$R B 2 c$ & 0,00152 & 0,00545 \\
\hline$R B 3 a$ & 0,00159 & 0,01082 \\
\hline$R B 3 b$ & 0,00180 & 0,01010 \\
\hline$R B 3 c$ & 0,00171 & 0,01004 \\
\hline RBla & 0,01029 & 0,00124 \\
\hline$R B I b$ & 0,01059 & 0,00114 \\
\hline$R B / C$ & 0,01170 & 0,00110 \\
\hline RBIIa & 0,01055 & 0,00507 \\
\hline$R B / l b$ & 0,01050 & 0,00543 \\
\hline RBIlc & 0,01037 & 0,00534 \\
\hline RBIIIa & 0,01027 & 0,01027 \\
\hline$R B I I / b$ & 0,01019 & 0,01014 \\
\hline$R B \| l / C$ & 0,01070 & 0,01070 \\
\hline
\end{tabular}




\section{IV) Amostras Comerciais}

a) Formulações líquidas: anteriormente ao preparo das amostras a serem avaliadas, analisou-se o branco das mesmas (BST), ou seja apenas os medicamentos solubilizados no solvente, sem a adição do padrão interno. Para isso, um volume de aproximadamente $50 \mu \mathrm{L}$ de cada uma das amostras líquidas foi dissolvido em 550 $\mu \mathrm{L}$ de DMSO- $\mathrm{d}_{6}$. As soluções obtidas foram transferidas para tubos de RMN e, após adição de aproximadamente $10 \mu \mathrm{L}$ de TMS, analisadas. As análises quantitativas dessas amostras foram realizadas em triplicatas, da seguinte maneira:

- quantificação - transferiram-se alíquotas dos medicamentos que contivessem em seus respectivos volumes uma massa de ativo de aproximadamente $5,0 \mathrm{mg}$ para microtubos, nos quais haviam massas de PI previamente pesadas. A estes microtubos foi adicionado um volume de DMSO- $\mathrm{d}_{6}$, tal que completasse os $600 \mu \mathrm{L}$ (volume total $=$ volume do medicamento líquido + volume de solvente) e agitou-se manualmente até completa homogeneização.

- recuperação - prepararam-se amostras (Res) da mesma maneira descrita anteriormente, pesando-se, juntamente com o $\mathrm{PI}$, uma massa de aproximadamente $3,00 \mathrm{mg}$ de SR.

Nas Tabelas 9 e 10 encontram-se maiores detalhes sobre o preparo destas amostras.

Tabela 9 - Dados sobre o preparo das amostras comerciais líquidas de paracetamol

\begin{tabular}{cccc}
\hline código & teor $(\mathbf{m g} / \mathbf{m L})$ & alíquota $(\mu \mathrm{L})$ & massa de PI $(\mathbf{g})$ \\
\hline Ty1 & \multirow{2}{*}{200} & 25 & 0,00999 \\
Ty2 & & 0,01000 \\
Ty3 & & & 0,01015 \\
\hline Gen1 & 250 & 0,01060 \\
Gen2 & 200 & & 0,01050 \\
Gen3 & & & 0,01042 \\
Res1 & \multirow{2}{*}{50} & 0,01036 \\
Res2 & 100 & & 0,01033 \\
Res3 & & & 0,01035 \\
\hline
\end{tabular}


Tabela 10 - Dados sobre o ensaio de recuperação das amostras comerciais líquidas de paracetamol

\begin{tabular}{cccc}
\hline código & alíquota $(\boldsymbol{\mu L})$ & massa de SR $(\mathbf{g})$ & massa de PI $(\mathbf{g})$ \\
\hline Res1 & \multirow{2}{*}{50} & 0,00354 & 0,01054 \\
Res2 & & 0,00311 & 0,01050 \\
Res3 & & 0,00359 & 0,01047 \\
\hline
\end{tabular}

b) Formulações sólidas: para os comprimidos simples e efervescentes, inicialmente determinou-se a massa de cada comprimido a ser analisado e, então, realizou-se a moagem dos mesmos utilizando-se almofariz e pistilo até obter-se um pó fino. Para a cápsula, pesou-se a massa do medicamento em pó que estava no interior do revestimento. Em seguida, preparou-se o branco das amostras (BST) pesando-se aproximadamente 10,0 mg de cada uma das formulações sólidas em microtubos tipo Eppendorf, nos quais foram adicionados $600 \mu \mathrm{L}$ de DMSO- $\mathrm{d}_{6}$. Em seguida, submeteram-se esses microtubos à agitação em vortex IKA $A^{\boxplus}$ MS3 basic durante 3 minutos a $3000 \mathrm{rpm}$ e, posteriormente, à centrifugação em uma centrífuga Eppendorf Mini Spec Plus durante 5 minutos a 10000 rpm. Então, $500 \mu \mathrm{L}$ das soluções obtidas (sobrenadantes ou não) foram transferidas para tubos de RMN. Por fim, foram adicionados ao tubo $100 \mu \mathrm{L}$ de DMSO- $\mathrm{d}_{6}$ e aproximadamente $10 \mu \mathrm{L}$ de TMS.

Essas amostras foram quantitativamente analisadas em triplicatas, conforme descrição a seguir:

- quantificação - pesaram-se, em microtubos, massas de PI e dos comprimidos, de acordo com a Tabela 11.

Aos microtubos contendo a amostra Gen, a qual não foi submetida ao ensaio de recuperação e nem se apresentou completamente solúvel, foram adicionados $800 \mu \mathrm{L}$ de DMSO-d . Então, agitou-se em um vortex durante 3 minutos a $3000 \mathrm{rpm}$. Após agitação, submeteu-se as amostras à centrifugação durante 5 minutos a 10000 rpm. Por fim, alíquotas de $600 \mu \mathrm{L}$ das soluções sobrenadantes foram transferidas para os tubos de RMN de $5 \mathrm{~mm}$, nos quais foram adicionados aproximadamente 10 $\mu \mathrm{L}$ de TMS (tetrametilsilano).

Aos microtubos que continham as amostras $\mathrm{Ty}$ e $\mathrm{Ci}$, as quais se mostraram totalmente solúveis e foram submetidas a ensaios de recuperação, adicionaram-se $1000 \mu \mathrm{L}$ de DMSO-d 6 e procedeu-se de maneira idêntica à descrita para a amostra Gen, transferindo apenas $500 \mu \mathrm{L}$ das soluções obtidas para o tubo, nos quais foram 
adicionados $100 \mu \mathrm{L}$ de DMSO- $\mathrm{d}_{6}$ e aproximadamente $10 \mu \mathrm{L}$ de TMS (tetrametilsilano). Reservou-se a solução restante para o ensaio de recuperação.

Tabela 11 - Dados sobre o preparo das amostras comerciais sólidas de paracetamol

\begin{tabular}{|c|c|c|c|c|c|}
\hline código & $\begin{array}{c}\text { tipo de } \\
\text { comprimido }\end{array}$ & $\begin{array}{c}\text { teor } \\
\text { (mg/comp.) }\end{array}$ & $\begin{array}{l}\text { massa do } \\
\text { comprimido } \\
\text { (g) }\end{array}$ & $\begin{array}{c}\text { massa de } \\
\text { amostra } \\
\text { (g) }\end{array}$ & $\begin{array}{c}\text { massa de } \\
\mathrm{PI}(\mathrm{g})\end{array}$ \\
\hline TyA & & & & 0,01170 & 0,01721 \\
\hline TyB & simples & 750 & 0,85867 & 0,01186 & 0,01601 \\
\hline TyC & & & & 0,01131 & 0,01689 \\
\hline GenA & & & & 0,00576 & 0,01212 \\
\hline GenB & simples & 750 & 0,82121 & 0,00596 & 0,01005 \\
\hline GenC & & & & 0,00589 & 0,01125 \\
\hline CiA & & & & 0,00833 & 0,01038 \\
\hline$C i B$ & cápsula & 400 & 0,45860 & 0,01018 & 0,01025 \\
\hline $\mathrm{CiC}$ & & & & 0,00842 & 0,01035 \\
\hline SonA & & & & 0,01576 & 0,01034 \\
\hline SonB & efervescente & 500 & 2,90080 & 0,01535 & 0,01011 \\
\hline SonC & & & & 0.01707 & 0.01005 \\
\hline
\end{tabular}

Por fim, foram adicionados $1100 \mu \mathrm{L}$ de DMSO- $_{6}$ aos microtubos que continham a amostra Son, a qual foi submetida ao ensaio de recuperação e não foi totalmente solúvel. Então, realizou-se o mesmo procedimento descrito para as amostras Ty e Ci.

- recuperação: adicionaram-se $500 \mu \mathrm{L}$ das soluções restantes que foram reservadas à microtubos contendo uma massa de SR previamente pesada e procedeu-se da mesma maneira descrita no parágrafo anterior. Na Tabela 12 encontram-se dados sobre o ensaio de recuperação, tais como, as massas de SR utilizadas e as massas de amostras e de PI contidas nas alíquotas analisadas. 
Tabela 12 - Dados sobre os ensaios de recuperação das amostras comerciais sólidas de paracetamol

\begin{tabular}{cccccc}
\hline código & $\begin{array}{c}\text { tipo de } \\
\text { comprimido }\end{array}$ & teor & $\begin{array}{c}\text { massa de SR } \\
(\mathbf{g})\end{array}$ & $\begin{array}{c}\text { massa de } \\
\text { amostra (g) }\end{array}$ & $\begin{array}{c}\text { massa de } \\
\text { PI (g) }\end{array}$ \\
\hline TyA & \multirow{2}{*}{ comprimido } & \multirow{2}{*}{750} & 0,00297 & 0,00585 & 0,00861 \\
TyB & simples & mg/comp. & 0,00456 & 0,00593 & 0,00801 \\
TyC & & & 0,00331 & 0,00566 & 0,00845 \\
\hline CiA & \multirow{2}{*}{ comprimido } & \multirow{2}{*}{400} & 0,00309 & 0,00417 & 0,00519 \\
CiB & revestido & mg/comp. & 0,00329 & 0,00509 & 0,00513 \\
CiC & & & 0,00320 & 0,00421 & 0,00518 \\
\hline SonA & \multirow{2}{*}{ comprimido } & \multirow{2}{*}{500} & 0,00493 & 0,00716 & 0,00470 \\
SonB & efervescente & $\mathrm{mg} / \mathrm{comp}$. & 0,00562 & 0,00698 & 0,00460 \\
SonC & & & 0,00541 & 0,00776 & 0,00457 \\
\hline
\end{tabular}

c) Análise de outros ativos: prepararam-se novas amostras Res e Son, também em triplicatas, para análise dos outros ativos presentes. Para isso, diluíram $450 \mu \mathrm{L}$ da amostra Res em $150 \mu \mathrm{L}$ de DMSO-d $\mathrm{d}_{6}$ e os $600 \mu \mathrm{L}$ da solução obtida foi transferida para um tubo de RMN de $5 \mathrm{~mm}$, no qual foram adicionados aproximadamente $10 \mu \mathrm{L}$ de TMS. Um branco da amostra Son em $\mathrm{D}_{2} \mathrm{O}$ foi previamente preparado dissolvendo-se aproximadamente $10 \mathrm{mg}$ da mesma em $600 \mu \mathrm{L}$ do solvente. As massas de Son pesadas para as quantificações (Tabela 9) foram dissolvidas em $1200 \mu \mathrm{L}$ de água deuterada $\left(\mathrm{D}_{2} \mathrm{O}\right)$, após agitação no vortex (3 minutos, $3000 \mathrm{rpm}$ ) e centrifugação (5 minutos, $10000 \mathrm{rpm}$ ), $600 \mu \mathrm{L}$ da solução obtida foi transferida para um tubo de RMN.

Na Tabela 13 encontram-se as massas utilizadas nestas análises, bem como informações adicionais:

Tabela 13 - Dados sobre o preparo das amostras comerciais de paracetamol para análise de outros analitos

\begin{tabular}{ccccc}
\hline código & Ativo & teor & $\begin{array}{c}\text { quantidade de } \\
\text { amostra }\end{array}$ & $\begin{array}{c}\text { massa de PI } \\
\text { (g) }\end{array}$ \\
\hline Res1 & maleato de & & & 0,01087 \\
Res2 & clorfeniramina & $2,0 \mathrm{mg} / \mathrm{mL}$ & $450 \mu \mathrm{L}$ & 0,01074 \\
$\operatorname{Res} 3$ & & & & 0,01022
\end{tabular}

(continua) 
(conclusão)

\begin{tabular}{ccccc}
\hline código & Ativo & teor & $\begin{array}{c}\text { quantidade de } \\
\text { amostra }\end{array}$ & $\begin{array}{c}\text { massa de PI } \\
(\mathbf{g})\end{array}$ \\
\hline SonA & & & $0,04679 \mathrm{~g}$ & 0,01054 \\
SonB & cafeína & $65 \mathrm{mg} / \mathrm{comp}$. & $0,04762 \mathrm{~g}$ & 0,01089 \\
SonC & & & $0,04607 \mathrm{~g}$ & 0,01016 \\
\hline
\end{tabular}

\subsubsection{Método para Quantificação de Glifosato:}

\section{I) Preparo dos Padrões Secundários}

Os padrões externos (PE) empregados foram construídos utilizando-se tubos de EPR (Ressonância Paramagnética Eletrônica) de diâmetro $2,5 \mathrm{~mm}$, os quais foram cortados na altura de um tubo de RMN e selado em chama de acetileno, após terem sidos preenchidos com aproximadamente $200 \mu \mathrm{L}$ de uma solução 0,0485 $\mathrm{mol} / \mathrm{L}$ de trifenil fosfato em clorofórmio deuterado.

A primeira padronização secundária deste padrão externo foi realizada através de análises de $\mathrm{RMN}$ de ${ }^{1} \mathrm{H}$ empregando a dimetil sulfona. Para isso, pesaram-se três massas $(0,00492 \mathrm{~g} ; 0,00479 \mathrm{~g}$ e 0,00494 g) de dimetil sulfona em microtubos, nos quais se adicionaram $420 \mu \mathrm{L}$ de $\mathrm{D}_{2} \mathrm{O}$, volume suficiente para que a solução do tubo de RMN ficassse na mesma altura da solução do PE. Após total solubilização, as soluções obtidas foram transferidas para tubos de RMN de $5 \mathrm{~mm}$, aos quais inseriu-se o padrão externo anteriormente à análise de cada um, tomandose sempre o cuidado de lavá-lo e secá-lo muito bem ao transferi-lo de um tubo para outro.

A segunda padronização deste mesmo padrão externo foi feita de modo idêntico à primeira, mas tomando-se o cuidado de usar tubos de RMN do mesmo fabricante e lote que seria empregado nas análises. As massas de $\mathrm{DMSO}_{2}$ usadas foram: $0,00477 \mathrm{~g} ; 0,00485 \mathrm{~g}$ e $0,00489 \mathrm{~g}$.

E a padronização do segundo padrão secundário foi realizada da mesma maneira descrita para a segunda padronização, usando as seguintes massas de $\mathrm{DMSO}_{2}: 0,00481 \mathrm{~g} ; 0,00488 \mathrm{~g} ; 0,00488 \mathrm{~g}$. 


\section{II) Estudos Preliminares}

Nos ensaios de seletividade/especificidade foram analisados os brancos: do solvente (BS), do padrão externo (BPE) e do padrão analítico (BPA). Para isso, primeiramente transferiu-se uma alíquota de $600 \mu \mathrm{L}$ do solvente ser empregado nas análises - água deuterada - para um tubo de RMN de $5 \mathrm{~mm}$.

Após aquisição espectral de $\mathrm{RMN}$ de ${ }^{1} \mathrm{H}$ e de ${ }^{31} \mathrm{P}$ do $\mathrm{BS}$, solubilizou-se uma pequena quantidade de PA no solvente previamente analisado, transferiu-se a solução obtida para um tubo de RMN, e novos espectros foram obtidos. Por fim, inseriu-se o PE no tubo e outros espectros de ${ }^{1} \mathrm{H}$ e ${ }^{31} \mathrm{P}$ foram adquiridos.

Nos ensaios de exatidão e repetitividade pesaram-se, em microtubos, massas de PA, de acordo com a Tabela 14.

Tabela 14 - Massas de glifosato (PA) utilizadas nos ensaios de Repetitividade e Exatidão dos estudos preliminares do método de RMNq para a determinação de gifosato

\begin{tabular}{cccc}
\hline \multirow{2}{*}{ replicata } & \multicolumn{3}{c}{ massa $\mathbf{( g )}$} \\
\cline { 2 - 4 } & Intervalo 1 & intervalo 2 & intervalo 3 \\
\hline 1 & 0,00109 & 0,00333 & 0,00486 \\
3 & 0,00110 & 0,00310 & 0,00495 \\
4 & 0,00157 & 0,00286 & 0,00483 \\
5 & 0,00105 & 0,00305 & 0,00476 \\
6 & 0,00111 & 0,00333 & 0,00497 \\
7 & 0,00107 & 0,00299 & 0,00497 \\
\hline
\end{tabular}

A cada um desses microtubos foram adicionados, com auxílio da micropipeta, $840 \mu \mathrm{L} \mathrm{D}_{2} \mathrm{O}$. Então, agitou-se em vortex $I K A^{\circledast}$ MS3 basic a $3000 \mathrm{rpm}$ até completa solubilização. Em seguida, transferiram-se alíquotas de $420 \mu \mathrm{L}$ das soluções obtidas para os tubos de RMN de $5 \mathrm{~mm}$ aleatórios (sem se preocupar com seus lotes/fabricantes), aos quais inseriu-se o padrão externo anteriormente à análise, tomando-se sempre o cuidado de lavá-lo e secá-lo muito bem ao transferi-lo de um tubo para outro.

Para investigar os resultados obtidos, primeiramente realizou-se um teste pesando-se as massas de PA apresentadas na Tabela 15. Essas massas foram solubilizadas diretamente em $420 \mu \mathrm{L}$ de $\mathrm{D}_{2} \mathrm{O}$ com auxílio do vórtex (5 min. a 3000 
rpm) e toda a solução obtida foi transferida para o tubo de RMN. Ainda investigando os resultados, um segundo teste foi feito procedendo-se da maneira idêntica ao primeiro teste, porém todos os tubos de RMN empregados eram de lotes idênticos de um mesmo fabricante. Na Tabela 15 também se encontram as massas utilizadas neste segundo teste.

Tabela 15 - Massas de glifosato (PA) utilizadas nos testes do método de RMNq para determinação de glifosato

\begin{tabular}{ccc}
\hline \multirow{2}{*}{ replicata } & \multicolumn{2}{c}{ massa (g) } \\
\cline { 2 - 3 } & teste 1 & teste 2 \\
\hline 1 & 0,00234 & 0,00248 \\
2 & 0,00260 & 0,00220 \\
3 & 0,00228 & 0,00257 \\
4 & 0,00216 & 0,00285 \\
5 & 0,00245 & 0,00208 \\
6 & 0,00219 & 0,00219 \\
7 & 0,00225 & 0,00213 \\
\hline
\end{tabular}

III) Validação

Para os ensaios de Precisão e Exatidão, massas de glifosato padrão (Tabela 16) foram pesadas em tubos tipo Eppendorf e a estes, $840 \mu \mathrm{L}$ de $\mathrm{D}_{2} \mathrm{O}$ foram adicionados. Após agitação no vórtex a 3000 rpm até completa solubilização, $420 \mu \mathrm{L}$ da solução obtida foram transferidos para tubos de RMN de $5 \mathrm{~mm}$ pertencentes ao mesmo lote e fabricante. O capilar contendo o padrão externo foi inserido um a um, anteriormente às análises, após ter sido muito bem lavado e seco.

A seletividade e especificidade do padrão analítico e dos produtos comerciais foram verificadas analisando-se novamente três amostras já analisadas, mas sem a presença do padrão externo. O mesmo foi feito empregando só o solvente. Já, os padrões externos foram analisados nesse mesmo solvente apenas uma vez.

Para os ensaios de limite de detecção pesou-se $1,10 \mathrm{mg}$ de PA, o qual foi solubilizado em $840 \mu \mathrm{L}$ de $\mathrm{D}_{2} \mathrm{O}$ e alíquotas da solução resultante $(21,18,10$ e $6 \mu \mathrm{L})$ foram transferidas para tubos de $\mathrm{RMN}$, nos quais completou-se o volume com $\mathrm{D}_{2} \mathrm{O}$ para $420 \mu \mathrm{L}$ e, então, inseriu-se o padrão externo. 
Tabela 16 - Massas (g) do padrão analítico de glifosato utilizadas nos ensaios de Exatidão e Precisão do método de RMNa para determinação de glifosato

\begin{tabular}{cccccc}
\hline Replicata & Recuperação 1 & $\begin{array}{c}\text { Recuperação 2 / } \\
\text { Repetitividade }\end{array}$ & Recuperação 3 & $\begin{array}{c}\text { Precisão } \\
\text { intermediária }\end{array}$ & Robustez \\
\hline 1 & 0,00126 & 0,00292 & 0,00513 & 0,00288 & 0,00288 \\
2 & 0,00096 & 0,00278 & 0,00492 & 0,00290 & 0,00356 \\
3 & 0,00100 & 0,00318 & 0,00566 & 0,00310 & 0,00297 \\
4 & 0,00110 & 0,00289 & 0,00515 & 0,00344 & 0,00320 \\
5 & 0,00134 & 0,00369 & 0,00493 & 0,00311 & 0,00343 \\
6 & 0,00101 & 0,00335 & 0,00492 & 0,00298 & 0,00284 \\
7 & 0,00135 & 0,00287 & 0,00509 & 0,00287 & 0,00306 \\
\hline
\end{tabular}

IV) Produtos Comerciais

Para cada uma das formulações líquidas codificadas por R, P, Ag, H, G, M, Ap, e $\mathrm{B}$, inicialmente três alíquotas de $10 \mu \mathrm{L}$ foram transferidas para os tubos tipo Eppendorf. Repetiu-se o preparo das amostras $\mathrm{P}$ e H, transferindo-se alíquotas de $20 \mu \mathrm{L}$, assim como $30 \mu \mathrm{L}$ da amostra $\mathrm{G}$.

Para a formulação sólida (S), foram pesadas três massas distintas: 0,00542 g; $0,00496 \mathrm{~g}$ e 0,00529g e para o ensaio de recuperação três massas de PA foram pesadas $(0,00109 \mathrm{~g} ; 0,00138 \mathrm{~g}$ e $0,00130 \mathrm{~g})$ em microtubos aos quais foram adicionados em cada $10 \mu \mathrm{L}$ da amostra $R$.

A partir de então, procedeu-se para todas as amostras de maneira idêntica a descrita na validação.

\subsubsection{Método para Quantificação de Ácidos Graxos em Óleos e Azeites:}

Transferiu-se uma alíquota $50 \mu \mathrm{L}$ de cada uma das 12 amostras de óleos de amendoins previamente extraídos das sementes e analisados por cromatografia gasosa, para microtubos, aos quais foram adicionados $550 \mu \mathrm{L}$ de clorofórmio deuterado $\left(\mathrm{CDCl}_{3}\right)$. Após homogeneização as soluções obtidas foram transferidas para tubos de RMN distintos, nos quais se acrescentou aproximadamente $10 \mu \mathrm{L}$ de TMS. 


\subsubsection{Método para Detecção de Adulteração de Azeites com Óleo de Soja em Embalagens Lacradas:}

Inicialmente, o mesmo procedimento descrito em 3.3.3 foi realizado para a amostra comercial de azeite de oliva, considerado padrão.

Após isso, em frascos âmbar de $100 \mathrm{~mL}$, prepararam-se diferentes misturas de massa total igual a $80 \mathrm{~g}$, variando-se a porcentagem em massa do azeite oliva e óleo de soja considerados padrões, de acordo com as Tabelas 17 e 18:

Tabela 17 - Massas de azeites de oliva e de óleo de soja utilizadas no preparo das amostras* para o ensaio de Linearidade

\begin{tabular}{cccc}
\hline ponto & massa de azeite $(\mathbf{g})$ & massa de óleo $(\mathbf{g})$ & $\% \mathbf{m} / \mathbf{m}$ azeite \\
\hline 1 & 80 & 0 & 100 \\
2 & 76 & 4 & 95 \\
3 & 72 & 8 & 90 \\
4 & 68 & 12 & 85 \\
5 & 64 & 16 & 80 \\
6 & 56 & 24 & 70 \\
7 & 48 & 32 & 60 \\
8 & 40 & 40 & 50 \\
\hline
\end{tabular}

* todas as amostras foram preparadas e analisadas em triplicata

Tabela 18 - Massas de azeites de oliva e de óleo de soja utilizadas no preparo das amostras* para os ensaios de Repetitividade e Precisão Intermediária

\begin{tabular}{cccc}
\hline replicata & massa de azeite $\mathbf{( g )}$ & massa de óleo $\mathbf{( g )}$ & $\% \mathbf{~ m} / \mathbf{m}$ azeite \\
\hline 1 & 80 & 0 & 100 \\
2 & 60 & 20 & 75 \\
3 & 40 & 40 & 50 \\
\hline
\end{tabular}

* todas as amostras foram preparadas e analisadas em quintuplicata

Para o ensaio de robustez, transferiram-se as misturas preparadas anteriormente para o ensaio de precisão intermediária para tubos tipo Falcon de 50 
$\mathrm{mL}$. A exatidão foi avaliada para cada uma das amostras preparadas nos ensaios de repetitividade, precisão intermediária e robustez.

\subsubsection{Método para Quantificação dos Constituintes da Silimarina:}

I) Extrações:

Todas as amostras de sementes foram previamente secas em uma estufa (BOEKEL Scientific, modelo 133000) a 40,0 $\pm 1,0 \stackrel{\circ}{ } \mathrm{C}$, trituradas a pó em um moedor de café (Toastmaster, modelo 1119) e armazenadas em dessecadores.

A primeira tentativa de extração foi realizada de acordo com Benthin e colaboradores, ${ }^{147}$ mas utilizando uma célula de $100 \mathrm{~mL}$. Na segunda tentativa, substitui-se o metanol por acetato de etila.

Após tentativas para melhorar a retirada do óleo do extrato de interesse alterando os tempos e número de ciclos, obteve-se o melhor resultado, empregando as condições descritas na Tabela 19, seguidas de uma partição líquido-líquido com éter de petróleo $(3 \times 75 \mathrm{~mL})$ e metanol $80 \%$ ( $1 \times 100 \mathrm{~mL})$, após secagem do acetato de etila em um rotaevaporador. O extrato final foi obtido depois do metanol ser seco, também em um rotaevaporador, e a água restante, liofilizada.

Tabela 19 - Condições empregadas na extração acelerada por solvente no Dionex 350 das sementes de Cardo-leiteiro

\begin{tabular}{lc}
\multicolumn{1}{c}{ parâmetro } & valor \\
\hline Quantidade de amostra & $5 \mathrm{~g}$ \\
Célula de extração & $100 \mathrm{~mL}$ \\
Pressão da extração & $140 \mathrm{bar}$ \\
Solvente 1 & Hexano \\
Tempo da primeira extração & 5 minutos \\
Temperatura da primeira extração & $100 \stackrel{\circ}{ } \mathrm{C}$ \\
Número de ciclos da primeira extração & 3 \\
Solvente 2 & acetato de etila \\
Tempo da segunda extração & 5 minutos \\
Temperatura da segunda extração & $100 \stackrel{\circ}{ } \mathrm{C}$ \\
Número de ciclos da primeira extração & 1 \\
\hline
\end{tabular}


Todos os extratos foram obtidos em triplicata, com exceção das amostras $\mathrm{E}$ e I, as quais foram obtidas em duplicata por não haver quantidade de sementes suficiente e a $B$, em sextuplicata, pois repetiu-se a primeira triplicata a fim se verificar o primeiro resultado obtido. As massas de sementes moídas utilizadas nas extrações estão descritas na Tabela 20.

Tabela 20 - Massa de sementes moídas da planta Cardo-leiteiro utilizada nas extrações

\begin{tabular}{|c|c|c|}
\hline código da amostra & replicata & massa (g) \\
\hline \multirow{3}{*}{ BRM } & $\mathrm{a}$ & 5,006 \\
\hline & $\mathrm{b}$ & 5,005 \\
\hline & $\mathrm{C}$ & 5,007 \\
\hline \multirow{3}{*}{$\mathrm{BR}$} & $a$ & 5,007 \\
\hline & $\mathrm{b}$ & 5,011 \\
\hline & $C$ & 5,006 \\
\hline \multirow{3}{*}{$P$} & $a$ & 5,006 \\
\hline & $b$ & 5,001 \\
\hline & $C$ & 5,001 \\
\hline \multirow{3}{*}{ C } & $\mathrm{a}$ & 5,003 \\
\hline & $b$ & 5,004 \\
\hline & $\mathrm{C}$ & 5,002 \\
\hline \multirow{6}{*}{$\mathrm{B}$} & $\mathrm{a}$ & 5,004 \\
\hline & $b$ & 5,001 \\
\hline & $\mathrm{C}$ & 5,006 \\
\hline & $\mathrm{d}$ & 5,015 \\
\hline & e & 5,028 \\
\hline & $f$ & 5,015 \\
\hline \multirow{3}{*}{ W } & $\mathrm{a}$ & 5,010 \\
\hline & $b$ & 5,005 \\
\hline & $c$ & 5,005 \\
\hline \multirow{2}{*}{$E$} & $\mathrm{a}$ & 5,425 \\
\hline & $\mathrm{b}$ & 5,406 \\
\hline \multirow{2}{*}{ I } & $\mathrm{a}$ & 5,131 \\
\hline & $b$ & 5,017 \\
\hline
\end{tabular}




\section{II) Análises de RMN}

Para os testes iniciais preparou-se uma solução de dimetil sufona pesando-se $5,80 \mathrm{mg}$ da mesma em um balão volumétrico de $1,0 \mathrm{~mL}$, o qual teve seu volume completado com DMSO- $\mathrm{d}_{6}$. Em seguida três massas distintas do material de referência 3,5 ácido dinitrobenzóico (3,71 mg; 3,34 mg e 3,18 mg) foram pesadas em tubos do tipo Eppendorf, nos quais se adicionaram $200 \mu \mathrm{L}$ de DMSO- $\mathrm{d}_{6}$ e $10 \mu \mathrm{L}$ da solução de dimetilsulfona. Por fim, $180 \mu \mathrm{L}$ das soluções obtidas foram transferidas para tubo de RMN de $3 \mathrm{~mm}$.

Previamente ao preparo das amostras para as análises quantitativas de RMN preparava-se uma nova solução de dimetilsulfona (PI) em DMSO-d 6 de concentração conhecida. As concentrações das soluções variaram entre $\cong 6,00$ $\pm 2,00 \mathrm{mg} / \mathrm{mL}$ (Tabelas 21 e 22).

Para as análises de RMN foram pesadas em tubos do tipo Ependorff aproximadamente $5,00 \mathrm{mg}$ de extrato ou do pó constituinte dos produtos comerciais (Tabela 21 e 22, respectivamente). A este tubo foi adicionado $200 \mu \mathrm{L}$ de DMSO- $\mathrm{d}_{6} \mathrm{e}$ $10 \mu \mathrm{L}$ da solução de PI. Em seguida agitaram-se em um vórtex para total homogeneização e para as amostras comerciais que possuíam constituintes em sua formulação que não eram completamente solúveis, houve a necessidade de centrifugação.

Por fim, $180 \mu \mathrm{L}$ da solução obtida foram transferidos para tubos de RMN de 3 $\mathrm{mm}$, os quais foram devidamente vedados.

Tabela 21 - Massas de extratos analisadas nas medidas de RMNq e a concentração da solução de PI utilizada

\begin{tabular}{cccc}
\hline $\begin{array}{c}\text { código da } \\
\text { amostra }\end{array}$ & replicata & $\begin{array}{c}\text { massa de } \\
\text { extrato } \\
\text { analisada }(\mathrm{mg})\end{array}$ & $\begin{array}{c}\text { concentração da solução } \\
\text { de PI empregada na }\end{array}$ \\
\hline respectiva análise $(\mathrm{mg} / \mathrm{mL})$
\end{tabular}

(continua) 
(conclusão)

\begin{tabular}{|c|c|c|c|}
\hline $\begin{array}{c}\text { código da } \\
\text { amostra }\end{array}$ & replicata & $\begin{array}{c}\text { massa de } \\
\text { extrato } \\
\text { analisada }(\mathrm{mg})\end{array}$ & $\begin{array}{c}\text { concentração da solução } \\
\text { de PI empregada na } \\
\text { respectiva análise (mg/mL) }\end{array}$ \\
\hline \multirow{3}{*}{$\mathrm{Br}$} & $A$ & 5,38 & \multirow{3}{*}{5,32} \\
\hline & B & 5,22 & \\
\hline & C & 5,59 & \\
\hline \multirow{3}{*}{$\mathrm{P}$} & $A$ & 5,49 & \multirow{3}{*}{5,55} \\
\hline & $B$ & 5,04 & \\
\hline & $\mathrm{C}$ & 5,22 & \\
\hline \multirow{3}{*}{ C } & $A$ & 5,07 & \multirow{3}{*}{5,55} \\
\hline & B & 5,32 & \\
\hline & $\mathrm{C}$ & 5,09 & \\
\hline \multirow{6}{*}{$B$} & $A$ & 4,72 & \multirow{3}{*}{5,32} \\
\hline & B & 5,36 & \\
\hline & C & 2,93 & \\
\hline & $\mathrm{D}$ & 5,19 & \multirow{3}{*}{5,42} \\
\hline & $E$ & 5,44 & \\
\hline & $\mathrm{F}$ & 5,71 & \\
\hline \multirow{3}{*}{ WF } & $A$ & 5,08 & \multirow{3}{*}{5,32} \\
\hline & $B$ & 5,25 & \\
\hline & C & 5,49 & \\
\hline \multirow{2}{*}{$E$} & $A$ & 5,49 & \multirow{2}{*}{6,52} \\
\hline & $B$ & 5,04 & \\
\hline \multirow{2}{*}{ I } & $A$ & 5,13 & \multirow{2}{*}{5,42} \\
\hline & $B$ & 4,96 & \\
\hline
\end{tabular}


Tabela 22 - Massas de produto comercial analisadas nas medidas de RMNq e a concentração da solução de PI utilizada

\begin{tabular}{|c|c|c|c|}
\hline $\begin{array}{l}\text { código da } \\
\text { amostra }\end{array}$ & replicata & $\begin{array}{c}\text { massa de } \\
\text { produto } \\
\text { analisada }(\mathrm{mg})\end{array}$ & $\begin{array}{c}\text { concentração da solução de } \\
\text { PI empregada na respectiva } \\
\text { análise }(\mathrm{mg} / \mathrm{mL})\end{array}$ \\
\hline \multirow{3}{*}{ USP } & $A$ & 4,75 & \multirow{3}{*}{6,52} \\
\hline & B & 5,47 & \\
\hline & $\mathrm{C}$ & 5,31 & \\
\hline \multirow{3}{*}{$P$} & $A$ & 5,03 & \multirow{3}{*}{6,52} \\
\hline & B & 5,59 & \\
\hline & $\mathrm{C}$ & 5,19 & \\
\hline \multirow{3}{*}{$\mathrm{G}$} & $A$ & 5,48 & \multirow{3}{*}{5,36} \\
\hline & $B$ & 5,49 & \\
\hline & $\mathrm{C}$ & 5,40 & \\
\hline \multirow{3}{*}{ C } & $A$ & 5,34 & \multirow{3}{*}{5,36} \\
\hline & $B$ & 5,43 & \\
\hline & $\mathrm{C}$ & 5,41 & \\
\hline \multirow{3}{*}{ B } & $A$ & 5,32 & \multirow{3}{*}{5,36} \\
\hline & $B$ & 5,33 & \\
\hline & $\mathrm{C}$ & 5,54 & \\
\hline \multirow{3}{*}{ NW } & $\mathrm{D}$ & 5,14 & \multirow{3}{*}{5,32} \\
\hline & $E$ & 5,17 & \\
\hline & $\mathrm{F}$ & 5,22 & \\
\hline \multirow{3}{*}{$\mathrm{NH}$} & $A$ & 5,22 & \multirow{3}{*}{5,32} \\
\hline & B & 5,22 & \\
\hline & $\mathrm{C}$ & 5,43 & \\
\hline \multirow{3}{*}{ SN } & $A$ & 5,34 & \multirow{3}{*}{5,32} \\
\hline & B & 5,22 & \\
\hline & $C$ & 5,34 & \\
\hline
\end{tabular}


(conclusão)

\begin{tabular}{cccc}
$\begin{array}{c}\text { código da } \\
\text { amostra }\end{array}$ & replicata & $\begin{array}{c}\text { massa de } \\
\text { produto } \\
\text { analisada (mg) }\end{array}$ & $\begin{array}{c}\text { concentração da solução de } \\
\text { Pl empregada na respectiva } \\
\text { análise (mg/mL) }\end{array}$ \\
\hline NB & A & 5,35 & 6,64 \\
& B & 4,95 & \multirow{2}{*}{6,64} \\
NA & A & 4,97 & \\
& B & 5,08 & 5,61 \\
SP & C & 5,27 & \\
& A & 5,00 & \\
& B & 4,48 & 7,79 \\
C & 4,97 & \\
\hline SB & A & 4,35 & \\
& B & 4,60 & \\
& C & 4,72 & \\
\hline
\end{tabular}




\section{RESULTADOS E DISCUSSÃO}

\subsection{Método para Quantificação de Paracetamol}

Os sinais de interesse para a quantificação do paracetamol foram os simpletos localizados em 1,99 ppm referente à metila do paracetamol $(3 \mathrm{H})$ e em 3,00 ppm, referente às metilas do $\mathrm{PI}(6 \mathrm{H})$. Um dos espectros obtidos nos ensaios da validação está ilustrado na Figura 6, na qual se pode observar estes sinais e as respectivas estruturas químicas dos compostos.

Figura 6 - Espectro de RMN de ${ }^{1} \mathrm{H}\left(9,4 \mathrm{~T} ; 23^{\circ} \mathrm{C}\right.$ e DMSO- $\left.\mathrm{d}_{6}\right)$ da amostra R3a e as estruturas químicas do analito (paracetamol) e do padrão interno $\left(\mathrm{DMSO}_{2}\right)$

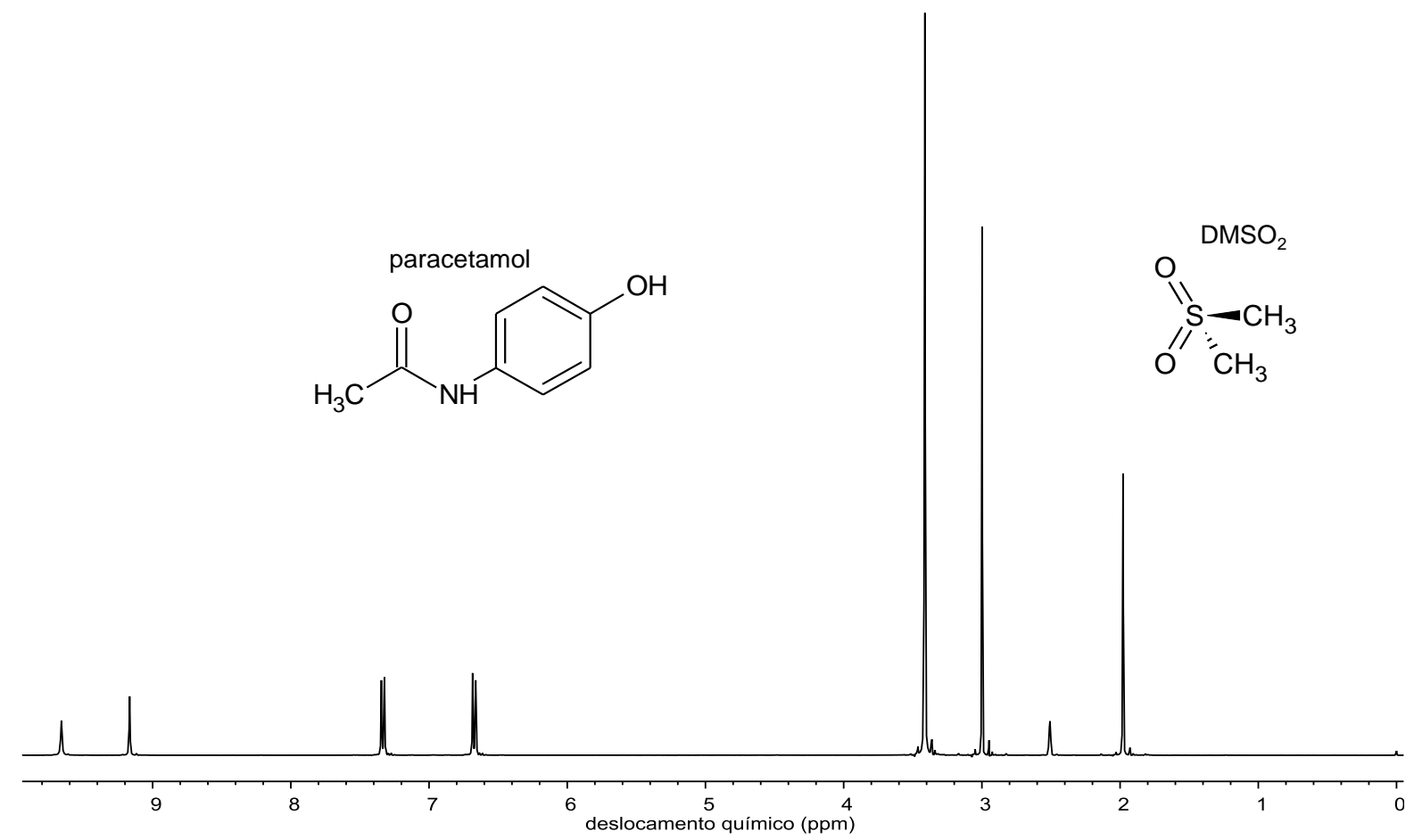

\subsubsection{Validação do Método Analítico:}

A validação do método para a quantificação de paracetamol foi realizada baseando-se na Resolução - RE № 899, de 29 de maio de 2003. De acordo com esta, o objetivo de uma validação é demonstrar que o método é apropriado para a finalidade pretendida, ou seja, a determinação qualitativa, semi-quantitativa e/ou quantitativa de fármacos e outras substâncias em produtos. ${ }^{44}$ 
Conforme descrito nesta resolução, considerando-se testes quantitativos para a determinação do princípio ativo em produtos farmacêuticos ou matérias-primas, em uma validação devem ser realizados os seguintes ensaios: especificidade, linearidade, intervalo, precisão (repetitividade e intermediária), exatidão e robustez.

\section{I) Especificidade:}

Para garantir que os sinais a serem integrados para a quantificação correspondam a apenas um composto foram obtidos espectros do solvente, do padrão interno e da substância de referência, separadamente. Desta maneira, verificou que os sinais presentes em cada um dos espectros não interferiam um nos outros.

Outra possível abordagem para dados de RMN, especificamente nos compostos que apresentam absorção em mais de uma frequência, seria utilizar as informações fornecidas através da integração dos sinais. Por exemplo, considerando o composto paracetamol, o qual possui mais de um ${ }^{1} \mathrm{H}$ magneticamente não equivalente, os valores das integrações de seus sinais, referenciando como 3 para a metila, devem ser 2 para cada um dos sinais na região aromática e 1 para cada um dos sinais na região mais desblindada, entre 9 e 10 ppm.

Assim, caso algum outro composto possua núcleos de ${ }^{1} \mathrm{H}$ que absorvam na mesma frequência dos ${ }^{1} \mathrm{H}$ do paracetamol, estes valores de integrais não serão verdadeiros. Essas integrações foram realizadas nos sinais referentes à metila e aos hidrogênios aromáticos no espectro de uma das amostras a serem quantificadas no próximo ensaio e comprovaram que realmente não havia interferentes em relação aos sinais do paracetamol.

\section{II) Linearidade e Intervalo:}

A curva de linearidade (Figura 7) foi construída com 5 concentrações diferentes do analito, conforme recomendação da Resolução RE $\mathrm{n}$ ㅇ 899. ${ }^{44} \mathrm{O}$ intervalo ficou determinado pelo menor e maior ponto dessa curva.

Observa-se na Figura 7 que a curva obtida possui um coeficiente de regressão $\left(r^{2}\right)$ igual a 0,9827 e, portanto, seu coeficiente de correlação $(r)$ é 0,9913. Acredita-se que, provavelmente, um maior número de pontos na curva contribuiria para um valor de $r$ ainda maior, porém, como o valor obtido foi superior ao critério 
mínimo de aceitação descrito na $\operatorname{RE~} n^{\circ} 899(r \geq 0,99)$, o ensaio de linearidade foi considerado válido.

Figura 7 - Curva analítica obtida no ensaio de Lineraridade da validação do método de RMNq para determinação de paracetamol

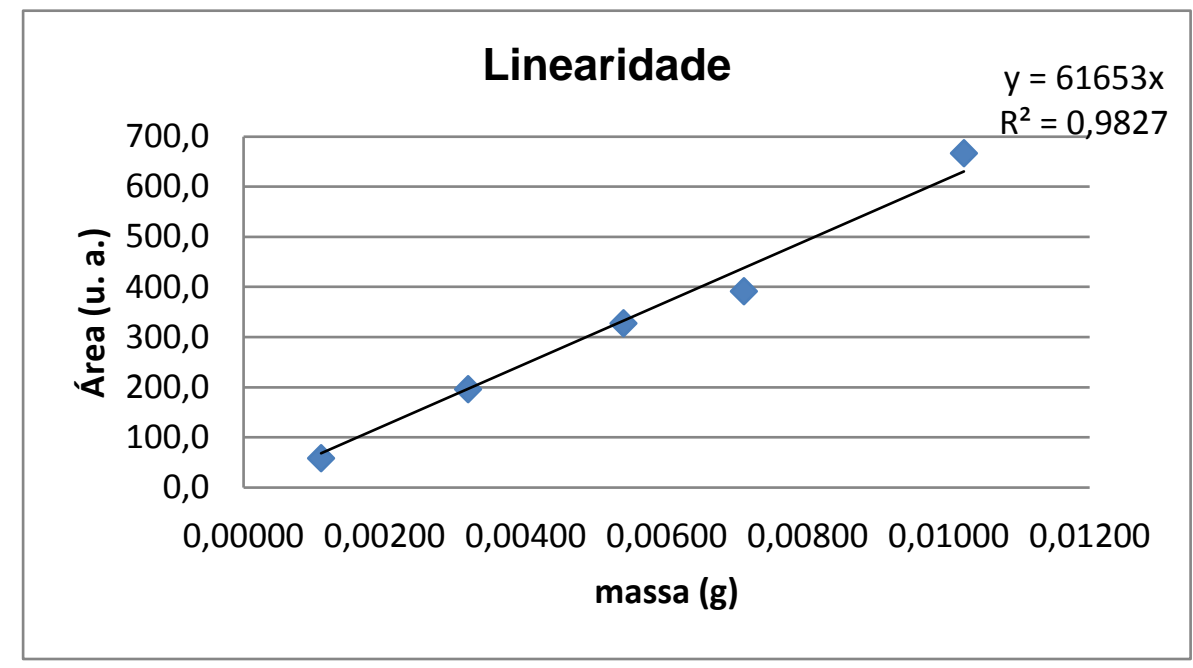

Apesar da normativa em questão exigir o ensaio de linearidade, para dados de RMN a necessidade deste ensaio pode ser questionada, devido a particularidades da técnica.

Em técnicas espectroscópicas, tais como UV e FTIR, as áreas dos sinais dependem de propriedades específicas das moléculas, como a absortividade molar (para UV) e o momento de dipolo (para FTIR), além da concentração das mesmas. Isso não ocorre com a área dos sinais de RMN de uma mesma amostra, as quais dependerão apenas da quantidade de núcleos absorventes, ou seja, da concentração.

Por exemplo, em uma amostra equimolar de dois compostos que possuam metilas em suas estruturas, as áreas de RMN dessas duas metilas serão iguais independentemente de sua estrutura química, explicitando a idêntica concentração molar dos compostos nessa amostra. No entanto, se um dos compostos tiver mais grupos cromóforos do que o outro, as áreas das bandas de absorção no UV não serão as mesmas. Por isso que essas técnicas espectroscópicas necessitam da construção de uma curva de calibração e da equação da mesma, enquanto que a RMN a dispensa, uma vez que seus resultados quantitativos podem ser obtidos diretamente da equação 7.

Além disso, considerando o fato de que a área do sinal de RMN sempre será proporcional ao número de núcleos, a linearidade poderia ser considerada como 
intrínseca da técnica, uma vez que em qualquer intervalo haverá linearidade. Sendo este intervalo delimitado pelo limite de quantificação (nível inferior) e pela solubilidade da amostra nos $600 \mu \mathrm{L}$ de solvente empregado no preparo da mesma ou pelo receptor (nível superior), pois, caso a amostra seja bastante solúvel, os sinais oriundos da sua alta concentração saturarão o receptor.

III) Exatidão:

O ensaio de exatidão foi realizado aplicando-se o método analítico proposto na análise de uma substância de pureza conhecida: a substância de referência de paracetamol.

De acordo com a normativa seguida,

\begin{abstract}
A exatidão do método deve ser determinada após o estabelecimento da linearidade, do intervalo linear e da especificidade do mesmo, sendo verificada a partir de, no mínimo, 9 determinações contemplando o intervalo linear do procedimento, ou seja, 3 (três) concentrações, baixa, média e alta, com 3 (três) replicatas cada. A exatidão é expressa pela relação entre a concentração média determinada experimentalmente e a concentração teórica correspondente ${ }^{44}$
\end{abstract}

Exatidão $(\%)=\frac{\text { concentração média experimental }}{\text { concentração teórica }} \times 100 \quad$ equação 9

Para a determinação da área do analito, realizou-se a integração do mesmo respeitando a sua largura de linha a meia altura $\left(20 \times v_{1 / 2}\right)$, da mesma maneira feita com o sinal do PI. Então, a área do sinal do PI foi referenciada como 1000 e obtevese o valor para a área do analito em relação a esta área de referência.

Os valores da concentração média experimental (teor, \% $\mathrm{m} / \mathrm{m}$ ) foram calculados a partir da equação 7 e os de exatidão, a partir da 9. Os resultados obtidos (Tabela 23) foram considerados satisfatórios e também válidos, baseando-se na ABNT NBR 14029 (98\%-102\%) já que não há especificação alguma na Resolução RE nำ899. ${ }^{44,45}$ 
Tabela 23 - Resultados obtidos no ensaio de Exatidão da validação do método de RMNq para determinação de paracetamol

\begin{tabular}{|c|c|c|c|c|c|}
\hline replicata & área analito & teor $(\% \mathrm{~m} / \mathrm{m})$ & $\begin{array}{c}\text { exatidão } \\
\text { (\%) }\end{array}$ & $\begin{array}{c}\text { média } \\
(\%)\end{array}$ & $\begin{array}{c}\text { média } \\
\text { Global (\%) }\end{array}$ \\
\hline R1a & 61,0 & 97,3 & 97,5 & & \\
\hline$R 1 b$ & 82,0 & 104,6 & 104,9 & 99,5 & \\
\hline$R 1 c$ & 67,7 & 95,8 & 96,2 & & \\
\hline$R 2 a$ & 338,1 & 97,8 & 98,1 & & \\
\hline$R 2 b$ & 326,8 & 99,9 & 100,3 & 99,8 & 99,4 \\
\hline$R 2 c$ & 327,0 & 100,5 & 100,8 & & \\
\hline R3a & 666,6 & 98,3 & 98,7 & & \\
\hline$R 3 b$ & 532,0 & 98,8 & 99,2 & 98,9 & \\
\hline$R 3 c$ & 490,3 & 98,5 & 98,9 & & \\
\hline
\end{tabular}

IV) Repetitividade e Precisão Intermediária:

Os ensaios de repetitividade, reprodutibilidade e de precisão intermediária analisam a precisão do método analítico. A precisão pode ser expressa como desvio padrão relativo (DPR) ou coeficiente de variação (CV\%), segundo a fórmula: ${ }^{44}$

$$
\text { DPR ou } C V(\%)=\frac{D P}{\text { Concentração média determinada }} \times 100 \quad \text { equação } 10
$$

No presente estudo o ensaio de reprodutibilidade não foi realizado, uma vez que o mesmo não é exigido para a concessão de registros. ${ }^{44}$

Conforme a Resolução RE no 899 , a repetibilidade do método foi verificada por 9 determinações, contemplando o intervalo linear do método com 3 replicatas cada, utilizando as mesmas amostras analisadas no ensaio de exatidão.

O ensaio de precisão intermediária foi realizado por outro analista, após dois dias, de acordo com o recomendado na normativa.

Os resultados obtidos em ambos os ensaios estão descritos nas de Tabelas 24 e 25. Observando os resultados obtidos no ensaio de repetitividade poderia se correlacionar a menor precisão das replicatas R1 à menor massa de SR pesada, uma vez que se aproxima do erro da balança. No entanto, esta hipótese não foi confirmada no ensaio de precisão intermediária.

Ambos os ensaios foram considerados válidos, pois resultaram em coeficientes de variação menores que o máximo permitido na Resolução RE ํo 899 $(\mathrm{CV} \% \leq 5,0)$. 
Tabela 24 - Resultados obtidos no ensaio de Repetitividade da validação do método de RMNa para determinação de paracetamol

\begin{tabular}{cccccc}
\hline replicata & área analito & teor $(\% \mathbf{m} / \mathbf{m})$ & média teor $(\% \mathbf{~ m} / \mathbf{m})$ & DP & CV (\%) \\
\hline$R 1 a$ & 61,0 & 97,3 & & & \\
$R 1 b$ & 82,0 & 104,6 & 99,2 & 4,7 & 4,7 \\
$R 1 c$ & 67,7 & 95,8 & & & \\
\hline$R 2 a$ & 338,1 & 97,8 & & & \\
$R 2 b$ & 326,8 & 99,9 & 99,4 & 1,4 & 1,4 \\
$R 2 c$ & 327,0 & 100,5 & & & \\
$R 3 a$ & 666,6 & 98,3 & & & \\
$R 3 b$ & 532,0 & 98,8 & 98,6 & 0,3 & 0,3 \\
$R 3 c$ & 490,3 & 98,5 & & & \\
\hline
\end{tabular}

Tabela 25 - Resultados obtidos no ensaio de Precisão Intermediária da validação do método de RMNq para determinação de paracetamol

\begin{tabular}{cccccc}
\hline replicata & área analito & teor $(\% \mathbf{~ m} / \mathbf{m})$ & média $_{\text {teor }}(\% \mathbf{~ m} / \mathbf{m})$ & DP & CV (\%) \\
\hline Pi1a & 72,8 & 98,3 & & & \\
Pi1b & 58,4 & 99,8 & 99,0 & 0,8 & 0,8 \\
Pil1c & 56,9 & 98,8 & & & \\
\hline Pi2a & 287,8 & 95,8 & & & \\
Pi2b & 312,4 & 100,2 & 97,3 & 2,5 & 2,6 \\
Pi2c & 359,3 & 95,9 & & & \\
\hline Pi3a & 436,5 & 96,6 & & & \\
Pi3b & 580,3 & 96,5 & 97,0 & 0,7 & 0,7 \\
Pi3c & 575,9 & 97,8 & & & \\
\hline
\end{tabular}

V) Robustez:

Durante o desenvolvimento do método, considerou-se a avaliação da robustez. Este ensaio é importante para se constatar a susceptibilidade do método às variações nas condições analíticas. Estas, então, deverão ser controladas e precauções devem ser incluídas no procedimento. ${ }^{44}$

A primeira variável modificada foi a massa de PI empregada nos ensaios. Diferentemente dos ensaios anteriores, nos quais se empregou aproximadamente 5,0 mg de Pl, empregou-se aproximadamente $1,0 \mathrm{mg}$ neste ensaio de robustez. Nestas condições verificou-se que a precisão e a exatidão, excederam o limite de 
CV aceito pela normativa (Tabela 26). Isso se deve, muito provavelmente, ao fato dessa massa estar mais próxima ao erro da balança. Concluiu-se, então, que uma massa de 1,0 mg de PI não poderia ser empregada na metodologia.

Tabela 26 - Resultados obtidos no ensaio de Robustez (variação da massa de PI) da validação do método de RMNa para determinação de paracetamol

\begin{tabular}{cccccc}
\hline replicata & área analito & teor $(\% \mathbf{~ m} / \mathbf{m})$ & média $_{\text {teor }}(\% \mathbf{~ m} / \mathbf{m})$ & DP & CV (\%) \\
\hline$R B 1 a$ & 188,6 & 98,6 & & & \\
$R B 1 b$ & 176,3 & 94,2 & 94,3 & 4,2 & 4,4 \\
$R B 1 c$ & 242,8 & 90,2 & & & \\
\hline$R B 2 a$ & 1022,4 & 90,8 & & & \\
$R B 2 b$ & 964,6 & 91,4 & 90,2 & 1,6 & 1,8 \\
$R B 2 c$ & 990,2 & 88,4 & & & \\
\hline$R B 3 a$ & 1918,2 & 90,2 & & & \\
$R B 3 b$ & 1753,5 & 100,0 & 93,2 & 5,9 & 6,3 \\
$R B 3 c$ & 1641,2 & 89,5 & & & \\
\hline
\end{tabular}

Em seguida novamente variou-se a massa de $\mathrm{PI}$, mas para um valor superior (10 mg) ao empregado nos outros ensaios, juntamente com o emprego de metanol deuterado no lugar no DMSO- $d_{6}$. Os resultados estão apresentados na Tabela 27.

Tabela 27 - Resultados obtidos no ensaio de Robustez (variação da massa de PI e solvente) da validação do método de RMNq para determinação de paracetamol

\begin{tabular}{cccccc}
\hline replicata & área analito & teor $(\% \mathbf{~ m} / \mathbf{m})$ & média $_{\text {teor }}(\% \mathbf{~ m} / \mathbf{m})$ & DP & CV (\%) \\
\hline RBla & 39,3 & 104,5 & & & \\
RBIb & 33,0 & 98,1 & 99,2 & 4,8 & 4,8 \\
RBIC & 27,9 & 95,1 & & & \\
\hline RBIla & 148,8 & 99,1 & & & \\
RBIlb & 158,8 & 98,3 & 98,5 & 0,5 & 0,5 \\
RBIll & 157,8 & 98,1 & & & \\
\hline RBIIla & 309,1 & 98,9 & & & \\
RBIIlb & 307,8 & 99,0 & 99,5 & 0,9 & 1,0 \\
RBIIlc & 314,3 & 100,6 & & & \\
\hline
\end{tabular}


Conforme pode ser observado na Tabela 27, essas modificações não resultaram em alterações significativas na precisão e na exatidão do método, quando comparadas ao ensaio de repetitividade. Concluiu-se que uma massa de PI superior a 5,0 mg poderia ser empregada, assim como outros solventes, desde que os sinais destes não coincidam com os sinais de interesse do analito e do PI, ou seja, que não interfira na seletividade/especificidade do método.

\subsubsection{Alteração dos Parâmetros Espectrais:}

Para a avaliação da interferência de parâmetros espectrais nos resultados, utilizaram-se as replicatas RIII, após um prévio estudo de estabilidade das mesmas, uma vez que as medidas não foram realizadas no mesmo dia do preparo das amostras. Os resultados obtidos (Tabela 28) mostraram que as ligeiras variações ocorridas, aumento da exatidão e redução da precisão, não foram significativas.

Tabela 28 - Resultados obtidos na avaliação da estabilidade das replicatas da amostra RIII

\begin{tabular}{cccccc}
\hline replicata & área analito & teor $(\% \mathbf{m} / \mathbf{m})$ & média $_{\text {teor }}(\% \mathbf{m} / \mathbf{m})$ & DP & CV (\%) \\
\hline RBIIla & 309,5 & 99,1 & & & \\
RBIIlb & 307,5 & 98,9 & 99,6 & 1,1 & 1,1 \\
RBIIlc & 315,3 & 100,9 & & & \\
\hline
\end{tabular}

A alteração dos parâmetros pw/p1 (duração do pulso) e np/td (número de pontos) levaram à modificação de outros dois parâmetros: d1 (tempo de espera entre os pulsos) e at/aq (tempo de aquisição), respectivamente. Diminuindo-se o valor de $\mathrm{pw} / \mathrm{p} 1$, pode-se reduzir o valor de $\mathrm{d} 1$, pois o retorno do vetor magnetização para pulsos mais curtos é mais rápido. Alterando o número de pontos (np/td), mantendo-se a janela espectral (sw), o tempo de aquisição (at/aq) é automaticamente modificado, isto porque ambos estão relacionados de acordo com a seguinte equação: ${ }^{19,20}$

$$
a t=\frac{n p}{2 s w} \quad \text { equação } 11
$$


Observando os resultados obtidos nos experimentos de variação desses quatro parâmetros espectrais (Tabelas 29 e 30) verificou-se que a influência dos mesmos foi mínima.

Tabela 29 - Resultados obtidos nos experimentos de variação de pw/p1 e de d1

\begin{tabular}{|c|c|c|c|c|c|c|}
\hline replicata & $\begin{array}{c}\mathrm{pw} / \mathrm{p} 1 \mathrm{e} \\
\mathrm{d} 1\end{array}$ & área analito & $\begin{array}{c}\text { teor } \\
(\% \mathrm{~m} / \mathrm{m})\end{array}$ & $\begin{array}{l}\text { média teor } \\
(\% \mathrm{~m} / \mathrm{m})\end{array}$ & DP & $\begin{array}{l}\text { CV } \\
(\%)\end{array}$ \\
\hline RBIIIa & \multirow{3}{*}{$\begin{array}{l}30^{\circ} \\
6,67 \mathrm{~s}\end{array}$} & 309,1 & 98,9 & \multirow{3}{*}{99,8} & \multirow{3}{*}{1,3} & \multirow{3}{*}{1,3} \\
\hline$R B I I I b$ & & 308,3 & 99,2 & & & \\
\hline RBIIIC & & 316,2 & 101,2 & & & \\
\hline RBIIIa & \multirow{3}{*}{$\begin{array}{c}45^{\circ} \\
8,57 \mathrm{~s}\end{array}$} & 308,6 & 98,8 & \multirow{3}{*}{99,6} & \multirow{3}{*}{1,3} & \multirow{3}{*}{1,3} \\
\hline$R B I I I b$ & & 307,8 & 100,0 & & & \\
\hline$R B \| l / C$ & & 316,0 & 101,1 & & & \\
\hline RBIIla & \multirow{3}{*}{$\begin{array}{c}90^{\circ} \\
17,15 \mathrm{~s}\end{array}$} & 309,5 & 99,1 & \multirow{3}{*}{99,6} & \multirow{3}{*}{1,1} & \multirow{3}{*}{1,1} \\
\hline$R B I I l b$ & & 307,5 & 98,9 & & & \\
\hline$R B I I C$ & & 315,3 & 100,9 & & & \\
\hline
\end{tabular}

Tabela 30 - Resultados obtidos nos experimentos de variação de np/td e de at/aq

\begin{tabular}{|c|c|c|c|c|c|c|}
\hline replicata & $\begin{array}{c}\text { np/ns e } \\
\text { at/aq }\end{array}$ & área analito & teor $(\% \mathrm{~m} / \mathrm{m})$ & $\begin{array}{c}\text { média teor }_{\text {to }} \\
(\% \mathrm{~m} / \mathrm{m})\end{array}$ & DP & CV (\%) \\
\hline RBIIIa & \multirow{3}{*}{$\begin{array}{l}32000 \\
3,33 \mathrm{~s}\end{array}$} & 309,6 & 99,1 & \multirow{3}{*}{99,7} & \multirow{3}{*}{1,3} & \multirow{3}{*}{1,3} \\
\hline$R B I I I b$ & & 307,6 & 98,9 & & & \\
\hline$R B I I / C$ & & 316,2 & 101,2 & & & \\
\hline RBIIIa & \multirow{3}{*}{$\begin{array}{l}64000 \\
6,67 s\end{array}$} & 309,5 & 99,1 & \multirow{3}{*}{99,6} & \multirow{3}{*}{1,1} & \multirow{3}{*}{1,1} \\
\hline$R B I I l b$ & & 307,5 & 98,9 & & & \\
\hline$R B / / I C$ & & 315,3 & 100,9 & & & \\
\hline RBIIla & \multirow{3}{*}{$\begin{array}{l}128000 \\
13,33 \mathrm{~s}\end{array}$} & 308,1 & 98,6 & \multirow{3}{*}{99,5} & \multirow{3}{*}{1,3} & \multirow{3}{*}{1,3} \\
\hline$R B I I / b$ & & 307,1 & 98,8 & & & \\
\hline$R B I / l C$ & & 315,5 & 101,0 & & & \\
\hline
\end{tabular}

Consequentemente, uma condição otimizada de análise para as amostras em questão seria utilizar 32000 pontos empregando pulsos de $30^{\circ}$. Desta maneira o tempo total de cada experimento seria reduzido, já que os valores de d1 e at/aq seriam menores. 
Outro parâmetro avaliado foi o número de sinais de RMN acumulados (nt/ns). Observou-se (Tabela 31) que a melhor precisão foi obtida quando se empregou apenas um transiente. Este fato pode ser explicado pelo único pulso dado, pois erros relacionados à calibração do mesmo, à sintonia da frequência do núcleo e do retorno do vetor magnetização para um próximo pulso, são minimizados. No presente estudo o emprego de um transiente reduziria significativamente o tempo da medida com uma razão S/R satisfatória, porém em casos de amostras menos concentradas, deve-se avaliar prioritariamente a razão S/R necessária.

Tabela 31 - Resultados obtidos nos experimentos de variação de nt/ns

\begin{tabular}{|c|c|c|c|c|c|c|}
\hline replicata & nt/ns & área analito & $\begin{array}{c}\text { teor } \\
(\% \mathrm{~m} / \mathrm{m})\end{array}$ & $\begin{array}{c}\text { média teor } \\
(\% \mathrm{~m} / \mathrm{m})\end{array}$ & DP & $\begin{array}{l}\text { CV } \\
(\%)\end{array}$ \\
\hline RBIIla & & 309,0 & 98,9 & & & \\
\hline$R B / I / b$ & 1 & 307,6 & 98,9 & 99,3 & 0,6 & 0,6 \\
\hline$R B I I C$ & & 312,3 & 99,9 & & & \\
\hline RBIIla & & 309,5 & 99,1 & & & \\
\hline$R B I I l b$ & 8 & 307,5 & 98,9 & 99,6 & 1,1 & 1,1 \\
\hline$R B I I I C$ & & 315,3 & 100,9 & & & \\
\hline RBIIla & & 308,7 & 98,8 & & & \\
\hline$R B I I I b$ & 16 & 307,3 & 98,8 & 99,5 & 1,2 & 1,2 \\
\hline$R B I I C$ & & 315,30 & 100,9 & & & \\
\hline
\end{tabular}

A alteração de ganho do receptor - receiver gain/rg (Tabela 32) não se mostrou ser um fator de forte influência nos resultados, portanto, este parâmetro pode ser ajustado da melhor maneira para cada amostra.

Tabela 32 - Resultados obtidos nos experimentos de variação de receiver gain/rg

\begin{tabular}{|c|c|c|c|c|c|c|}
\hline replicata & rg/gain & área analito & $\begin{array}{c}\text { teor } \\
(\% \mathrm{~m} / \mathrm{m})\end{array}$ & $\begin{array}{l}\text { média teor } \\
(\% \mathrm{~m} / \mathrm{m})\end{array}$ & DP & CV (\%) \\
\hline RBIIIa & & 310,8 & 99,5 & & & \\
\hline$R B I I I b$ & 22 & 307,3 & 98,8 & 99,7 & 1,0 & 1,0 \\
\hline$R B I I I C$ & & 314,8 & 100,7 & & & \\
\hline RBIIla & & 309,5 & 99,1 & & & \\
\hline$R B I I I b$ & 42 & 307,5 & 98,9 & 99,6 & 1,1 & 1,1 \\
\hline RBIIIC & & 315,3 & 100,9 & & & \\
\hline
\end{tabular}


Já a aquisição dos espectros sem giro da amostra se mostrou menos exata do que a com giro (Tabela 33). Isso pode estar relacionado ao intervalo de integração utilizado, pois, apesar deste ter sido múltiplo da largura de linha a meia altura (20x), em espectros adquiridos sem giro a largura de linha é muito superior, então muito provavelmente se o fator de multiplicação 20 fosse aumentado a exatidão melhoria já que uma maior região seria integrada. Neste caso, há risco do sinal de interesse ser integrado juntamente algum outro sinal interferente que absorva em radiofreqüências próximas. Em espectros mais complexos, o giro pode ser uma importante ferramenta para se melhorar a resolução espectral e, portanto, não deve ser dispensado.

Tabela 33 - Resultados obtidos nos experimentos de variação de giro

\begin{tabular}{|c|c|c|c|c|c|c|}
\hline replicata & $\operatorname{spin}(\mathrm{Hz})$ & área analito & teor $(\% \mathrm{~m} / \mathrm{m})$ & $\begin{array}{c}\text { média } \text { teor } \\
(\% \mathrm{~m} / \mathrm{m})\end{array}$ & DP & CV (\%) \\
\hline RBIIIa & & 307,5 & 98,4 & & & \\
\hline$R B I I l b$ & 0 & 305,6 & 98,3 & 98,8 & 0,8 & 0,8 \\
\hline RBIIIC & & 311,7 & 99,8 & & & \\
\hline RBIIIa & & 309,5 & 99,1 & & & \\
\hline$R B I I l b$ & 20 & 307,5 & 98,9 & 99,6 & 1,1 & 1,1 \\
\hline$R B \| / l C$ & & 315,3 & 100,9 & & & \\
\hline
\end{tabular}

Avaliando os parâmetros de processamento fn/si (número de pontos para processamento) e lb (line broading), observou-se que a aplicação do zero-filling não interferiu nas medidas quantitativas, assim como o lb (Tabelas 34 e 35). O ajuste desses parâmetros pode ser feito se baseando na resolução e razão $S / R$ desejadas.

Tabela 34 - Resultados obtidos nos experimentos de variação de lb

\begin{tabular}{|c|c|c|c|c|c|c|}
\hline replicata & $\mathbf{I b}$ & área analito & teor $(\% \mathrm{~m} / \mathrm{m})$ & média teor $(\% \mathrm{~m} / \mathrm{m})$ & DP & CV (\%) \\
\hline RBIIIa & & 309,4 & 99,0 & & & \\
\hline$R B \| I b$ & 0 & 307,3 & 98,8 & 99,8 & 1,5 & 1,5 \\
\hline RBIIlC & & 316,9 & 101,4 & & & \\
\hline RBIIIa & & 309,5 & 99,1 & & & \\
\hline$R B I I / b$ & 0,3 & 307,5 & 98,9 & 99,6 & 1,1 & 1,1 \\
\hline$R B I I / C$ & & 315,3 & 100,9 & & & \\
\hline
\end{tabular}

(continua) 
(conclusão)

\begin{tabular}{ccccccc} 
replicata & lb & área analito & teor $(\% \mathbf{m} / \mathbf{m})$ & média $_{\text {teor }}(\% \mathbf{m} / \mathbf{m})$ & DP & CV (\%) \\
\hline RBIIla & & 306,9 & 98,2 & & & \\
RBIIIb & 1 & 306,1 & 98,4 & 98,5 & 0,3 & 0,3 \\
RBIIIC & & 308,6 & 98,8 & & & \\
\hline
\end{tabular}

Tabela 35 - Resultados obtidos nos experimentos de variação de fn/si

\begin{tabular}{|c|c|c|c|c|c|c|}
\hline replicata & fn/si & área analito & teor $(\% \mathrm{~m} / \mathrm{m})$ & $\begin{array}{l}\text { média }_{\text {teor }} \\
(\% \mathrm{~m} / \mathrm{m})\end{array}$ & DP & CV (\%) \\
\hline RBIIIa & & 309,3 & 99,0 & & & \\
\hline$R B \| I b$ & $32 k$ & 308,0 & 99,1 & 99,5 & 0,9 & 0,9 \\
\hline$R B \| I C$ & & 314,4 & 100,6 & & & \\
\hline RBIIIa & & 309,5 & 99,1 & & & \\
\hline$R B I I l b$ & $64 k$ & 307,5 & 98,9 & 99,6 & 1,1 & 1,1 \\
\hline$R B \| I C$ & & 315,3 & 100,9 & & & \\
\hline RBIIla & & 308,4 & 98,7 & & & \\
\hline$R B I I l b$ & $128 \mathrm{k}$ & 308,5 & 99,2 & 99,5 & 1,1 & 1,1 \\
\hline$R B I I C$ & & 314,7 & 100,7 & & & \\
\hline
\end{tabular}

\subsubsection{Quantificação das Amostras Comerciais:}

Inicialmente avaliaram-se os espectros das amostras comerciais (brancos) para a verificação da seletividade/especificidade. Estas foram evidenciadas observando-se que o sinal presente em 1,99 ppm pertencia somente ao paracetamol e que não haviam sinais que coincidiriam com o sinal do $\mathrm{Pl}$ em 3,00 ppm. Os espectros de $\mathrm{RMN}$ de ${ }^{1} \mathrm{H}$ de todas as amostras comerciais avaliadas estão apresentados na Figura 8.

Anteriormente à medida quantitativa de cada uma das amostras, foram realizadas medidas de estimativas de $T_{1}$ para verificar se os excipientes interfeririam neste tempo e, consequentemente, se haveria necessidade de se alterar o d1. Como essa interferência não foi observada em nenhum caso pôde-se trabalhar com o mesmo valor de d1 empregado na validação. 
Por fim, empregando o método desenvolvido e validado analisaram-se algumas amostras comerciais de diferentes tipos de formulações.

Figura 8 - Espectro de RMN de ${ }^{1} \mathrm{H}\left(9,4 \mathrm{~T} ; 23^{\circ} \mathrm{C}\right.$ e DMSO- $\left.\mathrm{d}_{6}\right)$ das amostras comercias de paracetamol analisadas

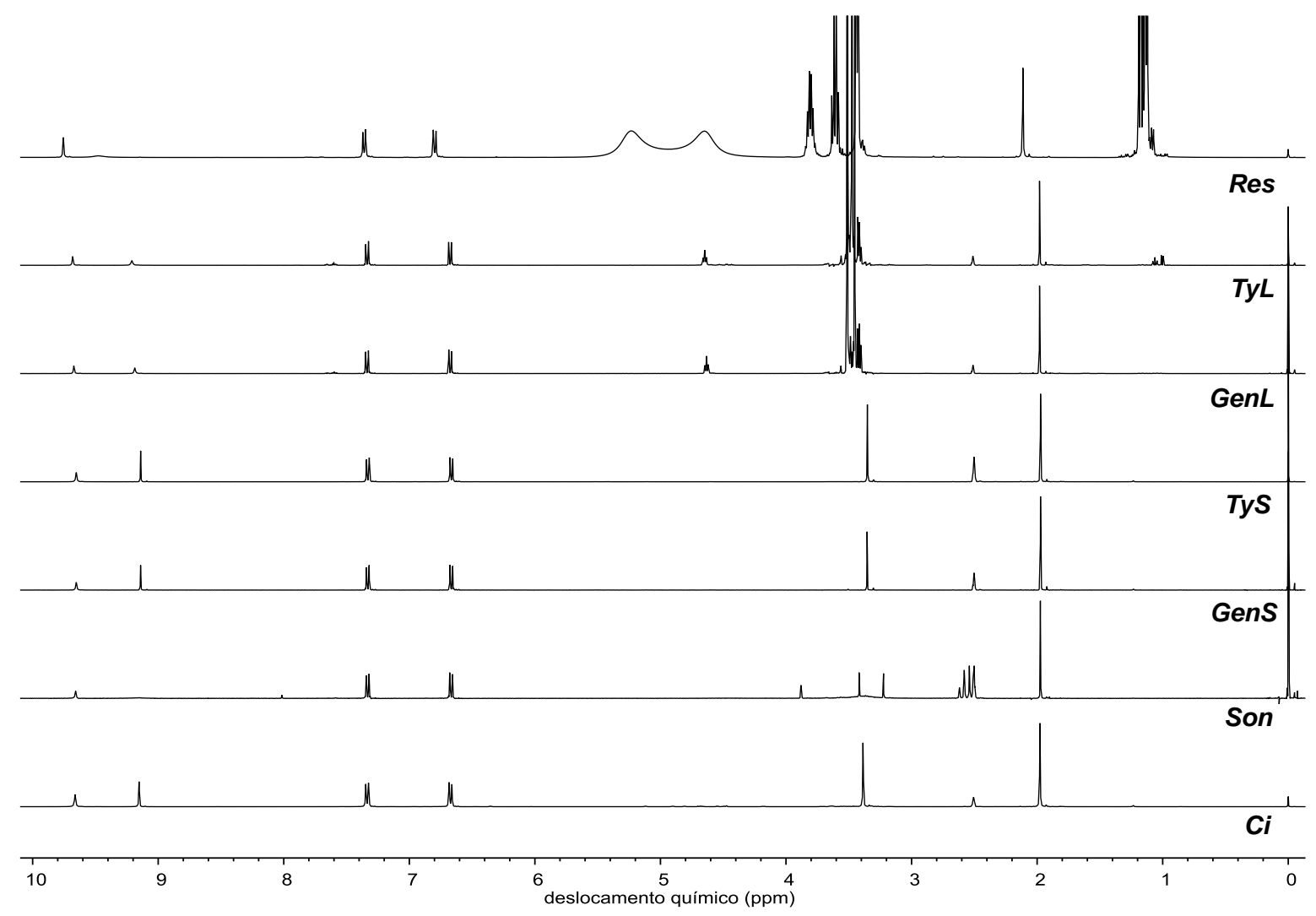

I) Formulações Líquidas:

A obtenção do valor das massas de analito foi feita através da equação 7 , modificada:

$$
m_{\text {analito }}=\frac{A_{x} \times N_{P I} \times M M_{x} \times m_{P I} \times P_{P I}}{A_{P I} \times N_{x} \times M M_{P I}} \quad \text { equação } 12
$$

A seguir, empregando o resultado obtido para a replicata Ty1, exemplifica-se o cálculo efetuado para a obtenção do teor:

$\frac{0,00448 \mathrm{~g} \text { paracetamol }}{25 \mu \mathrm{L} \text { de medicamento }} \times \frac{1000 \mu \mathrm{L}}{1 \mathrm{~mL}} \times \frac{1000 \mathrm{mg}}{1 \mathrm{~g}}=\frac{179,2 \mathrm{mg} \text { paracetamol }}{\mathrm{mL}}=179,2 \mathrm{mg} / \mathrm{mL}$ 
Os valores de teor obtidos desta maneira estão na Tabela 36. Considerando as concentrações descritas em suas bulas $(200 \mathrm{mg} / \mathrm{mL}$, para Ty e Gen, e 100 $\mathrm{mg} / \mathrm{mL}$, para Res), a média desses resultados mostram que os três produtos, atendem a exigência farmacopeica, pois a mesma normatiza que as variações do princípio ativo, paracetamol, em formulações líquidas estejam entre $90-110 \%$ no medicamento. $^{7}$

Tabela 36 - Quantificação das amostras comerciais líquidas de paracetamol analisadas

\begin{tabular}{ccccccc}
\hline amostra & área analito & $\begin{array}{c}\text { massa } \text { analito } \\
(\mathbf{g})\end{array}$ & $\begin{array}{c}\text { teor } \\
(\mathbf{m g} / \mathbf{m L})\end{array}$ & $\begin{array}{c}\text { média } \text { teor } \\
(\mathbf{m g} / \mathbf{m L})\end{array}$ & DP & CV (\%) \\
\hline Ty1 & 140,0 & 0,00448 & 179,2 & & & \\
Ty2 & 148,0 & 0,00474 & 189,4 & 183,4 & 5,4 & 2,9 \\
Ty3 & 139,8 & 0,00454 & 181,7 & & & \\
\hline Gen1 & 136,3 & 0,00462 & 184,9 & & & 2,8 \\
Gen2 & 143,8 & 0,00483 & 193,2 & 187,2 & 5,3 & \\
Gen3 & 137,5 & 0,00458 & 183,4 & & & 1,6 \\
\hline Res1 & 145,4 & 0,00482 & 96,4 & & & \\
Res2 & 148,9 & 0,00492 & 98,5 & 96,8 & & \\
Res3 & 144,0 & 0,00477 & 95,4 & & & \\
\hline
\end{tabular}

Como as amostras eram líquidas, o procedimento de preparo de amostra teve que ser um pouco diferente do realizado nos ensaios da validação. Devido a isso, um ensaio de recuperação foi realizado para a verificação da exatidão e da precisão. Este ensaio procedeu-se da maneira recomendada pela Resolução RE $n^{\circ} 899$ :

\footnotetext{
Nos casos em que amostras de todos os componentes do medicamento estão indisponíveis, se aceita a análise do método de adição de padrão, no qual se adiciona quantidades conhecidas do analito (padrão de referência) ao medicamento. ${ }^{44}$
}

A massa de analito determinada neste ensaio refere-se à quantidade presente nos $50 \mu \mathrm{L}$ de medicamento $(4,84 \mathrm{mg})$, de acordo com o teor quantificado anteriormente, somada à quantidade de SR adicionada. Dessa forma, o cálculo de recuperação foi realizado empregando a seguinte equação: 


$$
\text { Recuperação }(\%)=\frac{m_{\text {analito total }}}{m_{\text {analitono medicameno }}+m_{S R}} \times 100 \quad \text { equação13 }
$$

O resultado médio obtido no ensaio de recuperação (Tabela 37) foi considerado satisfatório e válido, uma vez que o CV está abaixo do máximo exigido pela normativa seguida e a média da porcentagem recuperação atende a ABNT NBR 14029 (98\%-102\%), já que também não há especificação alguma sobre recuperação na Resolução RE no $899 .{ }^{44,45}$

Tabela 37 - Ensaio de recuperação para as amostras comerciais líquidas de paracetamol

\begin{tabular}{|c|c|c|c|c|c|c|}
\hline amostra & área $a_{\text {analito }}$ & massa $_{\text {total }}(\mathrm{g})$ & rec. (\%) & média (\%) & DP & CV (\%) \\
\hline Res1 & 257,2 & 0,00868 & 103,6 & & & \\
\hline Res2 & 239,1 & 0,00804 & 101,1 & 101,3 & 2,2 & 2,2 \\
\hline Res3 & 241,9 & 0,00811 & 99,15 & & & \\
\hline
\end{tabular}

II) Formulações sólidas:

Embora tenha se analisado apenas alíquotas das soluções previamente preparadas, os valores das massas totais de analito podem ser obtidos da mesma maneira descrita para as formulações líquidas, empregando a equação 12, já a razão da massa de PI pela massa de amostra será constante, independentemente do volume analisado.

A determinação do teor está exemplificada em seguida, utilizando o resultado obtido para a amostra $T y A$, a massa do comprimido inteiro $(0,85867 \mathrm{~g})$ e a massa do comprimido analisada $(0,01170 \mathrm{~g})$.

$\frac{0,01041 \mathrm{~g} \text { paracetamol }}{0,01170 \mathrm{~g} \text { medicamento }} \times \frac{0,85867 \mathrm{~g} \text { medicamento }}{1 \text { comprimido }} \times \frac{1000 \mathrm{mg}}{1 \mathrm{~g}}=\frac{764,00 \mathrm{mg} \text { paracetamol }}{\text { comprimido }}=764,00 \mathrm{mg} / \mathrm{comp}$.

Os valores de teor obtidos estão na Tabela 38. Considerando as concentrações descritas em suas bulas (750 mg/comp., para Ty e Gen; 400 mg/comp., para o $\mathrm{Ci}$, e $500 \mathrm{mg} / \mathrm{comp}$., para Son), a média desses resultados mostram que os produtos codificados por $\mathrm{Ty}$, Gen e $\mathrm{Ci}$, atendem a exigência farmacopeica, pois a mesma normatiza que as variações do princípio ativo, 
paracetamol, em comprimidos estejam entre 95 - 105\% no medicamento. ${ }^{7}$ Como a variação para a amostra Son foi de $91,98 \%$, esta amostra foi considerada suspeita.

\begin{tabular}{ccccccc} 
Tabela 38 - Quantificação dos amostras comerciais sólidas de paracetamol analisadas & \\
\hline amostra & área & $\begin{array}{c}\text { massa } \text { analito } \\
\text { analito }\end{array}$ & $\begin{array}{c}\text { teor } \\
(\mathbf{g})\end{array}$ & $\begin{array}{c}\text { média } \text { teor } \\
\text { (mg/comp.) }\end{array}$ & $\begin{array}{c}\text { DP } \\
\text { (mg/comp.) }\end{array}$ & $\begin{array}{c}\text { CV } \\
\text { (\%) }\end{array}$ \\
\hline TyA & 189,0 & 0,01041 & 764,0 & & & \\
TyB & 200,3 & 0,01026 & 743,1 & 761,4 & 17,1 & 2,2 \\
TyC & 189,3 & 0,01023 & 776,9 & & & \\
\hline GenA & 128,9 & 0,00500 & 712,6 & & & \\
GenB & 175,2 & 0,00564 & 776,6 & 746,9 & 3,3 & 4,3 \\
GenC & 149,7 & 0,00539 & 751,5 & & & \\
\hline Cia & 217,4 & 0,00722 & 397,5 & & & \\
CiB & 258,7 & 0,00849 & 382,4 & 390,2 & & \\
CiC & 216,6 & 0,00718 & 390,9 & & & \\
\hline SonA & 77,4 & 0,00256 & 471,2 & & & \\
SonB & 74,1 & 0,00240 & 452,8 & 459,9 & 9,9 & 2,1 \\
SonC & 83,4 & 0,00268 & 455,7 & & &
\end{tabular}

Assim como para as amostras líquidas, o procedimento de preparo de amostra para tipo de comprimido teve que ser um pouco diferente do realizado nos ensaios da validação, uma vez que as amostras sólidas nem sempre foram totalmente e/ou facilmente solúveis no solvente empregado. Isso se deve à presença de outros compostos, denominados excipientes. Novamente realizaram-se ensaios de recuperação para a verificação da exatidão e da precisão conforme as recomendações da Resolução RE n 899, descritas anteriormente.

A massa de analito determinada neste ensaio refere-se à quantidade do mesmo presente nas alíquotas de solução de medicamento analisadas, somada à massa SR adicionada. Dessa forma, primeiramente calculou-se a quantidade de analito presente na alíquota analisada. Para isso, aplicou-se a seguinte equação, considerando o resultado médio do teor, determinado anteriormente:

$$
m_{\text {alíquota }}=V_{\text {alíquota }} \times \frac{m_{\text {amostra }}}{V_{\text {total }}} \times \frac{1 \text { comp. }}{m_{\text {comp. }}} \times \text { Teor }_{\text {médio }}
$$

$\mathrm{Na}$ qual, 
$m_{\text {aliquota }}=$ massa de analito presente na alíquota analisada;

$V_{\text {aliquota }}$ volume da alíquota de solução analisada;

$m_{\text {amostra }}=$ massa de amostra pesada para o preparo da solução;

$V_{\text {total }}=$ volume total da solução;

$m_{\text {comp. }}=$ massa do comprimido inteiro.

Após a determinação da massa de analito presente na alíquota analisada, efetuou-se o cálculo de recuperação, também empregando a equação 13.

Os ensaios de recuperação apresentaram boa precisão para todas as amostras (Tabela 39). No entanto, a porcentagem de recuperação para o comprimido simples foi inferior aos $98 \%$, exigidos na ABNT NBR 14029. Além disso, considerando-se o resultado obtido no ensaio de recuperação para comprimido efervescente, não se pode afirmar com segurança o teor da amostra Son, considerada suspeita.

Cabe ressaltar que na Resolução RE no 899 não constam especificações sobre a validade de resultados obtidos em ensaios de exatidão/recuperação.

Tabela 39 - Ensaios de recuperação para as amostras comerciais sólidas de paracetamol

\begin{tabular}{ccccccc}
\hline amostra & área $_{\text {analito }}$ & massa $_{\text {total }}(\mathbf{g})$ & rec. (\%) & média (\%) & DP & CV (\%) \\
\hline TyA & 272,6 & 0,00751 & 91,8 & & & \\
TyB & 337,4 & 0,00864 & 89,2 & 90,8 & 1,4 & 1,5 \\
TyC & 284,8 & 0,00770 & 91,4 & & & \\
\hline Cia & 398,8 & 0,00662 & 98,9 & & & \\
CiB & 446,8 & 0,00733 & 97,3 & 98,1 & 0,8 & 0,8 \\
CIC & 402,7 & 0,00667 & 98,2 & & & \\
\hline SonA & 398,5 & 0,00599 & 98,4 & & & \multirow{2}{*}{ Son } \\
SonB & 439,7 & 0,00647 & 96,4 & 97,8 & 1,0 & 1,2 \\
SonC & 446,9 & 0,00653 & 98,6 & & & \\
\hline
\end{tabular}

4.1.4 Quantificação Simultânea de Outros Analitos:

Com o intuito de se demonstrar a viabilidade de quantificações simultâneas via $\mathrm{RMN}$, duas das amostras comerciais analisadas anteriormente, as quais 
possuíam outros ativos em sua composição, foram novamente estudadas. Na tabela 40 encontram-se maiores detalhes sobre os analitos avaliados.

Tabela 40 - Dados sobre os outros analitos quantificados em amostras comerciais de paracetamol

\begin{tabular}{cccc}
\hline amostra & ativo & teor & \\
Res & $\begin{array}{c}\text { maleato de } \\
\text { clorfeniramina }\end{array}$ & $2,0 \mathrm{mg} / \mathrm{mL}$ \\
Son & cafeína & $65 \mathrm{mg} / \mathrm{comp}$. & \\
& &
\end{tabular}

Como a concentração desses ativos nos medicamentos é inferior à do paracetamol, preparam-se amostras mais concentradas a fim de se aumentar a razão $S / R$ dos sinais mesmos.

Nas Figuras 9 e 10 estão os espectros dessas duas amostras, nos quais podem ser observadas as regiões integradas em cada uma das amostras.

Figura 9 - Espectro de RMN de ${ }^{1} \mathrm{H}$ (9,4 T; 23ํㅡ C DMSO-d6) da amostra ResC. Acima, ampliação da região de 9,40 a 7,57 ppm para visualização do sinal do maleato de clorfeniramina
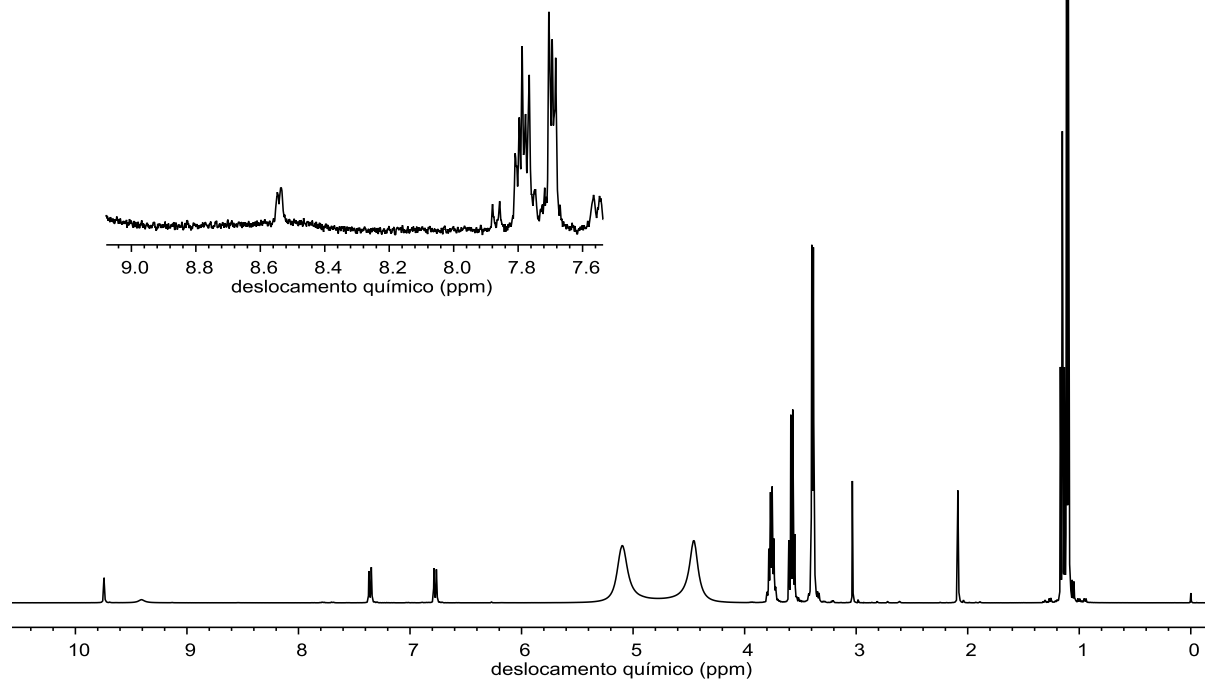
Figura 10 - Espectro de RMN de ${ }^{1} \mathrm{H}\left(9,4 \mathrm{~T} ; 2^{2}{ }^{\circ} \mathrm{C}_{\text {e }} \mathrm{D}_{2} \mathrm{O}\right)$ da amostra SonC. Acima, ampliação da região de 7,87 a 7,09 ppm para visualização do sinal da cafeína

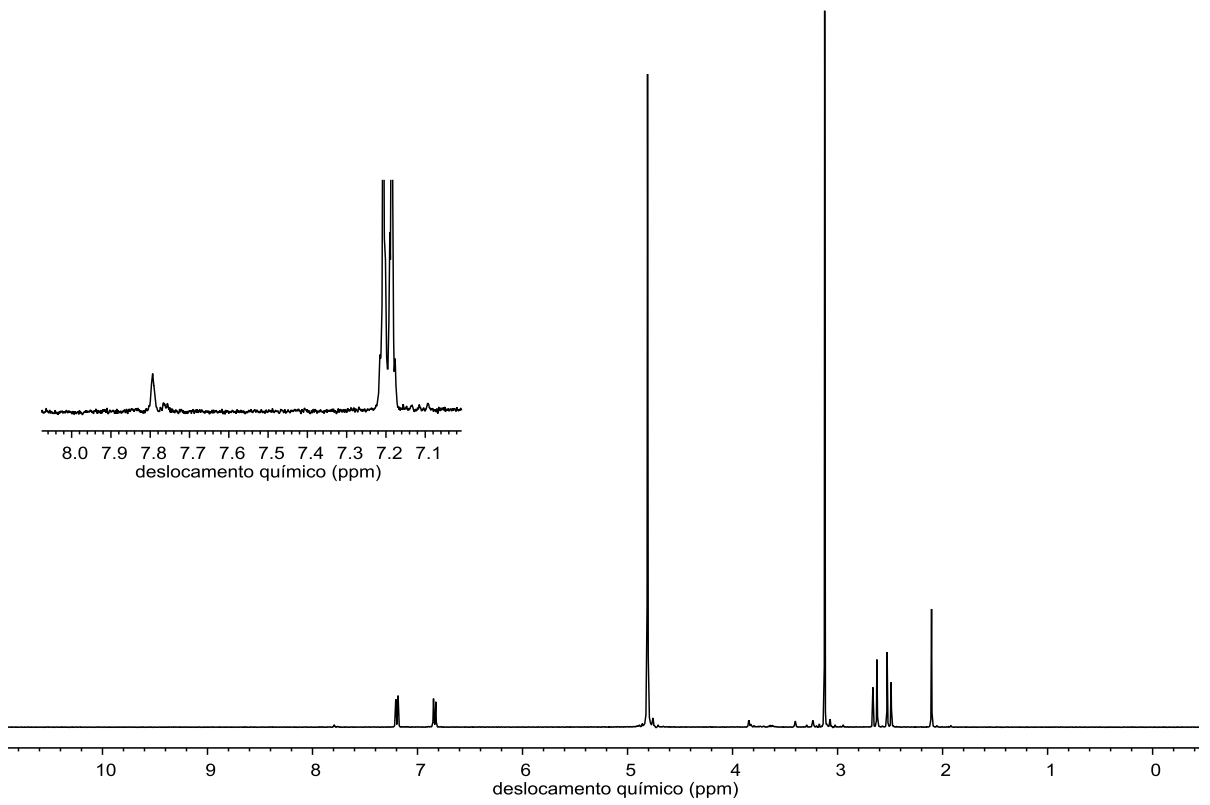

O sinal empregado para a quantificação do maleato de clorfeniramina situado em 8,54 ppm refere-se ao hidrogênio orto ao nitrogênio do anel heteroaromático. Para a cafeína, empregou-se o sinal situado em 7,79 ppm, referente ao hidrogênio olefínico.

Os resultados obtidos para a quantificação desses ativos, simultaneamente ao paracetamol em uma mesma medida, se mostraram bastante promissores, uma vez que podem ser melhorados através de otimizações no método analítico, e estão descritos nas Tabelas 41 e 42.

Tabela 41 - Quantificação simultânea de paracetamol (A) e maleato de clorfeniramina (B) na amostra Res

\begin{tabular}{|c|c|c|c|c|c|c|}
\hline analito & área analito & massa analito $(\mathrm{g})$ & $\begin{array}{c}\text { teor } \\
(\mathrm{mg} / \mathrm{mL})\end{array}$ & $\begin{array}{l}\text { média }_{\text {teor }} \\
(\mathrm{mg} / \mathrm{mL})\end{array}$ & DP & CV (\%) \\
\hline & 1189,3 & 0,04137 & 91,9 & & & \\
\hline \multirow[t]{3}{*}{$A$} & 1276,8 & 0,04389 & 97,5 & 96,8 & 4,6 & 4,7 \\
\hline & 1389,5 & 0,04545 & 101,0 & & & \\
\hline & 5,2 & 0,00098 & 2,2 & & & \\
\hline \multirow[t]{2}{*}{$\mathrm{B}$} & 4,7 & 0,00089 & 2,0 & 2,0 & 0,1 & 5,6 \\
\hline & 5,0 & 0,00088 & 2,0 & & & \\
\hline
\end{tabular}


Tabela 42 - Quantificação simultânea de paracetamol (A) e cafeína (B) na amostra Son

\begin{tabular}{ccccccc}
\hline analito & área analito & massa analito $(\mathbf{g})$ & $\begin{array}{c}\text { teor } \\
(\mathbf{m g} / \mathbf{m L})\end{array}$ & $\begin{array}{c}\text { média teor } \\
(\mathbf{m g} / \mathbf{m L})\end{array}$ & DP & CV (\%) \\
\hline \multirow{3}{*}{ A } & 201,9 & 0,00341 & 422,2 & & & \\
& 198,8 & 0,00347 & 422,1 & 421,8 & 0,7 & 0,2 \\
& 205,6 & 0,00334 & 420,9 & & & \\
\hline \multirow{3}{*}{ B } & 7,7 & 0,00050 & 61,9 & & & \\
& 8,0 & 0,00054 & 65,8 & 65,1 & 2,9 & 4,5 \\
& 8,6 & 0,00054 & 67,6 & & & \\
\hline
\end{tabular}

\subsubsection{Análises Qualitativas das Formulações Comerciais:}

Analisando qualitativamente os espectros de $\mathrm{RMN}$ de ${ }^{1} \mathrm{H}$ das formulações comerciais foi possível se identificar alguns de seus excipientes, em algumas delas.

$\mathrm{Na}$ amostra Res identificou-se o álcool etílico, o propilenoglicol e, possivelmente, o metilparabeno (Tabelas 43 e 44). A ampliação do espectro dessa amostra está ilustrado na Figura 11, na qual constam as atribuições para esses três compostos.

Tabela 43 - Fórmula estrutural dos excipientes identificados na amostra Res

álcool etílico (A)

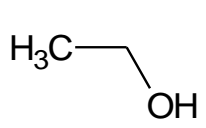

propilenoglicol (B)

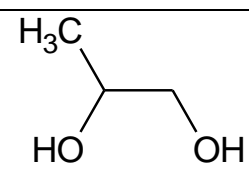

metilparabeno (C)

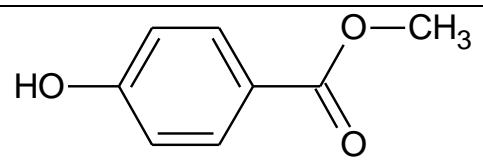

Tabela 44 - Identificação de alguns dos excipientes identificados na amostra Res

\begin{tabular}{ccccc}
\hline molécula & $\begin{array}{c}\text { sinal } \\
\text { atribuído }\end{array}$ & $\boldsymbol{\delta}^{1} \mathbf{H}(\mathbf{p p m})$ & multiplicidade & $\boldsymbol{J}(\mathbf{H z})$ \\
\hline \multirow{2}{*}{ álcool etílico } & $-\mathrm{CH}_{3}$ & 1,17 & tripleto & 7,10 \\
& $-\mathrm{CH}_{2}$ & 3,61 & quadrupleto & 7,10 \\
\hline \multirow{2}{*}{ propilenoglicol } & $-\mathrm{CH}_{3}$ & 1,13 & dupleto & 6,29 \\
& $-\mathrm{CH}$ & 3,81 & multipleto & - \\
& $-\mathrm{CH}_{2}$ & 3,43 & dupleto & 5,55 \\
\hline metilparabeno & $-\mathrm{CH}_{3}$ & 3,44 & simpleto & - \\
\hline
\end{tabular}


Figura 11 - Ampliação do espectro de RMN de ${ }^{1} \mathrm{H}(4,25$ a 0,50 ppm) da amostra Res ilustrando a atribuição dos excipientes identificados: A) álcool etílico; B) propilenoglicol e C) metilparabeno

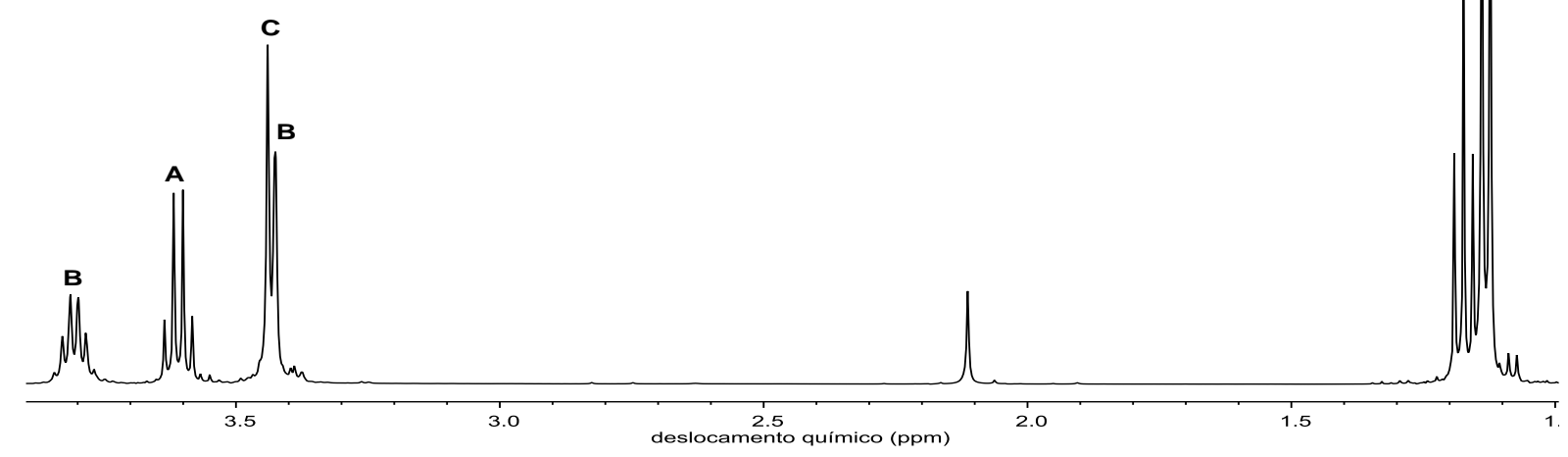

Nas formulações líquidas Ty e Gen identificaram-se o excipiente denominado macrogol. Esta identificação foi baseada no tripleto $(J=5,45 \mathrm{~Hz}$ ) situado em 4,63 ppm, no espectro da amostra Gen, e em 4,65 ppm, no espectro da Ty. Este sinal foi atribuído aos hidrogênios metilênicos. Na Figura 12 estão ilustradas os espectros de ambas as amostras, bem como a ampliação do sinal descrito e a estrutura do macrogol.

Figura 12 - Região espectral de RMN de ${ }^{1} \mathrm{H}$ (4,80 a 4,40 ppm) destacando o sinal do macrogol das formulações líquidas: A) Ty e B) Gen

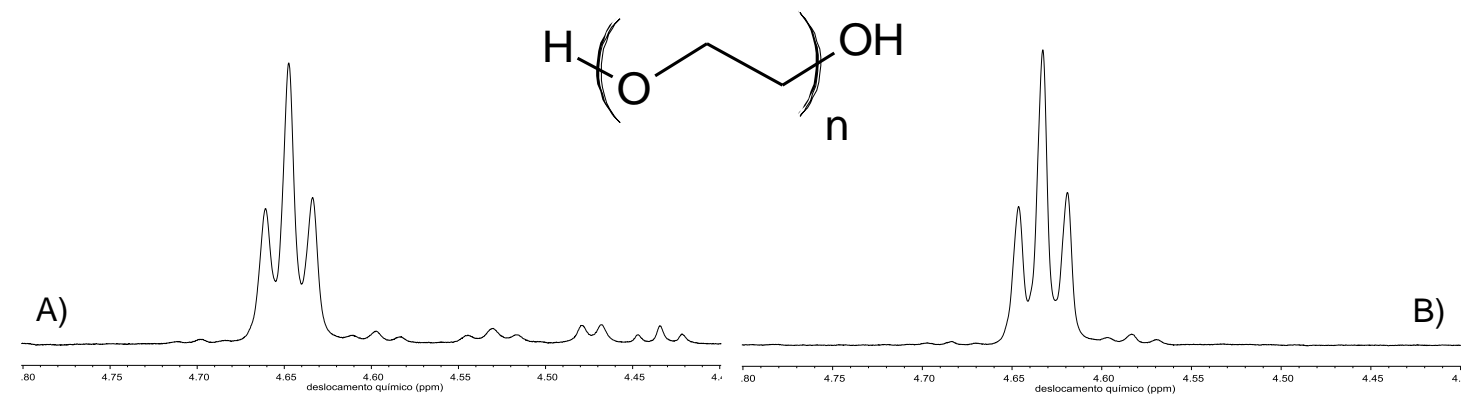

A partir dessas informações qualitativas, se poderia ainda realizar as quantificações desses excipientes simultaneamente as dos ativos, da mesma maneira demonstrada no item 4.1.4. 


\subsection{Método para Quantificação de Glifosato}

\subsubsection{Preparo dos Padrões Secundário:}

A utilização de um padrão externo (PE) de trifenil fosfato deveu-se principalmente a dois fatores: possibilidade de realizar as análises quantitativas sequenciais de $\mathrm{RMN}$ de ${ }^{1} \mathrm{H}$ e de ${ }^{31} \mathrm{P}$, dispensando um novo preparo da mesma amostra, e avaliar o emprego de um PE, uma vez que padrão interno já havia sido empregado e avaliado no método desenvolvido para o paracetamol.

Apesar da concentração da solução do padrão de referência de trifenil fosfato ser conhecida, a padronização secundária se fez necessária, pois havia a possibilidade de erros nas transferências das alíquotas de $200 \mu \mathrm{L}$ da solução para os tubos de EPR e da evaporação do solvente $\left(\mathrm{CDCl}_{3}\right)$ durante a manipulação da solução.

Na Figura 13 A está o espectro de RMN ${ }^{1} \mathrm{H}$ de uma das replicatas adquiridas na primeira padronização e a estrutura química do trifenil fosfato. O multipleto situado em 7,45-7,25 ppm refere-se aos 6 núcleos de ${ }^{1} \mathrm{H}$ aromáticos em posição orto e o outro multipleto (7,25-7,07 ppm) aos demais hidrogênios aromáticos, além do sinal residual do solvente $\mathrm{CDCl}_{3}$. O pico situado em 3,14 ppm refere-se ao núcleos de ${ }^{1} \mathrm{H}$ das metilas pertencentes a dimetil sulfona e o situado em 4,81 ppm, ao resíduo de solvente (HDO). Observa-se que todos os sinais são levemente alargados e isto se deve à aquisição sem giro da amostra, necessária pelo fato de haver um tubo (tubo de EPR contendo o trifenil fosfato) dentro do outro (tubo de RMN). A partir da área do sinal da $\mathrm{DMSO}_{2}$ (referenciada como 1000), das massas conhecidas de dimetil sulfona e da área do multipleto situado em 7,45-7,25 ppm, pôde-se determinar a massa de trifenil fosfato presente no PE empregando a equação 12. Os resultados obtidos estão relatados na Tabela 45.

A segunda padronização do primeiro padrão foi necessária, pois este procedimento havia sido feito em um tubo aleatório e em um equipamento diferente daquele no qual seria feita a validação do método. Um dos espectros obtidos está ilustrado na Figura $13 \mathrm{~B}$, na qual a melhora de resolução devido ao maior campo está explicitada. 
Figura 13 - Espectros de $\mathrm{RMN}$ de ${ }^{1} \mathrm{H}$ de amostras em $\mathrm{D}_{2} \mathrm{O}$ contendo trifenil fosfato (estrutura química ilustrada) e dimetil sulfona. Em A) espectro adquirido em um espectrômetro de 9,4 T e em B) em um espectrômetro de $14,1 \mathrm{~T}$

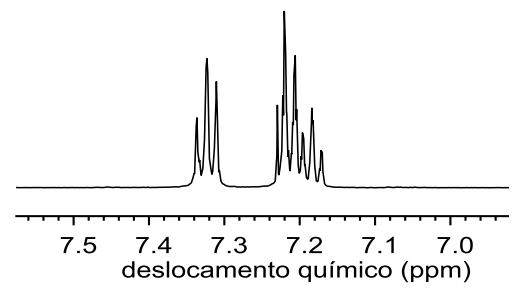

ul
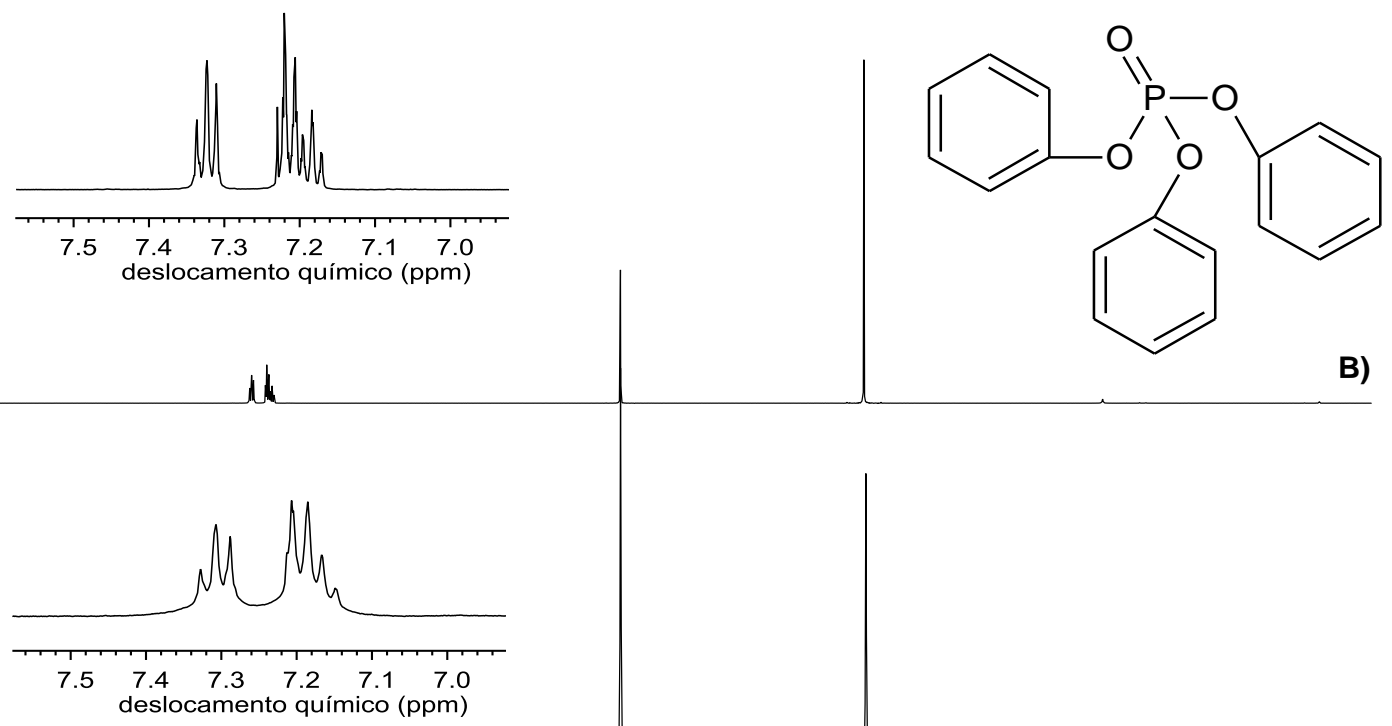

$M$

Para resultados mais seguros, considerou-se que esta segunda padronização deveria ser realizada exatamente nas mesmas condições do método a ser validado, uma vez que nos novos tubos o volume de $420 \mu \mathrm{L}$ da solução de $\mathrm{DMSO}_{2}$ não ficou exatamente na mesma altura da solução de trifenil fosfato, evidenciando a diferença de espessura do tubo de RMN de $5 \mathrm{~mm}$.

Esta observação foi confirmada através do resultado obtido (Tabela 45), pois a concentração de trifenil fosfato em relação à da $\mathrm{DMSO}_{2}$ estava maior que a anterior, revelando que havia menos moléculas de $\mathrm{DMSO}_{2}$ na região da bobina, pois sua solução estava em um nível acima do anterior.

Após a validação do método, este PE foi quebrado por acidente e a construção de um novo se fez necessário para ser empregado na quantificação das amostras comerciais. A nova concentração, também descrita na Tabela 45, provavelmente se deve à parcial evaporação do solvente, resultando em uma solução mais concentrada e, consequentemente, mais moléculas de trifenil fosfato na região de detecção. 
Tabela 45 - Resultados obtidos nas padronizações do PE de trifenil fosfato

\begin{tabular}{cccccc}
\hline padrão & área analito & $\begin{array}{c}\text { massa } \\
(\mathbf{m g})\end{array}$ & $\begin{array}{c}\text { média massa } \\
(\mathbf{m g})\end{array}$ & DP & $\begin{array}{c}\text { CV } \\
(\%)\end{array}$ \\
\hline 1 & 148,9 & 2,53 & & & \\
(1 $1^{\text {a }}$ padronização) & 155,1 & 2,57 & 2,53 & 0,04 & 1,7 \\
& 145,5 & 2,48 & & & \\
\hline 1 & 349,8 & 2,88 & & & \\
$\left(2^{\text {a }}\right.$ padronização $)$ & 351,0 & 2,94 & 2,94 & 0,06 & 1,9 \\
& 354,4 & 2,99 & & & \\
\hline & 441,5 & 3,67 & & & \\
& 429,2 & 3,62 & 3,67 & 0,06 & 1,5 \\
& 442,4 & 3,73 & & & \\
\hline
\end{tabular}

\subsubsection{Estudos Preliminares:}

Após as estimativas dos valores de $\mathrm{T}_{1}$ para $\mathrm{O}$ núcleo de ${ }^{1} \mathrm{H}$ e de ${ }^{31} \mathrm{P}$, a aquisição dos brancos, através dos quais foram evidenciadas a seletividade e especificidade da mesma maneira discutida para o paracetamol, e empregando o primeiro PE previamente quantificado, iniciaram-se os ensaios que seriam considerados na validação: exatidão e repetitividade.

De acordo com a ABNT NBR 14029, no ensaio de exatidão devem ser analisadas sete replicatas de três pontos diferentes: nominal, inferior e superior e nos demais (repetitividade, precisão intermediária e robustez), apenas o ponto nominal, também em sete replicatas. ${ }^{45}$ Devido à baixa solubilidade do glifosato, esta faixa teve que ser bastante estreita: $1,0 \mathrm{mg} ; 3,0 \mathrm{mg}$ e 5,0 $\mathrm{mg}$. Mesmo assim, a quantidade prevista inicialmente de solvente $(420 \mu \mathrm{L})$ não foi suficiente para solubilizar 5,0 mg de glifosato (PA) na temperatura do laboratório e, por isso, optouse em dobrar o volume do solvente, acrescentando mais $420 \mu \mathrm{L}$ do mesmo aos microtubos, e analisar apenas uma alíquota de $420 \mu \mathrm{L}$, que era suficiente para que as soluções do tubo do PE e a do tubo de RMN ficassem na mesma altura.

Dessa maneira, foram analisadas por $\mathrm{RMN}$ de ${ }^{1} \mathrm{H}$ e de ${ }^{31} \mathrm{P}$ as 21 amostras. $\mathrm{Na}$ Figura 14 A) e B) estão apresentados, respectivamente, um dos espectros de ${ }^{1} \mathrm{H} \mathrm{e}$ um dos de ${ }^{31} \mathrm{P}$ obtidos, juntamente com a estrutura química do glifosato (anteriormente à dissociação). 
Figura 14 - A) Ampliação do espectro de $\mathrm{RMN}$ de ${ }^{1} \mathrm{H}\left(8,0\right.$ - 2,5 ppm) e B) Espectro de RMN de ${ }^{31} \mathrm{P}$ de uma das amostras analisadas nos ensaios de exatidão/repetitividade $\left(9,4 \mathrm{~T} ; 23^{\circ} \mathrm{C}\right.$ e $\left.\mathrm{D}_{2} \mathrm{O}\right)$
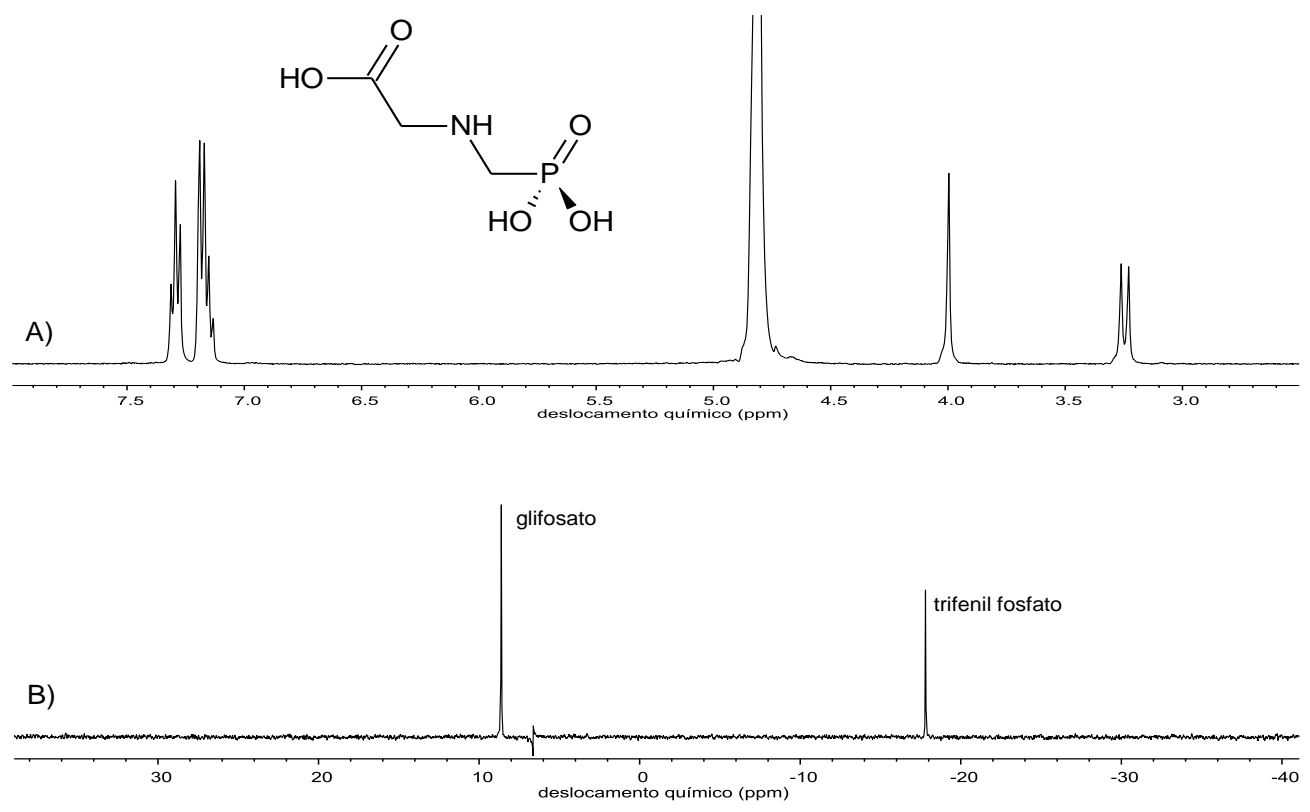

Observa-se no espectro de ${ }^{31} \mathrm{P}$ um sinal defasado, "spike", devido a problemas eletrônicos no equipamento, mas isto não interferiu nas medidas, uma vez que não se sobrepunha aos sinais de interesse.

Para as quantificações foram integrados o multipleto do PE situado em 7,457,25 ppm (agora considerando sua área igual a 1000) e o simpleto do glifosato situado em 4,02 ppm, nas análises de ${ }^{1} \mathrm{H}$, e os dois únicos simpletos presentes no espectro (-17,8 ppm, referente ao PE, e o 8,62 ppm, ao glifosato), nas análises de ${ }^{31} \mathrm{P}$. Os resultados obtidos estão descritos nas Tabelas $46-48$.

Tabela 46 - Resultados obtidos nos ensaios preliminares de Exatidão/Repetitividade das análises de $\mathrm{RMNq}$ de ${ }^{1} \mathrm{H}$ para determinação de glifosato

\begin{tabular}{ccccccc}
\hline replicata & área analito & $\begin{array}{c}\text { teor } \\
(\% \mathbf{~ m} / \mathbf{m})\end{array}$ & $\begin{array}{c}\text { média } \\
(\% \mathbf{~ m} / \mathbf{m})\end{array}$ & $\begin{array}{c}\text { exatidão } \\
(\%)\end{array}$ & DP & $\begin{array}{c}\text { CV } \\
(\%)\end{array}$ \\
\hline 1a & 138,0 & 99,4 & & & & \\
1b & 142,8 & 102,0 & & & & \\
1c & 192,4 & 96,2 & & & & \\
1d & 127,5 & 95,4 & 99,0 & 99,8 & 2,8 & 2,9 \\
1e & 138,6 & 98,1 & & & & \\
1f & 134,4 & 98,7 & & & & \\
1g & 162,9 & 103,2 & & & &
\end{tabular}


(conclusão)

\begin{tabular}{|c|c|c|c|c|c|c|}
\hline replicata & área analito & $\begin{array}{c}\text { teor } \\
(\% \mathrm{~m} / \mathrm{m})\end{array}$ & $\begin{array}{c}\text { média teor }_{\text {( }} \\
(\% \mathrm{~m} / \mathrm{m})\end{array}$ & $\begin{array}{c}\text { exatidão } \\
(\%)\end{array}$ & DP & $\begin{array}{l}\text { CV } \\
(\%)\end{array}$ \\
\hline $2 a$ & 416,7 & 98,3 & \multirow{7}{*}{97,6} & \multirow{7}{*}{98,4} & \multirow{7}{*}{2,9} & \multirow{7}{*}{3,} \\
\hline $2 b$ & 375,2 & 95,1 & & & & \\
\hline $2 c$ & 363,2 & 99,7 & & & & \\
\hline $2 d$ & 359,3 & 92,5 & & & & \\
\hline $2 e$ & 421,4 & 99,4 & & & & \\
\hline $2 f$ & 370,9 & 97,4 & & & & \\
\hline $2 g$ & 383,7 & 100,8 & & & & \\
\hline $3 a$ & 579,7 & 93,7 & \multirow{7}{*}{96,6} & \multirow{7}{*}{97,4} & \multirow{7}{*}{5,1} & \multirow{7}{*}{5,3} \\
\hline $3 b$ & 614,5 & 97,5 & & & & \\
\hline $3 c$ & 580,0 & 94,3 & & & & \\
\hline $3 d$ & 564,8 & 93,2 & & & & \\
\hline $3 e$ & 589,8 & 93,2 & & & & \\
\hline $3 f$ & 614,5 & 97,1 & & & & \\
\hline $3 g$ & 653,9 & 107,4 & & & & \\
\hline
\end{tabular}

Tabela 47. Resultados obtidos nos ensaios preliminares de Exatidão/Repetitividade das análises de $\mathrm{RMN}$ de ${ }^{31} \mathrm{P}$ para determinação de glifosato

\begin{tabular}{ccccccc}
\hline replicata & área analito & $\begin{array}{c}\text { teor } \\
(\% \mathbf{~ m} / \mathbf{m})\end{array}$ & $\begin{array}{c}\text { média teor } \\
(\% \mathbf{~ m} / \mathbf{m})\end{array}$ & $\begin{array}{c}\text { exatidão } \\
(\%)\end{array}$ & DP & $\begin{array}{c}\text { CV } \\
(\%)\end{array}$ \\
\hline 1a & 434,2 & 104,3 & & & & \\
1b & 407,6 & 97,0 & & & & \\
$1 \mathrm{c}$ & 534,4 & 89,1 & & & & \\
1d & 386,0 & 96,2 & 97,4 & 98,2 & 5,3 & 5,4 \\
$1 \mathrm{e}$ & 399,0 & 94,1 & & & & \\
1f & 423,7 & 103,7 & & & & \\
1g & 460,4 & 97,2 & & & &
\end{tabular}


(conclusão)

\begin{tabular}{|c|c|c|c|c|c|c|}
\hline replicata & área analito & $\begin{array}{c}\text { teor } \\
(\% \mathrm{~m} / \mathrm{m})\end{array}$ & $\begin{array}{c}\text { média teor } \\
(\% \mathrm{~m} / \mathrm{m})\end{array}$ & $\begin{array}{c}\text { exatidão } \\
(\%)\end{array}$ & DP & $\begin{array}{l}\text { CV } \\
(\%)\end{array}$ \\
\hline $2 a$ & 1231,7 & 96,8 & \multirow{7}{*}{102,4} & \multirow{7}{*}{103,2} & \multirow{7}{*}{4,5} & \multirow{7}{*}{4,4} \\
\hline $2 b$ & 1164,4 & 98,3 & & & & \\
\hline $2 c$ & 1072,2 & 98,1 & & & & \\
\hline $2 d$ & 1245,5 & 106,9 & & & & \\
\hline $2 e$ & 1315,5 & 103,4 & & & & \\
\hline $2 f$ & 1214,3 & 106,3 & & & & \\
\hline $2 g$ & 1217,0 & 106,6 & & & & \\
\hline $3 a$ & 1757,9 & 94,7 & \multirow{7}{*}{99,8} & \multirow{7}{*}{100,6} & \multirow{7}{*}{5,4} & \multirow{7}{*}{5,4} \\
\hline $3 b$ & 1815,3 & 96,0 & & & & \\
\hline $3 c$ & 1815,0 & 98,4 & & & & \\
\hline $3 d$ & 1763,7 & 97,0 & & & & \\
\hline $3 e$ & 1898,4 & 100,0 & & & & \\
\hline $3 f$ & 1931,2 & 101,7 & & & & \\
\hline $3 g$ & 2024,2 & 110,9 & & & & \\
\hline
\end{tabular}

Tabela 48 - Média global das 21 amostras analisadas nos ensaios de Exatidão/Repetitividade do estudo preliminar para determinação de glifosato

\begin{tabular}{ccccc}
\hline método & teor $(\% \mathbf{~ m} / \mathbf{m})$ & exatidão $(\%)$ & DP & CV (\%) \\
\hline${ }^{1} \mathrm{H}$ & 97,7 & 98,5 & 3,7 & 3,8 \\
${ }^{31} \mathrm{P}$ & 99,9 & 100,7 & 4,7 & 4,7 \\
\hline
\end{tabular}

Observou-se que os métodos propostos tiveram boa exatidão, pois os resultados globais médios para ambos estão de acordo com a norma (98\% $102 \%$ ). ${ }^{45}$ No entanto, o mesmo não ocorre com a precisão, pois os coeficientes de variação de ambos os métodos estão acima do aceito ( $C V \leq 2,0 \%){ }^{45}$

Para investigar se este resultado estava relacionado a possíveis erros provenientes das transferências de volumes (2 pipetagens para completar os $840 \mu \mathrm{L}$ e 1 para transferir a alíquota de $420 \mu \mathrm{L}$ para o tubo de $\mathrm{RMN}$ ) preparou-se mais uma septuplicata de massa $\cong 2,0 \mathrm{mg}$, a qual se solubilizaria diretamente nos $420 \mu \mathrm{L}$. Os resultados encontram-se na Tabela 49. 
Tabela 49 - Resultados obtidos no Teste 1 do método para determinação de glifosato

\begin{tabular}{|c|c|c|c|c|c|c|}
\hline replicata & área analito & $\begin{array}{c}\text { teor } \\
(\% \mathrm{~m} / \mathrm{m})\end{array}$ & $\begin{array}{l}\text { média teor }_{\text {( }} \\
(\% \mathrm{~m})\end{array}$ & $\begin{array}{c}\text { exatidão } \\
\text { (\%) }\end{array}$ & DP & $\begin{array}{l}\text { CV } \\
\text { (\%) }\end{array}$ \\
\hline${ }^{1} \mathrm{Ha}$ & 595,9 & 100,0 & \multirow{7}{*}{102,0} & \multirow{7}{*}{102,8} & \multirow{7}{*}{3,5} & \multirow{7}{*}{3,4} \\
\hline${ }^{1} \mathrm{Hb}$ & 656,2 & 99,1 & & & & \\
\hline${ }^{1} \mathrm{H} \mathrm{C}$ & 597,1 & 102,8 & & & & \\
\hline${ }^{1} \mathrm{H} \mathrm{d}$ & 572,7 & 104,1 & & & & \\
\hline${ }^{1} \mathrm{He}$ & 649,8 & 104,1 & & & & \\
\hline${ }^{1} \mathrm{Hf}$ & 595,6 & 106,8 & & & & \\
\hline${ }^{1} \mathrm{Hg}$ & 555,0 & 96,9 & & & & \\
\hline${ }^{31} \mathrm{P} \mathrm{a}$ & 1822,6 & 102,0 & \multirow{7}{*}{100,2} & \multirow{7}{*}{101,0} & \multirow{7}{*}{3,1} & \multirow{7}{*}{3,1} \\
\hline${ }^{31} \mathrm{P} \mathrm{b}$ & 1974,7 & 99,4 & & & & \\
\hline${ }^{31} \mathrm{P} \mathrm{C}$ & 1721,5 & 98,8 & & & & \\
\hline${ }^{31} \mathrm{P} \mathrm{d}$ & 1629,2 & 98,7 & & & & \\
\hline${ }^{31} \mathrm{Pe}$ & 1825,5 & 97,5 & & & & \\
\hline${ }^{31} \mathrm{Pf}$ & 1782,9 & 106,6 & & & & \\
\hline${ }^{31} \mathrm{P} \mathrm{g}$ & 1688,9 & 98,3 & & & & \\
\hline
\end{tabular}

Apesar de CV ter diminuído revelando a melhora no método, o seu valor ainda ficou acima de 2,0 \% e a exatidão do método de ${ }^{1} \mathrm{H}$ ficou comprometida por estar acima do permitido. Analisando-se os resultados obtidos a partir dos espectros de ${ }^{1} \mathrm{H}$ observou-se que os dois primeiros resultados, que são consideravelmente diferentes dos demais, eram provenientes de amostras que foram preparadas em tubos de RMN iguais entre si (mesmo lote e mesmo fabricante) e iguais aos que foram utilizados na padronização, mas diferentes dos demais.

Então, um novo teste foi realizado com outra septuplicata para investigar se o tubo de RMN interferia nos resultados. Na Tabela 50 pode-se observar que a precisão melhorou ainda mais e o valor de CV ficou abaixo do exigido pela norma, assim como a exatidão.

Provavelmente, os tubos de diferentes fabricantes tenham espessuras ligeiramente diferentes e essa diferença é suficiente para interferir nos resultados. Essa interferência não foi significativa nas análises do paracetamol, pois a alteração no resultado é insignificante, já que a quantidade de amostra analisada e de PI (moléculas na região da bobina de detecção) está igualmente distribuída. 
Tabela 50 - Resultados obtidos no Teste 2 do método para determinação de glifosato

\begin{tabular}{|c|c|c|c|c|c|c|}
\hline replicata & área analito & $\begin{array}{c}\text { teor } \\
(\% \mathrm{~m} / \mathrm{m})\end{array}$ & $\begin{array}{l}\text { média teor } \\
(\% \mathrm{~m} / \mathrm{m})\end{array}$ & $\begin{array}{c}\text { exatidão } \\
(\%)\end{array}$ & DP & $\begin{array}{l}\text { CV } \\
\text { (\%) }\end{array}$ \\
\hline${ }^{1} \mathrm{Ha}$ & 617,6 & 97,8 & & & & \\
\hline${ }^{1} \mathrm{Hb}$ & 551,3 & 98,4 & & & & \\
\hline${ }^{1} \mathrm{H} \mathrm{C}$ & 637,0 & 97,3 & & & & \\
\hline${ }^{1} \mathrm{H} \mathrm{d}$ & 697,5 & 96,1 & 98,1 & 98,9 & 1,6 & 1,6 \\
\hline${ }^{1} \mathrm{He}$ & 528,5 & 99,8 & & & & \\
\hline${ }^{1} \mathrm{Hf}$ & 560,4 & 100,5 & & & & \\
\hline${ }^{1} \mathrm{Hg}$ & 525,9 & 97,0 & & & & \\
\hline${ }^{31} \mathrm{P} \mathrm{a}$ & 1908,6 & 100,7 & & & & \\
\hline${ }^{31} \mathrm{P} \mathrm{b}$ & 1667,4 & 99,2 & & & & \\
\hline${ }^{31} \mathrm{P} \mathrm{C}$ & 1991,7 & 101,4 & & & & \\
\hline${ }^{31} \mathrm{P} \mathrm{d}$ & 2200,7 & 101,1 & 99,4 & 100,8 & 1,4 & 1,4 \\
\hline${ }^{31} \mathrm{P} \mathrm{e}$ & 1549,5 & 97,5 & & & & \\
\hline${ }^{31} \mathrm{Pf}$ & 1663,8 & 99,4 & & & & \\
\hline${ }^{31} \mathrm{P} \mathrm{g}$ & 1630,2 & 100,2 & & & & \\
\hline
\end{tabular}

\subsubsection{Validação do Método:}

A validação do método foi reiniciada, após 8 meses, em um novo equipamento de RMN (600 MHz), empregando um novo padrão analítico de glifosato e utilizando-se tubos de um mesmo lote e fabricante. No entanto, os primeiros ensaios novamente não foram exatos e precisos, conforme exigência da normativa. A investigação por esses novos resultados revelou que o problema, nesta ocasião, estava na balança que estava sendo utilizada.

\section{I) Seletividade e Especificidade}

Os ensaios para garantir a seletividade e especificidade foram refeitos para ambos os núcleos $\left({ }^{1} \mathrm{H}\right.$ e $\left.{ }^{31} \mathrm{P}\right)$, analisando em triplicata os brancos de solvente e do padrão analítico de glifosato. Os brancos dos padrões externos foram analisados apenas uma vez cada. Não foi observada a presença de interferentes nos espectros obtidos. 
II) Exatidão e Precisão

A partir de então, iniciou-se o emprego de outra balança semi-microanalítica e obtiveram-se os resultados desejados. Os resultados dos ensaios de Exatidão e Repetitividade encontram-se descritos nas Tabelas 51e 52.

Tabela 51 - Resultados obtidos nos ensaios de Exatidão/Repetitividade das análises de RMN de ${ }^{1} \mathrm{H}$ na validação do método para determinação de glifosato

\begin{tabular}{|c|c|c|c|c|c|c|}
\hline replicata & área analito & $\begin{array}{c}\text { teor } \\
(\% \mathrm{~m} / \mathrm{m})\end{array}$ & $\begin{array}{c}\text { média }_{\text {teor }} \\
(\% \mathrm{~m} / \mathrm{m})\end{array}$ & exatidão (\%) & DP & $\begin{array}{l}\text { CV } \\
(\%)\end{array}$ \\
\hline $1 \mathrm{a}$ & 135,1 & 98,0 & & & & \\
\hline $1 b$ & 104,2 & 99,2 & & & & \\
\hline $1 c$ & 110,8 & 101,2 & & & & \\
\hline $1 d$ & 119,5 & 99,3 & 99,9 & 100,0 & 1,7 & 1,7 \\
\hline $1 e$ & 145,9 & 99,5 & & & & \\
\hline $1 f$ & 114,1 & 103,2 & & & & \\
\hline $1 \mathrm{~g}$ & 146,4 & 99,1 & & & & \\
\hline $2 a$ & 312,9 & 97,9 & & & & \\
\hline $2 b$ & 301,0 & 99,0 & & & & \\
\hline $2 c$ & 350,1 & 100,6 & & & & \\
\hline $2 d$ & 321,3 & 101,6 & 100,6 & 100,7 & 1,7 & 1,7 \\
\hline $2 e$ & 405,3 & 100,4 & & & & \\
\hline $2 f$ & 374,3 & 102,1 & & & & \\
\hline $2 g$ & 322,6 & 102,7 & & & & \\
\hline $3 a$ & 560,7 & 99,9 & & & & \\
\hline $3 b$ & 542,6 & 100,8 & & & & \\
\hline $3 c$ & 602,5 & 97,3 & & & & \\
\hline $3 d$ & 556,4 & 98,7 & 98,9 & 99,0 & 1,7 & 1,8 \\
\hline $3 e$ & 528,7 & 98,0 & & & & \\
\hline $3 f$ & 519,8 & 96,6 & & & & \\
\hline $3 g$ & 562,6 & 101,0 & & & & \\
\hline
\end{tabular}


Tabela 52 - Resultados obtidos nos ensaios de exatidão/repetitividade das análises de RMN de ${ }^{31} \mathrm{P}$ na validação do método para determinação de glifosato

\begin{tabular}{|c|c|c|c|c|c|c|c|}
\hline replicata & área analito & $\begin{array}{c}\text { teor } \\
(\% \mathrm{~m} / \mathrm{m})\end{array}$ & $\begin{array}{c}\text { média teor } \\
(\% \mathrm{~m} / \mathrm{m})\end{array}$ & $\begin{array}{c}\text { exatidão } \\
(\%)\end{array}$ & & DP & $\begin{array}{l}\text { CV } \\
\text { (\%) }\end{array}$ \\
\hline $1 \mathrm{a}$ & 398,2 & 96,3 & \multirow{7}{*}{98,1} & \multirow{7}{*}{\multicolumn{2}{|c|}{98,2}} & \multirow{7}{*}{1,9} & \multirow{7}{*}{1,8} \\
\hline $1 b$ & 313,4 & 99,5 & & & & & \\
\hline $1 \mathrm{c}$ & 331,2 & 100,9 & & & & & \\
\hline $1 d$ & 352,3 & 97,6 & & & & & \\
\hline $1 e$ & 421,3 & 95,8 & & & & & \\
\hline $1 f$ & 325,8 & 98,3 & & & & & \\
\hline $1 \mathrm{~g}$ & 441,0 & 99,5 & & & & & \\
\hline $2 a$ & 919,9 & 96,0 & \multirow{7}{*}{98,3} & \multirow{7}{*}{98,4} & & \multirow{7}{*}{1,4} & \multirow{7}{*}{1,5} \\
\hline $2 b$ & 892,4 & 97,8 & & & & & \\
\hline $2 c$ & 1020,3 & 97,8 & & & & & \\
\hline $2 d$ & 946,2 & 99,8 & & & & & \\
\hline $2 e$ & 1191,8 & 98,4 & & & & & \\
\hline $2 f$ & 1103,5 & 100,4 & & & & & \\
\hline $2 g$ & 923,2 & 98,0 & & & & & \\
\hline $3 a$ & 1697,1 & 100,8 & \multirow{7}{*}{100,9} & \multirow{7}{*}{101,0} & \multirow{7}{*}{1,1} & & \multirow{7}{*}{1,1} \\
\hline $3 b$ & 1643,7 & 101,8 & & & & & \\
\hline $3 c$ & 1893,3 & 101,9 & & & & & \\
\hline $3 d$ & 1693,9 & 100,2 & & & & & \\
\hline $3 e$ & 1643,1 & 101,5 & & & & & \\
\hline $3 f$ & 1594,6 & 98,7 & & & & & \\
\hline $3 g$ & 1693,4 & 101,4 & & & & & \\
\hline
\end{tabular}

Como pôde ser observado, para ambos os núcleos a exatidão e a precisão ficaram dentro do exigido pela normativa. Cabe ressaltar que o intervalo de integração foi previamente analisado e fixado para todas as replicatas pertencentes a cada um dos ensaios, mas houve ligeira variação neste intervalo entre os ensaios, devido a variações na largura de linha.

No ensaio de precisão intermediária, variou-se o analista e o dia de análise e, no de robustez, duas variáveis foram avaliadas: a pesagem das amostras em um dia e o preparo e análise das mesmas, em outro (RB1); e a integração do dupleto 
referente ao glifosato (RB2). Essa escolha deveu-se ao fato das pesagens, eventualmente, ter de ser realizadas em um dia, mas as análises só em outro. E a diferente integração, caso houvesse a necessidade de se integrar o dupleto, devido à falta de seletividade no simpleto, integrado nos ensaios de precisão e exatidão. Os resultados obtidos nesses ensaios estão descritos nas Tabelas 53 e 54 .

Tabela 53 - Resultados obtidos nos ensaios de Precisão Intermediária (Pi) e Robustez (RB) das análises de $\mathrm{RMNq}$ de ${ }^{1} \mathrm{H}$ na validação do método para determinação de glifosato

\begin{tabular}{|c|c|c|c|c|c|c|}
\hline replicata & área analito & $\begin{array}{c}\text { teor } \\
(\% \mathrm{~m} / \mathrm{m})\end{array}$ & $\begin{array}{l}\text { média teor } \\
(\% \mathrm{~m} / \mathrm{m})\end{array}$ & $\begin{array}{c}\text { exatidão } \\
(\%)\end{array}$ & DP & $\begin{array}{l}\text { CV } \\
\text { (\%) }\end{array}$ \\
\hline Pia & 280,6 & 89,1 & \multirow{7}{*}{101,3} & \multirow{7}{*}{101,4} & \multirow{7}{*}{1,8} & \multirow{7}{*}{1,7} \\
\hline Pib & 324,0 & 102,1 & & & & \\
\hline Pic & 346,8 & 102,3 & & & & \\
\hline Pid & 380,0 & 101,0 & & & & \\
\hline Pie & 335,2 & 98,5 & & & & \\
\hline Pif & 337,5 & 103,5 & & & & \\
\hline Pig & 315,0 & 100,3 & & & & \\
\hline RB1a & 322,2 & 102,3 & \multirow{7}{*}{100,8} & \multirow{7}{*}{100,9} & \multirow{7}{*}{1,6} & \multirow{7}{*}{1,6} \\
\hline RB1b & 385,8 & 99,1 & & & & \\
\hline RB1c & 332,5 & 102,3 & & & & \\
\hline RB1d & 354,6 & 101,3 & & & & \\
\hline Rb1e & 378,5 & 100,9 & & & & \\
\hline RB1f & 316,5 & 101,9 & & & & \\
\hline RB1g & 328,6 & 98,1 & & & & \\
\hline RB2a & 320,7 & 101,8 & \multirow{7}{*}{101,3} & \multirow{7}{*}{101,4} & \multirow{7}{*}{1,1} & \multirow{7}{*}{1,1} \\
\hline RB2b & 392,8 & 100,8 & & & & \\
\hline RB2c & 331,0 & 101,9 & & & & \\
\hline RB2d & 350,5 & 100,1 & & & & \\
\hline RB2e & 387,4 & 103,2 & & & & \\
\hline RB2f & 315,1 & 101,4 & & & & \\
\hline RB2g & 334,8 & 100,0 & & & & \\
\hline
\end{tabular}


Tabela 54 - Resultados obtidos nos ensaios de Precisão Intermediária (Pi) e Robustez (RB) das análises de RMN de ${ }^{31} \mathrm{P}$ na validação do método para determinação de glifosato

\begin{tabular}{ccccccc}
\hline replicata & área analito & $\begin{array}{c}\text { teor } \\
(\% \mathbf{~ m} / \mathbf{m})\end{array}$ & $\begin{array}{c}\text { média } \\
(\% \mathbf{~ m} / \mathbf{m})\end{array}$ & $\begin{array}{c}\text { exatidão } \\
(\%)\end{array}$ & DP & $\begin{array}{c}\text { CV } \\
(\%)\end{array}$ \\
\hline Pia & 839,5 & 88,8 & & & & \\
Pib & 974,2 & 102,4 & & & & \\
Pic & 1020,4 & 100,3 & & & & \\
Pid & 1139,8 & 101,0 & 100,9 & 101,0 & 2,0 & 2,0 \\
Pie & 1014,3 & 99,4 & & & & \\
Pif & 1017,0 & 104,0 & & & & \\
Pig & 927,6 & 98,5 & & & & \\
\hline RB1a & 953,4 & 100,9 & & & & \\
RB1b & 1159,5 & 99,2 & & & & \\
RB1c & 1007,3 & 103,3 & & & & \\
RB1d & 1066,4 & 101,5 & 100,5 & & \\
RB1e & 1113,0 & 98,9 & & & & \\
RB1f & 943,2 & 101,2 & & & & \\
RB1g & 978,5 & 97,4 & & & & \\
\hline
\end{tabular}

Os ensaios de robustez e de precisão intermediária também foram satisfatórios. No entanto, no ensaio de $\mathrm{Pi}$, a replicata de número 1 foi desconsiderada nos resultados apresentados (tanto no ${ }^{1} \mathrm{H}$, quanto no ${ }^{31} \mathrm{P}$ ). Essa exclusão é permitida pela própria normativa, desde que se justifique através do Teste de Grubbs (G). ${ }^{45}$

Este teste possibilita a verificação de um valor disperso, o qual geralmente é maior ou menor que aos valores de um grupo de dados. Para isso é necessário calcular-se a média e o desvio padrão dos valores pertencentes a este grupo de dados, sem considerar o valor suspeito $\left(x_{n}\right)$. Com os valores obtidos e o valor suspeito realiza-se um dos seguintes cálculos: ${ }^{45}$

- para valores maiores:

$$
G=\frac{\left(x_{n}-\bar{x}\right)}{D P}
$$

- para valores menores:

$$
G=\frac{\left(\bar{x}-x_{n}\right)}{D P}
$$


Então, o resultado $(G)$ obtido deve ser comparado aos valores da Tabela de Valores Críticos para o Teste de Grubbs $\left(G_{c}\right)$, caso $G$ seja maior que $\circ G_{c}(1 \%)$, poderá ser excluído. Este tipo de exclusão pode ser feita em até $22,2 \%$ dos dados, acima disso, o ensaio deve ser refeito. ${ }^{45}$

No presente estudo, considerando o grupo de dados que continha 7 replicatas, uma delas poderia excluída. Então se calculou os valores de $\mathrm{G}$ para a replicata 1 do ensaio de precisão intermediária e obteve-se $G=7,012$, para o resultado de ${ }^{1} \mathrm{H}$, e $\mathrm{G}=6,016$, para o de ${ }^{31} \mathrm{P}$. Como $\circ \mathrm{G}_{\mathrm{c}}(1 \%)$, para um grupo de dados no qual $n=7$ é igual a 2,139, essa replicata pôde ser excluída e os ensaios, considerados válidos. ${ }^{45}$

$\mathrm{Na}$ tabela 55 apresentam-se as médias globais dos resultados obtidos na validação para ambos os núcleos, na qual se observa que 0 método de ${ }^{1} \mathrm{H}$ foi ligeiramente mais preciso e o de ${ }^{31} \mathrm{P}$, mais exato.

Tabela 55 - Média global das 21 amostras analisadas nos ensaios de Exatidão/Repetitividade na validação do método para determinação de glifosato

\begin{tabular}{ccccc}
\hline método & teor $(\% \mathbf{m} / \mathbf{m})$ & exatidão $(\%)$ & DP & CV (\%) \\
\hline${ }^{1} \mathrm{H}$ & 100,5 & 100,6 & 1,7 & 1,7 \\
${ }^{31} \mathrm{P}$ & 99,7 & 99,8 & 2,0 & 2,0 \\
\hline
\end{tabular}

III) Linearidade, Sensibilidade e Faixa deTrabalho

Apesar da discussão feita na validação do paracetamol sobre a desnecessidade de verificação da linearidade em validação de métodos de RMN, a curva analítica foi construída empregando os mesmos pontos analisados no ensaio de exatidão (utilizando os valores de massa pesados), uma vez que a normativa não especifica a quantidade de pontos necessários, apenas descreve que cada ponto deve ser realizado em sete replicatas.

Como o valor das áreas do analito é determinado em relação à área do padrão externo, uma normalização se torna necessária, seja dividindo a área do PE pelo número de seus núcleos que absorvem na frequência monitorada, ou multiplicando a área do analito por esse número.

No presente estudo, optou-se por multiplicar a área do analito pelo número de núcleos absorventes do trifenil fosfato. Assim, os valores das áreas dos ${ }^{1} \mathrm{H}$ do glifosato foram multiplicados por 6 . Essa normalização não foi necessária para as 
áreas dos sinais de ${ }^{31} \mathrm{P}$, pois o trifenil fosfato possui apenas 1 núcleo absorvendo radiofrequência. As curvas obtidas podem ser visualizadas na Figura 15.

De acordo com NBR14029, curvas com o coeficiente de regressão acima de 0,97 são válidas. Assim, as curvas analíticas obtidas foram aceitas, pois apresentaram $r^{2}=0,9985$, para ${ }^{1} \mathrm{H}$, e $r^{2}=0,9988$, para ${ }^{31} \mathrm{P} .{ }^{45}$

A sensibilidade dos métodos foi determinada simultaneamente com a curva e expressa pelo coeficiente angular. ${ }^{45}$ Assim, pode se inferir que a sensibilidade do método de ${ }^{1} \mathrm{H}(652,3)$ foi aproximadamente o dobro da sensibilidade do método ${ }^{31} \mathrm{P}$ $(328,78)$. Isso já era esperado uma vez que dois núcleos de ${ }^{1} \mathrm{H}$ de glifosato foram monitorados, enquanto monitorou-se apenas um núcleo de ${ }^{31} \mathrm{P}$, o único presente na molécula.

Cabe ressaltar que em métodos de RMN o valor de sensibilidade é relativo, uma vez que os valores de área (eixo y) foram determinados a partir da área do padrão de trifenil fosfato, o qual foi referenciado como 1000. Assim, ao se comparar sensibilidades de métodos de RMN o valor da área do padrão deve ser referenciado igualmente em ambos os métodos e a quantidade de núcleos absorventes, normalizados, conforme descrito anteriormente.

Figura 15 - Curvas analíticas obtidas no ensaio de linearidade das validações dos métodos de RMNq de ${ }^{1} \mathrm{H}$ e de ${ }^{31} \mathrm{P}$

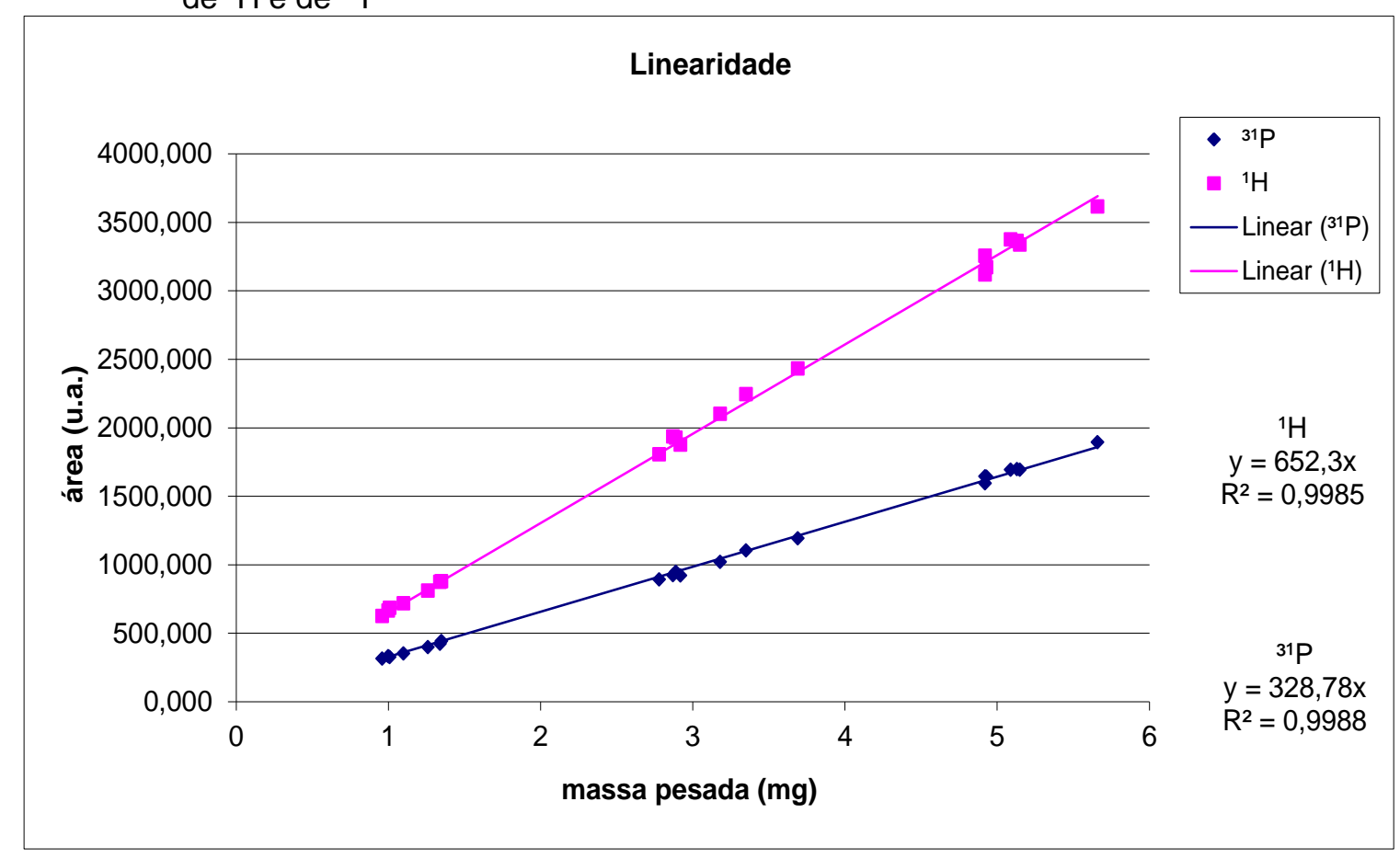


Além disso, é importante deixar claro que a diferença de sensibilidade do equipamento em relação a cada núcleo se pronunciou na razão $S / R$, a qual foi bem maior nos espectros de ${ }^{1} \mathrm{H}$ do que nos de ${ }^{31} \mathrm{P}$. Esta diferença não se pronuncia na sensibilidade dos métodos uma vez que a receptividade dos núcleos é anulada ao se fazer a razão entre a área de analito e a área de padrão.

\section{IV) Limites de Quantificação e de Detecção}

Juntamente com as curvas analíticas, também foram obtidos a faixa linear de trabalho (1,00 mg - 5,00 mg) e o Limite de Quantificação (LQ), o qual é a concentração mais baixa que se pode garantir precisão e exatidão $(1,00 \mathrm{mg})$.

Já o Limite de Detecção do Equipamento (LDE) foi determinado em outro ensaio, no qual se partiu de uma solução de concentração conhecida e foram feitas sucessivas diluições e aquisições espectrais até que a razão $S / R$ ficou próxima a 3 nos espectros de ${ }^{31} \mathrm{P}$, conforme recomendado na normativa. ${ }^{45}$ Como o método desenvolvido visa análises de ${ }^{1} \mathrm{H}$ e de ${ }^{31} \mathrm{P}$ consecutivas analisando a mesma amostra, a concentração do LDE deve atender ao núcleo que possui menor sensibilidade perante ao equipamento, que no caso é o ${ }^{31} \mathrm{P}$. A concentração que resultou nessa razão $\mathrm{S} / \mathrm{R}$ foi uma solução de $600 \mu \mathrm{L}$ na qual continha $0,012 \mathrm{mg}$ de glifosato $(0,02 \mathrm{mg} / \mathrm{mL})$.

Para o limite de deteç̧ão do método (LDM) deveriam ser feitas sucessivas diluições até o sinal do analito não ser mais detectado. Em seguida, a concentração anteriormente a esta que não houve detecção, deveria ser analisada em sete replicatas para que o desvio padrão seja calculado em então, determinar-se o LDM da seguinte maneira: $L D M=0+t D P$, onde $t$ é a variável de Student. ${ }^{45}$

No presente estudo não considerou este ensaio aplicável uma vez que, em análises de ingredientes ativos, esse limite (assim como demonstrado para o limite de detecção do equipamento) está muito abaixo do limite de quantificação, o qual pode ser relativamente alto, já que os analitos de interesse se encontram em alta concentração na matriz.

\section{V) Incerteza de Medição}

Por fim, foi feito o cálculo da incerteza combinada $\left(u_{c}\right)$ e extendida $(U)$ dos métodos, se baseando trabalho de Malz e Jancke, no qual se emprega a equação 14 , onde $x$ é o analito e $P I$, o padrão. ${ }^{24}$ 
equação 14 $u_{c}\left(P_{x}\right)=P_{x} \sqrt{\left(\frac{u\left(A_{X} / A_{P I}\right)}{A_{X} / A_{P I}}\right)^{2}+\left(\frac{u\left(M M_{X}\right)}{M M_{X}}\right)^{2}+\left(\frac{u\left(M M_{P I}\right)}{M M_{P I}}\right)^{2}+\left(\frac{u(m)}{m_{X}}\right)^{2}+\left(\frac{u(m)}{m_{P I}}\right)^{2}+\left(\frac{u\left(P_{P I}\right)}{P_{P I}}\right)^{2}}$

No entanto foi necessário adicionar a esta equação as incertezas relacionadas às transferências de volume, uma vez que no método desenvolvido a massa pesada foi solubilizada em $840 \mu \mathrm{L}\left(\mathrm{V}_{1}\right)$ e depois uma alíquota de $420 \mu \mathrm{L}\left(\mathrm{V}_{2}\right)$, foi transferida para análise. Então, empregou-se a equação 15 e a exemplificação a seguir, baseia-se nos resultados do método de ${ }^{1} \mathrm{H}$.

equação 15

$u_{c}\left(P_{x}\right)=P_{x} \sqrt{\left(\frac{u\left(A_{X} / A_{P I}\right)}{A_{X} / A_{P I}}\right)^{2}+\left(\frac{u\left(M M_{X}\right)}{M M_{X}}\right)^{2}+\left(\frac{u\left(M M_{P I}\right)}{M M_{P I}}\right)^{2}+\left(\frac{u(V)}{V_{1}}\right)^{2}+\left(\frac{u(V)}{V_{2}}\right)+\left(\frac{u(m)}{m_{X}}\right)^{2}+\left(\frac{u(m)}{m_{P I}}\right)^{2}+\left(\frac{u\left(P_{P I}\right)}{P_{P I}}\right)^{2}}$

A incerteza da razão das áreas pode ser determinada através do desvio padrão da razão das áreas de $n$ amostras, dividido pela raiz quadrada de $n$. Então, para considerar todas as 41 replicatas analisadas na validação é necessário normalizá-las pela massa pesada, uma vez que diferentes massas resultariam em diferentes áreas, e em seguida dividir o valor obtido por 1000, que é o valor da área do padrão. Após isso, o valor de desvio padrão obtido foi de 0,001908 e dividindo-o pela raiz de 41 , obteve-se uma incerteza $\left(u\left(A_{x} / A_{P I}\right)\right)$ de 0,000298.

As incertezas das massas molares são calculadas através da soma quadrática das incertezas de massa de cada um dos elementos pertencentes a uma determinada molécula. Essas incertezas de massa atômicas são tabeladas e podem ser encontradas na literatura. ${ }^{148} \mathrm{Na}$ tabela 56 encontram-se os valores de incertezas de massas atômicas dos elementos presentes no glifosato, no trifenil fosfato e no $\mathrm{DMSO}_{2}$, e em seguida os cálculos de incerteza de suas massas moleculares.

Tabela 56 - Valores de incertezas de massas atômicas

\begin{tabular}{cccc}
\hline elemento & $\boldsymbol{u}$ massa atômica & elemento & u massa atômica \\
\hline C & 0,0008 & $\mathrm{H}$ & 0,00007 \\
$\mathrm{O}$ & 0,0003 & $\mathrm{~N}$ & 0,0002 \\
$\mathrm{P}$ & 0,000002 & $\mathrm{~S}$ & 0,005 \\
\hline
\end{tabular}

Fonte: IUPAC, $2009 .{ }^{148}$ 
- $u$ glifosato $\left(\mathrm{C}_{3} \mathrm{H}_{8} \mathrm{NO}_{5} \mathrm{P}\right)$ :

$u M M=\sqrt{(3 \times 0,0008)^{2}+(8 \times 0,00007)^{2}+(0,0002)^{2}+(5 \times 0,0003)^{2}+(0,000002)^{2}}=0,00289$

- $u$ trifenil fosfato $\left(\mathrm{C}_{18} \mathrm{H}_{15} \mathrm{O}_{4} \mathrm{P}\right)$ :

$u M M=\sqrt{(18 \times 0,0008)^{2}+(15 \times 0,00007)^{2}+(4 \times 0,0003)^{2}+(0,000002)^{2}}=0,0145$

- $u$ dimetil sulfona $\left(\mathrm{C}_{2} \mathrm{H}_{6} \mathrm{O}_{2} \mathrm{~S}\right)$ :

$u M M=\sqrt{(2 \times 0,0008)^{2}+(6 \times 0,00007)^{2}+(2 \times 0,0003)^{2}+(0,005)^{2}}=0,00530$

De acordo com a normativa, se uma especificação declara a leitura de uma balança ou pipeta dentro de um determinado intervalo, $\pm 0,01 \mathrm{mg}$ para a balança e \pm $1,0 \mu \mathrm{L}$ para a micropipeta de 100-1000 $\mu \mathrm{L}$ empregadas nesta validação, sem um nível de confiança e não há razões para se esperar valores extremos prováveis, a incerteza é determinada dividindo-se este intervalo por raiz de 6. Assim, a incerteza de massa pesada $(u(\mathrm{~m}))$ foi 0,00408 e a da pipeta $(u(\mathrm{~V})) 0,408 .{ }^{45}$

Para se determinar a incerteza da massa do padrão, no presente caso, devese considerar a padronização secundária, a qual empregou a equação 12. Assim a incerteza combinada do padrão pode ser calculada empregando a equação 15 modificada:

$u_{c}\left(m_{x}\right)=m_{x} \sqrt{\left(\frac{u\left(A_{X} / A_{P I}\right)}{A_{X} / A_{P I}}\right)^{2}+\left(\frac{u\left(M M_{X}\right)}{M M_{X}}\right)^{2}+\left(\frac{u\left(M M_{P I}\right)}{M M_{P I}}\right)^{2}+\left(\frac{u(m)}{m_{P I}}\right)^{2}\left(\frac{u(V)}{V_{2}}\right)^{2}+\left(\frac{u\left(P_{P I}\right)}{P_{P I}}\right)^{2}}$

Da mesma forma demonstrada anteriormente, determinou-se a incerteza da razão de áreas das triplicatas usadas na padronização $(u(A)=0,000175)$ e da massa $(u(m)=0,00408)$. A incerteza das massas molares já havia sido previamente calculada e a da pureza do padrão de $\mathrm{DMSO}_{2}$ veio definida em seu certificado de análise, que é igual a 0,32 , para a quantidade de $\mathrm{DMSO}_{2}$ utilizada na padronização. Assim, realizando o cálculo acima, substituindo por estes valores:

$u_{c}\left(m_{x}\right)=2,94 \sqrt{\left(\frac{0,000175}{0,0727}\right)^{2}+\left(\frac{0,0145)}{326,28}\right)^{2}+\left(\frac{0,00530}{94,1338}\right)^{2}+\left(\frac{0,00408}{4,84}\right)^{2}+\left(\frac{0,408}{420}\right)^{2}+\left(\frac{0,32}{99,65}\right)^{2}}=0,0159$ 
Uma vez que todas as incertezas de entrada estão definidas e $P x$ é a média de teor global (Tabela 55), bastou substituí-las na equação 15, para que a incerteza combinada do método de RMN de ${ }^{1} \mathrm{H}$ fosse determinada.

$u_{c}\left(P_{x}\right)=100,47 \sqrt{\left(\frac{0,000298}{0,110}\right)^{2}+\left(\frac{0,00289}{169,07}\right)^{2}+\left(\frac{0,0145}{326,28}\right)^{2}+\left(\frac{0,00408}{3,11}\right)^{2}+\left(\frac{0,00408}{2,94}\right)^{2}+\left(\frac{0,408}{840}\right)^{2}+\left(\frac{0,408}{420}\right)^{2}+\left(\frac{0,0156}{100}\right)^{2}}=0,334$

Para o cálculo da incerteza combinada do método de ${ }^{31} \mathrm{P}$ substituiu-se a incerteza das áreas e o $P x$, uma vez que todas as outras grandezas de entrada são as mesmas. Dessa maneira a incerteza combinada do método de ${ }^{31} \mathrm{P}$ obtida foi de 0,384 .

A incerteza expandida $(U$ ) é obtida através da multiplicação dessas incertezas combinadas pelo fator de abrangência, o qual é recomendado 2 para quase todos os fins e fornece $95 \%$ de confiança. ${ }^{45}$ Assim, a incerteza expandida do método de ${ }^{1} \mathrm{H}$ foi $U=0,702$ e a do método de ${ }^{31} \mathrm{P}, U=0,768$.

\subsubsection{Análises dos Produtos Comerciais:}

Nove amostras comerciais foram analisadas: oito formulações líquidas e uma sólida. Os brancos dessas amostras foram analisados posteriormente às análises quantitativas, uma vez que foi só retirar o capilar e completar o volume de solução de amostra para $600 \mu \mathrm{L}$.

Os espectros de RMN ${ }^{1} \mathrm{H}$ dessas amostras estão ilustrados na Figura 16. Nessa figura 16 observou-se que não havia sinais na região do trifenil fosfato e, portanto, a quantificação feita anteriormente não estava comprometida. O mesmo foi observado e concluído nos espectros de ${ }^{31} \mathrm{P}$. No entanto, em algumas amostras há sinais de ${ }^{1} \mathrm{H}$ sobrepostos ao simpleto integrado na validação e, por isso, para essas amostras, integrou-se o dupleto para a quantificação.

Observou-se também que nas formulações codificadas por $\mathrm{S}$, B e $\mathrm{H}$ O glifosato se encontra na sua forma ácida, enquanto que nas demais na forma de sal de isopropilamina. Essas informações nem sempre estão claras nos rótulos dos produtos e são importantes para uma quantificação correta.

Além disso, observaram-se ligeiras variações no deslocamento químico dos sinais dessas amostras. Essas diferenças podem ser provenientes de alguns fatores, 
tais como: o glifosato estar na forma ácida ou na forma de sal; presença dos inertes nas formulações ou ainda pelas diferentes possíveis formas zwinteriônicas presentes nas soluções analisadas, uma vez que o equilíbrio envolvido entre elas pode se deslocar favorecendo, ou não, uma determinada forma.

Esta última possibilidade, somada ao fato do $\mathrm{pH}$ da amostra padrão de

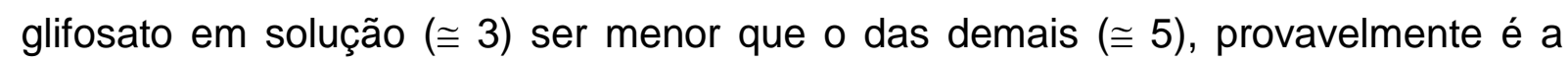
melhor explicação para significativa diferença dos deslocamentos químicos nas

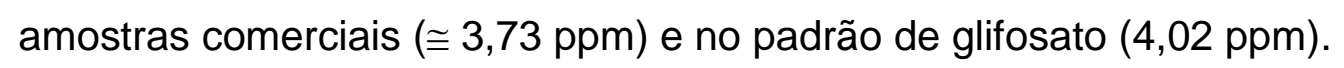

Figura 16 - Espectros de RMN de ${ }^{1} \mathrm{H}\left(14,1 \mathrm{~T} ; 2^{2}{ }^{\circ} \mathrm{C}\right.$ e $\left.\mathrm{D}_{2} \mathrm{O}\right)$ das amostras comerciais de herbicidas contendo glifosato

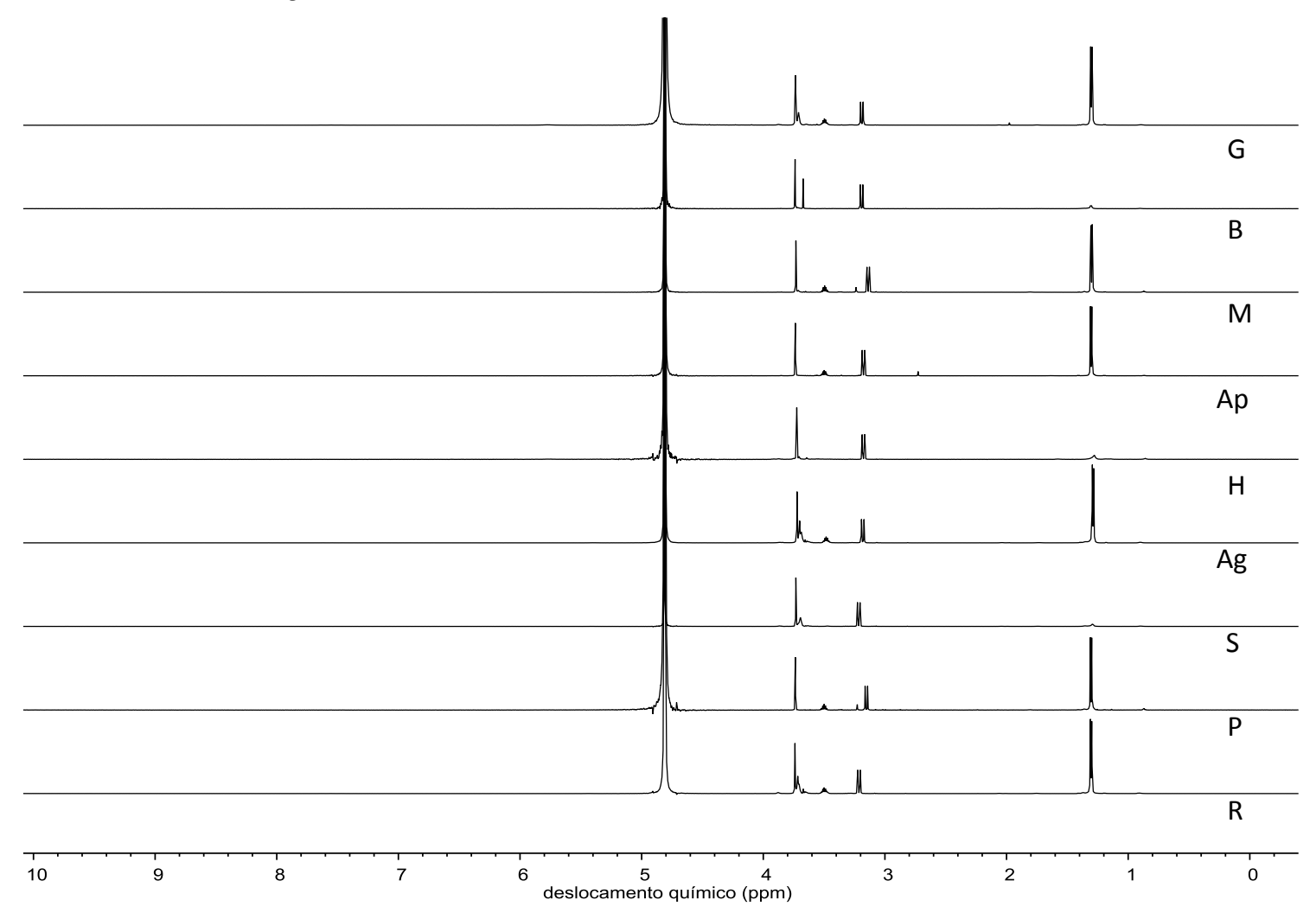

Essas variações também foram observadas nos espectros de ${ }^{31} \mathrm{P}$ (Figura 17), quando referenciados pelo sinal do trifenil fosfato, em -17,8 ppm. 
Figura 17 - Espectros de $R M N$ de ${ }^{31} \mathrm{P}\left(14,1 \mathrm{~T} ; 23^{\circ} \mathrm{C}\right.$ e $\left.\mathrm{D}_{2} \mathrm{O}\right)$ das amostras comerciais de herbicidas contendo glifosato

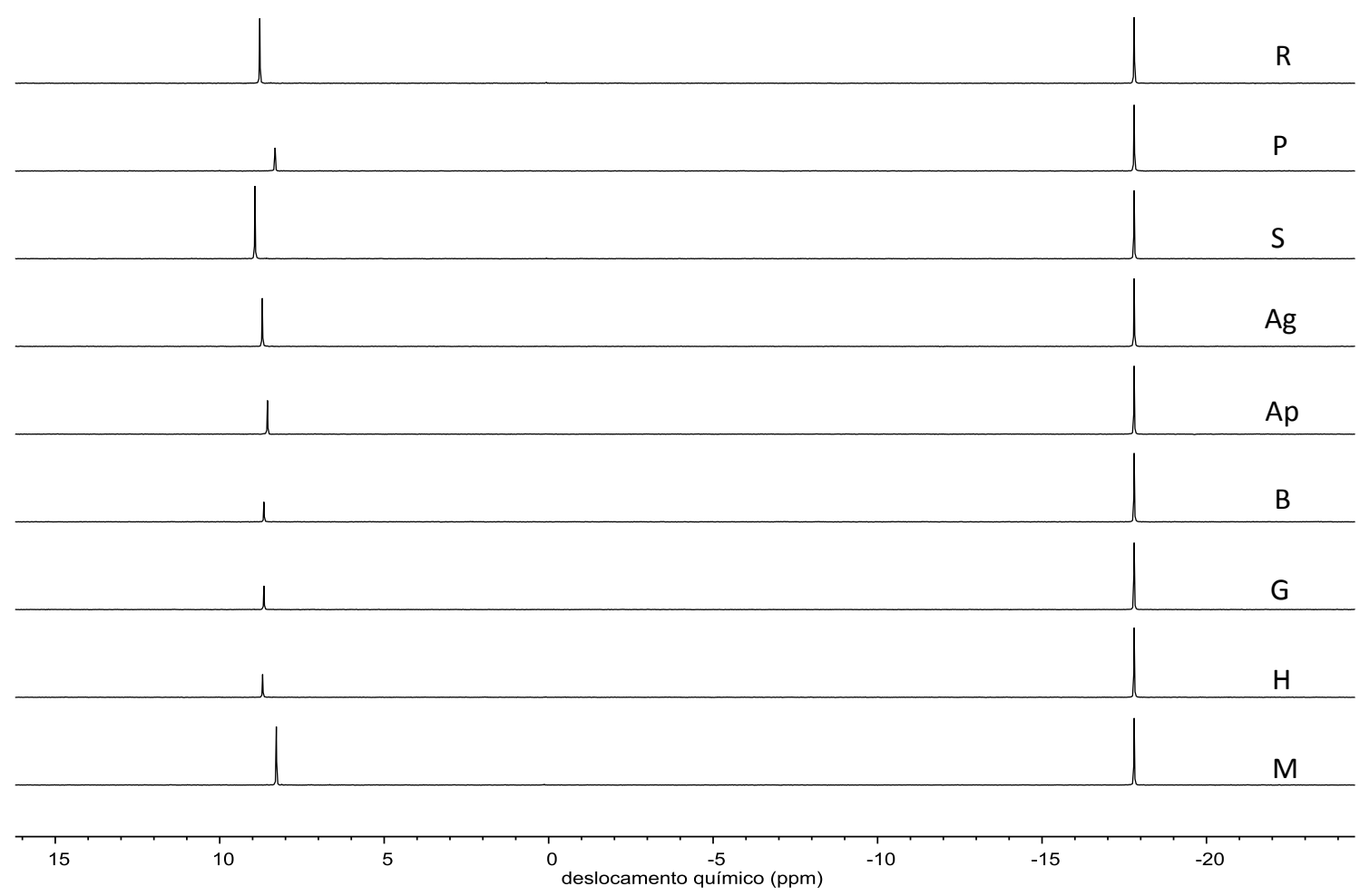

\section{I) Formulação sólida}

Para a formulação sólida, calculou-se, de acordo com a descrição de seu rótulo, a massa que deveria ser pesada na qual contivesse aproximadamente 2,50 mg. Então, três massas de aproximadamente $5,00 \mathrm{mg}$ foram pesadas e analisadas, conforme o método validado. Os resultados obtidos por RMN de ${ }^{1} \mathrm{H}$ e de ${ }^{31} \mathrm{P}$ estão mostrados na Tabela 57.

Tabela 57 - Resultados obtidos na quantificação da amostra comercial sólida de glifosato (S) por RMNq de ${ }^{1} \mathrm{H}$ e de ${ }^{31} \mathrm{P}$

\begin{tabular}{|c|c|c|c|c|c|c|c|}
\hline replicata & $\begin{array}{c}\text { massa de } \\
\text { produto }(\mathrm{mg})\end{array}$ & área (u.a.) & $\begin{array}{c}\text { massa de } \\
\text { glifosato } \\
(\mathrm{mg})\end{array}$ & $\begin{array}{c}\text { teor } \\
(\% \mathrm{~m} / \mathrm{m})\end{array}$ & $\begin{array}{c}\text { média } \\
(\% \mathrm{~m} / \mathrm{m})\end{array}$ & DP & $\begin{array}{l}\text { CV } \\
(\%)\end{array}$ \\
\hline${ }^{1} \mathrm{H} 1$ & 5,42 & 325,8 & 1,86 & 34,3 & & & \\
\hline${ }^{1} \mathrm{H} 2$ & 4,96 & 295,7 & 1,69 & 34,0 & 34,5 & 0,6 & 1,8 \\
\hline${ }^{1} \mathrm{H} 3$ & 5,19 & 320,1 & 1,83 & 35,2 & & & \\
\hline${ }^{31} \mathrm{P} 1$ & 5,42 & 1002,7 & 1,91 & 35,2 & & & \\
\hline${ }^{31} \mathrm{P} 2$ & 4,96 & 924,6 & 1,76 & 35,5 & 35,5 & 0,4 & 1,0 \\
\hline${ }^{31} \mathrm{P} 3$ & 5,19 & 979,6 & 1,86 & 35,9 & & & \\
\hline
\end{tabular}


Calculando as incertezas de medições para essa amostra, similarmente ao feito na validação, obteve-se uma incerteza expandida $(U)$ igual a 0,726 , para 0 método de ${ }^{1} \mathrm{H}$ e 0,444 para o do ${ }^{31} \mathrm{P} ;(\mathrm{k}=2,95 \%)$. Assim, o teor de glifosato na amostra $\mathrm{S}$ de acordo com o método de ${ }^{1} \mathrm{H}$ é $34,50 \pm 0,73 \% \mathrm{~m} / \mathrm{m}$ e de acordo com o de ${ }^{31} \mathrm{P}$ é $35,51 \pm 0,44 \% \mathrm{~m} / \mathrm{m}$.

Considerando o valor que estava descrito no rótulo desse produto $(65 \% \mathrm{~m} / \mathrm{m})$ e a média dos resultados obtidos pelos dois métodos de RMN, verificou-se que o real teor é aproximadamente $53,85 \%$ do informado.

\section{II) Formulações Líquidas}

Assim como para a formulação sólida, calculou-se a quantidade de amostra do produto, neste caso o volume, que contivesse aproximadamente 5,00 mg. Como nos rótulos de todos esses produtos descrevia uma concentração de $480 \mathrm{~g} / \mathrm{L}$, uma alíquota de $10 \mu \mathrm{L}$ seria suficiente para, após o preparo da amostra de acordo com o método desenvolvido, haver aproximadamente $2,40 \mathrm{mg}$.

No entanto, após a aquisição espectral da primeira replicata das amostras $\mathrm{H}$, $P$ e G observou-se que a concentração de glifosato estava abaixo de $1,0 \mathrm{mg}$, ou seja, abaixo do limite de quantificação do método, fora da faixa de trabalho. Por este motivo, para estas amostras teve de se preparar novas amostras com alíquotas de volume maior.

Devido à variação dos deslocamentos químicos o intervalo de integração teve que ser analisado e fixado para cada uma das amostras. Uma vez fixado, o intervalo foi repetido na integração das demais replicatas.

Analisando os resultados obtidos, para a maioria das amostras de formulação líquida observou que, quando consideradas as triplicatas, os coeficientes de variação ficavam acima de 2,0\%. Esta ligeira piora na precisão, provavelmente deveu-se à transferência de volume ao invés da pesagem, evidenciando que os erros relacionados à pipetagem foram maiores.

Como a normativa não especifica o número de replicatas que devem ser analisadas para a quantificação, optou-se por excluir uma das replicatas, responsável pela diminuição da precisão. No entanto, se o intervalo de integração, inicialmente fixado, fosse ligeiramente alterado, os resultados das triplicatas seriam satisfatórios, dispensando a exclusão de uma das replicatas. 
Essa exclusão só não foi necessária para as amostras $G$ e $P$, que tiveram volumes de alíquotas maiores transferidos. Este fato corrobora com a explicação dada anteriormente, uma vez que para volumes maiores, os erros são menores.

Assim, os resultados obtidos por RMN de ${ }^{1} \mathrm{H}$ e de ${ }^{31} \mathrm{P}$ estão apresentados nas Tabelas 58 e 59.

Tabela 58 - Resultados obtidos na quantificação das amostras comerciais líquidas de glifosato por $\mathrm{RMNq}$ de ${ }^{1} \mathrm{H}$

\begin{tabular}{|c|c|c|c|c|c|c|c|}
\hline amostra & $\begin{array}{l}\text { alíquota } \\
(\mu \mathrm{L})\end{array}$ & área (u.a.) & $\begin{array}{c}\text { massa de } \\
\text { glifosato } \\
(\mathrm{mg})\end{array}$ & $\begin{array}{c}\text { teor } \\
(\% \mathrm{~m} / \mathrm{m})\end{array}$ & $\begin{array}{l}\text { média } \\
(\% \mathrm{~m} / \mathrm{m})\end{array}$ & DP & $\begin{array}{l}\text { CV } \\
\text { (\%) }\end{array}$ \\
\hline R 1 & \multirow{2}{*}{10} & 271,5 & 4,23 & 423,1 & \multirow{2}{*}{423,1} & \multirow{2}{*}{0,1} & \multirow{2}{*}{0,0} \\
\hline R 2 & & 271,4 & 4,23 & 423,0 & & & \\
\hline P 1 & \multirow{3}{*}{20} & 122,5 & 1,93 & 96,5 & \multirow{3}{*}{96,4} & \multirow{3}{*}{1,2} & \multirow{3}{*}{1,3} \\
\hline P 2 & & 120,7 & 1,90 & 95,1 & & & \\
\hline P 3 & & 123,8 & 1,95 & 97,6 & & & \\
\hline $\mathrm{Ag} 1$ & \multirow{2}{*}{10} & 233,6 & 3,64 & 364,0 & \multirow{2}{*}{359,7} & \multirow{2}{*}{6,2} & \multirow{2}{*}{1,7} \\
\hline $\operatorname{Ag} 2$ & & 228,0 & 3,55 & 355,3 & & & \\
\hline H 1 & \multirow{2}{*}{20} & 103,4 & 1,21 & 60,4 & \multirow{2}{*}{60,5} & \multirow{2}{*}{0,2} & \multirow{2}{*}{0,3} \\
\hline $\mathrm{H} 2$ & & 103,9 & 1,21 & 60,7 & & & \\
\hline G 1 & \multirow{3}{*}{30} & 120,6 & 1,92 & 64,1 & \multirow{3}{*}{63,6} & \multirow{3}{*}{1,0} & \multirow{3}{*}{1,5} \\
\hline G 2 & & 117,6 & 1,88 & 62,5 & & & \\
\hline G 3 & & 120,9 & 1,93 & 64,3 & & & \\
\hline M 1 & \multirow{2}{*}{10} & 270,0 & 4,21 & 420,7 & \multirow{2}{*}{424,7} & \multirow{2}{*}{5,6} & \multirow{2}{*}{1,3} \\
\hline M 2 & & 275,1 & 4,29 & 428,6 & & & \\
\hline B 1 & \multirow{2}{*}{10} & 102,9 & 1,60 & 160,4 & \multirow{2}{*}{161,5} & \multirow{2}{*}{1,5} & \multirow{2}{*}{0,9} \\
\hline B 2 & & 104,3 & 1,63 & 162,5 & & & \\
\hline Ap 1 & \multirow{2}{*}{10} & 159,3 & 2,48 & 248,2 & \multirow{2}{*}{249,2} & \multirow{2}{*}{1,4} & \multirow{2}{*}{0,5} \\
\hline Ap 2 & & 160,5 & 2,50 & 250,2 & & & \\
\hline
\end{tabular}


Tabela 59 - Resultados obtidos na quantificação das amostras comerciais líquidas de glifosato por $\mathrm{RMNq}$ de ${ }^{31} \mathrm{P}$

\begin{tabular}{|c|c|c|c|c|c|c|c|}
\hline amostra & $\begin{array}{l}\text { alíquota } \\
(\mu \mathrm{L})\end{array}$ & área (u.a.) & $\begin{array}{c}\text { massa de } \\
\text { glifosato } \\
(\mathrm{mg})\end{array}$ & $\begin{array}{c}\text { teor } \\
(\% \mathrm{~m} / \mathrm{m})\end{array}$ & $\begin{array}{l}\text { média } \\
(\% \mathrm{~m} / \mathrm{m})\end{array}$ & DP & $\begin{array}{l}\text { CV } \\
\text { (\%) }\end{array}$ \\
\hline R 1 & \multirow{2}{*}{10} & 815,8 & 4,24 & 423,7 & \multirow{2}{*}{418,5} & \multirow{2}{*}{7,3} & \multirow{2}{*}{1,8} \\
\hline R 2 & & 795,8 & 4,13 & 413,4 & & & \\
\hline P 1 & \multirow{3}{*}{20} & 377,2 & 1,98 & 99,1 & \multirow{3}{*}{99,1} & \multirow{3}{*}{1,0} & \multirow{3}{*}{1,0} \\
\hline P 2 & & 373,4 & 1,96 & 98,1 & & & \\
\hline P 3 & & 381,2 & 2,00 & 100,2 & & & \\
\hline $\mathrm{Ag} 1$ & \multirow{2}{*}{10} & 698,4 & 3,63 & 362,8 & \multirow{2}{*}{358,4} & \multirow{2}{*}{6,2} & \multirow{2}{*}{1,7} \\
\hline $\operatorname{Ag} 2$ & & 681,6 & 3,54 & 354,0 & & & \\
\hline H 1 & \multirow{2}{*}{20} & 309,7 & 1,21 & 60,3 & \multirow{2}{*}{59,5} & \multirow{2}{*}{1,1} & \multirow{2}{*}{1,9} \\
\hline $\mathrm{H} 2$ & & 301,5 & 1,17 & 58,7 & & & \\
\hline G 1 & \multirow{3}{*}{30} & 364,1 & 1,94 & 64,5 & \multirow{3}{*}{65,4} & \multirow{3}{*}{0,9} & \multirow{3}{*}{1,4} \\
\hline G 2 & & 367,8 & 1,96 & 65,2 & & & \\
\hline G 3 & & 374,5 & 1,99 & 66,4 & & & \\
\hline M 1 & \multirow{2}{*}{10} & 827,4 & 4,30 & 429,8 & \multirow{2}{*}{426,8} & \multirow{2}{*}{4,3} & \multirow{2}{*}{1,0} \\
\hline M 2 & & 815,8 & 4,24 & 423,7 & & & \\
\hline B 1 & \multirow{2}{*}{10} & 325,9 & 1,69 & 169,3 & \multirow{2}{*}{166,9} & \multirow{2}{*}{3,3} & \multirow{2}{*}{2,0} \\
\hline B 2 & & 316,9 & 1,65 & 164,6 & & & \\
\hline Ap 1 & \multirow{2}{*}{10} & 481,6 & 2,50 & 250,2 & \multirow{2}{*}{248,9} & \multirow{2}{*}{1,8} & \multirow{2}{*}{0,7} \\
\hline Ap 2 & & 476,8 & 2,48 & 247,6 & & & \\
\hline
\end{tabular}

Para a verificação da exatidão um teste de recuperação foi realizado, no qual massas de glifosato padrão (1,17 e 1,37 mg) foram adicionadas a alíquotas de $10 \mu \mathrm{L}$ do produto $\mathrm{R}$ e o preparo das amostras procedeu-se da mesma maneira feita para as demais formulações líquidas. Para se calcular a recuperação considerou-se nas análises de ${ }^{1} \mathrm{H}$, o teor de glifosato na amostra $\mathrm{R}$, determinado anteriormente via RMN de ${ }^{1} \mathrm{H}$ e o mesmo foi feito nas análises de ${ }^{31} \mathrm{P}$. Na Tabela 60 encontram-se os resultados. 
Tabela 60 - Resultados obtidos no teste de recuperação da amostra comercial líquida $R$

\begin{tabular}{ccccc}
\hline replicata & $\begin{array}{c}\text { massa de } \\
\text { glifosato na } \\
\text { amostra (mg) }\end{array}$ & $\begin{array}{c}\text { massa de glifosato } \\
\text { total }(\mathbf{m g})\end{array}$ & $\begin{array}{c}\text { massa de glifosato } \\
\text { recuperada (mg) }\end{array}$ & Rec. (\%) \\
\hline${ }^{1} \mathrm{H} 1$ & 4,23 & 5,40 & 1,17 & 100,4 \\
${ }^{1} \mathrm{H} 2$ & 5,62 & 1,39 & 101,7 \\
\hline${ }^{31} \mathrm{P} 1$ & 5,18 & 5,38 & 1,19 & 101,8 \\
${ }^{31} \mathrm{P} 2$ & & 5,56 & 1,37 & 100,1 \\
\hline
\end{tabular}

*resultados provenientes das quantificações via RMN dos núcleos correspondentes

Apesar de uma replicata também ter sido desconsiderada no teste de recuperação, os resultados de exatidão obtidos para a duplicata foram satisfatórios, não invalidando os resultados apresentados nas Tabelas 58 e 59. Cabe ressaltar que resultados mais precisos e exatos poderiam vir a ser obtidos empregando-se 0 método exatamente como foi desenvolvido, ou seja, pesando-se as amostras.

A incerteza do resultado de cada uma das amostras foi calculada conforme exemplificado para a validação de ${ }^{1} \mathrm{H}$, no entanto a incerteza da massa pesada de PA foi substituída pela incerteza da micropipeta de 10-100 $\mu \mathrm{L}\left(u=0,1 / 6^{1 / 2}=0,0408\right)$ empregada para a transferência da alíquota das formulações líquidas. Na Tabela 61 estão mostradas as incertezas expandidas dos métodos de ${ }^{1} \mathrm{H}$ e de ${ }^{31} \mathrm{P}$ para cada uma das amostras.

Observa-se na Tabela 61 que as incertezas expandidas, para a maioria das amostras, foram maiores para o método de ${ }^{31} \mathrm{P}$ que para $\mathrm{o}$ de ${ }^{1} \mathrm{H}$. Isso se deve às incertezas de áreas, única grandeza de entrada diferente em ambos os métodos. A maior variação nas áreas determinadas nos espectros do núcleo de ${ }^{31} \mathrm{P}$, possivelmente é devido a sua menor razão $S / R$.

Além disso, pode-se perceber que os valores de incertezas para as formulações líquidas foram maiores que a incerteza da formulação sólida e a incerteza obtida na validação do método. Este fato pode estar relacionado novamente às pipetagens das alíquotas dos produtos, ausentes na validação e na análise da amostra sólida. 
Tabela 61 - Incertezas Expandidas dos resultados obtidos para as amostras comerciais líquidas de glifosato

\begin{tabular}{ccc}
\hline amostra & $\boldsymbol{U}-\mathbf{1}_{\mathbf{H}}$ & $\boldsymbol{U}-{ }^{31} \mathbf{P}$ \\
\hline R & 3,58 & 15,10 \\
P & 2,48 & 2,11 \\
Ag & 12,70 & 12,80 \\
H & 0,48 & 2,28 \\
G & 1,95 & 1,88 \\
M & 4,21 & 9,23 \\
B & 3,29 & 6,79 \\
Ap & 3,43 & 4,13 \\
\hline
\end{tabular}

$\mathrm{Na}$ Figura 18 pode ser visualizada uma melhor comparação entre os teores de glifosato obtidos a partir dos dois métodos desenvolvidos, com o valor descrito nas bulas desses produtos.

Figura 18 - Gráfico de barras para comparação entre os teores de glifosato $(\% \mathrm{~m} / \mathrm{m})$ determinados pelos métodos de $\mathrm{RMNq}$ de ${ }^{1} \mathrm{H}$ e ${ }^{31} \mathrm{P}$ desenvolvidos e os valores descritos nos rótulos dos produtos

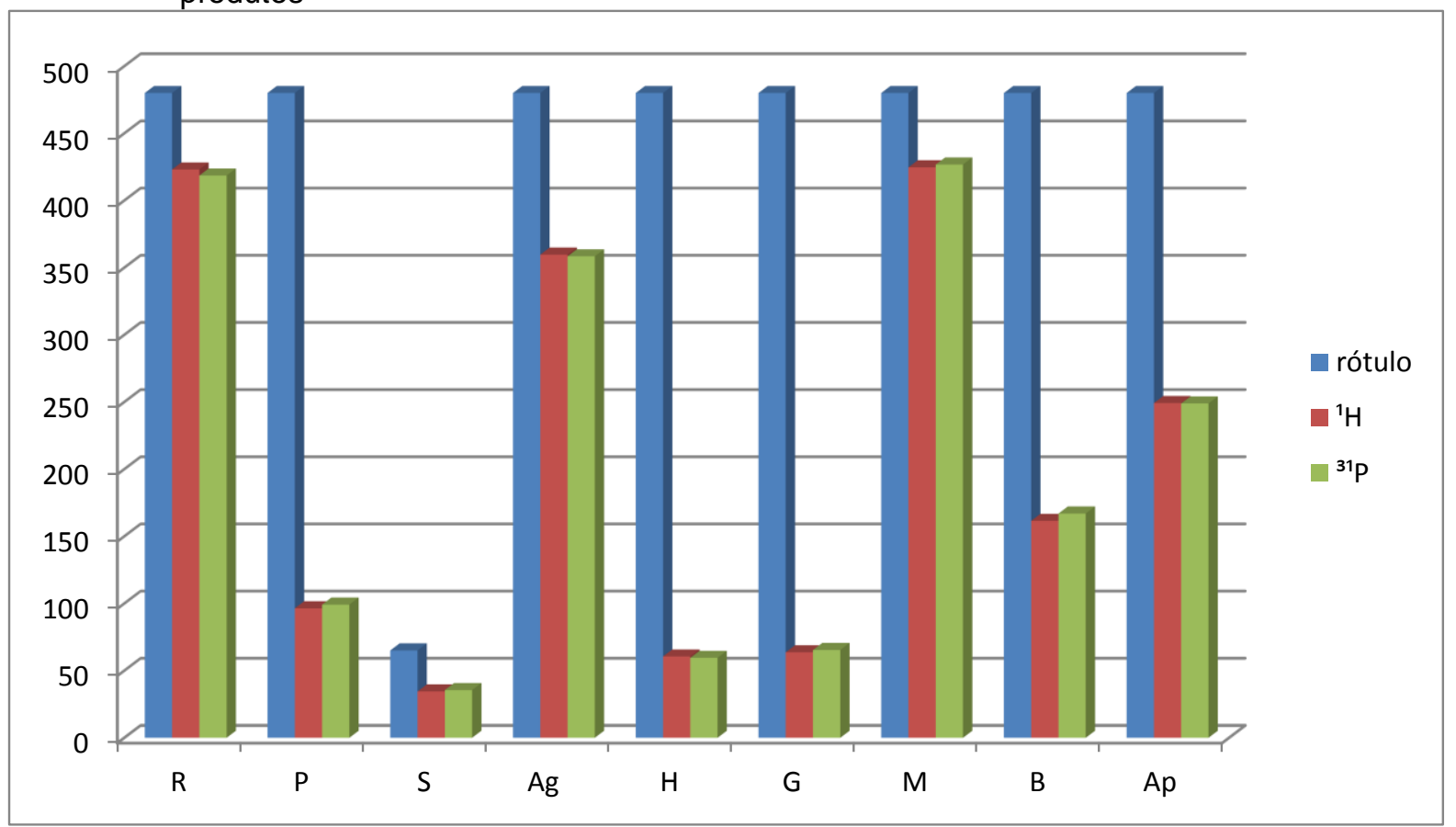

A ótima concordância entre os resultados obtidos pelos métodos de ${ }^{1} \mathrm{H}$ e de ${ }^{31} \mathrm{P}$ ficou evidenciada, assim como a grande discrepância existente entre a quantidade de ingrediente ativo descrito no rótulo a quantidade real presente nos produtos. 


\subsection{Avaliação do Emprego do Método de Diagonalização Filtrada (FDM) para Processamento de Espectros de RMN Quantitativos}

Apesar das vantagens do emprego da RMN em análises quantitativas, os espectros de amostras complexas, tais como produtos formulados, podem conter um grande número de sinais e estes sinais podem sobrepor-se. Assim, a medição quantitativa fica impraticável porque não há seletividade.

Para resolver este problema, métodos convencionais utilizam-se da adição de reagentes de deslocamento ("shift reagents"), empregam RMN de ${ }^{13} \mathrm{C}$, a qual é inviável para análises em rotina devido ao longo tempo dos experimentos, e existem ainda uma série de processos matemáticos que podem ser aplicados para separação dos sinais, entretanto nenhum deles é extensivamente difundido entre os usuários de RMN.

O Método de Diagonalização Filtrada (FDM) é um desses métodos e foi introduzido como uma ferramenta alternativa para análise espectral em experimentos de RMN por Mandestam. ${ }^{149} \mathrm{O}$ FDM consiste em um método paramétrico não-linear para ajuste dos sinais no domínio do tempo. É um procedimento de ajuste dos sinais (fitting procedures) e não em uma transformação como no caso da Transformada de Fourier. ${ }^{150}$

Um importante aspecto da FDM é que ele pode modelar os sinais dentro de um intervalo de frequências especificadas, isto é, em vez de processar as características espectrais de todo o espectro, pode-se selecionar uma pequena janela espectral para ser processada. Entre outras aplicações práticas do FDM, recentemente foi utilizado para remover seletivamente sinais de solventes a partir de espectros de RMN, sem influenciar ou perturbar os sinais mais próximos. ${ }^{151}$

O emprego do Método de Diagonalização Filtrada (FDM) tem sido utilizado pelo grupo de RMN da Embrapa instrumentação em análises qualitativas. ${ }^{152} \mathrm{E}$ no presente estudo se avaliou em colaboração com um aluno de doutorado em Física do grupo de RMN da Embrapa Instrumentação, a utilização do Método de Diagonalização Filtrada (FDM) para processar espectros contendo sinais sobrepostos que interferem na quantificação dos analitos, separando os sinais de interesse de tal forma a possibilitar uma integração efetiva.

Alguns dos espectros de $\mathrm{RMN}$ de ${ }^{1} \mathrm{H}$ de paracetamol adquiridos anteriormente foram também processados pelo FDM empregando um software desenvolvido pelo 
Prof. Dr. Claudio José Magon do Instituto de Física de São Carlos USP, o qual foi implementado em linguagem $\mathrm{C} / \mathrm{C}++$ no ambiente Code Builder do OriginPro-8 (OriginLab Corporation). Apenas os primeiros 1500 pontos do sinal adquirido foram utilizados e para regularização dos sinais, utilizou-se o método pseudo-noise $(q=0$, 01 com 10 médias), o qual possui a característica de remover artefatos de ruído eficientemente, não causando distorções no formato da linha, o que torna adequado para processos quantitativos. O processamento de dados através do FDM está esquematizado na Figura 19.

Figura 19 - Representação esquemática do processamento de dados através do FDM

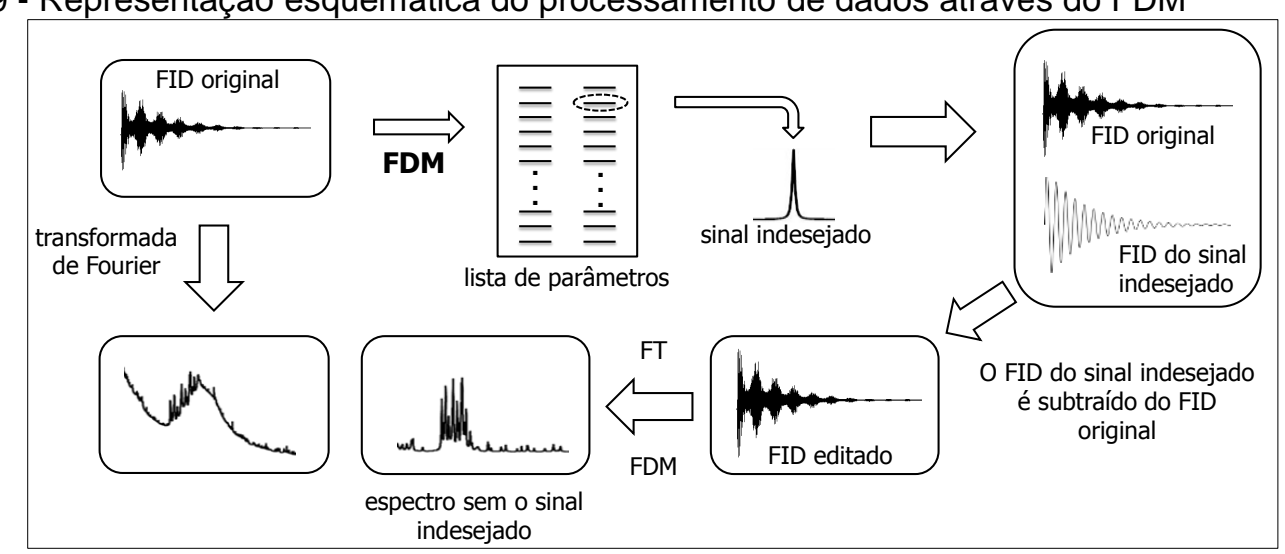

Fonte: Tiago B. Moraes

Primeiramente, processaram-se espectros de três amostras de concentração de paracetamol conhecida e os resultados obtidos a partir de ambos os métodos (FT e FDM) estão correlacionados na Figura 20. A comparação da exatidão e precisão de ambos os processamentos, na Tabela 62.

Figura 20 - Gráfico da correlação da razão das áreas do analito e do $\mathrm{PI}\left(\mathrm{A}_{\text {analito }} / \mathrm{A}_{\mathrm{PI}}\right)$ obtidas a partir dos espectros processados via FT (eixo x) e FDM (eixo y)

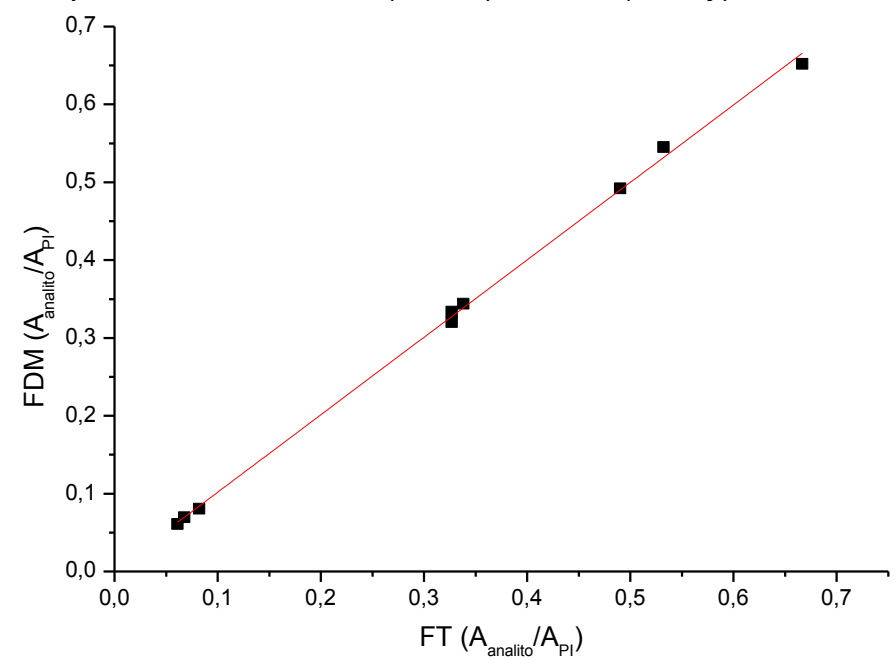


Tabela 62 - Comparação entre precisão e exatidão obtidas a partir do processamento feito via FT e via FDM

\begin{tabular}{cccc}
\hline Ensaio & FT (original) & FDM (editado) & Valor Aceito \\
\hline Exatidão & $99,1 \%$ & $99,5 \%$ & $98-102 \%$ \\
Precisão & $\mathrm{CV}=3,6 \%$ & $\mathrm{CV}=3,5 \%$ & $\mathrm{CV} \leq 5,0 \%$ \\
\hline
\end{tabular}

Como a correlação $\left(r^{2}=0,99845\right)$, a precisão e exatidão foram consideradas bastante satisfatórias, os espectros de uma amostra comercial que apresentava linhas largas (Figura $21 \mathrm{~A}$ ) foram igualmente processados, mas as linhas largas foram excluídas através do FDM (Figura 21 B). Nessa condição, observou-se que os resultados quantitativos do paracetamol não foram afetados pela exclusão do sinal (Tabela 63).

Figura 21 - Espectro de RMN de ${ }^{1} \mathrm{H}$ : a) processado via $\mathrm{FT}$, no qual se observam os sinais largos em 5,07 e 4,42 ppm, e b) processado via FDM, no qual observa-se, em preto, os sinais largos que foram subtraídos e, em vermelho, após a exclusão das linhas largas

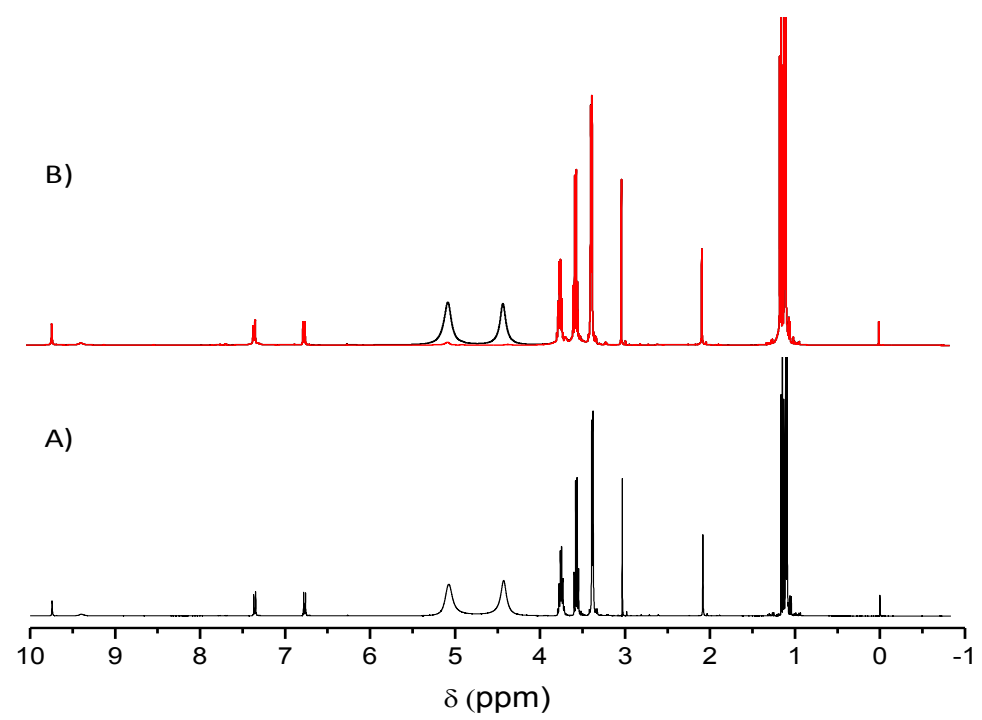

Tabela 63 - Comparação dos resultados de teor de paracetamol obtidos através do processamento via FT e via FDM com exclusão de linhas

\begin{tabular}{ccccc}
\hline replicata & $\mathbf{F T}-\mathbf{A}_{\text {analito }} / \mathbf{A}_{\mathbf{P I}}$ & $\mathbf{F D M}-\mathbf{A}_{\text {analito }} / \mathbf{A}_{\text {PI }}$ & Teor via FT & Teor via FDM \\
\hline 1 & 1,2 & 1,2 & & \\
2 & 1,3 & 1,3 & $96,8 \mathrm{mg} / \mathrm{mL}$ & $96,3 \mathrm{mg} / \mathrm{mL}$ \\
3 & 1,4 & 1,4 & & \\
\hline
\end{tabular}


Por fim, os espectros de outra amostra comercial de paracetamol que continha o sinal de água se sobrepondo a um dos sinais da cafeína, o qual poderia ser empregado para integração (Figura $22 \mathrm{~A}$ e B) foram submetidos a este tipo de processamento e seus resultados foram comparados aos obtidos por FT.

Novamente os resultados obtidos por FDM concordaram com os obtidos por FT (Tabela 64), o que evidencia a possibilidade de se empregar o método FDM para processamento e quantificação de espectros complexos. A confirmação dessa possibilidade ainda está sendo mais bem investigada em estudos que se encontram em andamento.

Figura 22 - Ampliações de espectros de RMN de ${ }^{1} \mathrm{H}$ nos quais se visualizam os sinais da cafeína sobrepostas no espectro original (A), processado via $F T$, e o espectro editado (B), processado via FDM<smiles>Cn1c(=O)c2c(ncn2C)n(C)c1=O</smiles>

b
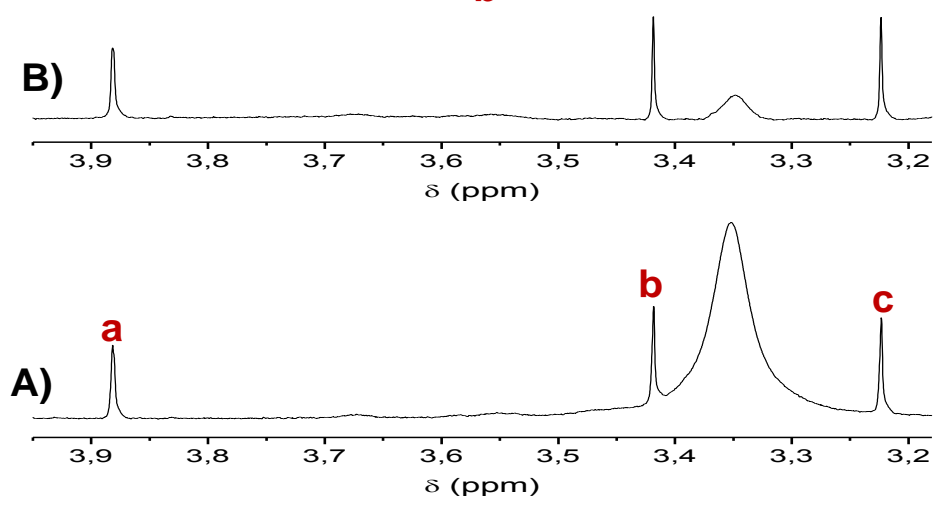

Tabela 64 - Resultados obtidos a partir do processamento via FT (linhas a) e via FDM (demais linhas)
\begin{tabular}{|c|ccc|} 
analito & \multicolumn{4}{c|}{ Cafeína (mg/ compr.) } \\
sinal & Linha a (FT) & Linha b (FDM) & Linha c (FDM) \\
teor & 65,9 & 65,2 & 65,5 \\
DP & 0,3 & 0,5 & 1,0 \\
CV (\%) & 0,5 & 0,8 & 1,5
\end{tabular}




\subsection{Método para Quantificação de Ácidos Graxos em Óleos e Azeites}

Em algumas das pesquisas que vêm sendo desenvolvidas pelo grupo de RMN da Embrapa Instrumentação há a necessidade de se determinar o teor de ácidos graxos em óleos de sementes para se correlacionar aos resultados obtidos por RMN no domínio do tempo (RMN-DT) e essa determinação vem sendo feita via cromatografia gasosa.

Trabalhos encontrados na literatura da RMN em alta resolução para análises quantitativas de ácidos graxos em óleos e azeites evidenciam o potencial da técnica neste tipo de aplicação. ${ }^{85,121-124}$ No presente trabalho avaliou-se a viabilidade de se empregar a RMN em alta resolução para este tipo de determinação, em substituição às análises cromatográficas, uma vez que as reações de transesterificações, as quais podem ser precursoras de erros na medida quantitativa, não seriam mais necessárias.

Assim, óleos de amendoins que já haviam sido extraídos e analisados por CG por uma aluna do grupo para determinação do teor de oléico foram analisados por RMN em alta resolução.

Analisando-se um dos espectros obtidos (Figura 23), com auxílio de dados da literatura, foi possível identificar os sinais dos ácidos graxos e, consequentemente, inferir que: ${ }^{85,122,153}$

- a área do sinal situado em 2,31 ppm refere-se a todos ácidos graxos (100\%);

- a área do sinal em 2,01 ppm refere-se apenas aos ácidos graxos insaturados;

- assim, a área que seria correspondente apenas aos saturados pode ser calculada subtraindo-se a metade da área dos insaturados da área total;

- para calcular-se o teor de saturados, basta dividir a área dos saturados pela área total e multiplicar por $100 \%$;

- a área do sinal em 2,8 ppm refere-se apenas ao linoleico (pois se houvesse também o linolênico presente haveria um sinal em $0,9 \mathrm{ppm}$, referente a sua metila terminal);

- para o cálculo do teor de linoleico deve-se dividir a sua área pela área total e multiplicar por 100

- para o cálculo do teor de oleico:

Teor oleico $=100 \%-$ teor de saturado - teor de linoléico 
Figura 23 - Espectros de $\mathrm{RMN}$ de ${ }^{1} \mathrm{H}\left(9,4 \mathrm{~T} ; 23^{\circ} \mathrm{C}\right.$ e $\left.\mathrm{CDCl}_{3}\right)$ da amostra AT869 com as atribuições dos sinais referentes aos ácidos graxos, cujas estruturas químicas, retiradas da fonte citada abaixo, estão ilustradas

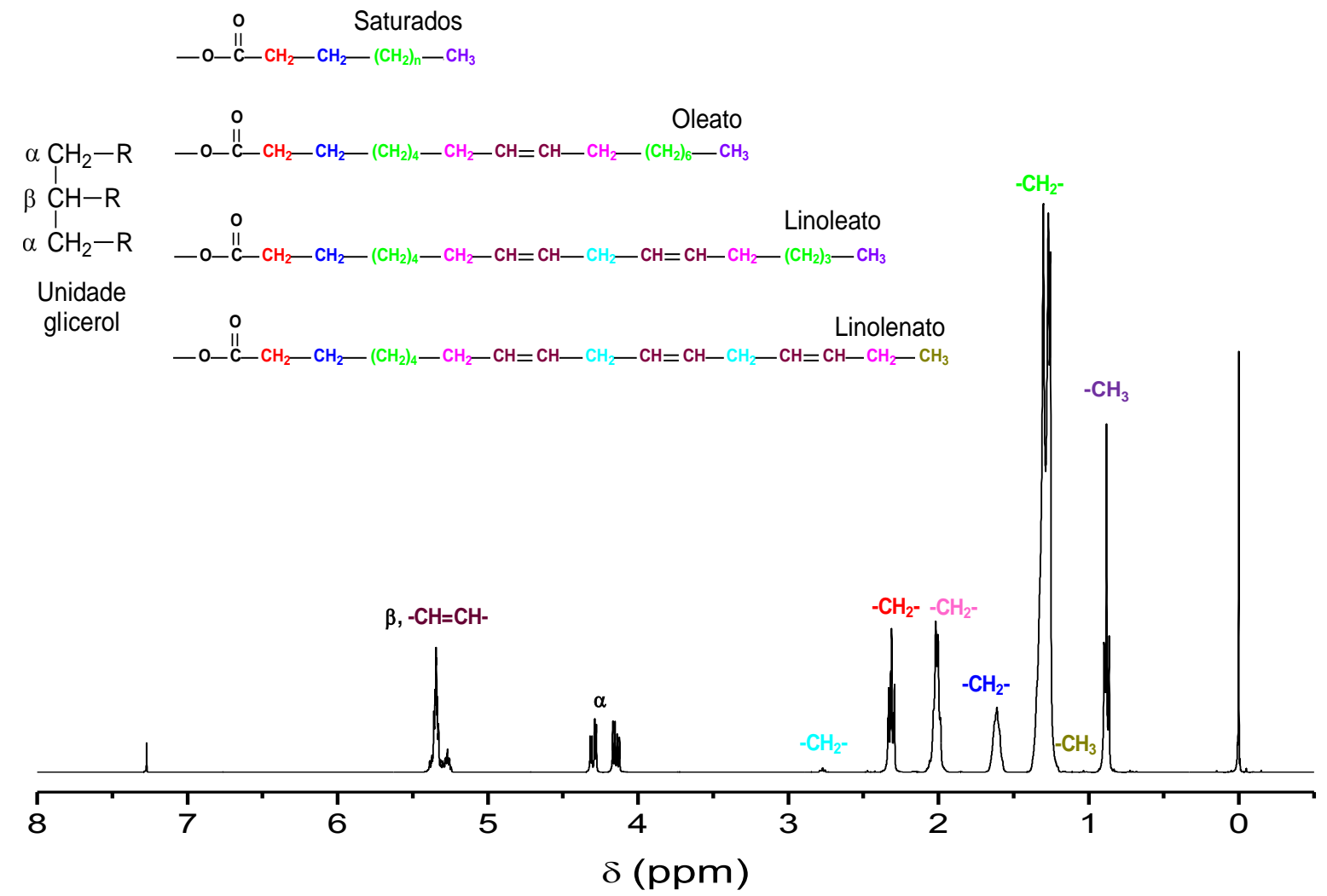

Fonte: Barison, tese de doutorado, $2005{ }^{85}$

Desta maneira determinou-se o teor de oleico em todos os óleos extraídos e os resultados obtidos foram correlacionados com os obtidos por cromatografia gasosa. A correlação obtida pode ser visualizada na Figura 24.

Como pode ser observado, obteve-se uma excelente correlação, o que evidencia a possibilidade de substituição das análises cromatográficas para determinação do teor de ácidos graxos pelas espectroscópicas de RMN de alta resolução, uma vez que estas são realizadas diretamente do óleo extraído, dispensando as etapas analíticas relacionadas às reações de transesterificações, as quais podem trazer erros adicionais às medidas. 
Figura 24 - Gráfico de correlação entre os resultados obtidos por RMN e os obtidos por CG

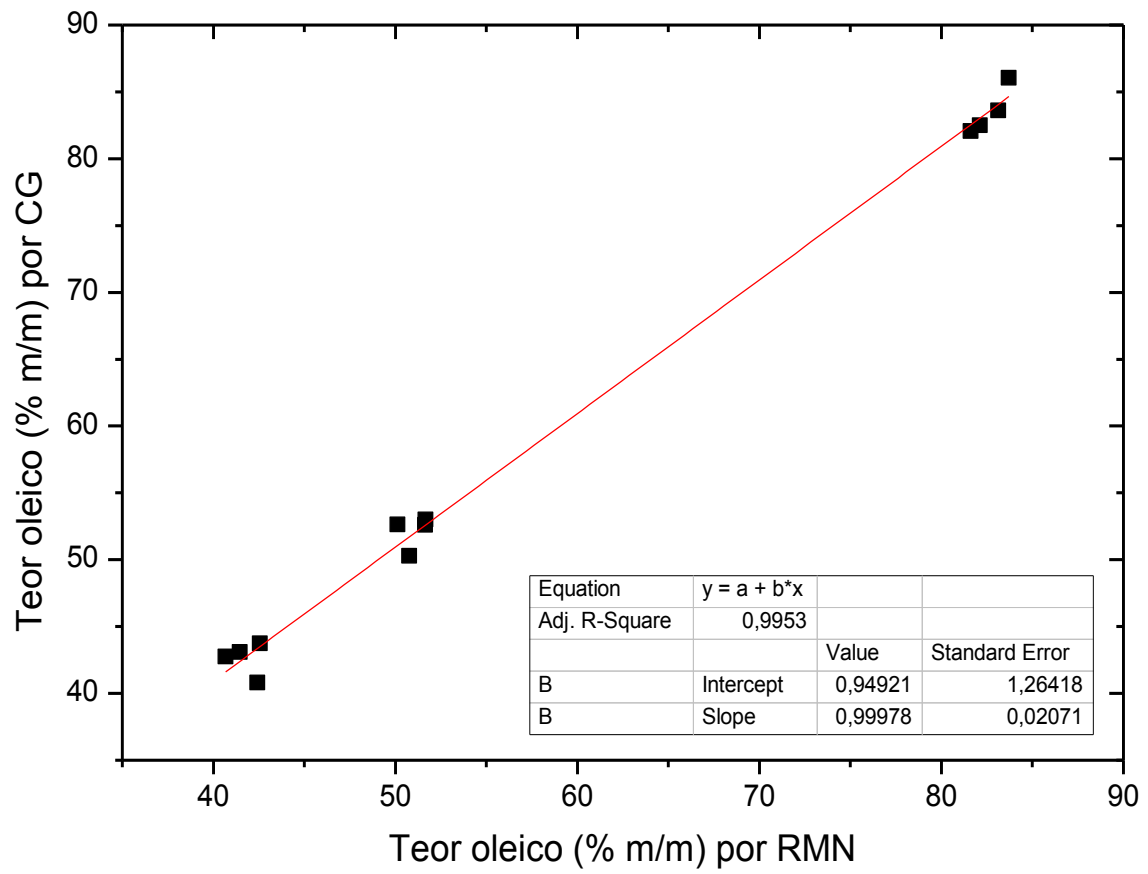

\subsection{Método para Detecção de Adulteração de Azeite com Óleo de Soja em Embalagens Lacradas}

O método desenvolvido para detecção de adulteração de azeite com óleo de soja em embalagens lacradas baseia-se na diferença de viscosidade do óleo de soja e do azeite, resultante de suas diferentes composições em ácidos graxos. O óleo de soja tem como principal constituintes dos triacilglicerídeos, o ácido linolênico (C18:2), que leva a um óleo menos viscoso do que o óleo de oliva, que é rico em ácido oleico (C18:1).

Assim, a medida de $T_{2}$, através do ajuste monoexponencial do decaimento do sinal de RMN, usando a sequência CPMG (Figura 25), pode ser usado para determinar a adulteração de azeite de oliva com óleo de soja, uma vez que viscosidade tem correlação inversa com o tempo de relaxação transversal $\left(T_{2}\right)$.

O grande diferencial do método proposto é fato dessas medidas poderem ser realizadas em embalagens lacradas, dispensando qualquer preparo de amostra ou a perda do produto, o qual poderá ser comercializado normalmente após análise. $\mathrm{Na}$ Figura 26 exemplifica-se isso, na qual se pode visualizar uma garrafa de azeite sendo inserida no interior do espectrômetro utilizado. 
Figura 25 - Decaimentos de amostras de óleo de soja e azeite de oliva obtidos a partir da sequência CPMG para medidas de $T_{2}$

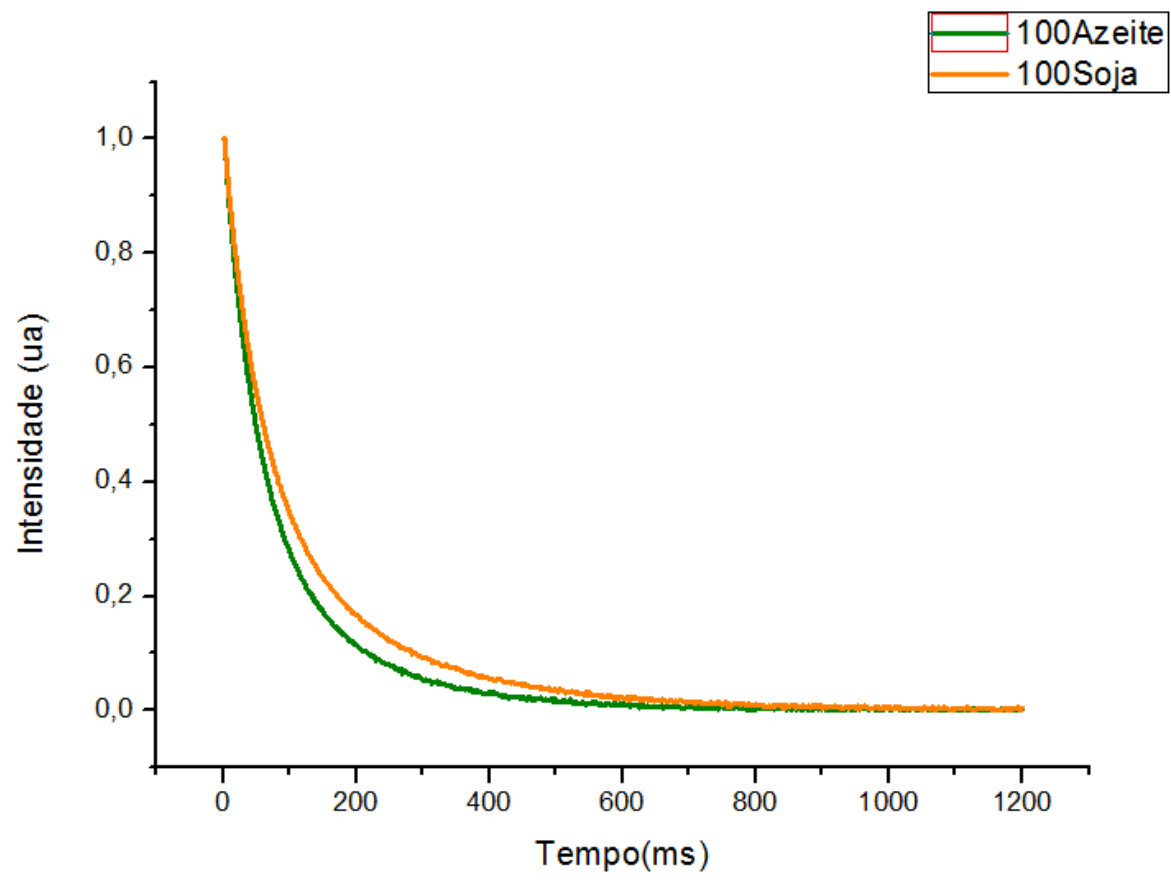

Figura 26 - Fotos do espectrômetro empregado nas medidas de RMN-DT dos azeites de oliva

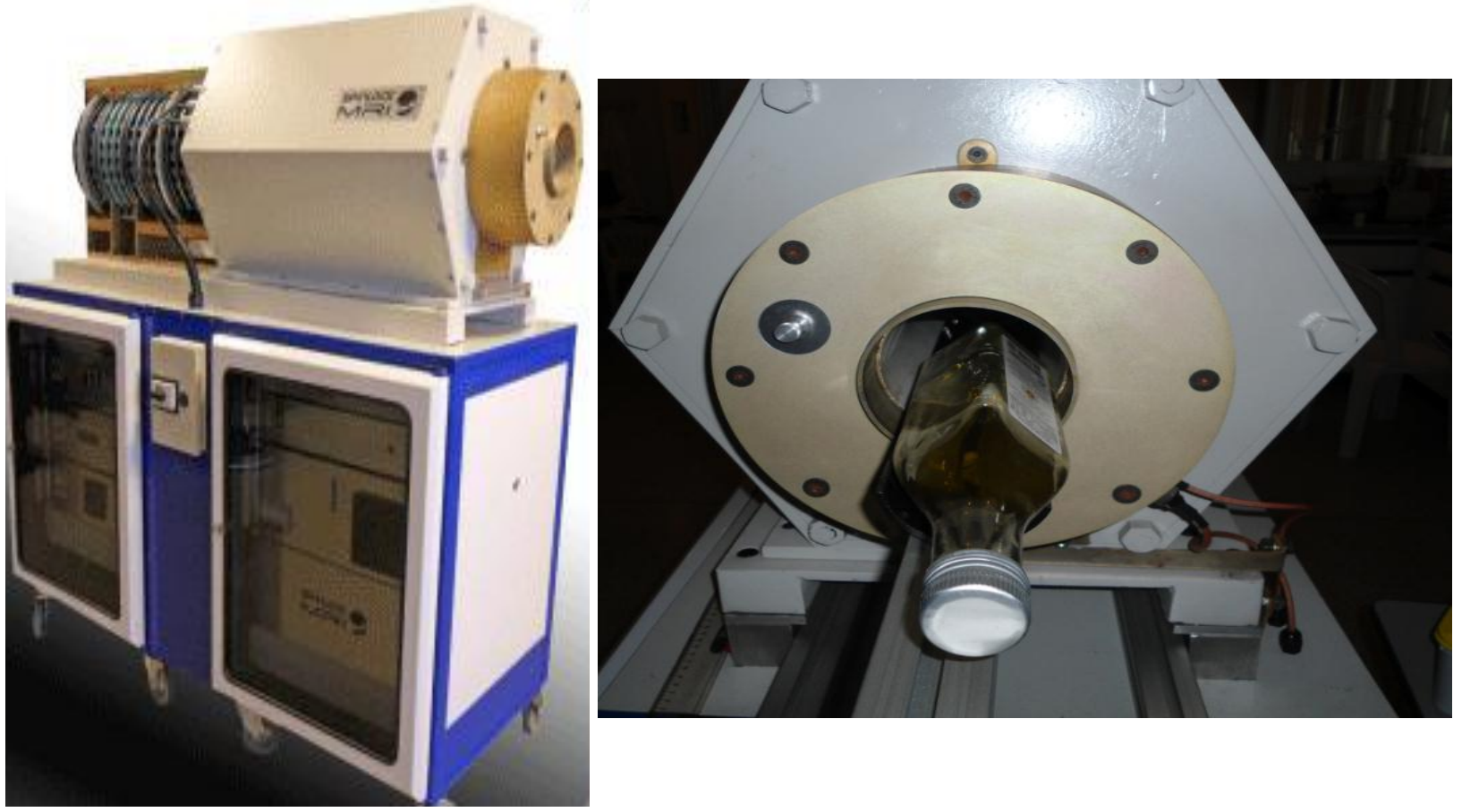

Inicialmente as análises de RMN em alta resolução se fizeram necessárias para a verificação da autenticidade do azeite a vir ser empregado como padrão, uma vez que em azeites de oliva o teor de ácido linolênico não deve ultrapassar 1,0\%. ${ }^{105}$ 
Da mesma maneira descrita para o óleo de amendoim e considerando justamente a área do sinal situado em 0,9 ppm, ausente nos óleos analisados anteriormente, determinou-se o teor deste ácido graxo (0,97\%), o que permitiu o emprego deste azeite como padrão.

Em óleos de soja este ácido graxo está presente em maior concentração e ao adulterar-se um azeite com óleo de soja, a quantidade de acido linolênico no azeite excede ao permitido.

A validação do método para detecção de adulteração de azeite com óleo de soja foi procedida de acordo com a Resolução RE 899, uma vez que a mesma é reconhecida e aceita pelos órgãos regulamentadores para a validação de qualquer metodologia analítica, mesmo esta normativa sendo mais específica e utilizada para análises de fármacos.

A faixa de trabalho considerada foi de 100 a $50 \% \mathrm{~m} / \mathrm{m}$ de azeite, pois abaixo disso, qualquer amostra já pode ser considerada adulterada independentemente do teor de óleo de soja.

A curva de calibração foi construída com amostras inseridas nos frascos âmbar em oito concentrações, em triplicatas. O coeficiente de correlação obtido $(r=0,991)$ revela uma boa linearidade. Na Figura 27 está ilustrada a reta obtida e sua respectiva equação, a qual foi empregada para a determinação do teor de azeite a partir dos valores de $T_{2}$ medidos para as demais amostras analisadas na validação e as amostras comerciais.

O ensaio de repetitividade foi realizado em três concentrações diferentes (início, meio e fim da curva) em quintuplicata e observou-se (Tabela 65) que os coeficientes de correlação foram inferiores os máximo permitido pela normativa (CV $\leq 5 \%$ ). O mesmo foi feito e obtido (Tabela 66) no ensaio de precisão intermediária, no qual se variou o dia de análise e o analista.

Como as embalagens comerciais de azeite podem variar o tamanho e 0 material, no ensaio de robustez transferiram-se as mesmas amostras preparadas no ensaio de precisão intermediária para tubos de plásticos de volume menor para verificar a influência destes fatores. De acordo com os resultados obtidos (Tabela 67), as possíveis interferências não comprometeram a precisão do método. 
Figura 27 - Curva analítica obtida no ensaio de Linearidade da validação do método para detecção de adulteração de azeites com óleo de soja

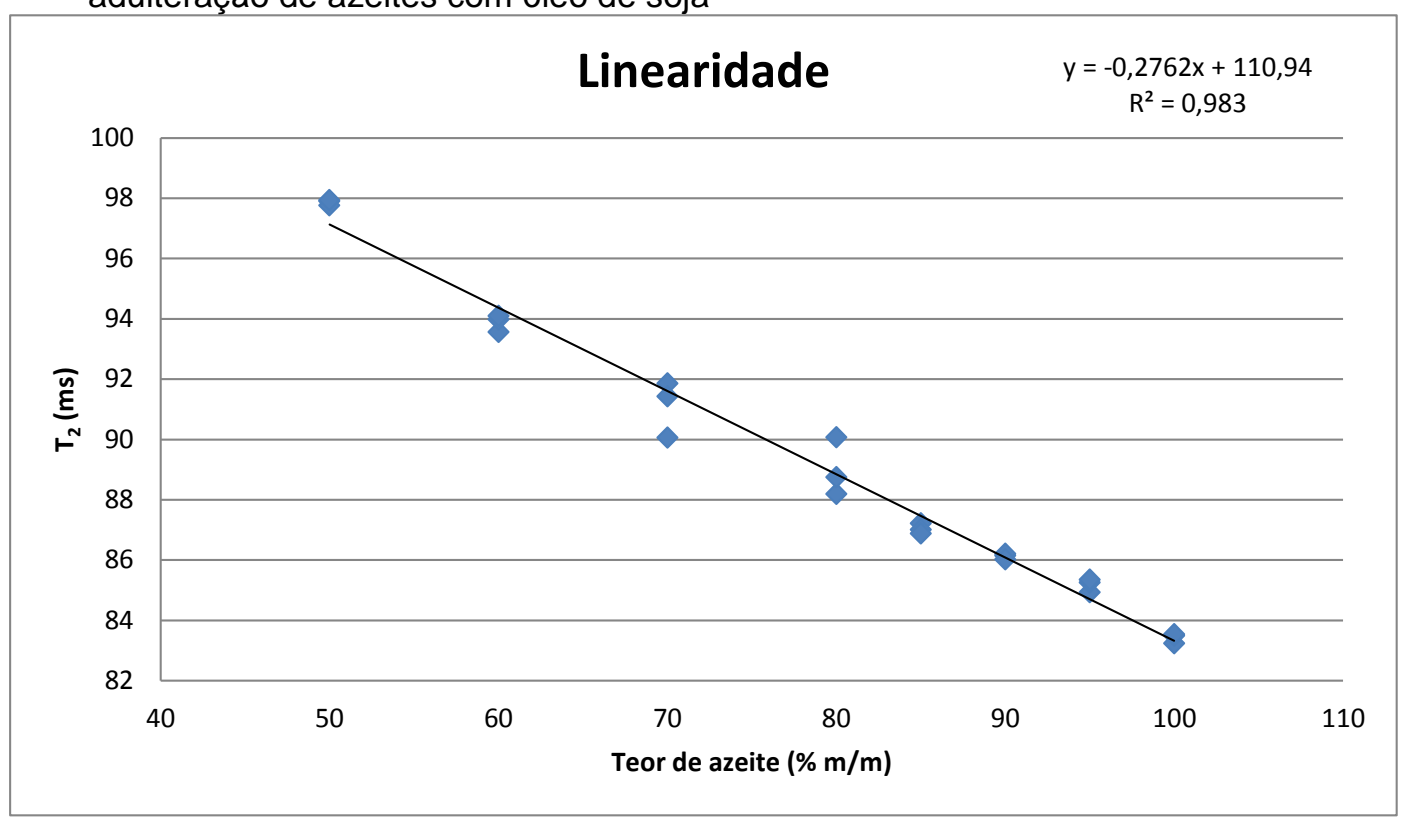

Tabela 65 - Resultado obtido no ensaio de Repetitividade da validação do método para detecção de adulteração de azeites com óleo de soja

\begin{tabular}{|c|c|c|c|c|c|}
\hline $\begin{array}{c}\text { teor }(\% \mathrm{~m} / \mathrm{m}) \\
\text { teórico }\end{array}$ & $\mathrm{T}_{2}$ (ms) & $\begin{array}{c}\text { teor }(\% \mathrm{~m} / \mathrm{m}) \\
\text { experimental }\end{array}$ & $\begin{array}{c}\text { média teor } \\
(\% \mathrm{~m} / \mathrm{m})\end{array}$ & DP & CV (\%) \\
\hline 50 & 94,8 & 58,4 & & & \\
\hline 50 & 96,1 & 53,8 & & & \\
\hline 50 & 95,9 & 54,6 & 56,4 & 2,1 & 3,7 \\
\hline 50 & 95,1 & 57,2 & & & \\
\hline 50 & 94,9 & 58,0 & & & \\
\hline 75 & 88,5 & 81,3 & & & \\
\hline 75 & 88,6 & 80,9 & & & \\
\hline 75 & 88,8 & 80,3 & 79,0 & 3,8 & 4,8 \\
\hline 75 & 88,7 & 80,4 & & & \\
\hline 75 & 91,0 & 72,2 & & & \\
\hline 100 & 83,5 & 99,3 & & & \\
\hline 100 & 83,5 & 99,4 & & & \\
\hline 100 & 83,3 & 100,1 & 99,3 & 0,4 & 0,4 \\
\hline 100 & 83,5 & 99,4 & & & \\
\hline 100 & 83,5 & 99,3 & & & \\
\hline
\end{tabular}


Tabela 66 - Resultado obtido no ensaio de Precisão Intermediária da validação do método para detecção de adulteração de azeites com óleo de soja

\begin{tabular}{cccccc}
\hline $\begin{array}{c}\text { teor }(\% \mathbf{m} / \mathbf{m}) \\
\text { teórico }\end{array}$ & $\mathbf{T}_{\mathbf{2}}(\mathbf{m s})$ & $\begin{array}{c}\text { teor }(\% \mathbf{m} / \mathbf{m}) \\
\text { experimental }\end{array}$ & $\begin{array}{c}\text { média } \text { teor } \\
(\% \mathbf{m} / \mathbf{m})\end{array}$ & DP & CV (\%) \\
\hline 50 & 95,1 & 57,2 & & & \\
50 & 96,2 & 53,5 & & & \\
50 & 95,7 & 55,1 & 56,3 & & \\
50 & 95,2 & 57,1 & & & \\
50 & 94,8 & 58,5 & & & \\
75 & 88,8 & 80,3 & & & \\
75 & 90,0 & 76,0 & & & \\
75 & 89,7 & 76,8 & 77,4 & & \\
75 & 89,4 & 78,0 & & & \\
75 & 90,0 & 75,8 & & & \\
100 & 83,6 & 98,9 & & & \\
100 & 83,8 & 98,2 & & & \\
100 & 84,1 & 97,3 & 98,9 & & \\
100 & 83,7 & 98,8 & & & \\
100 & 84,1 & 97,1 & & & \\
\hline
\end{tabular}

Tabela 67 - Resultado obtido no ensaio de Robustez da validação do método para detecção de adulteração de azeites com óleo de soja

\begin{tabular}{cccccc}
\hline $\begin{array}{c}\text { teor }(\% \mathbf{m} / \mathbf{m}) \\
\text { teórico }\end{array}$ & $\mathbf{T}_{\mathbf{2}}(\mathbf{m s})$ & $\begin{array}{c}\text { teor }(\% \mathbf{m} / \mathbf{m}) \\
\text { experimental }\end{array}$ & $\begin{array}{c}\text { média teor } \\
(\% \mathbf{m} / \mathbf{m})\end{array}$ & DP & CV (\%) \\
\hline 50 & 95,9 & 54,4 & & & \\
50 & 95,8 & 54,8 & & & \\
50 & 96,2 & 53,4 & 53,9 & & \\
50 & 96,0 & 54,1 & & & \\
50 & 96,3 & 53,0 & & & \\
\hline 75 & 91,1 & 71,9 & & & \\
75 & 90,7 & 73,2 & & & \\
75 & 89,6 & 77,2 & 74,1 & & \\
75 & 90,7 & 73,5 & & & \\
75 & 90,3 & 74,7 & & & \\
(continua) & & & & & \\
\end{tabular}


(conclusão)

\begin{tabular}{cccccc}
\hline $\begin{array}{c}\text { teor }(\% \mathbf{m} / \mathbf{m}) \\
\text { teórico }\end{array}$ & $\mathbf{T}_{\mathbf{2}}(\mathbf{m s})$ & $\begin{array}{c}\text { teor }(\% \mathbf{m} / \mathbf{m}) \\
\text { experimental }\end{array}$ & $\begin{array}{c}\text { média teor } \\
(\% \mathbf{m} / \mathbf{m})\end{array}$ & DP & CV (\%) \\
\hline 100 & 84,9 & 94,3 & & & \\
100 & 84,8 & 94,6 & & & \\
100 & 85,8 & 91,1 & 94,3 & 1,6 & 1,7 \\
100 & 84,7 & 95,1 & & & \\
100 & 85,1 & 93,7 & & & \\
\hline
\end{tabular}

Por fim, verificou-se a exatidão do método (Tabela 68) empregando a equação da reta obtida na curva analítca construída para determinar o teor de todas as replicatas obtidas nos demais ensaios (repetitividade - R; Precisão intermediária $\mathrm{Pi}$ e robustez - RB)

Tabela 68 - Resultado obtido no ensaio de Exatidão da validação do método para detecção de adulteração de azeites com óleo de soja

\begin{tabular}{|c|c|c|c|c|c|}
\hline ensaio & $\begin{array}{c}\text { teor }(\% \mathrm{~m} / \mathrm{m}) \\
\text { teórico }\end{array}$ & $\mathrm{T}_{2}(\mathrm{~ms})$ & $\begin{array}{c}\text { teor }(\% \mathrm{~m} / \mathrm{m}) \\
\text { medido }\end{array}$ & $\begin{array}{l}\text { média Teor } \\
(\% \mathrm{~m} / \mathrm{m})\end{array}$ & exatidão \\
\hline \multirow{5}{*}{$\mathrm{Pi}$} & 50 & 95,1 & 57,2 & \multirow{15}{*}{55,5} & \multirow{15}{*}{111,1} \\
\hline & 50 & 96,2 & 53,5 & & \\
\hline & 50 & 95,7 & 55,1 & & \\
\hline & 50 & 95,2 & 57,1 & & \\
\hline & 50 & 94,8 & 58,5 & & \\
\hline \multirow{5}{*}{$\mathrm{RB}$} & 50 & 95,9 & 54,4 & & \\
\hline & 50 & 95,8 & 54,8 & & \\
\hline & 50 & 96,2 & 53,4 & & \\
\hline & 50 & 96,0 & 54,1 & & \\
\hline & 50 & 96,3 & 53,0 & & \\
\hline \multirow{5}{*}{$\mathrm{R}$} & 50 & 94,8 & 58,4 & & \\
\hline & 50 & 96,1 & 53,8 & & \\
\hline & 50 & 95,9 & 54,6 & & \\
\hline & 50 & 95,1 & 57,2 & & \\
\hline & 50 & 94,9 & 58,0 & & \\
\hline
\end{tabular}


(conclusão)

\begin{tabular}{|c|c|c|c|c|c|}
\hline ensaio & $\begin{array}{c}\text { teor }(\% \mathrm{~m} / \mathrm{m}) \\
\text { teórico }\end{array}$ & $\mathrm{T}_{2}(\mathrm{~ms})$ & $\begin{array}{c}\text { teor }(\% \mathrm{~m} / \mathrm{m}) \\
\text { medido }\end{array}$ & $\begin{array}{l}\text { média Teor } \\
(\% \mathrm{~m} / \mathrm{m})\end{array}$ & exatidão \\
\hline \multirow{5}{*}{$\mathrm{Pi}$} & 75 & 88,8 & 80,3 & \multirow{15}{*}{76,8} & \multirow{15}{*}{102,4} \\
\hline & 75 & 90,0 & 76,0 & & \\
\hline & 75 & 89,7 & 76,8 & & \\
\hline & 75 & 89,4 & 78,0 & & \\
\hline & 75 & 90,0 & 75,8 & & \\
\hline \multirow{5}{*}{$\mathrm{RB}$} & 75 & 91,1 & 71,9 & & \\
\hline & 75 & 90,7 & 73,2 & & \\
\hline & 75 & 89,6 & 77,2 & & \\
\hline & 75 & 90,7 & 73,5 & & \\
\hline & 75 & 90,3 & 74,7 & & \\
\hline \multirow{5}{*}{$\mathrm{R}$} & 75 & 88,5 & 81,3 & & \\
\hline & 75 & 88,6 & 80,9 & & \\
\hline & 75 & 88,8 & 80,3 & & \\
\hline & 75 & 88,7 & 80,4 & & \\
\hline & 75 & 91,0 & 72,2 & & \\
\hline \multirow{5}{*}{$\mathrm{Pi}$} & 100 & 83,6 & 98,9 & \multirow{15}{*}{98,9} & \\
\hline & 100 & 83,8 & 98,2 & & \\
\hline & 100 & 84,1 & 97,3 & & \\
\hline & 100 & 83,7 & 98,8 & & \\
\hline & 100 & 84,1 & 97,1 & & \\
\hline \multirow{5}{*}{$\mathrm{RB}$} & 100 & 84,9 & 94,3 & & \\
\hline & 100 & 84,8 & 94,6 & & \\
\hline & 100 & 85,8 & 91,1 & & 98,9 \\
\hline & 100 & 84,7 & 95,1 & & \\
\hline & 100 & 85,1 & 93,7 & & \\
\hline \multirow{5}{*}{$\mathrm{R}$} & 100 & 83,5 & 99,3 & & \\
\hline & 100 & 83,5 & 99,4 & & \\
\hline & 100 & 83,3 & 100,1 & & \\
\hline & 100 & 83,5 & 99,4 & & \\
\hline & 100 & 83,5 & 99,3 & & \\
\hline
\end{tabular}


A partir dos dados da Tabela 68 pode-se obter uma exatidão global igual a $104,1 \%$. Estes resultados são satisfatórios, pois, a variação de exatidão pode estar relacionada às próprias variações naturais da composição de ácidos graxos em azeites ou em óleos. Assim, o método desenvolvido pode vir a ser melhorado para quantificações, mas é suficientemente adequado para a deteç̧ão de adulterações, conforme proposto inicialmente.

Após a validação do método, 12 amostras comerciais foram avaliadas e se detectou adulteração em uma delas, cujo teor de azeite foi igual a $18 \% \mathrm{~m} / \mathrm{m}$. Esse resultado confere com dados encontrados no site da Associação Brasileira de Produtores, Importadores e Comerciante de Azeite de Oliveira (www.oliva.org.br), no qual se encontra uma lista com marcas de azeites irregulares. ${ }^{154}$

\subsection{Método para Quantificação dos Constituintes da Silimarina}

\subsubsection{Extrações:}

Inicialmente houve a necessidade de adaptação do método de extração descrita na farmacopéia americana (USP Dietary Supplements Compendium) ${ }^{155}$ para empregar-se o Sistema de Extrator Acelerado por Solvente e obter-se um extrato de composição química semelhante à que seria obtida através do método farmacopeico.

Na primeira tentativa, procedeu-se de acordo com Benthin e colaboradores, ${ }^{147}$ mas o perfil espectral do extrato obtido possuiu algumas pequenas diferenças quando comparado ao espectro do extrato padrão (Figura 28A), como pode se visualizar na Figura 28B, principalmente na região ampliada, a qual contém a maioria dos sinais referentes aos constituintes da silimarina.

Em seguida, substitui o metanol, por acetato de etila e o perfil espectral foi bastante similar ao do extrato padrão (Figura 28C). No entanto, a quantidade de óleo presente, evidenciada na parte destacada pela linha tracejada no espectro, não permitiu a obtenção de um extrato em forma de pó e nem a secagem completa do acetato de etila, o que interferiu nas medidas quantitativas, uma vez que a massa pesada a ser analisada por RMN não se referiria apenas ao extrato e sim também ao óleo e ao solvente de extração. 
Mesmo após inúmeras tentativas de desengorduramento: moer mais as sementes, passar o pó obtido por peneiras granulométrias, aumentar o número de ciclos de hexano e o tempo do mesmo; os resultados obtidos continuaram apresentando alto teor de lipídeos.

O pó de extrato desejado só foi obtido após a realização de uma partição líquido - liquido com a fração do acetato de etila obtido do extrator. Assim, após a extração no extrator e secagem no rotaevaporador adicionava-se $80 \mathrm{~mL}$ de metanol puro e mais $20 \mathrm{~mL}$ de água, após agitação transferia-se para o funil de separação no qual se adicionava $75 \mathrm{ml}$ de éter de petróleo, agita-se e mantinha-se a fase metanólica. Após 3 vezes, a fase metanólica era seca em rotaevapordor e a água em um liofilizador. $O$ extrato em forma de pó obtido pode ser visualizado na Figura 29.

Figura 28 - Espectro de RMN de ${ }^{1} \mathrm{H}\left(14,1 \mathrm{~T} ; 23^{\circ} \mathrm{C}\right.$ e DMSO- $\left.\mathrm{d}_{6}\right)$ : A) do extrato padrão de referência; $\left.\mathrm{B}\right)$ a primeira tentativa de extração e $\mathrm{C}$ ) a segunda tentativa de extração

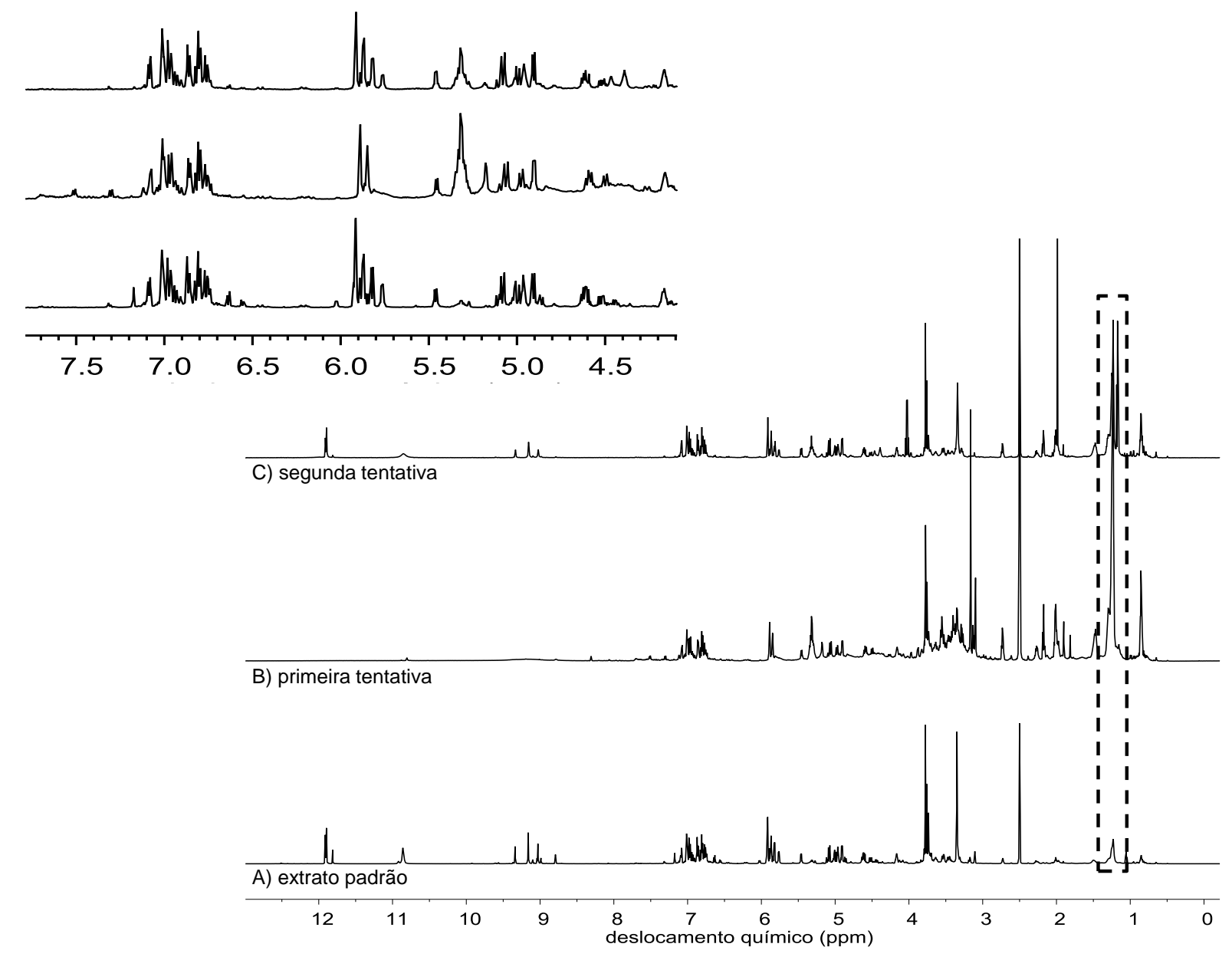


Figura 29 - Fotografias do extrato em pó obtido após otimização do processo de extração das sementes da planta Cardo-leiteiro
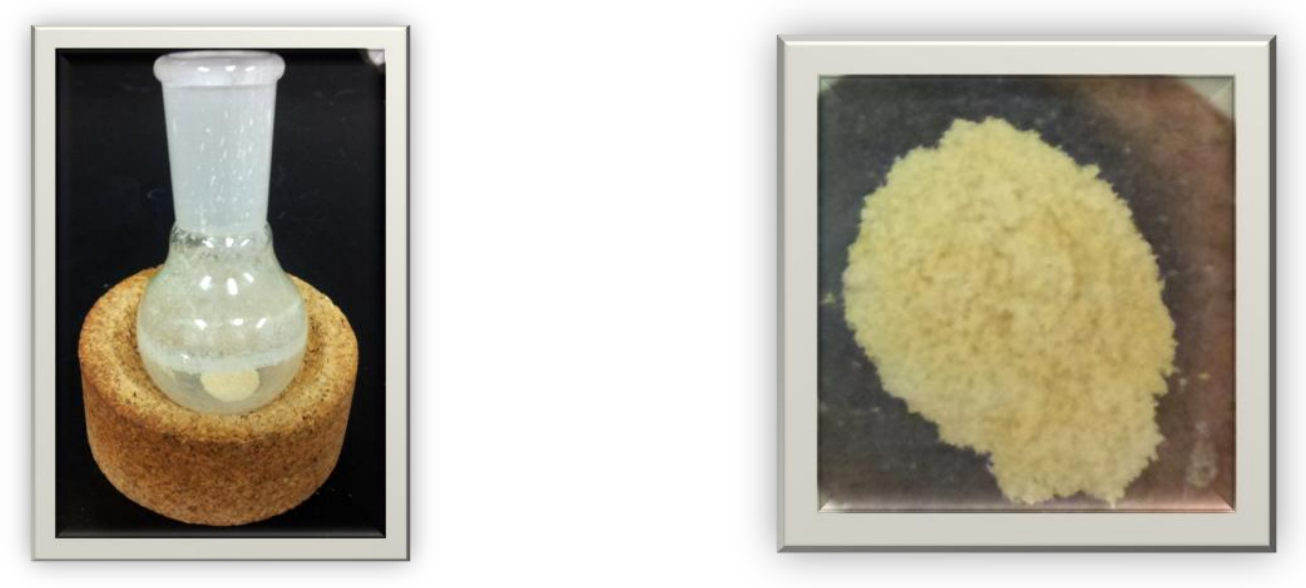

Dessa forma repetiu-se o procedimento em triplicatas para todas as amostras de sementes e os rendimentos obtidos estão apresentados na Tabela 69.

Tabela 69 - Dados referentes aos rendimentos obtidos nas extrações das sementes da planta Cardoleiteiro

\begin{tabular}{|c|c|c|c|c|c|c|}
\hline amostra & replicata & $\begin{array}{l}\text { massa de } \\
\text { semente } \\
\text { em pó (g) }\end{array}$ & $\begin{array}{c}\text { massa de } \\
\text { extrato } \\
\text { (g) }\end{array}$ & $\begin{array}{c}\text { média do } \\
\text { rendimento } \\
\text { da extração } \\
\text { (\% m/m) }\end{array}$ & DP & CV (\%) \\
\hline & $a$ & 5,00627 & 0,06486 & & & \\
\hline \multirow[t]{3}{*}{ BRM } & $b$ & 5,00517 & 0,06197 & 1,30 & 0,06 & 4,51 \\
\hline & $C$ & 5,00723 & 0,06785 & & & \\
\hline & $a$ & 5,00731 & 0,04101 & & & \\
\hline \multirow[t]{3}{*}{$\mathrm{Br}$} & $b$ & 5,01079 & 0,04265 & 0,84 & 0,02 & 2,73 \\
\hline & C & 5,00579 & 0,04324 & & & \\
\hline & $a$ & 5,00595 & 0,03111 & & & \\
\hline \multirow[t]{3}{*}{$\mathrm{P}$} & $b$ & 5,00087 & 0,03414 & 0,67 & 0,05 & 7,17 \\
\hline & $\mathrm{C}$ & 5,00102 & 0,03585 & & & \\
\hline & $a$ & 5,00260 & 0,04876 & & & \\
\hline \multirow[t]{2}{*}{ C } & $b$ & 5,00378 & 0,04337 & 0,95 & 0,08 & 8,22 \\
\hline & $\mathrm{C}$ & 5,00196 & 0,05098 & & & \\
\hline
\end{tabular}

(continua) 


\begin{tabular}{|c|c|c|c|c|c|c|}
\hline amostra & replicata & $\begin{array}{l}\text { massa de } \\
\text { semente } \\
\text { em pó (g) }\end{array}$ & $\begin{array}{c}\text { massa de } \\
\text { extrato } \\
\text { (g) }\end{array}$ & $\begin{array}{c}\text { média do } \\
\text { rendimento } \\
\text { da extração } \\
(\% \mathrm{~m} / \mathrm{m})\end{array}$ & DP & CV (\%) \\
\hline \multirow{6}{*}{ B } & $\mathrm{a}$ & 5,00438 & 0,01018 & \multirow{3}{*}{0,19} & \multirow{3}{*}{0,01} & \multirow{3}{*}{5,98} \\
\hline & $b$ & 5,00079 & 0,00903 & & & \\
\hline & $c$ & 5,00609 & 0,00954 & & & \\
\hline & $d$ & 5,01543 & 0,01793 & \multirow{3}{*}{0,39} & \multirow{3}{*}{0,04} & \multirow{3}{*}{9,86} \\
\hline & e & 5,02838 & 0,02178 & & & \\
\hline & $f$ & 5,01532 & 0,01918 & & & \\
\hline \multirow{3}{*}{ WF } & $a$ & 5,00951 & 0,03989 & \multirow{3}{*}{0,82} & \multirow{3}{*}{0,06} & \multirow{3}{*}{6,76} \\
\hline & $b$ & 5,00527 & 0,04423 & & & \\
\hline & c & 5,00482 & 0,03908 & & & \\
\hline \multirow{2}{*}{$E$} & $a$ & 5,42544 & 0,04759 & \multirow{2}{*}{0,92} & \multirow{2}{*}{0,06} & \multirow{2}{*}{6,42} \\
\hline & $b$ & 5,40572 & 0,05193 & & & \\
\hline \multirow{2}{*}{1} & $\mathrm{a}$ & 5,13134 & 0,04388 & \multirow{2}{*}{0,92} & \multirow{2}{*}{0,09} & \multirow{2}{*}{9,83} \\
\hline & $b$ & 5,01662 & 0,04931 & & & \\
\hline
\end{tabular}

O método de extração otimizado apresentou uma boa precisão, uma vez que seus coeficientes de variação ficaram todos abaixo de $10 \%$. Apesar de todos os rendimentos terem sido inferiores ao descrito na farmacopéia $(>2,0 \%)^{155}$, a massa obtida foi o suficiente para as análises de $\mathrm{RMN}$ e, de acordo com os espectros de RMN de ${ }^{1} \mathrm{H}$, a composição era bastante semelhante ao do extrato padrão revelando que os constituintes da silimarina tinham sido extraídos conforme desejado.

Vale ressaltar que a amostra $\mathrm{B}$, que se obteve a menor quantidade de extrato, era mais oleosa que as demais e este fato interferiu negativamente em todo o processo de extração, desde a moagem das sementes.

\subsubsection{Análises de RMNa de ${ }^{1} \mathrm{H}$ :}

Inicialmente realizou-se um teste para verificar a exatidão e precisão do método a ser utilizada no preparo de amostra empregando exatamente os mesmos 
materiais a serem utilizados nas análises e o material de referência dimetilsulfona como PI para quantificar o outro material de referência, 3,5 ácido dinitrobenzóico. Os resultados obtidos estão apresentados na Tabela 70 e revelam que o método de preparo de amostra é viável por ter apresentado bons resultados relacionados à precisão e exatidão.

Tabela 70 - Resultados de Precisão e Exatidão obtidos no teste de preparo de amostra do método de análise dos extratos e amostras comerciais da planta Cardo-leiteiro

massa do 3,5

replicata

$$
\text { ácido }
$$

exatidão

(\%)

dinitrobenzóico

via $\mathrm{RMNq}(\mathrm{mg})$

\begin{tabular}{llllll}
\hline A & 3,63 & 98,3 & & & \\
B & 3,23 & 97,1 & 98,1 & 0,9 & 0,9 \\
C & 3,13 & 98,9 & & & \\
\hline
\end{tabular}

Anteriormente às análises quantitativas obtiveram-se espectros de $\mathrm{RMN}$ de ${ }^{1} \mathrm{H}$ de todas as amostras para verificar se não havia sinais presente na região do sinal do PI (2,99 ppm). Como este fato foi confirmado pode-se empregar a dimetilsulfona como padrão interno em todas as amostras.

Nas Figuras 30 e 31 encontram-se os espectros de RMNq de ${ }^{1} \mathrm{H}$ dos extratos e das amostras comerciais, respectivamente. Observaram-se algumas diferenças nos espectros das amostras estudadas: as amostras de flores brancas apresentaram espectros distintos entre si, a amostra I não possui sinal algum que possa ser atribuído aos constituintes da silimarina, enquanto que a amostra $E$ possui todos exceto os sinais da silidianina; as amostras comerciais possuem alguns sinais distintos devido à diferença de formulação; as amostras comerciais C e NB apresentaram espectros idênticos mesmo sendo comercializadas por empresas diferentes, provavelmente ambas as empresas possuem um mesmo fornecedor de matéria prima.

Além disso, observou-se que os sinais referentes aos grupos hidroxilas apresentaram-se com diferentes intensidades e larguras de linha, o que provavelmente deve-se à capacidade de troca de seu hidrogênio, com outros núcleos de hidrogênio presentes no meio, tal como os ${ }^{1} \mathrm{H}$ da água, por exemplo. 
Figura 30 - Espectros de RMNq de ${ }^{1} \mathrm{H}\left(14,1 \mathrm{~T} ; 23^{\circ} \mathrm{C}\right.$ e DMSO- $\left.\mathrm{d}_{6}\right)$ dos extratos das sementes da planta Cardo-leiteiro obtidos

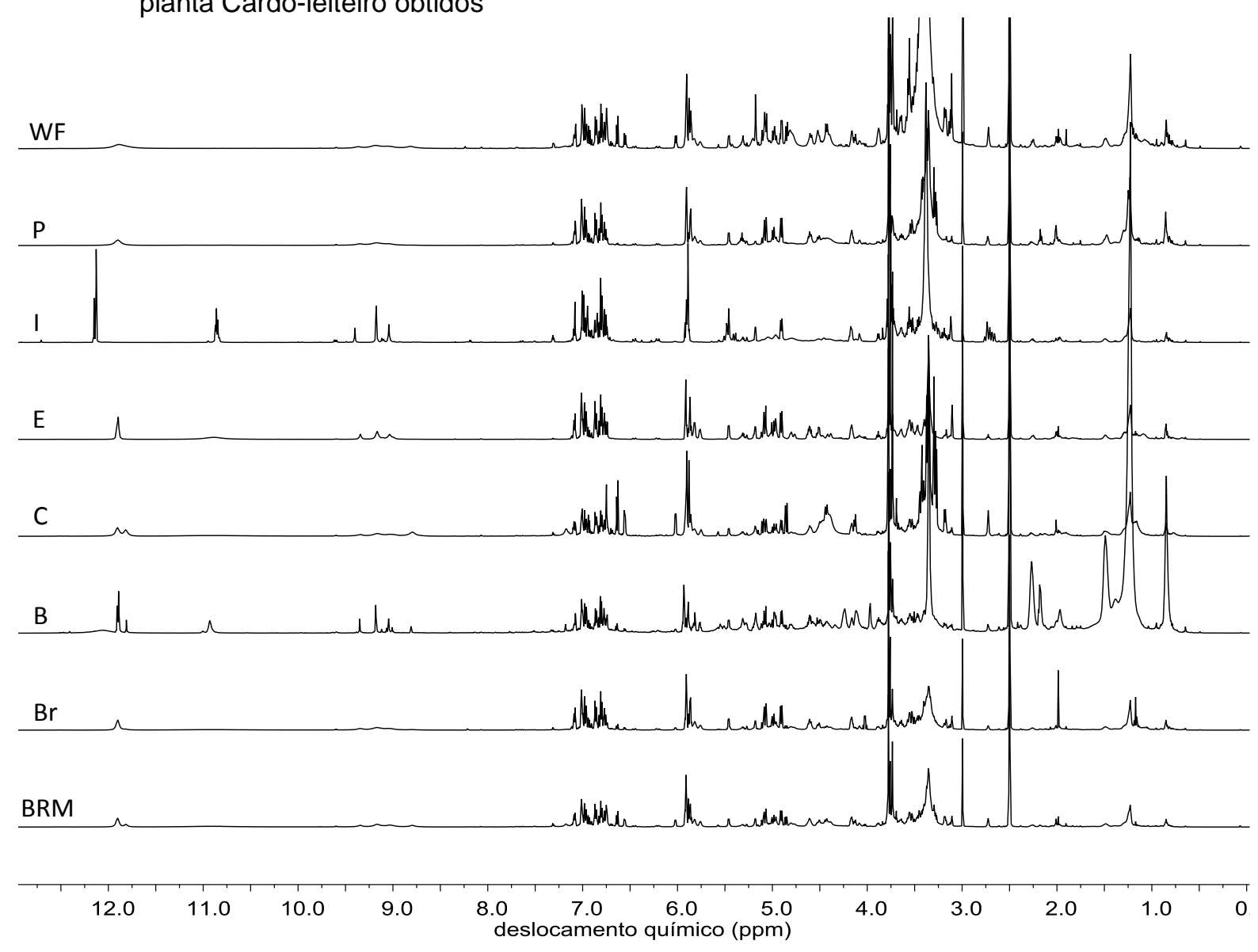

Figura 31 - Espectros de RMNq de ${ }^{1} \mathrm{H}\left(14,1 \mathrm{~T} ; 23^{\circ} \mathrm{C}\right.$ e DMSO- $\left.\mathrm{d}_{6}\right)$ dos produtos comerciais contendo extratos das sementes da planta Cardo-leiteiro

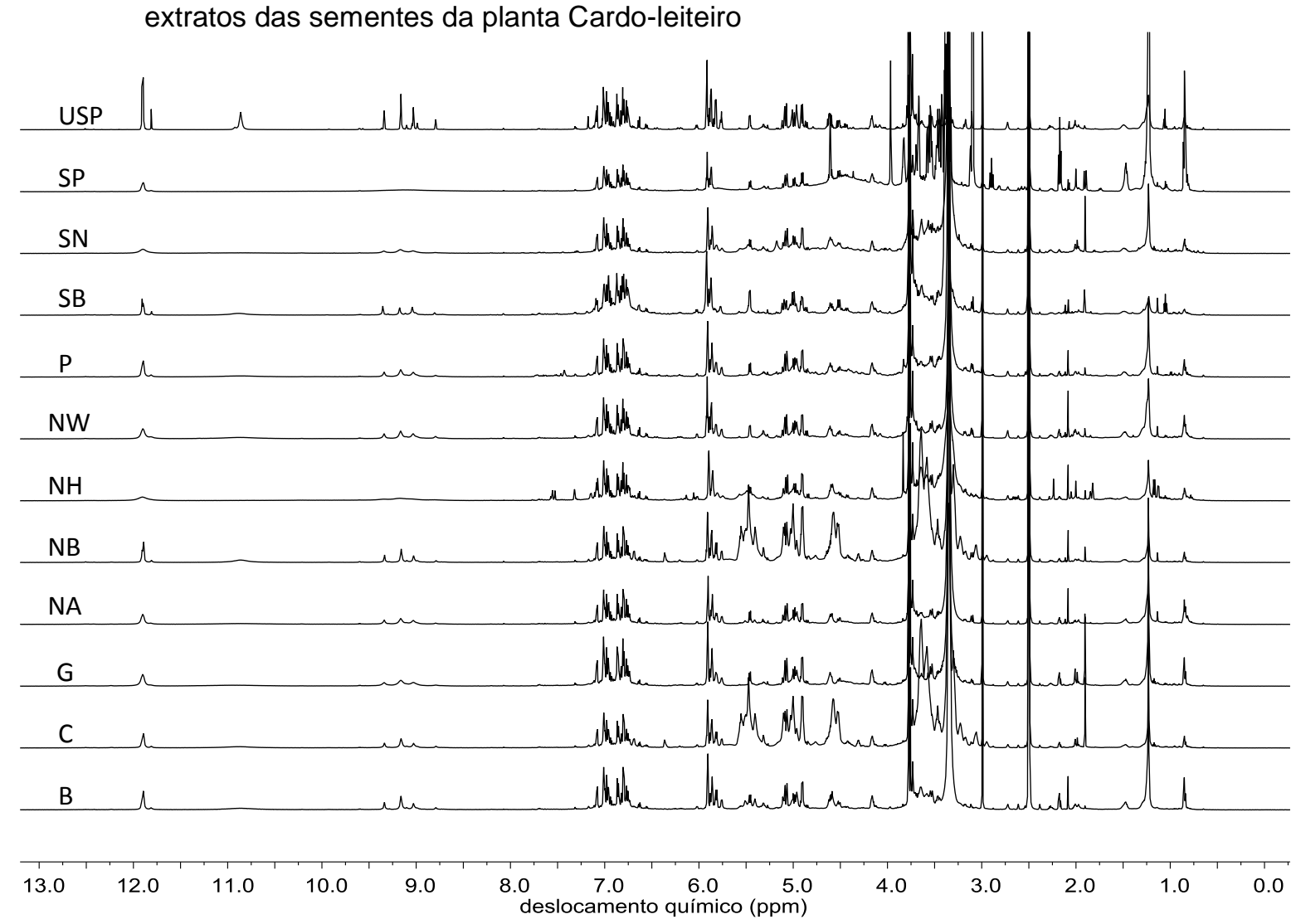


A atribuição dos sinais dos compostos constituintes da silimarina está descrita na literatura. ${ }^{131,156}$ Os sinais empregados para a integração e, consequentemente, quantificação absoluta, foram: dupleto em 6,93 ppm referente às isolibinas; simpleto largo em 6,82 ppm referente à silicristina; duplo dupleto em 6,55 ppm referente à silidianina e multipleto em 5,57 ppm referente à isosilicristina.

Devido à falta de seletividade de sinais apenas referentes às silibinas, sua quantificação total foi feita a partir do teor de silibinas somado ao teor de isosilibinas subtraído do teor total de isosilibinas. A região considerada na integração refere-se à região espectral na qual estão presentes os sinais dos hidrogênios aromáticos orto ao grupo metoxila ( $\cong 7,11-7,06 \mathrm{ppm}$ ) de cada uma dos quatro compostos (silibina $A$ e $B$ e isosilibina $A$ e $B$ ).

Os isômeros silibina $A$ e $B$ não puderam ser quantificados separadamente apenas por integração, pois todos seus sinais possuem deslocamentos químicos muito semelhantes e se sobrepunham. O mesmo ocorreu com os isômeros isolibilina A e B. Assim, nesse primeiro momento determinou-se apenas o teor total de silibina $\mathrm{e}$ isosilibina.

$\mathrm{Na}$ Figura 32 encontram-se assinalados os sinais empregados na integração para cada um dos analitos quantificados e os resultados obtidos para todas as amostras estão apresentados nas Tabelas 71 e 72.

Figura 32 - Assinalamento dos sinais de RMN de ${ }^{1} \mathrm{H}$ empregados para a quantificação dos constituintes da silimarina

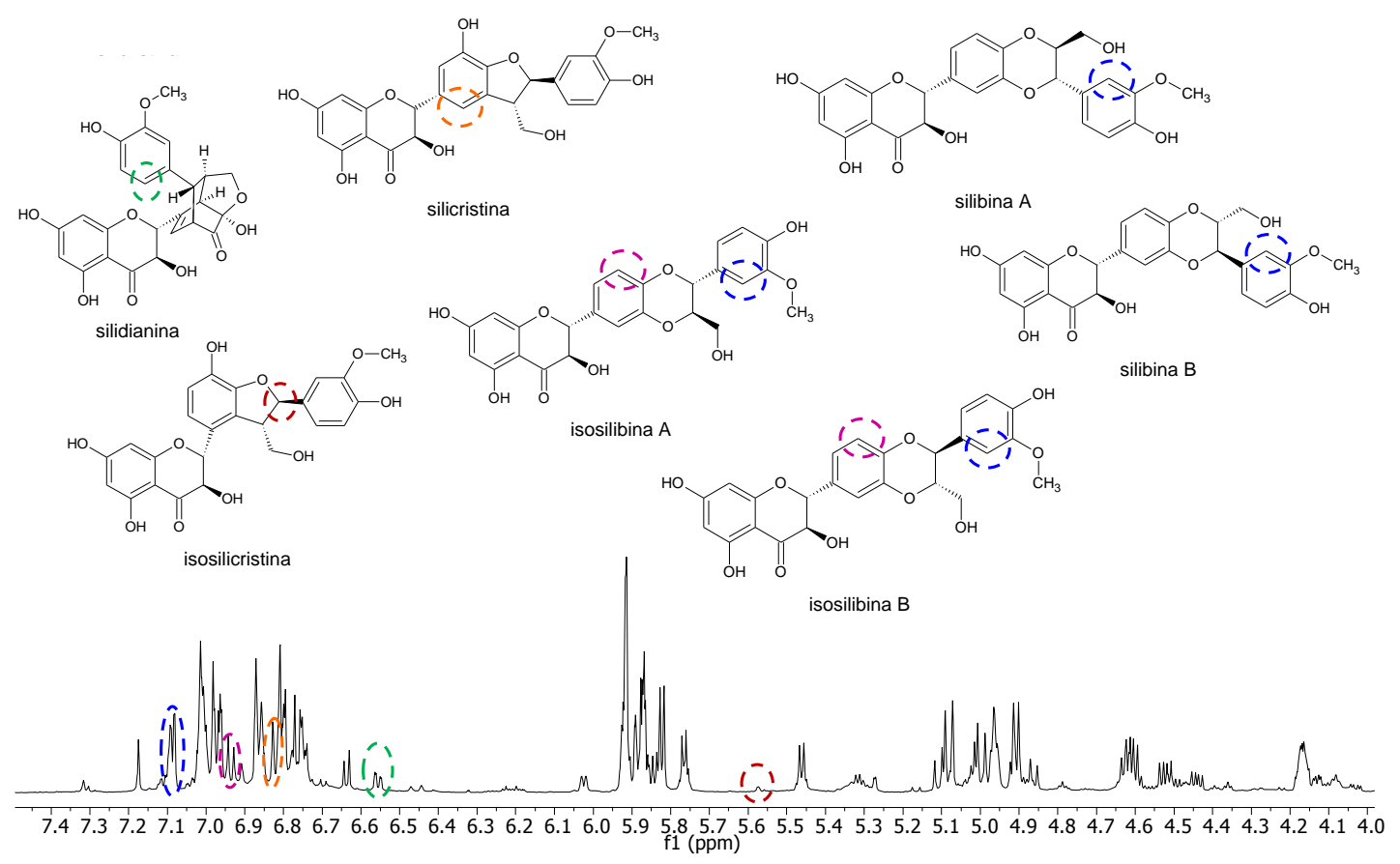


Tabela 71 - Teor dos constituintes da silimarina nos extratos determinados via RMNa

\begin{tabular}{ccccccc}
\hline \multirow{2}{*}{ amostra / } & \multicolumn{5}{c}{ teor $(\% \mathbf{m} / \mathbf{m})$} \\
\cline { 2 - 6 } composto & $\begin{array}{c}\text { silibina } \\
\text { A e B }\end{array}$ & $\begin{array}{c}\text { isosilibina } \\
\text { A e B }\end{array}$ & silicristina & isosilicristina & silidianina & TOTAL \\
\hline BRM & 20,8 & 15,6 & 12,7 & 3,7 & 16,3 & 69,1 \\
Br & 24,4 & 14,3 & 13,1 & 2,1 & 5,2 & 59,1 \\
P & 24,7 & 13,3 & 14,3 & 2,4 & 2,3 & 57,0 \\
C & 10,6 & 12,8 & 6,1 & 3,8 & 24,7 & 58,0 \\
B & 7,9 & 8,0 & 6,2 & 1,8 & 3,4 & 27,2 \\
WF & 15,2 & 15,6 & 7,8 & 4,0 & 13,2 & 55,8 \\
E & 33,6 & 13,6 & 18,3 & 1,7 & 0,0 & 67,2 \\
I & 0,0 & 0,0 & 0,0 & 0,0 & 0,0 & 0,0 \\
\hline
\end{tabular}

Tabela 72 - Teor dos constituintes da silimarina nas amostras comerciais determinados via RMNa

\begin{tabular}{ccccccc}
\hline \multirow{2}{*}{ amostra / } & \multicolumn{5}{c}{ teor $(\% \mathbf{m} / \mathbf{m})$} \\
\cline { 2 - 7 } composto & $\begin{array}{c}\text { silibina } \\
\text { A e B }\end{array}$ & $\begin{array}{c}\text { isosilibina } \\
\text { A e B }\end{array}$ & silicristina & isosilicristina & silidianina & TOTAL \\
\hline USP & 26,4 & 12,6 & 16,0 & 2,8 & 9,5 & 67,2 \\
P & 9,8 & 6,1 & 7,2 & 2,3 & 3,5 & 28,8 \\
G & 15,2 & 8,1 & 9,4 & 2,3 & 3,2 & 38,3 \\
C & 12,8 & 5,2 & 5,4 & 3,0 & 2,6 & 29,0 \\
B & 8,3 & 3,7 & 4,5 & 1,0 & 1,8 & 19,1 \\
NW & 11,1 & 7,1 & 8,0 & 1,4 & 4,4 & 31,9 \\
NH & 9,9 & 4,6 & 8,6 & 2,1 & 3,6 & 28,8 \\
SN & 9,4 & 4,3 & 5,2 & 1,6 & 2,7 & 23,1 \\
NB & 11,2 & 5,1 & 6,0 & 3,8 & 2,3 & 28,4 \\
NA & 8,1 & 5,7 & 6,7 & 1,4 & 2,3 & 24,2 \\
SP & 5,8 & 9,3 & 6,8 & 2,1 & 3,0 & 26,9 \\
SB & 10,5 & 13,9 & 21,1 & 4,1 & 7,7 & 57,1 \\
\hline
\end{tabular}

Em todos os extratos a quantidade total dos constituintes da silimarina foram inferiores aos descritos na farmacopéia americana, ${ }^{155}$ a qual cita $80 \%$, no entanto essa porcentagem pode variar de acordo com uma série de fatores tais como: idade da planta, solo, condições de armazenamento, secagem, etc. 
Considerando a complexidade das matrizes e dos espectros, pode-se considerar que o método proposto possui uma boa precisão, uma vez que os coeficientes de variação para todos os constituintes não ultrapassaram 7\%.

Para melhor compreensão desses resultados, na Figura 33 mostra-se um gráfico comparativo entre os constituintes e as amostras, no qual nota-se que o teor dos constituintes da silimarina é superior nos extratos, pois nos produtos comerciais havia na massa analisada componentes da formulação, além de extrato. No entanto, somente o teor de silimimarina total em 6 das 11 amostras comerciais avaliadas estavam de acordo com seus rótulos, considerando a tolerância faramacopéica ( \pm 10\%). ${ }^{155} \mathrm{Na}$ Tabela 73 estão descritos os resultados obtidos em comparação aos valores descritos em suas bulas.

Figura 33 - Gráfico comparativo dos teores dos constituintes $(\% \mathrm{~m} / \mathrm{m})$ da silimarina (silibinas - lilás; isosilibinas - violeta; silicristina - amarelo; isosilicristina - verde; silidianina - rosa) entre todas as amostras analisadas

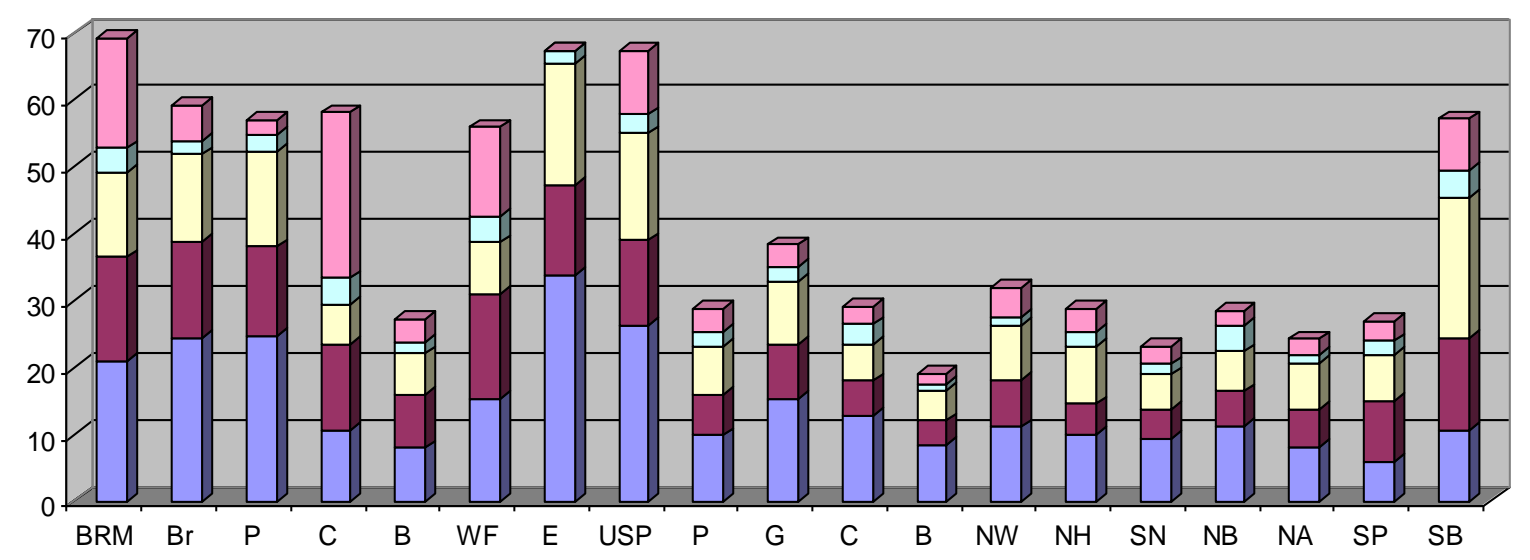

Tabela 73 - Teores de silimarina descritos na bulas e determinados via $\mathrm{RMNq}$

\begin{tabular}{cccc}
\hline amostra & $\begin{array}{c}\text { teor descrito na } \\
\text { bula (mg/ cápsula) }\end{array}$ & $\begin{array}{c}\text { teor obtido via RMNq } \\
\text { (mg/cápsula) }\end{array}$ & variação (\%) \\
\hline P & 160 & 193 & 21 \\
G & 160 & 260 & 62 \\
C & 140 & 151 & 8 \\
B & 80 & 82 & 3 \\
NW & 140 & 158 & 13 \\
NH & 140 & 147 & 5 \\
SN & 96 & 94 & -2
\end{tabular}


(conclusão)

\begin{tabular}{cccc}
\hline amostra & $\begin{array}{c}\text { teor descrito na } \\
\text { bula (mg/ cápsula) }\end{array}$ & $\begin{array}{c}\text { teor obtido via RMNq } \\
\text { (mg/cápsula) }\end{array}$ & variação (\%) \\
\hline $\mathrm{NB}$ & 140 & 144 & 3 \\
$\mathrm{NA}$ & 140 & 128 & -8 \\
$\mathrm{SP}^{*}$ & 163 & 262 & 61 \\
$\mathrm{SB}^{* *}$ & 80 & 57 & 29 \\
\hline
\end{tabular}

${ }^{*}$ tablete; ${ }^{* \star} \% \mathrm{~m} / \mathrm{m}$

\subsubsection{HiFSA:}

Como os compostos silibina $A$ e $B$ e isosilibina $A$ e $B$ possuem espectros de RMN de ${ }^{1} \mathrm{H}$ bastante similar, no qual há sobreposição da maioria dos sinais, empregou-se uma ferramenta computacional, HiFSA, para determinar-se a quantidade de cada um desses isômeros.

O software utilizado no presente estudo $(\mathrm{PERCH})^{157}$ pode ser empregado em diversas finalidades, tais como: processamento de espectros de RMN; modelagem molecular, predição de espectros de RMN; análises espectrais e quantificação (RMNq).

Quando todos esses empregos são aliados para a obtenção de um só objetivo, a criação de um fingerprint, por exemplo, essa abordagem é denominada HiFSA ( ${ }^{1} \mathrm{H}$ iterative Full Spin Analysis).

A aplicação desse "método" é feita em etapas, as quais serão brevemente descritas. A primeira etapa consiste apenas na aquisição e processamento do espectro de RMN de ${ }^{1} \mathrm{H}$ e a segunda na importação do FID obtido para o software. A partir de então vários arquivos são criados na mesma pasta do arquivo inicial.

$\mathrm{Na}$ terceira etapa, processamentos adicionais no espectro podem ser realizados utilizando a ferramenta PAC. Nesse momento, regiões de desinteresse podem ser excluídas.

$\mathrm{Na}$ quarta etapa é feita a modelagem molecular a partir de um software complementar (Molecular Modeling Software - MMS), no qual se desenha a estrutura química do composto de interesse e a aperfeiçoa através da otimização de sua geometria, dinâmica molecular e análise conformacional. Em seguida, um espectro de RMN é simulado baseando-se na estrutura química aperfeiçoada. 
A criação do fingerprint é feita na quinta etapa, quando se compara o espectro simulado ao espectro real, inicialmente importado. A partir dessa comparação, ajustam-se os valores dos deslocamentos químicos do espectro simulado exatamente iguais ao do espectro real.

Então, na sexta etapa é feito um fitting iterativo no qual são ajustadas as constantes de acoplamentos e as larguras de linhas do espectro simulado, resultando em um espectro idêntico ao real. Na Figura 34 está ilustrado o resultado de tal simulação.

Por fim, um arquivo de texto é gerado contento uma lista com as atribuições completas de todos os núcleos, incluindo a população dos mesmos. Este arquivo de texto pode ser manipulado e, por exemplo, misturas de compostos em diferentes proporções podem ser simuladas ao acrescentar as lista de informações dos mesmos em um mesmo arquivo.

Estudos diversos empregando o método HiFSA têm sido desenvolvidos também por pesquisadores do Departamento de Química Medicinal e Farmacognosia da Faculdade de Farmácia, na Universidade de Illinois em Chicago. ${ }^{52,144,156}$

Figura 34 - Ilustração do resultado espectral obtido empregando o método HiFSA

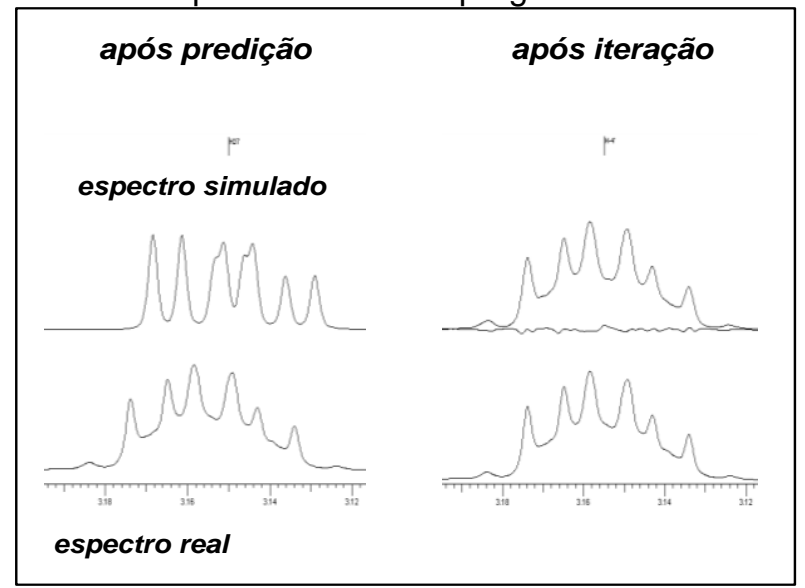

Fonte: Apresentação do Dr. Napolitano em um seminário interno do grupo

Em um trabalho anterior, o grupo do professor Dr. Pauli, construiu fingerprints para os compostos silibina A e B e isosilibina A e B. ${ }^{156}$ Então, bastou-se simular a somatória desses fingerprints exatamente na região em que somente há sinal destes quatro compostos $(7,06$ a 7,11 ppm, mostrada na Figura 35$)$ de tal forma que ficassem idênticos aos sinais dos espectros quantitativos reais. 
Figura 35 - llustração da região espectral empregada nas simulações via HiFSA para determinação das silibinas $\mathrm{A}$ e $\mathrm{B}$ e isosilibinas $\mathrm{A}$ e $\mathrm{B}$
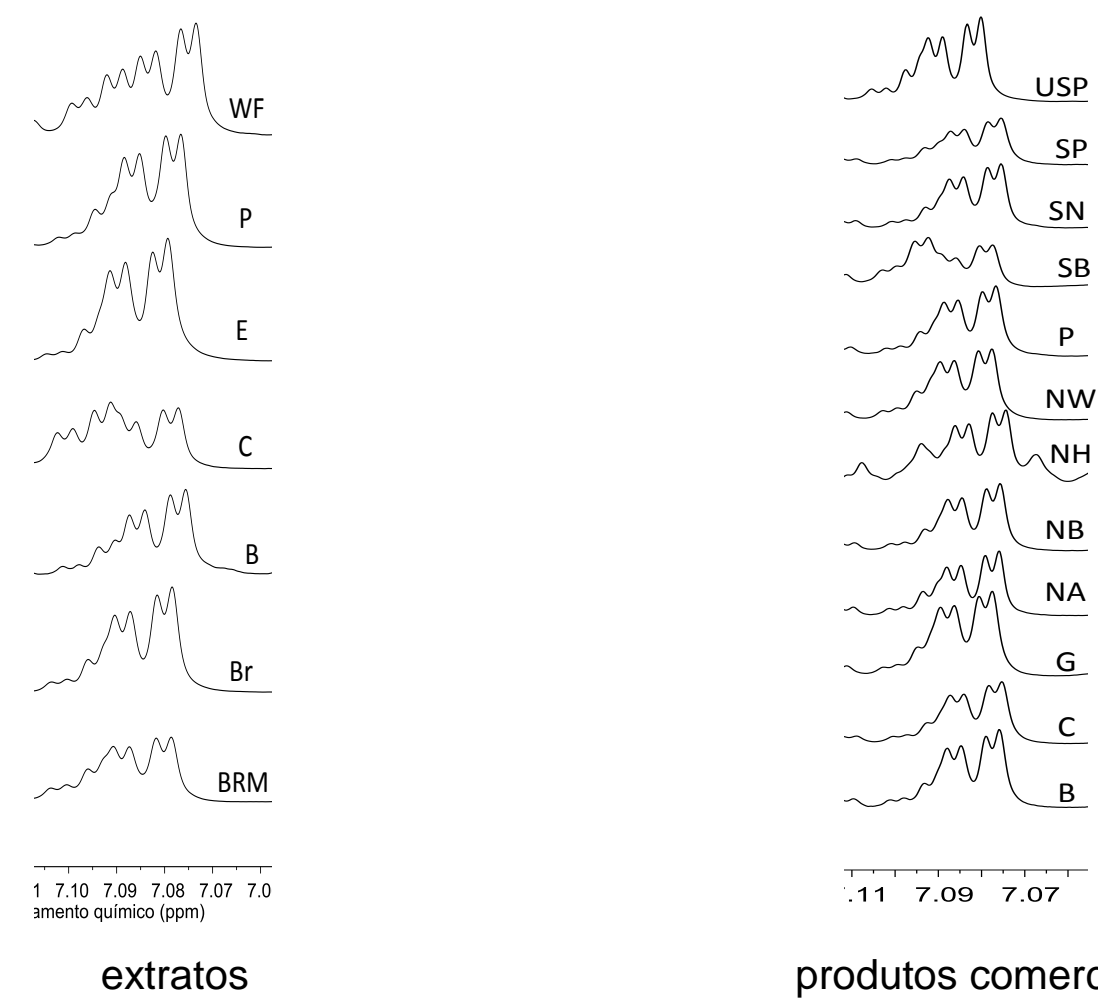

produtos comerciais

Desta maneira, o programa forneceu em seu arquivo de texto a informação sobre a porcentagem de população de cada um dos isômeros presentes no sinal simulado, idêntico ao sinal real. Como a quantidade absoluta da mistura já havia sido obtida por RMNq, pôde-se obter a quantidade absoluta de cada um dos isômeros (Tabelas 74 e 75).

Tabela 74 - Teor dos isômeros (iso)silibinas A e B presentes nos extratos das sementes da planta Cardo-leiteiro determinado via HiFSA e RMNa

\begin{tabular}{ccccc}
\hline \multirow{2}{*}{ amostra/composto } & \multicolumn{4}{c}{ teor (\% m/m) } \\
\cline { 2 - 5 } & silibina A & silibina B & isosilibina A & isosilibina B \\
\hline BRM & 9,2 & 11,6 & 10,9 & 4,6 \\
Br & 10,7 & 13,8 & 10,7 & 3,6 \\
P & 11,2 & 13,5 & 10,5 & 2,8 \\
C & 4,3 & 6,3 & 7,9 & 4,9 \\
B & 3,5 & 4,4 & 6,0 & 2,0 \\
WF & 6,3 & 8,9 & 10,1 & 5,5 \\
E & 15,3 & 18,4 & 10,9 & 2,7 \\
I & 0,0 & 0,0 & 0,0 & 0,0 \\
\hline
\end{tabular}


Tabela 75 - Teor dos isômeros (iso)silibinas A e B presentes nas amostras comerciais contendo extratos das sementes da planta Cardo-leiteiro determinado via HiFSA e RMNa

\begin{tabular}{ccccc}
\hline \multirow{2}{*}{ amostra/composto } & \multicolumn{4}{c}{ teor $(\% \mathbf{m} / \mathbf{m})$} \\
\cline { 2 - 5 } silibina A & silibina B & isosilibina A & isosilibina B \\
\hline USP & 11,4 & 14,9 & 9,4 & 3,2 \\
P & 4,3 & 5,5 & 5,1 & 1,0 \\
G & 6,9 & 8,4 & 6,3 & 1,9 \\
C & 5,6 & 7,2 & 3,9 & 1,2 \\
B & 3,7 & 4,6 & 2,8 & 0,9 \\
NW & 4,9 & 6,1 & 5,3 & 1,8 \\
NH & 4,5 & 5,4 & 2,5 & 2,1 \\
SN & 4,2 & 5,2 & 3,3 & 1,0 \\
NB & 4,9 & 6,3 & 3,9 & 1,2 \\
NA & 3,5 & 4,6 & 4,4 & 1,3 \\
SP & 2,5 & 3,3 & 7,2 & 2,0 \\
SB & 3,7 & 6,8 & 11,0 & 2,9 \\
\hline
\end{tabular}

Para melhor visualização desses resultados, nas Figuras 36 e 37 mostram-se gráficos comparativos entre esses constituintes e as amostras.

Figura 36 - Gráfico comparativo dos teores $(\% \mathrm{~m} / \mathrm{m})$ da silibina A, em azul, e da silibina B, em vermelho, entre todas as amostras analisadas

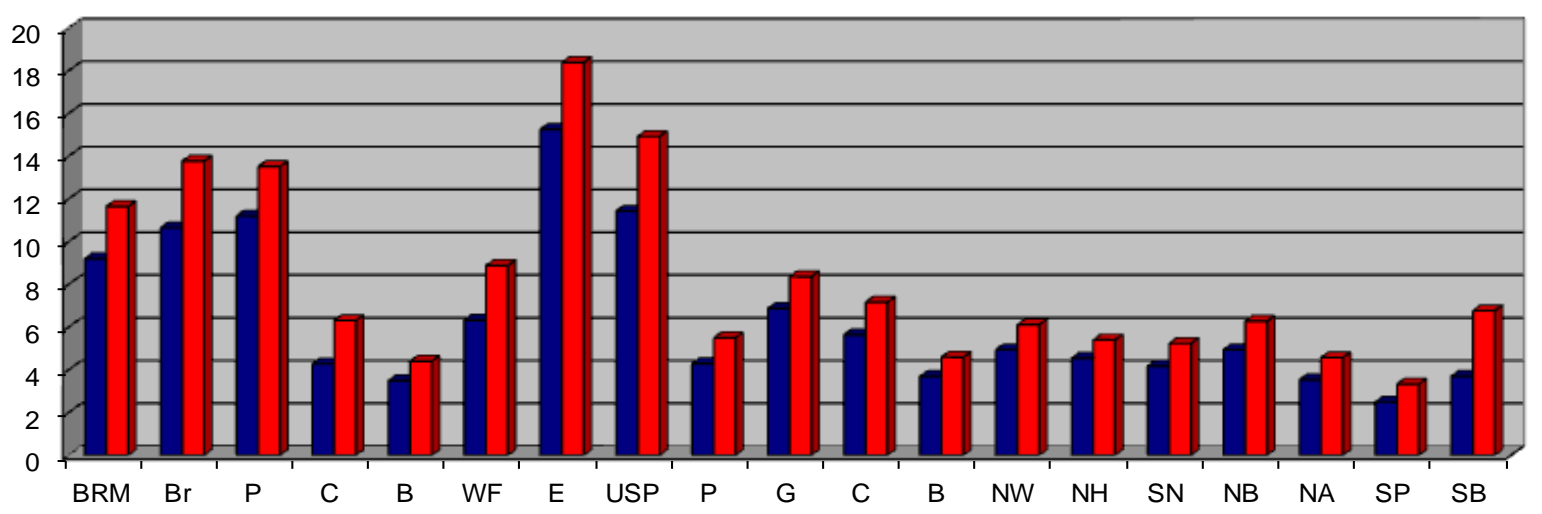


Figura 37 - Gráfico comparativo dos teores $(\% \mathrm{~m} / \mathrm{m})$ da isosilibina A, em verde, e da isosilibina $B$, em amarelo, entre todas as amostras analisadas

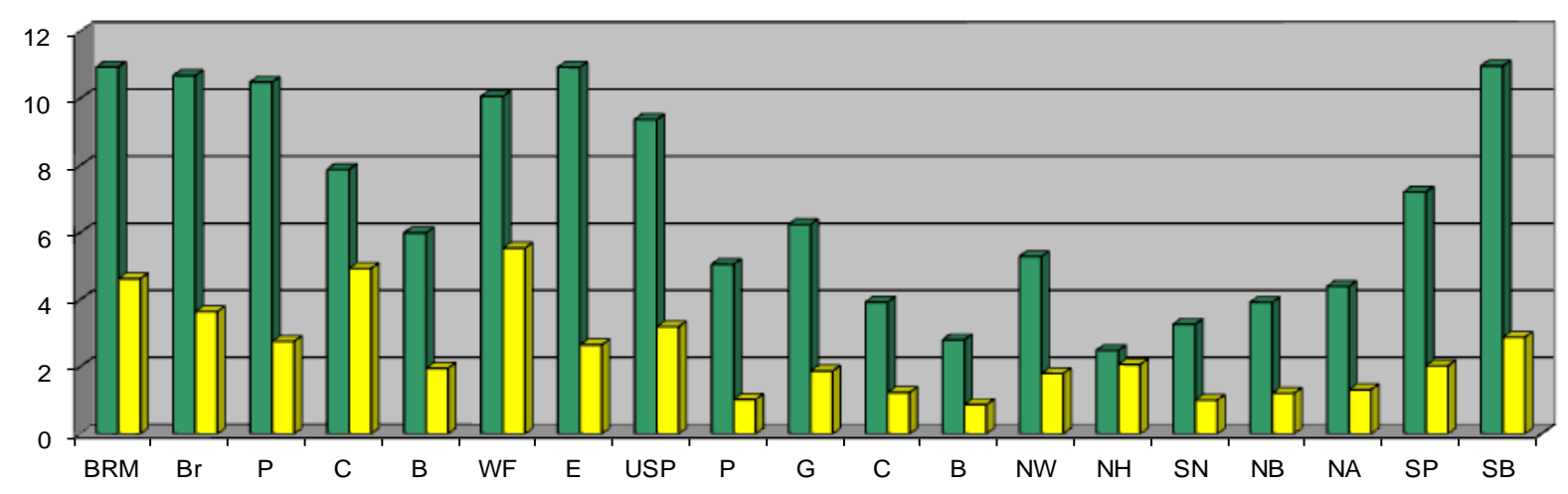

Um fato interessante observado é que em todas as amostras o isômero isosilibina $A$ e a silibina $B$ são superiores que a isosilibina $B$ e silibina $A$. Isto pode estar associado ao metabolismo da planta, o qual pode ter certa estereosseletividade ou apenas à maior estabilidade química desses compostos, nas condições de análise.

\subsubsection{Análise de Componentes Principais:}

Para obterem-se maiores informações sobre as amostras estudadas submeteram-se os espectros obtidos à análise de componentes principais.

Para a realização destas análises, basta organizarem todos os dados obtidos sobre as amostras em questão em uma matriz de dados, na qual as amostras (n) são as linhas e as variáveis (i) são as colunas. A partir dessa matriz os dados são analisados de diferentes maneiras de acordo com o método quimiométrico empregado.

As análises exploratórias são inicialmente utilizadas para determinar algumas relações gerais entre os dados, revelando quais amostras são semelhantes ou diferentes entre si através do agrupamento ou não, respectivamente, das mesmas.

Dentre as técnicas quimiométricas exploratórias mais comumente empregadas pode-se citar a análise de componentes principais (Principal Components Analysis - PCA), a qual foi empregada no presente estudo e consiste em um método não supervisionado de análise multivariada dos dados.

A análise de componentes principais diminui a dimensionalidade dos dados através da combinação linear das variáveis originais reduzindo o número das 
mesmas. ${ }^{158,159}$ Essas novas variáveis são denominadas "componentes principais". Dessa forma, as informações mais relevantes ficam concentradas nas primeiras componentes e estas são suficientes para descrever o sistema e extrair suas informações. ${ }^{158,} 159$

A explicação do que cada componente principal representa pode ser obtida através dos loadings, que são os pesos dados a cada variável original. O gráfico de PCA é mostrado na forma planar (Figura 38) ou tridimensional e a partir da análise do mesmo é possível verificar o agrupamento das amostras que são semelhantes entre si e ainda a discriminação em classes.

Figura 38 - Representação esquemática da forma de visualização bidimensional dos resultados de PCA

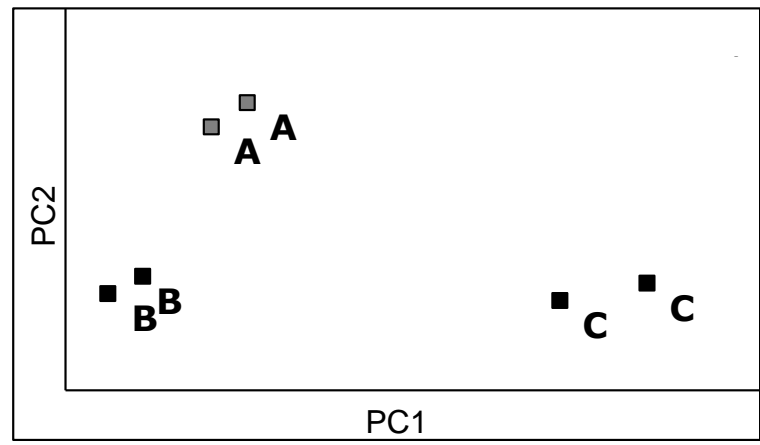

Para a PCA do presente estudo limitou-se à região espectral na qual continha a maior e mais significantes sinais dos constituintes da silimarina (7.35 - $3.67 \mathrm{ppm})$, a qual foi transformada em simples buckets retangulares com $0.01 \mathrm{ppm}$ de largura. Os dados foram normalizados pela área total da região analisada e a variância explicada aplicada a todas as análises foi de $95 \%$.

Primeiramente avaliaram-se apenas os extratos e observou-se na Figura 39 que a maioria deles se agrupou ao extrato da semente padrão, revelando a idoneidade das amostras e que o fator localidade não foi relevante, já que as amostras foram obtidas de diferentes partes do mundo.

Já as amostras C, I e B, diferentemente das demais não se agruparam. Analisando o gráfico de loadings verificou-se que a amostra $C$ possui uma quantidade muito maior de silidianina que as demais; a amostra $B$ possui menos constituintes da silimarina, além de sinais da formulação, enquanto que a amostra I, conforme já discutido anteriormente, possui uma composição diferentes das demais 
amostras, não possuindo sinal alguns dos compostos aqui estudados e quantificados.

Figura 39 - Gráfico de scores dos extratos das sementes da planta Cardo-leiteiro obtido por PCA:

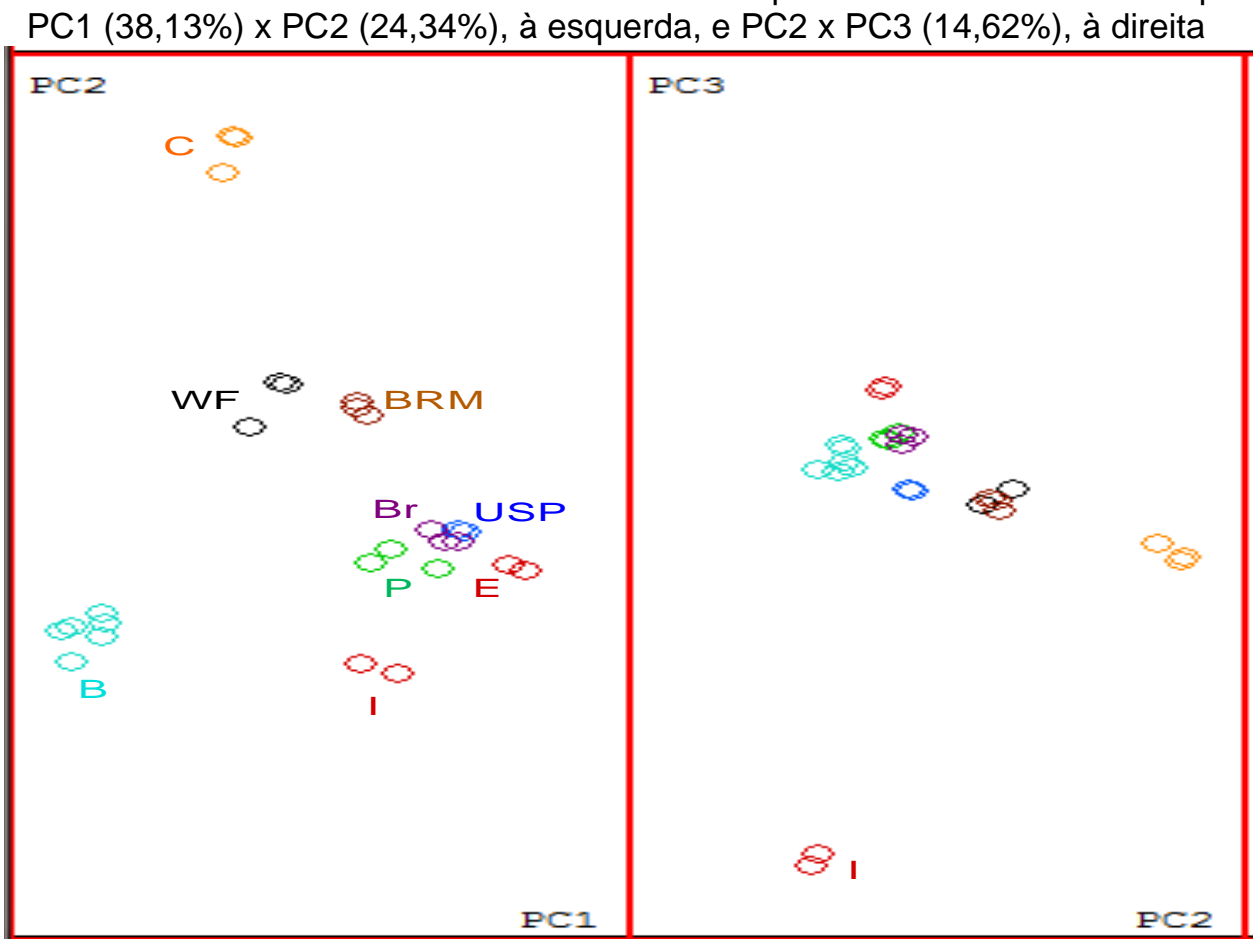

Analisando apenas as amostras comerciais (Figura 40) observou-se que a maioria delas se agrupou ao extrato padrão revelando a similaridade entre as mesmas. No entanto, a amostra SP se diferenciou das demais devido a algum componente da formulação não identificado, já que diferentemente das demais amostras, esta era tablete e não cápsula, e as amostras C e NB, já discutidas anteriormente formaram um grupo a parte.

Por fim ao analisar todas as amostras (Figura 41) observou-se um grande grupo contendo tanto o extrato padrão quanto o extrato obtido a partir da semente padrão e uma leve tendência de separação entre extratos e produtos comerciais, o que pode ser devido ao fato de haver outros componentes presentes, como os excipientes da formulação, por exemplo. As amostras que foram diferentes das demais já foram discutidas nos parágrafos anteriores. 
Figura 40 - Gráfico de scores dos produtos comerciais contendo extratos das sementes da planta Cardo-leiteiro obtido por PCA: PC1 (48,87\%) x PC2 $(26,96 \%)$, à esquerda, e PC2 x PC3 $(8,42 \%)$, à direita

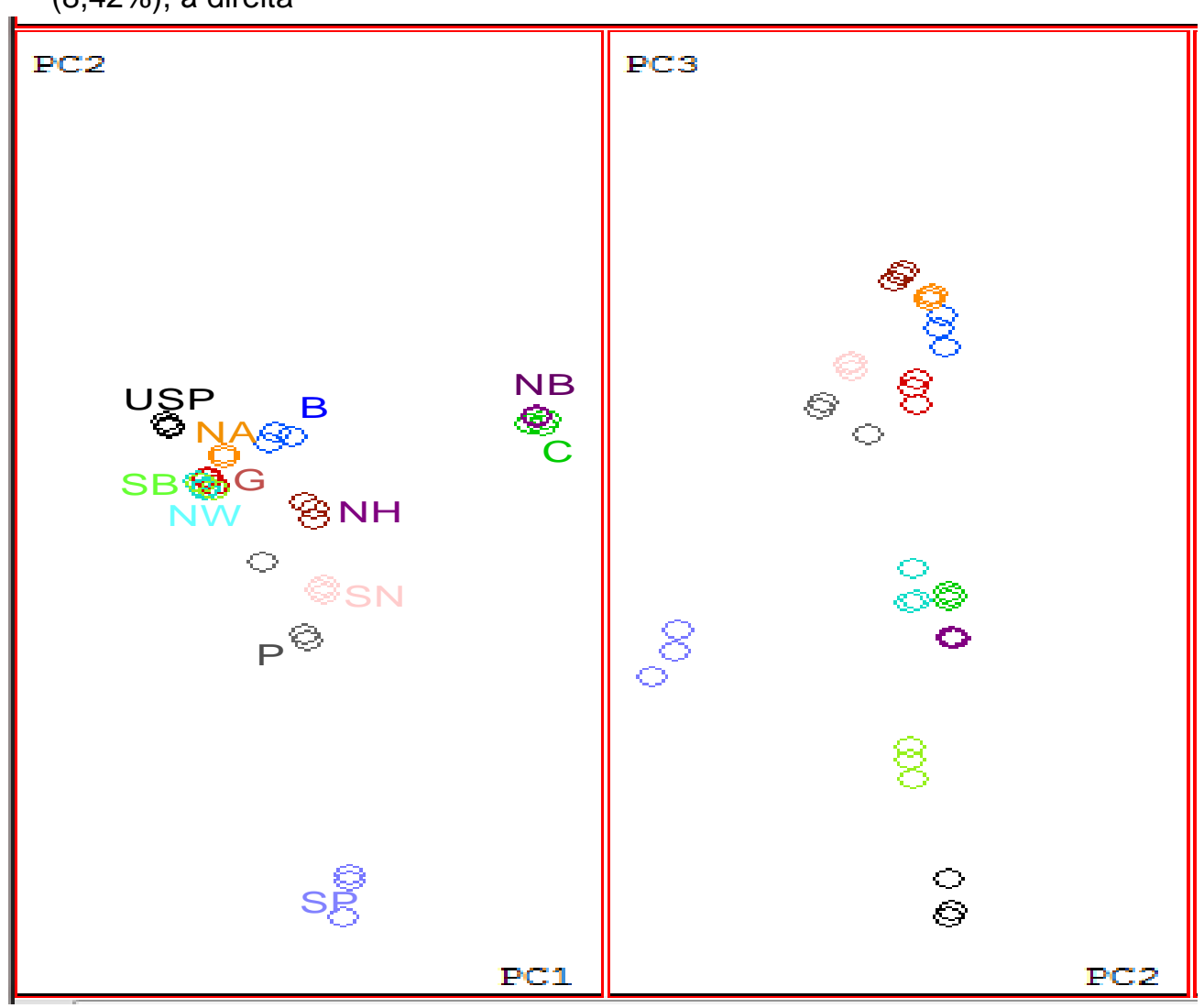

Figura 41 - Gráfico de scores de todas as amostras (padrões em verde, extratos em azul e produtos comerciais em preto) obtido por PCA: PC1 (32,16\%) x PC2 (21,65\%)

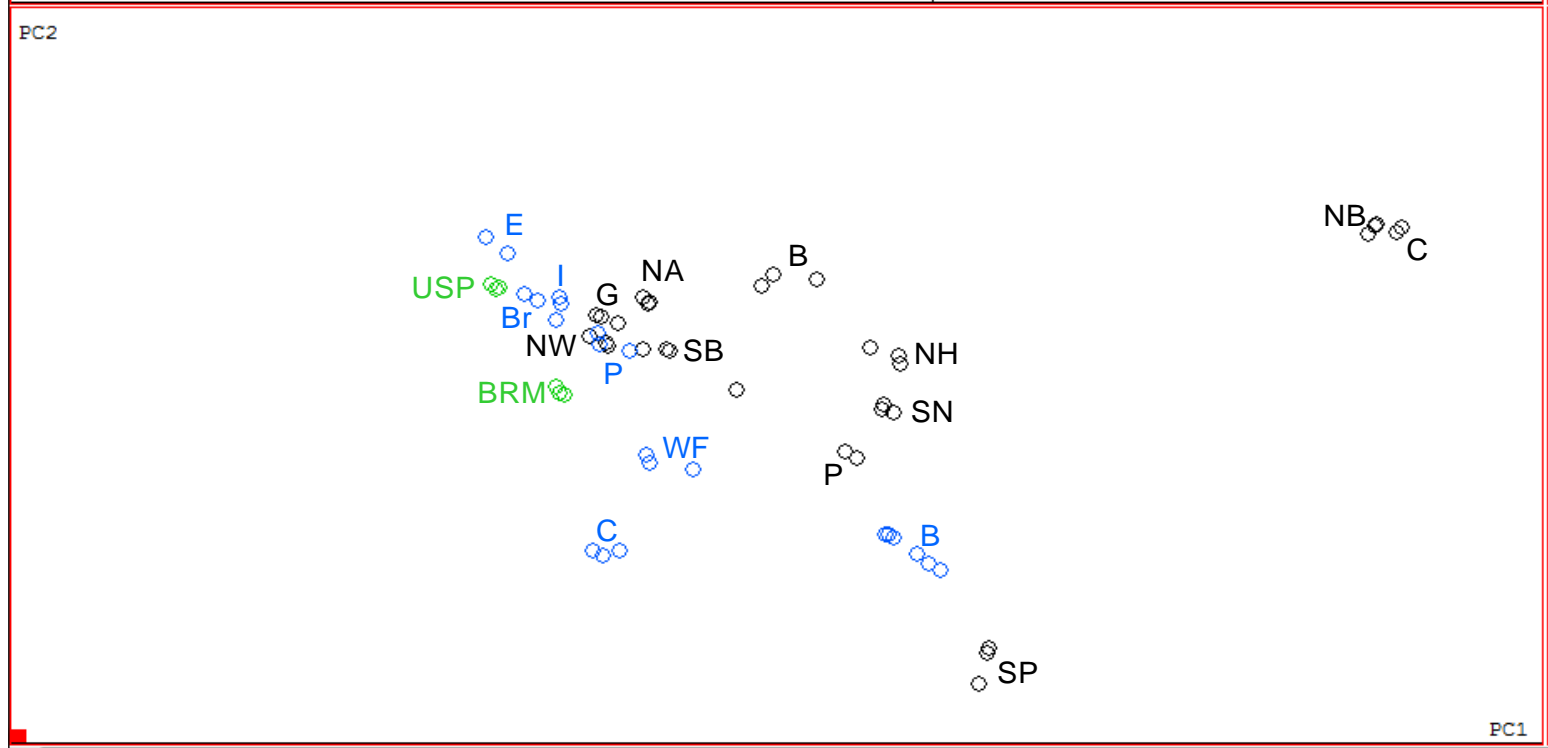




\section{CONCLUSÕES}

O presente estudo demonstrou a viabilidade da aplicação da técnica de RMN em alta resolução para análises quantitativas do ativo paracetamol em formulações farmacêuticas via experimentos de ${ }^{1} \mathrm{H}$. A quantificação simultânea de ativos diferentes se mostrou ser um método bastante promissor, assim como as análises qualitativas dos espectros das amostras comerciais, as quais permitiram a identificação de alguns dos compostos presentes na formulação (excipientes) de algumas das amostras analisadas.

Observaram-se como determinados parâmetros espectrais de aquisição e de processamento podem influenciar (ou não) nos resultados da medida e concluiu-se que, considerando a complexidade espectral da amostra, as informações fornecidas através dessas interferências são úteis na otimização do tempo de medida.

Os estudos preliminares relacionados às análises de glifosato mostraram que o emprego de um PE pode ser mais rápido e prático, mas tem que se preocupar com os tubos de RMN utilizados, uma vez que uma pequena variação em sua espessura pode comprometer a qualidade dos resultados.

Após esse cuidado, métodos de $\mathrm{RMN}$ de ${ }^{1} \mathrm{H}$ e de ${ }^{31} \mathrm{P}$ para medidas sequenciais puderam ser validados de acordo com a normativa específica e aplicados para análises de produtos comerciais. Estes apresentaram grande discrepância entre os teores de glifosato descritos em seus rótulos e os determinados no presente estudo, evidenciando a necessidade de melhorias no controle de qualidade desses produtos.

O FDM se mostrou uma ferramenta promissora para quantificações de compostos em amostras complexas, os quais possuem sinais de RMN sobrepostos.

O emprego da RMN em alta resolução se mostrou um excelente método alternativo para quantificação de ácidos graxos em óleos, uma vez que dispensa as reações de transesterificações, necessárias para as análises cromatográficas.

Um método para detecção de adulteração de azeites com óleo de soja em embalagens lacradas empregando a RMN-DT foi desenvolvido e validado. Sua aplicação pode vir a contribuir na detecção de fraude em azeite de oliva com óleo de soja ou outros óleos poliinsaturados, até mesmo por consumidores, com a disponibilização de aparelhos de RMN-DT, em pontos de venda. 
O método desenvolvido para o fitoterápico Cardo-leiteiro possibilitou uma análise detalhada de seus constituintes através de três diferentes abordagens complementares por RMN: (i) a $\mathrm{RMNq}$ de ${ }^{1} \mathrm{H}$ que permitiu a quantificação das principais flavolignanas presentes na silimarina; (ii) aplicação da HiFSA aliada à RMNq, a qual permitiu a quantificação dos complexos componentes específicos da (iso) silinina A e B e (iii) a análise de PCA que estabeleceu as semelhanças, assim como diferenças, entre os produtos comerciais e os extratos.

$\mathrm{O}$ uso dessas três diferentes abordagens estudadas e desenvolvidas para a planta Cardo-Leiteiro pode vir a ser útil em análises quali-quantitativas de fitoterápicos provenientes de plantas medicinais diversas, além de poder ser implementada em estudos de outros tipos de matrizes complexas.

Assim, considerando os resultados obtidos neste trabalho de doutorado, fica evidenciada que a potencialidade de técnicas de RMN deveria ser mais explorada para análises de produtos farmacêuticos e agrícolas, pois seu uso mais frequente e difundido poderia contribuir significativamente para a melhora da qualidade desses produtos. 


\section{REFERÊNCIAS BIBLIOGRÁFICAS}

1- AMERICAN OIL CHEMISTS' SOCIETY. Ch 2-91: Determination of Fatty Acids in Olive Oils by Capillary GLC. 2009.

2- MBINZE, J. K. ; DISPAS, A.; LEBRUN, P.; MBAY, J. M. T.; HABYALIMANA, V.; KALENDA, N.; ROZET, E.; HUBERT, Ph.; MARINI, R. D. Application of an innovative design space optimization strategy to the development of LC methods for the simultaneous screening of antibiotics to combat poor quality medicines. Journal of Pharmaceutical and Biomedical Analysis, v. 85, p.83-92, 2013.

3- DI STEFANO, V.; AVELLONE, G.; BONGIORNO, D.; CUNSOLO, V.; MUCCILLI, V.; SFORZA, S.; DOSSENA, A.; DRAHOS, L.; VÉKEY, K. Applications of liquid chromatography-mass spectrometry for food analysis. Journal of Chomatography A, v. 1259, p. 74-85, 2012.

4- KRISHNAIAH, C.; MURTHY, M. V.; KUMAR, R.; MUKKANTI, K. Development of a stability-indicating UPLC method for determining olanzapine and its associated degradation products present in active pharmaceutical ingredients and pharmaceutical dosage forms. Journal of Pharmaceutical and Biomedical Analysis, v. 54, n. 4, p. 667-673, 2011.

5- SANTOS, J. V.; CARVALHO, L. A. E. B.; PINA, M. E. Development and Validation of a RP-HPLC Method for the Determination of Zidovudine and Its Related Substances in Sustained-release Tablets. Analytical Sciences, v. 27, n. 3, p. 283-289, 2011.

6- SILVA, G. R.; LAGES, G. P.; PIANETTI, G. A.; NUNAN, E. A.; SOARES, C. D. V.; CAMPOS, L. M. M. Determinação de Lamivudina, Estavudina e Nevirapina em Comprimidos por Cromatografia Líquida de Alta Eficiência. Química Nova, v. 29, n. 6, p. 1159-1163, 2006.

\section{7- AGÊNCIA NACIONAL DE VIGILÂNCIA SANITÁRIA (ANVISA). Farmacopeia Brasileira. Brasília, 2010, Ed.5, v. 2, p.1189-1193.}

8- ARMENTA, S.; GARRIGUES, S.; DE LA GUARDIA, M. Determination of iprodione in agrochemicals by infrared and Raman spectrometry. Analytical and Bioanalytical Chemistry, v. 387, n. 8, p. 2887-2894, 2007.

9- KOLOMIETS, O.; HOFFMANN, U.; GELADI, P.; SIESLER, H. W. Quantitative determination of pharmaceutical drug formulations by near-infrared spectroscopic Imaging. Applied Spectroscopy, v. 62, n. 11, p.1200-1208, 2008.

10- DINC, E.; SERIN, C.; TUGCU-DEMIROZ, F.; DOGANAY, T. Dissolution and assaying of multicomponent tablets by chemometric methods using computer-aided spectrophotometer. International Journal of Pharmaceutics, v. 250, n. 2, p. 339-350, 2003.

11- CANTARELLI, M. A.; PELLERANO, R. G.; MARCHEVSKY, E. J.; CAMINA, J. M. Simultaneous Determination of Amoxicillin and Diclofenac in Pharmaceutical Formulations Using UV Spectral Data and the PLS Chemometric Method. Analytical Sciences, v. 27, n.1, p. 73-78, 2011.

12- MATKOVIC, S. R.; VALLE, G.M.; BRIAND, L. E. Quantitative analysis of ibuprofen in pharmaceutical formulations through FTIR spectroscopy. Latin American Applied Research, v. 35, n. 3, p. 189-195, 2005. 
13- ROGGO, Y.; CHALUS, P.; MAURER, L.; LEMA-MARTINEZ, C.; EDMOND, A.; JENT, N. A review of near infrared spectroscopy and chemometrics in pharmaceutical technologies. Journal of Pharmaceutical and Biomedical Analysis, v. 44, n. 3-SI, p. 683-700, 2007.

14- SALGUERO-CHAPARRO, L.; BAETEN, V.; ABBAS, O.; PEÑA-RODRÍGUEZ, F. On-line analysis of intact olive fruits by vis-NIR spectroscopy: Optimisation of the acquisition parameters. Journal of Food Engineering, v.112, n. 3, p. 152-157, 2012.

15- CANTARELLI, M. A.; PELLERANO, R. G.; MARCHEVSKY, E. J.; CAMINA, J. M. Simultaneous Determination of Amoxicillin and Diclofenac in Pharmaceutical Formulations Using UV Spectral Data and the PLS Chemometric Method. Analytical Sciences, v. 27, n. 1, p. 73-78, 2011.

16- SANCHES, Fátima Aparecida Castrine. Desenvolvimento de uma Metodologia para o Controle de Qualidadede Medicamento Injetável, sem Violação da Ampola, usando Espectroscopia NIR e Técnicas Quimiométricas. 2009. 88 f. Dissertação (Mestrado em Química Analítica) - Departamento de Química, Centro de Ciências Exatas e da Natureza, Universidade Federal da Paraíba, João Pessoa, 2009.

17- LACHENMEIER, D. W. Rapid quality control of spirit drinks and beer using multivariate data analysis of Fourier transform infrared spectra. Food Chemistry, v. 101, n. 2, p. 825832, 2007.

18- EUSTAQUIO, A.; BLANCO, M.; JEE, R. D.; MOFFAT, A. C. Determination of paracetamol in intact tablets by use of near infrared transmittance spectroscopy. Analytica Chimica Acta, v. 383, n. 3, p. 283-290, 1999.

19- GIL, V. M. S.; GERALDES, C. F. G. C. Ressonância Magnética Nuclear-

Fundamentos, Métodos e Aplicações. Lisboa: Calouste Gulbenkian, 1987. 1012 p.

20- CLARIDGE, T. D. W. High Resolution NMR Techniques in Organic Chemistry. Oxford: Tetrahedron Organic Chemistry Series, 1999. 382 p.

21- LEVITT, M.H.; Spin Dynamics - Basics of Nuclear Magnetic

Ressonance.Chichester: John Wiley \& Sons Ltd, 2007. 714 p.

22- COLNAGO, L.A.; Análise do Teor de Óleo em Sementes por RMN. Circular Técnica da Embrapa - Centro Nacional de Pesquisa e Desenvolvimento da Instrumentação Agropecuária, n. 3/96, 1996. Disponível em:

<http://www.infoteca.cnptia.embrapa.br/bitstream/doc/27416/1/CiT0396.pdf>. Acesso em: 01 dez. 2013.

23- HOLZGRABE, U.; DIEHL, B.; WAWER, I.; NMR Spectroscopy in Pharmaceutical Analysis. [S.I.]: Elsevier, 2008. 501 p.

24- MALZ, F.; JANCKE, H.; Validation of Quantitative NMR. Journal of Pharmaceutical and Biomedical Analysis, v. 38, n. 5, p. 813-823, 2005.

25- CORRÊA, C. C.; Análise da Qualidade de Carne Bovina por Ressonância Magnética Nuclear em Baixa Resolução. 2007. 119 f. Dissertação (Mestrado em Química Analítica) - Instituto de Química de São Carlos, Universidade de São Paulo, São Carlos, 2007.

26- SANTOS, P. M.; Desenvolvimento da técnica de precessão livre no estado estacionário para aumento da razão sinal ruído em espectros de RMN de alta 
resolução. 2009. 107 f. Dissertação (Mestrado em Química Analítica) - Instituto de Química de São Carlos, Universidade de São Paulo, São Carlos, 2009.

27- JUNGNICKEL, J. L.; FORBES, J. W. Quantitative Measurement of Hydrogen Types by Integrated Nuclear Magnetic Resonance Intensities. Analytical Chemistry, v. 35, n. 8, p. 938-942, 1963.

28- HOLLIS, D. P. Quantitative Analysis of Aspirin, Phenacetin, and Caffeine Mixtures by Nuclear Magnetic Resonance Spectrometry. Analytical Chemistry, v. 35, n. 11, p. 16821684, 1963.

29- PODGORSKII, V. V.; MIKHALEV, A. S.; KALABIN, G. A. Quantitative NMR Spectroscopy for Quality Control of Drugs and Pharmaceuticals. Pharmaceutical Chemistry Journal, v. 45, n. 3, p. 194-197, 2011.

30- LIU, N. Q.; CHOI, Y.H.; VERPOORTE, R.; VAN DER KOOY, F. Comparative Quantitative Analysis of Artemisinin by Chromatography and qNMR. Phytochemical Analysis, v. 21, n. 5, p. 451-456, 2010.

31- CHOI. Y. H.; KIM, H. K.; WILSON, E. G.; ERKELENS, C.; TRIJZELAAR, B.; VERPOORTE, R. Quantitative analysis of retinol and retinol palmitate in vitamin tablets using ${ }^{1} \mathrm{H}$-nuclear magnetic resonance spectroscopy. Analytica Chimica Acta, v. 512, n. 1, p.141147, 2004.

32- COLNAGO, L. A.; AZEREDO, R. B. V.; SOUSA, A. A.; ENGELSBERG, M. Aplicações da Espectroscopia de RMN (CWFP) na Medida de Umidade em Sementes e Grãos. Circular Técnica da Embrapa - Centro Nacional de Pesquisa e Desenvolvimento da Instrumentação Agropecuária, 4 p., 2002. Disponível em:

http://www.infoteca.cnptia.embrapa.br/bitstream/doc/28441/1/CiT142002.pdf. Acesso em: 01 dez. 2013.

33- INTERNATIONAL ORGANIZATION FOR STANDARDIZATION. ISO/CD 10565:1995. Oilseeds - Simultaneous Determination of Oil and Water Contents - Method Using Pulsed Nuclear Magnetic Resonance Spectrometry, 1995.

34- CHINACHOTI, P.; KRYGSMAN, P. H. Application of Low-Resolution NMR for Simultaneous Moisture and Oil Determination in Food (Oilseeds). Current Protocols in Food Analytical Chemistry, unit A1.3, 2001.

35- CORREAA, C. C.; FORATO, L.; COLNAGO, L. A. High-throughput non-destructive nuclear magnetic resonance method to measure intramuscular fat content in beef.

Analytical and Bioanalytical Chemistry. v. 393, n. 4, p. 1357-1360, 2009.

36- CABEÇA, L. F.; MARCONCINI, L. V.; MAMBINI, G. P.; AZEREDO, R. B. V.; COLNAGO, L. A. Monitoring the Transesterification Reaction Used in Biodiesel Production, with a Low Cost Unilateral Nuclear Magnetic Resonance Sensor. Energy \& Fuels, v. 25, n. 6, p. 26962701, 2011.

37- RIBEIRO, F. Z.; MARCONCINI, L. V.; TOLEDO, I. B.; AZEREDO, R. B. V.; BARBOSA, L. L.; COLNAGO, L. A. Nuclear magnetic resonance water relaxation time changes in bananas during ripening: a new mechanism. Journal of the Science of Food and Agriculture, v. 90, n. 12, p. 2052-2057, 2010.

38- BARROS, C. B.; COLNAGO, L. A. Uso da Ressonância Magnética Nuclear de Baixo Campo na Determinação Rápida do Teor de Umidade em Madeiras. Recomendação 


\section{Técnica da Embrapa - Centro Nacional de Pesquisa e Desenvolvimento da} Instrumentação Agropecuária, n. 12/99, 1999. Disponível em:

<http://www.infoteca.cnptia.embrapa.br/bitstream/doc/29510/1/RT1299.pdf>. Acesso em: 01 dez. 2013.

39- COLNAGO, L. A.; ENGELSBERG, M.; SOUZA, A. A.; BARBOSA, L. L. HighThroughput, Non-Destructive Determination of Oil Content in Intact Seeds by Continuous Wave-Free Precession NMR. Analytical Chemistry, v. 79, n. 3, p. 1271-1274, 2007.

40- PRESTES, R. A.; COLNAGO, L. A.; FORATO, L. A.; VIZZOTTO, L.; NOVOTNY, E. H.; CARRILHO, E. A rapid and automated low resolution NMR method to analyze oil quality in intact oilseeds. Analytica Chimica Acta, v. 596, n. 2, p. 325-329, 2007.

41- AZEREDO, R. B. de V.; COLNAGO, L. A.; ENGELSBERG, M.; Quantitative analysis using steady-state free precession nuclear magnetic resonance. Analytical Chemistry, v. 72, p. 2401-2405, 2000.

42- AZEREDO, R. B. de V.; COLNAGO, L. A., SOUSA, A. A.; ENGELSBERG, M. Continuous wave-free precession: a practical analytical tool for low resolution NMR measuremnts. Analytica Chimica Acta, v. 478, n. 2, p. 313-320, 2003.

43- ANDRADE, F. D.; NETTO, A. M.; COLNAGO, L. A. Qualitative analysis by online nuclear magnetic resonance using Carr-Purcell-Meiboom-Gill sequence with low refocusing flip angles. Talanta, v. 84, n. 1, p. 84-88, 2011.

44- AGÊNCIA NACIONAL DA VIGILÂNCIA SANITÁRIA (ANVISA). Guia para validação de métodos analíticos e bioanalíticos. Brasília, 2003. Disponível em:

$<$ http://portal.anvisa.gov.br/wps/wcm/connect/4983b0004745975da005f43fbc4c6735/RE_89 9_2003_Determina+a+publica\%C3\%A7\%C3\%A30+do+Guia+para+valida\%C3\%A7\%C3\%A $30+$ de + m\%C3\%A9todos+anal\%C3\%ADticos+e+bioanal\%C3\%ADticos.pdf?MOD=AJPERES >. Acesso em 01 dez. 2013.

45- ASSOCIAÇÃO BRASILEIRA DE NORMAS TÉCNICAS. NBR 14029:2005: Agrotóxicos e Afins - Validação de Métodos Analíticos. Rio de Janeiro, 2005. 19 p.

46- TAVARES, L. A.; FERREIRA, A. G. Análises Quali- e Quantitativa de Cafés Comerciais via Ressonância Magnética Nuclear. Química Nova, v. 29, n. 5, p. 911-915, 2006.

47- MANIARA, G.; RAJAMOORTHI, K.; RAJAN, S.; STOCKTON, G. W. Method Performance and Validation for Quantitative Analysis by ${ }^{1} \mathrm{H}$ and ${ }^{31} \mathrm{P}$ NMR Spectroscopy. Applications to Analytical Standards and Agricultural Chemicals. Analytical Chemistry, v. 70, p. 4921-4928, 1998.

48- HE, W.; DU, F.; WU, Y.; WANG, Y.; LIU, X.; LIU, H.; ZHAO, X. Quantitative ${ }^{19}$ F NMR method validation and application to the quantitative analysis of a fluoro-polyphosphates mixture. Journal of Fluorine Chemistry, v. 127, n. 6, p. 809-815, 2006.

49- GADAPE, H. H.; PARIKH, K. S. Quantitative determination and validation of metformin hydrochloride in pharmaceutical using quantitative nuclear magnetic resonance spectroscopy, E-Journal of Chemistry, v. 8, n. 2, p. 767-781, 2011.

50- GADAPE, H. H.; PARIKH, K. S. Quantitative determination and validation of carvedilol in pharmaceuticals using quantitative nuclear magnetic resonance spectroscopy. Analytical Methods, v. 3, p. $2341-2347,2011$. 
51- BEKIROGLU, S.; MYRBERG, O.; OSTMAN, K.; EK, M.; ARVIDSSON, T.; RUNDLÖF, T.; HAKKARAINEN, B. Validation of a quantitative NMR method for suspected counterfeit products exemplified on determination of benzethonium chloride in grapefruit seed extracts. Journal of Pharmaceutical and Biomedical Analysis, v. 47, n.4 - 5, p. 958-961, 2008.

52- GÖDECKE, T.; NAPOLITANO, J. G.; RODRIGUEZ-BRASCO, M. F.; CHEN, S. N.; JAKI, B. U.; LANKIN, D. C.; PAULI, G. F. Validation of a Generic Quantitative H-1 NMR Method for Natural Products Analysis. Phytochemical Analysis, v. 24, n. 6, p. 581-597, 2013.

53- WANG, B,; GOODPASTER, A. M.; KENNEDY, M. A. Coefficient of variation, signal-tonoise ratio, and effects of normalization in validation of biomarkers from NMR-based metabonomics studies. Chemometrics ans Intelligent Laboratory Systems, v. 128, n. 15, p. 9-16, 2013.

54- HOLZGRABE, U.; DEUBNER, R.; SCHOLLMAYER, C.; WAIBEL, B. Quantitative NMR spectroscopy - applications in drug analysis. Journal of Pharmaceutical and Biomedical Analysis, v. 38, n. 5, p. 806-812, 2005.

55- HOLZGRABE, U.; DIEHL, B. W. K.; WAWER, I. NMR spectroscopy in pharmacy. Journal of Pharmaceutical and Biomedical Analysis, v. 17, n. 4 -5, p. 557-616, 1998.

56- AMERICAN OIL CHEMISTS' SOCIETY. Cd 16b-93. Solid fat content (SFC) by low resolution magnetic resonance (NMR), using the direct method, 2000.

57- INTERNATIONAL ORGANIZATION FOR STANDARDIZATION. ISO/CD 8292-1:1995. Animal and vegetable fats and oils -- Determination of solid fat content by pulsed NMR - Part 1: Direct method, 2008.

58- AMERICAN OIL CHEMISTS' SOCIETY. AOCS 16b-81. Solid fat content (SFC) by low resolution nuclear magnetic resonance (NMR), using the indirect method, 2000.

59- INTERNATIONAL ORGANIZATION FOR STANDARDIZATION. ISO/CD 8292-2:1995. Animal and vegetable fats and oils -- Determination of solid fat content by pulsed NMR - Part 2: Indirect method, 2008.

60- INTERNATIONAL ORGANIZATION FOR STANDARDIZATION. IUPAC 2.150. Solid content determination in fats by NMR - Low-resolution nuclear magnetic resonance, 1987.

61- AMERICAN OIL CHEMISTS' SOCIETY. AOCS AK 4-95. Simultaneous determination of oil and moisture contents of oilseeds using pulsed NMR spectroscopy, 1995.

62- INTERNATIONAL ORGANIZATION FOR STANDARDIZATION. ISO 10632.

Simultaneous determination of oil and water contents: Method using pulsed nuclear magnetic resonance spectrometry, 1993.

63- AMERICAN OIL CHEMISTS' SOCIETY. AOCS AK 5-01. Simultaneous determination of oil and moisture contents of oilseed residues using pulsed NMR spectroscopy, 2001.

64- AMERICAN SOCIETY FOR TESTING AND MATERIALS. ASTM D7171-05. Standard Test Method for Hydrogen Content of Middle Distillate Petroleum Products by LowResolution Pulsed Nuclear Magnetic Resonance Spectroscopy, 2011.

65- ANTHONISEN, D. G.; SCHIRMER, M. A.; ANTHONISEN, E. F.; SILVA, S. D. A.; MILANI, M.; CASAGRANDE JÚNIOR, J. G. Validação da espectroscopia de ressonância magnética nuclear (RMN) na determinação do teor de óleo em sementes de mamona. Comunicado Técnico da Embrapa - Clima Temperado, 8 p., 2006. Disponível em: 
<http://www.infoteca.cnptia.embrapa.br/bitstream/doc/746152/1/comunicado153.pdf>. Acesso em: 01 dez. 2013.

66- LOURENÇÃO, B. C.; MEDEIROS, R. A.; ROCHA-FILHO, R. C.; MAZO, L. H.; FATIBELLO-FILHO, O. Simultaneous voltammetric determination of paracetamol and caffeine in pharmaceutical formulations using a boron-doped diamond electrode.Talanta, $\mathrm{v}$. 78, n. 3, p. 748-752, 2009.

67- U. S. FOOD AND DRUG ADMINISTRATION (FDA). Acetaminophen: Background and Overview, 2009. Disponível em:

$<$ http://www.fda.gov/downloads/AdvisoryCommittees/CommitteesMeetingMaterials/Drugs/Dr ugSafetyandRiskManagementAdvisoryCommittee/UCM175767.pdf>. Acesso em: 01 dez. 2013.

68- BASTOS, C. A. Otimização de metodologia por cromatografia líquida em fase reversa por pareamento iônico para análise simultânea de paracetamol, cloridrato de fenilefrina e maleato de carbinoxamina em formulações farmacêuticas. 2008. $69 \mathrm{f}$. Dissertação (Mestrado em Química) - Departamento de Química, Universidade Federal de Juiz de Fora, Juiz de For a, 2008.

69- SUAREZ, W. T.; VIEIRA, H. J.; FATIBELLO-FILHO, O. Determinação de paracetamol em produtos farmacêuticos empregando um sistema de análise por injeção em fluxo com geração de ácido nitroso. Eclética Química, v. 30, n. 1, p. 21 -28, 2005.

70- VIEIRA, I. O.; LUPETTI, K. O.; FATIBELLO-FILHO, O. Determinação de paracetamol em produtos farmacêuticos usando um biossensor de pasta de carbono modificado com extrato bruto de abobrinha (cucurbita pepo). Química Nova, v. 26, n. 1, p. 39-43, 2003.

71- ANICETO, C.; FATIBELLO-FILHO, O. Determinação espectrofotométrica por injeção em fluxo de paracetamol (acetaminofeno) em formulações farmacêuticas. Química Nova, v. 25, n. 3, p. 387-391, 2002.

72- OLIVEIRA, G. G.; JANEGITZ, B. C.; BATISTÃO, M .B.; SALAMI, F. H.; FATIBELLOFILHO, O.; LEITE, O. D. Determinação de Paracetamol pela Inibição da Reação quimiluminescente do Luminol-Hipoclorito de Sódio em um Sistema deANÁLISE em Fluxo Empregando o Conceito de Multicomutação. Química Nova, v. 32, n. 7, p.1755-1759, 2009.

73- BAPTISTAO, M.; ROCHA, W. F. D.; POPPI, R. J.; Quality control of the paracetamol drug by chemometrics and imaging spectroscopy in the near infrared region. Journal of Molecular Structure, v. 1002, n. 1-3, p. 167-171, 2011.

74- GANDHI, S. V.; RANHER, S. S.; DESHPANDE, P. B.; SHAH, D .K. Simultaneous HPTLC Determination of Nabumetone and Paracetamol in Combined Tablet Dosage Form. Journal of the Brazilian Chemical Society, v. 22, n. 6, p. 1068-1072, 2011.

75- GÜZEL, R.; EKSI, H,; DINC, E.; SOLAK, A. O. Determination of Acetaminophen in Commercial Formulations Using Silver Nanostructured Aniline Modified Pencil Graphite Electrode. Journal of the Electrochemical Society, v. 160, n. 8, p. 119-124, 2013.

76- BALES, J. R.; BELL, J. D.; NICHOLSON, J. K.; SADLER, P. J.; HUGHES, R. D.; BENNETT, P. N.; WILLIAMS, R. Metabolic profiling of body-fluids by proton nmr - selfpoisoning episodes with paracetamol (acetaminophen). Magnetic Resonance in Medicine, v. 6, n. 3, p. 300-306, 1988. 
77- NICOLESCU, A.; SIMIONESCU, N.; URSU, L.; DELEANU, C.; SIMIONESCU, B. C. The effect of therapeutic doses of paracetamol and aspirin on the NMR profile of urine at 400 $\mathrm{MHz}$. Revue Roumaine de Chimie, v. 57, n. 7-8, p. 653-658, 2012.

78- NICHOLLS, A. W.; CADDICK, S.; WILSON, I. D.; FARRANT, R. D.; LINDON, J. C.; NICHOLSON J. K. High resolution NMR spectroscopic studies on the metabolism and futile deacetylation of 4-hydroxyacetanilide (paracetamol) in the rat. Biochemical Pharmacology, v. 49 , n. 8 , p. $1155-64,1995$.

79- MOYNIHAN, H. A.; O'HARE, I. P. Spectroscopic characterisation of the monoclinic and orthorhombic forms of paracetamol. International Journal of Pharmaceutics, v. 247, n. 12, p. 179-185, 2002.

80- SCHANTZ, S.; HOPPU, P.; JUPPO, A. M. A Solid-State NMR Study of Phase Structure, Molecular Interactions, and Mobility in Blends of Citric Acid and Paracetamol. Journal of Pharmaceutical Sciences, v. 98, n. 5, p. 1862-1870, 2009.

81- RUNDLOF, T.; MATHIASSON, M.; BEKIROGLU, S.; HAKKARAINEN, B.; BOWDEN, T.; ARVIDSSON, T. Survey and qualification of internal standards for quantification by $\mathrm{H}-1 \mathrm{NMR}$ spectroscopy. Journal of Pharmaceutical and Biomedical Analysis, v. 52, n. 5, p. 645$651,2010$.

82- HUSAIN, S.; KIFAYATULLAH, M.; SEKAR, R. Simultaneous determination of mefenamic acid and paracetamol in pharmaceutical preparations by ${ }^{1} \mathrm{H}$ Nuclear Magnetic Resonance Spectroscopy. Indian Journal of Chemical Technology, v. 8, n. 3, p. 191-194, 2001.

83- REBELO, R.M.; VASCONCELOS, R.A.; BUYS, B.D.M.C.; REZENDE, J.A.; MORAES, K.O.C.; OLIVEIRA, R.P.; Produtos agrotóxicos e afins comercializados em 2009 no Brasil: uma abordagem ambiental. Ibama, Brasília, 2010. Disponível em: <http://www.ibama.gov.br/phocadownload/Qualidade_Ambiental/produtos_agrotoxicos_com ercializados_brasil_2009.pdf>. Acesso em $01 \mathrm{dez} .2013$.

84- AGÊNCIA NACIONAL DE VIGILÃNCIA SANITÁRIA (ANVISA). Sala de Imprensa. Seminário volta a discutir mercado de agrotóxicos em 2012. Brasília, 2012. Disponível em: <http://portal.anvisa.gov.br/wps/content/anvisa+portal/anvisa/sala+de+imprensa/menu++noticias+anos/2012+noticias/seminario+volta+a+discutir+mercado+de+agrotoxicos+em+20 12>. Acesso em 01 dez. 2013.

85- BARISON, A.; Emprego da RMN HR-MAS e análises quimiométricas no reconhecimento e avaliação de soja (Glycine max) geneticamente modificada. 2005. 245 f. Tese (Doutorado em Química Oragânica), Departamento de Química, Universidade Federal de São Carlos, São Carlos, 2005.

86- AMARANTE JUNIOR, O.P.; SANTOS, T. C. R.; BRITO, N. M; RIBEIRO, M. L.; Glifosato: Propriedades, Toxicidade, Usos e Legislação. Química Nova, v. 25, n. 4, p. 589-593, 2002.

87- CIKALO, M. G.; GOODALL, D. M.; MATTHEWS, W. Analysis of glyphosate using capillary electrophoresis with indirect detection. Journal of Chromatography A, v. 745, n. 1 -2 , p. 189-200, 1996.

88- BOTERO-COY, A. M.; IBÁÑEZ, M.; SANCHO, J. V.; HERNÁNDEZ, F. Direct liquid chromatography-tandem mass spectrometry determination of underivatized glyphosate in rice, maize and soybean. Journal of Chromatography A, v. 1313, n. SI, p. 157-165, 2013. 
89- BOTERO-COY, A. M.; IBANEZ, M.; SANCHO, J. V.; HERNANDEZ, F. Improvements in the analytical methodology for the residue determination of the herbicide glyphosate in soils by liquid chromatography coupled to mass spectrometry. Journal of Chromatography A, v. 1292, n. SI, p. 132-141, 2013.

90- HONG, T. P.; WHANG, C. W. A simple and rapid screening method for glyphosate in water using flow-injection with electrochemiluminescence detection. Analytical Methods, v.5, n. 21, p. 6186-619, 2013.

91- PINTADO, S,; MONTOYA, M. R.; RODRIGUEZ-AMARO, R.; MAYEN, M,; MELLADO, J. M. R. Electrochemical Determination of Glyphosate in Waters Using Electrogenerated Copper Ílons. International Journal of Electrochemical Science, v. 7, n. 3, p. 2523-2530, 2012.

92- BOL'SHAKOV, D. S.; TRETIAKOV, A. V. Determination of glyphosate and aminomethylphosphonic acid in surface water and vegetable oil by capillary zone electrophoresis. Journal of Analytical Chemistry,v. 67, n. 4, p. 386-391, 2012.

93- DA SILVA, A. S.; FERNANDES, F. C. B.; TOGNOLLI, J. O.; PEZZA, L.; PEZZA, H. R. A simple and green analytical method for determination of glyphosate in commercial formulations and water by diffuse reflectance spectroscopy. Spectrochimica Acta Part AMolecular and Biomolecular Spectroscopy, v. 79, n. 5, p. 1881-1885, 2011.

94- DA SILVA, A. S.; PEZZA, L.; PEZZA, H. R. Flow-injection spectrophotometric determination of glyphosate in commercial formulations of herbicides. Química Nova, v. 35, n. 1, p. 114-118, 2012.

95- MORLIER, L. W.; TOMKINS, D. F. Liquid chromatographic determination of glyphosate in water-soluble granular formulations: Collaborative study. Journal of AOAC International, v. 80 , n. 3 , p. $464-468,1997$.

96- GAVLICK, W. K.; TOMKINS, D. F. An updated liquid chromatographic assay for the determination of glyphosate in technical material and formulations Journal of AOAC International, v. 91, n. 1, p. 1-4, 2008.

97- COLLABORATIVE INTERNATIONAL PESTICIDES ANALYTICAL COUNCIL (CIPAC). MT 284. Handbook 1C, 2009.

98- ASSOCIATION OF ANALYTICAL COMMUNITIES (AOAC). AOAC Official Method 996.12. Glyphosate in Water-Soluble Granular Formulations, 2002. Disponível em: <http://down.40777.cn/stardard/8/7.7.12\%20AOAC\%20Official\%20Method\%20996.12\%20Gl yphosate\%20in\%20Water-Soluble.pdf>. Acesso em: 02 dez. 2013.

99- BRASIL. Agência Nacional de Vigilância Sanitária. ANVISA. Consulta Pública ㄲo 2 de 25 de janeiro de 2011. Diário Oficial da União, Brasília, 28 de janeiro de 2011.

100- AL DEEN, T. S.; HIBBERT, D. B.; HOOK, J. M.; WELLS, R. J. Quantitative Nuclear Magnetic Resonance Spectrometry II. Purity of Phosphorus-Based Agrochemicals Glyphosate (N-(phosphonomethyl)-glycine) and Profenofos (O-(4-bromo-2-chlorophenyl) Oethyl S-propyl phosphorothioate) measured by ${ }^{1} \mathrm{H}$ and ${ }^{31} \mathrm{P}$ QNMR spectrometry. Analytica Chimica Acta, v. 474, p. 125-135, 2002.

101- AL DEEN, T. S.; HIBBERT, D. B.; HOOK, J. M.; WELLS, R. J. An uncertainty budget for the determination of the purity of glyphosate by quantitative nuclear magnetic resonance (QNMR) spectroscopy. Accreditation and Quality Assurance, v. 9, p. 55-63, 2004. 
102- SHAMSIPUR, M.; SARKOUHI, M.; HASSAN, J. Selective monitoring of organophosphorus pesticidesby ${ }^{31} \mathrm{P}-\mathrm{NMR}$ spectroscopy: application to purity assay of technical products and concentration determination of formulated samples. Applied Magnetic Resonance, v. 42, p. 227-237, 2012.

103- CARTIGNY, B.; AZAROUAL, N.; MATHIEU, D.; PARMENTIER, E.; VERMEERSCH, G.; LHERMITTE, M. Quantitative determination of glyphosate in human serumby ${ }^{1} \mathrm{H}$ NMR spectroscopy. Talanta, v. 74, p. 1075-1078, 2008.

104- CARTIGNY, B.; AZAROUAL, N.; IMBENOTTEC, M.; MATHIEU, D.; VERMEERSCH, G.; GOULLE, J. P.; LHERMITTE, M. Determination of glyphosate in biological fluids by ${ }^{1} \mathrm{H}$ and ${ }^{31} \mathrm{P}$ NMR spectroscopy. Forensic Science International, v. 143, p. 141-145, 2004.

105- BRASIL. Ministério da Agricultura, Pecuária e Abastecimento (MAPA). Gabinete do Ministro. Instrução Normativa № 1, 30 de janeiro de 2012. Diário Oficial da União, Brasília, 01 de fev. 2012.

106- DIMITRIOS, B.; Oil - Constituents, Quality, Health Properties and Bioconversions. [S.I]: InTech, 2012.

107- MARTIN-PELAEZ, S.; COVAS, M. I.; FITO, M.; KUSAR, A.; PRAVST, I. Health effects of olive oil polyphenols: Recent advances and possibilities for the use of health claims.

Molecular Nutrition \& Food Research, v. 57, n. 5, p. 760-771, 2013.

108- CARAMIA, G.; GORI, A.; VALLI, E.; CERRETANI, L. Virgin olive oil in preventive medicine: From legend to epigenetics. European Journal Of Lipid Science And Technology, v.114, n. 4, p. 375-388, 2012.

109- GHANBARI, R.; ANWAR, F.; ALKHARFY, K. M.; GILANI, A. H.; SAARI, N.; Valuable Nutrients and Functional Bioactives in Different Parts of Olive (Olea europaea L.) - A Review. International Journal of Molecular Sciences, v. 13, n. 3, p. 3291-3340, 2012

110- INTERNATIONAL OLIVE COUNCIL. Disponível em:

<http://www.internationaloliveoil.org/estaticos/view/131-world-olive-oil-figures >. Acesso em 02 dez. 2013.

111- REVISTA VEJA. Nem tão virgem assim. Disponível em:

http://veja.abril.com.br/noticia/ciencia/nem-tao-virgem-assim. Acesso em 02 dez. 2013.

112- AMERICAN OIL CHEMISTS' SOCIETY. Ch 1-91: Preparation of Methyl Esters of Long-Chain Fatty Acids, 2009.

113- BEN-AYED, R.; KAMOUN-GRATI, N.; REBAI, A. An Overview of the Authenticationof Olive Tree and Oil. Comprehensive Reviews in Food Science and Food Safety, v. 12, n. 2, p. $218-227,2013$.

114- TORRECILLA, J. S.; CANCILLA, J. C., MATUTE, G.; DÍAZ-RODRÍGUEZ, P.; FLORES, A.I. Self-organizing maps based on chaotic parameters to detect adulterations of extra virgin olive oil with inferior edible oils. Journal of Food Engineering, v. 118, n. 4, p. 400-405, 2013.

115- VIETINA, M.; AGRIMONTI, C.; MARMIROLI, N. Detection of plant oil DNA using high resolution melting (HRM) post PCR analysis: A tool for disclosure of olive oil adulteration.

Food Chemistry, v. 141, n. 4, p. 3820-3826, 2013. 
116- DA SILVA, S. A.; TAKEMOTO, E.; CANO, C. B. Stigmastadiene and specific extitntion $(270 \mathrm{~nm})$ to evaluate the presence of refined oils in virgin olive oil commercialized in Brazil.

Food Science and Technology, v. 33, n. 3, p. 479-484, 2013.

117- YANG, Y.; FERRO, M. D.; CAVACO, I.; LIANG, Y. Z.; Detection and Identification of Extra Virgin Olive Oil Adulteration by GC-MS Combined with Chemometrics. Journal of Agricultural and Food Chemistry, v. 61, n. 15, p. 3693-3702, 2013.

118- LIBISH, T. M.; BOBBY, M. C.; LINESH, J.; MATHEW, S.; PRADEEP, C.; NAMPOORI, V. P. N.; BISWAS, P.; BANDYOPADHYAY, S.; DASGUPTA, K.; RADHAKRISHNAN, P. Detection of adulteration in virgin olive oil using a fiber optic long period grating based sensor. Laser Physics, v. 23, n. 4, 5 p., 2013. Disponível em: < http://iopscience.iop.org/1555-6611/23/4/045112/pdf/1555-6611_23_4_045112.pdf>. Acesso em 01 dez. 2013.

119- OUSSAMA, A.; ELABADI, F.; PLATIKANOV, S.; KZAIBER, F.; TAULER, R. Detection of Olive Oil Adulteration Using FT-IR Spectroscopy and PLS with Variable Importance of Projection (VIP). Journal of the American Oil Chemists' Society, v. 89, n. 10, p. 18071812, 2012.

120- DONG, W.; ZHANG, Y. Q.; ZHANG, B.; WANG, X. P. Quantitative analysis of adulteration of extra virgin olive oil using Raman spectroscopy improved by Bayesian framework least squares support vector machines. Analytical Methods, v. 4, n. 9, p. 27722777, 2012.

121- FANG, G.; GOH, J. Y.; TAY, M.; LAU, H. F.; LI, S. F. Y. Characterization of oils and fats by ${ }^{1} \mathrm{H}$ NMR and GC/MS fingerprinting: Classification, prediction and detection of adulteration. Food Chemistry, v. 138, n. 2 - 3, p, 1461-1469, 2013.

122- ALONSO-SALCES, R. M.; HOLLAND, M. V.; GUILLOU, C.; HÉBERGER, K. Quality Assessment of Olive Oil by ${ }^{1} \mathrm{H}-N M R$ Fingerprinting. In: Olive Oil - Constituents, Quality, Health Properties and Bioconversions. InTech, v. 01, p. 185-210.

123- FRAGAKI, G.; SPYROS, A.; SIRAGAKIS, G.; SALIVARAS, E.; DAIS, P. Detection of Extra Virgin Olive Oil Adulteration with Lampante Olive Oil and Refined Olive Oil Using Nuclear Magnetic Resonance Spectroscopy and Multivariate Statistical Analysis. Journal of Agricultural and Food Chemistry, v. 53, n. 8, p. 2810-2816, 2005.

124- DEL COCO, L.; SCHENA, F. P.; FANIZZI, F. P. ${ }^{1} \mathrm{H}$ Nuclear Magnetic Resonance Study of Olive Oils Commercially Available as Italian Products in the United States of America.

Nutrients, v. 4, n. 5, 343-355, 2012.

125- YALCIN, H.; TOKER, O. S.; OZTURK, I.; DOGAN, M.; KISI, O. Prediction of fatty acid composition of vegetable oils based on rheological measurements using nonlinear models. European Journal of Lipid Science and Technology, v. 114, n. 10, p. 1217-1224, 2012.

126- ZHANG, Q.; SALEH, A. S. M.; SHEN, Q. Discrimination of Edible Vegetable Oil Adulteration with Used Frying Oil by Low Field Nuclear Magnetic Resonance. Food and Bioprocess Technology, v. 6, n. 9, p. 2562-2570, 2013.

127- HARLEY, S. J.; LIM, V.; STUCKY, P. A.; AUGUSTINE, M. P. Using low frequency full bottle diamagnetic screening to study collectible wine. Talanta, v. 85, n. 5, p. 2437-2444, 2011. 
128- SOBIESKI, D. N.; MULVIHILL, G.; BROZ, J. S.; AUGUSTINE, M. P. Towards rapid throughput NMR studies of full wine bottles. Solid State Nuclear Magnetic Resonance, v. 29, n. $1-3$, p. 191-198, 2006.

129- WEEKLEY, A. J.; BRUINS, P.; SISTO, M.; AUGUSTINE, M. P. Using NMR to study full intact wine bottles. Journal of Magnetic Resonance, v.161, n. 1, p. 91-98, 2003.

130- SIMÕES, C. M. O. Farmacognosia: da Planta ao Medicamento. Porto Alegre: UFRGS Editora, 2007. 1104 p.

131- KIM, N. C.; GRAF, T. N.; SPARACINO, C. M.; WANI, M. C.; WALL, M. E.; Complete isolation and characterization of silybins and isosilybins from milk thistle (Silybum marianum). Organic \& Biomolecular Chemistry, v. 1, n. 10 , p. 1684-1689, 2003.

132- SANTOS, M. S.; PEREIRA-FILHO, E. R.; FERREIRA, A. G.; BOFFO, E. F.; FIGUEIRA, G. M. Authenticity study of Phyllanthus species by NMR and FT-IR Techniques coupled with chemometric methods. Química Nova, v. 35, n. 11, p. 2210-2217, 2012.

133- DAOLIO, C.; BELTRAME, F. L.; FERREIRA, A. G.; CASS, Q. B.; CORTEZ, D. A. G.; FERREIRA M. M. C. Classification of commercial catuaba samples by NMR, HPLC and chemometrics. Phytochemical Analysis, v.19, n. 3, p. 218-228, 2008.

134- MATTOLI, L.; CANGI, F.; MAIDECCHI, A.; GHIARA, C.; RAGAZZI, E.; TUBARO, M.; STELLA, L.; TISATTO, F.; TRALDI, P. Metabolomic fingerprint of plant extracts. Journal of Mass Spectrometry, v. 41, n. 12, p. 1534-1545, 2006.

135- DANIEL, C.; KERSTEN, T.; KEHRUS, S.; KONIG, G. M.; KNOSS, W. Metabolomic Fingerprint of Medicinal Plants Using ${ }^{1} \mathrm{H}$ NMR and HPLC/ELSD in combination with PCA. Planta Medica, v. 73, n. 9, p. 910-910, 2007.

136- VAN DER KOOY, F.; MALTESE, F.; CHOI, Y. H.; KIM, H. K.; VERPOORTE, R. Quality Control of Herbal Material and Phytopharmaceuticals with MS and NMR Based Metabolic Fingerprint. Planta Medica, v. 75, n. 7, p. 763-775, 2009.

137- FREDERICH, M.; JANSEN, C.; DE TULLIO, P.; TITS, M.; DEMOULIN, V.; ANGENOT, L. Metabolomic Analysis of Echinacea spp. by ${ }^{1} \mathrm{H}$ Nuclear Mangnetic Resonance Spectrometry and Multivariate Data Analysis Technique. Phytochemical Analysis, v. 21, n. 1, 61-65, 2010.

138- SCHRIPSEMA, J.; LEMOS, M. A.; DAGNINO, D. S. NMR based Metabolomic Investigation of the Brazilian Medicinal Plant Carqueja: Baccharis trimera (Less.) DC. Planta Medica, v. 77, n. 12, p. 1325-1326, 2011.

139- PAULI, G. F.; JAKI, B. U.; LANKIN, D. C. Quantitative ${ }^{1 H}$ NMR: Development and Potential of a Method for Natural Products Analysis. Journal of Natural Products, v. 68, p. 133-149, 2005.

140- PAULI, G. F.; JAKI, B. U.; LANKIN, D. C. A Routine Experimental Protocol for qHNMR Illustrated with Taxol. Journal of Natural Products, v. 70, n. 4, p. 589-595, 2007.

141- PAULI, G. F.; GÖDECKE, T.; JAKI, B. U.; LANKIN, D. C. Quantitative ${ }^{1 H}$ NMR. Development and Potential of an Analytical Method: An Update. Journal of Natural Products, v. 75, n. 4, p. 834-851, 2012.

142- QIU, F.; IMAI, A.; MCALPINE, J. B.; LANKIN, D. C.; BURTON, I.; KARAKACH, T.; FARNSWORTH, N. R.; CHEN, S. N.; PAULI, G. F.; Dereplication, residual complexity, and 
Rational Naming: The Case of the Actaea Triterpenes. Journal of Natural Products, v. 75, n. 3, p. 432-443, 2012.

143- PAULI, G. F.; CHEN, S. N.; FRIESEN, J. B.; MCALPINE, J. B.; JAKI, B. U.; Analysis and Purification of Bioactive Natural Products: The AnaPurNa Study. Journal of Natural Products, v. 75, n. 6, p. 1243-1255, 2012.

144- NAPOLITANO, J. G.; GÖDECKE, T.; RODRÍGUES-BRASCO, M. F.; JAKI, B. U.; CHEN, S. N.; LANKIN, D. C.; PAULI, G. F. The Tandem of Full Spin Analysis and qNMR for the Quality Control of Botanicals Exemplified with Ginkgo biloba. Journal of Natural Products, v. 75, n. 2, p. 238-248, 2012.

145- GÖDECKE, T.; YAO, P.; NAPOLITANO, J. G.; NIKOLIC, D.; DIETZ, B. M.; BOLTON, J. L.; VAN BREEMEN, R. B.; FARNSWORTH, N. R.; CHEN, S. N.; LANKIN, D. C.; PAULI, G. F. Integrated Standardization Concept for Angelica Botanicals Using Quantitative NMR. Fitoterapia, v. 83, n. 1, p. 18-32, 2012.

146- GRIFFITHS, L.; IRVING, A. M. Assay by nuclear magnetic resonance spectroscopy: quantification limits. Analyst, v. 123, p. 1061-1068, 1998.

147- BENTHIN, B.; DANS, H.; HAMBURGUER, M. Pressurized Liquid Extraction of Medicinal Plants. Journal of Chromatography A, v. 837, n. 1 -2, p. 211-219, 1999.

148- WIESER, M. E.; BERGLUND, M. Atomic weights of the elements 2007 (IUPAC Technical Report). Pure and Applied Chemistry, v. 81, n. 11, p. 2131-2156, 2009.

149- MANDELSHTAM, V. A. FDM: the filter diagonalization method for data processing in NMR experiments. Progress in Nuclear Magnetic Resonance Spectroscopy, v. 38, p. 159-196, 2001.

150- MANDELSHTAM, V. A.; TAYLOR, H. S. Harmonic inversion of time signals and its applications. Journal of Chemical Physics, v. 107, p. 6756-6769, 1997.

151- DAI, B.; EADS, C. D. Efficient removal of unwanted signals in NMR spectra using the filter diagonalization method. Magnetic Resonance Chemistry, v. 48, n. 3, p. 230-234, 2010.

152- MARIA, R. M.; MORAES, T. B.; MAGON, C. J.; VENÂNCIO, T.; ALTEI, W. F.; ANDRICOPULO, A. D.; COLNAGO, L. A. Processing of high resolution magic angle spinning spectra of breast cancer cells by the filter diagonalization method. Analyst, v. 137, n. 19, p. 4546-4551, 2012.

153- SKIERA, C.; STELIOPOULOS, P.; KUBALLA, T.; HOLZGRABE, U.; DIEHL, B.; Determination of free fatty acids in edible oils by ${ }^{1} \mathrm{H}$ NMR spectroscopy. Lipid Technology, v. 24, n. 12, 279-281, 2012.

154- ASSOCIAÇÃO BRASILEIRA DE PRODUTORES, IMPORTADORES E COMERCIANTES DE AZEITE DE OLIVEIRA. Programa de Controle da Pureza dos Azeites. Disponível em: <http://www.oliva.org.br/controle-da-pureza.php>. Acesso em: 02 dez. 2013.

155- DSC. United State Pharmacopeia Dietary Supplements Compendium. 1 ${ }^{a}$ Ed. v. 1, 2012.

156- NAPOLITANO, J. G.; LANKIN, D. C.; GRAF, T. N.; FRIESEN, J. B.; CHEN, S. N.; MCALPINE, J. B.; OBERLIES, N. H.; PAULI, G. F.; HiFSA fingerprinting applied to isomers 
with near-identical NMR spectra: the silybin/isosilybin case. The Journal of Organic Chemistry, v. 78, n. 7, p. 2827-2839, 2013.

157- KORHONEN, S. P.; Analysis and assignment of NMR spectra using PERCH. In: From Problem to Solution - CSC's Chemistry Modeling Guide. CSC Scientific Computing Ltd., Finland, $1^{\underline{a}}$ edição, p. 80-89.

158- BEEBE, K.; PELL, R.; SEAHOLTS, N. B. Chemometric: A practical guide. New York: John Wiley \& Sons, 1998. 360 p.

159- BRERETON, R. G. Chemometrics: Data Analysis for the Laboratory and Chemical Plant. New York: John Wiley \& Sons, 2002. 504 p. 